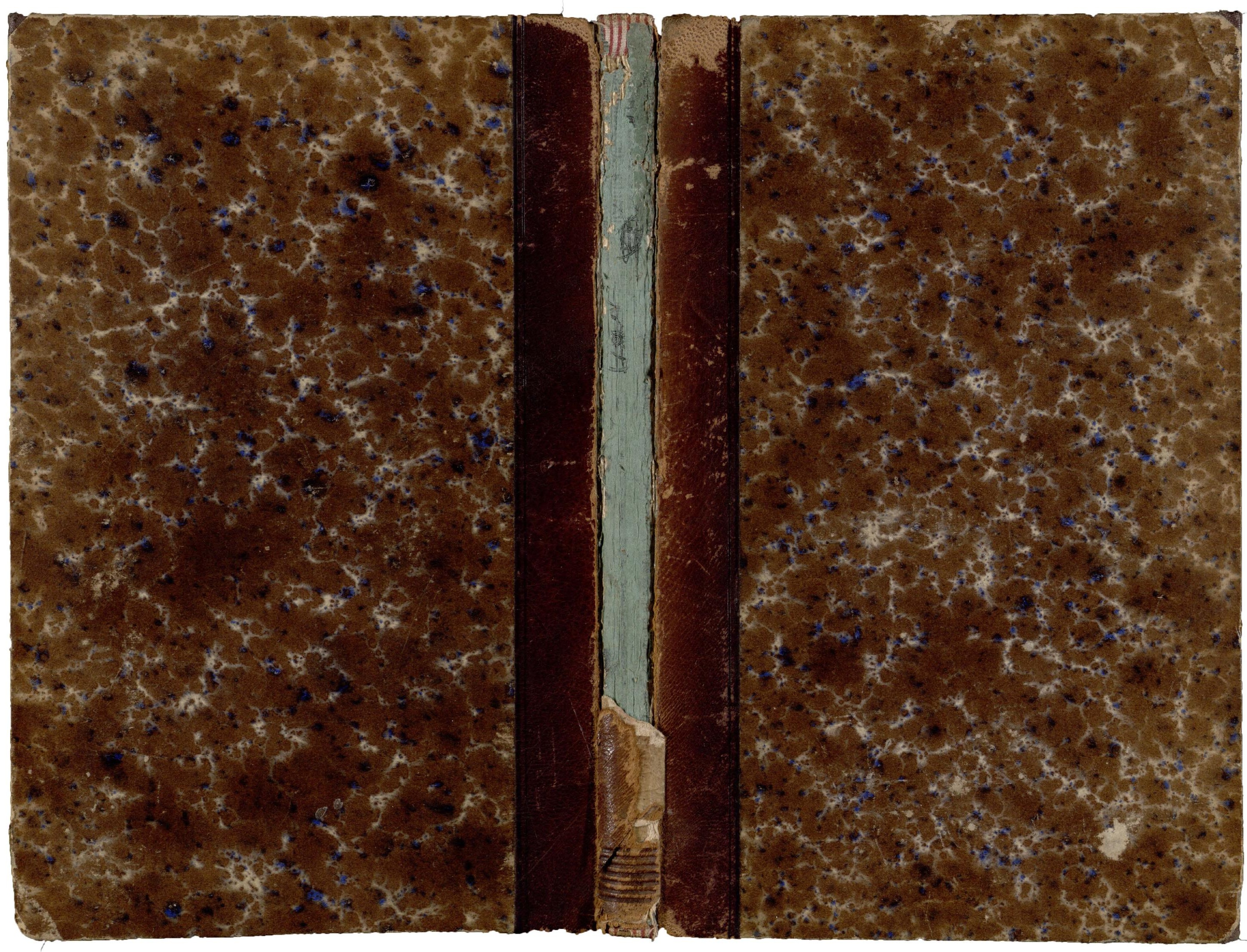



Huluty

1205 

(․ $\mathrm{HAGEN}$,

\section{WAHRSCHEINIICHKEITS-RECHNUNG.}





\section{GRUNDZÜGE}

DER

\section{WAHRSCHEINLICHKEITS-RECHNUNG}

VON

G. H AGEN.

GABINET MATEMATYCZA

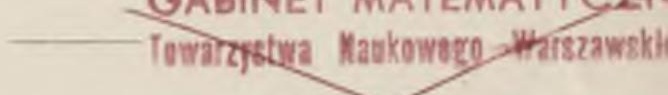

DRITTE, UMGEARBEITETE AUFLAGE.

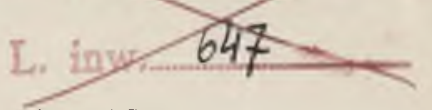

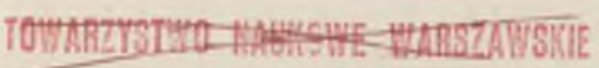

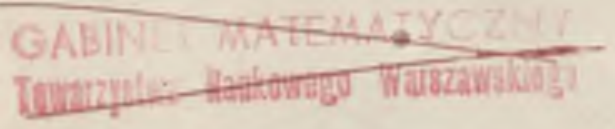

\section{BERLIN.}

VERIAG VON ERNST \& KORN (GROPIUS'SCIE BUCH- UND KUNSTHANDLUNG).

1882. 
อ

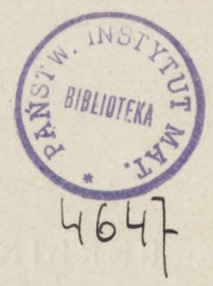

G.M. II. $38 \%$

www.rcin.org.pl 


\section{GABINET MATEMATYCZNY}

\section{Vorwort}

z ur dritten A uflage.

Vorliegende Grundzïgẻ der Wahrscheinlichkeits-Rechnung stellte ich 1837 zusammen, um die sichere Methode zur Verwerthung von Messungen und Beobachtungen, die ich bei längerer Beschäftigung mit astronomischen Studien und Rechnungen kennen gelernt latte, in die IngenieurWissenschaften einzuführen. Mein hochverehrter Lehrer und väterlicher Freund Bessel, dessen Vorträge und Anweisungen ich vorzugsweise hier wiedergebe, warnte mich sogleich vor der Erwartung eines baldigen Erfolges: zeln Jahre werden vergehn, bevor meine Absicht gefalst wird, und andre zehn Jahre werde man noch iiberlegen, ob man davon Gebrauch machen solle.

Dieser Ausspruch hat sich so sehr bestätigt, dafs auch gegenwärtig, nach 45 Jahren, diese Methode, wenigstens bei uns, in den wissenschaftlichen Wasserbau noch nicht Eingang gefunden, und meine dahingerichteten sonstigen Bemühungen keine Nachfolge gefunden haben.

Gegenwärtig scheint indessen ein Umschwung sich vorzubereiten. Merriman in New-Haven (Connecticut) machte 1877 im Franklin-Journal die Amerikanischen Ingenieure auf meine Schrift aufmerksam, indem er nicht nur einige Hauptsätze daraus mittheilte, sondern auch die Anwendung derselben an einem Beispiel zeigte. Eben so hat der Englische Ingenieur Cunningham in Roorkee (OstIndien) unter Bezugnahme auf diese Mittheilung im FranklinJournal naclı der Methode der kleinsten Quadrate aus seinen zahlreichen hydrometrischen Messungen am GangesCanal einige Resultate zu ziehn versucht. Besonders wichtig ist es aber, dals die zweite Ausgabe dieser Schrift beinale vollständig vergriffen ist.

Bei Bearbeitung der dritten Auflage schienen wieder vielfache Zusätze und Aenderungen nothwendig, um sowohl 
das Verständnifs zu erleiclitern, als auch um möglichen Bedenken vorzubeugen. Den Hauptsatz, der die Beziehung zwischen der Grölse der Beobachtungs-Fehler und der Wahrscheinlichkeit ihres Vorkommens ausdrickt, habe ich wieder aus den Binomial-Coefticienten hergeleitet, indem diese genau in derselben Art sich bilden, wie die BeobachtungsFehler. Ich wurde zur Beihehaltung dieser Herleitung um so mehr veranlafist, als auch Wittstein in der Uebersetzung von Navier's Jifferenzial- und Integral-Rechnung mir hierin gefolgt ist. Ich habe aber noch gezeigt, dal's schon unter Annahme von nur zehn Fehler-Quellen dieses zuerst von Gauls aufgestellte Gesetz in iiberraschender Schärfe sich darstellt.

Die Beispiele der Anwendung sind zum Theil verändert. Den letzten Abschnitt, der vom Nivelliren handelt, habe ich mit manchen Zusätzen wieder aufgenommen, indem die darin enthaltenen Mittheilungen iiber Prüfung, Berichtigung und Behandlung der Mefsinstrumente nicht allein für den Ingenieur wichtig sein dürften.

Sollte mir vielleicht der Vorwurf' gemacht werden, ich sei in Betreff der Anordnung und Ansführung der Rechnungen zu weit gegangen, und habe manches allgemein Bekannte oder an sich Verständliche mitgetheilt, so diurfte mich der Mangel an Uebung im Zahlenrechnen, den ich bei Studirenden oft bemerkt habe, entschuldigen. Der Unterricht in technischen höhern Lehranstalten gestattet freilich keine ausgedehnten Ueloungen in der Anwendung des Erlernten, doch dürfte dafïir einige Zeit gewonnen werden, wenn die Mittheilung der Lehrsätze anf das wirkliche Bedürfni vergirender Reihen, durch Einführung von Näherungswerthen, die man leicht berichtigt, durch Anwendung der mechanischen Quadraturen und dergleichen, sind viele Aufgaben bequem, und oft sogar noch schneller zu lösen, als auf directem Wege, wenn man die Grenzen der jedesmal erforderlichen Schärfe nicht überschreitet. In letzter Beziehung bemerkt man vielfach maalslose Uebertreibungen. Wenn Erfahrungs-Coefficienten benutzt werden, die nur 
selten bis anf ein Procent, meist aber kaum bis auf zehn Procent sicher sind, so werden die Rechnnngen mit siebenstelligen Isogaritlmen-Tafeln ausgeführt, und man gelangt zu Resultaten, die bis auf den millionsten Theil ihres Werthes sicher zu sein scheinen, die aber wirklich doch nicht genauer sein können, als die Voraussetzungen, von denen man ausgegangen ist. In kürzerer Zeit und mit geringerer Mühe würde man bei Benutzung fünfstelliger und oft selbst vierstelliger T'Tafeln in genügender Schärfe den Zweck vollständig erreicht haben. Doch auch der Gebrauch dieser 'Tafeln erfordert Uebung.

Indem die Mathematik schon vielfach im gewöhnlichen Leben, ganz besonders aber in den Ingenieur-Wissenschaften, vom höchsten Werth ist, so sollte das Studium derselben ebenso, wie in anderen Verhältnissen geschielıt, auf ihre Anwenkung gerichtet sein. Der Tischler, der einen Lehrling annimmt, zeigt demselben, wie er den Hobel fassen und führen soll, und veranlalst ihm, durch fortgesetzte Uebung die nöthige Geschicklichkeit im Gebranche sich anzueignen. In ähnlicher Weise habe ich mich bemüht, gleichsam die Handgriffe bei Ausführung von Rechnungen zu zeigen und durch Beispiele zu exläutern.

Berlin, im Januar 1882.

G. HaGen. 
www.rcin.org.pl 


\section{Inhalts-Nachweisung.}

I. Abschnitt. Allgemeine Grundsätze der WalırscheinlichkeitsReclinung.

5. 1. 'Zufitlige Frscheinungen - Selte

$\$ 2$. Irrungen und 'Täuschungen

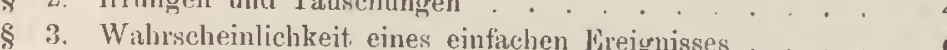

$\$ 4$. Wahrscheinlichkeit zweier ron einander malsringiger Freignisse

\$. Walurscheinlichkeit, zwcier von piniunder ahoüngiger Hreignisse . . . . . . . . . . . . . 10

6. Wahrscheinlichkeit der Ursache eines Kreignisses . . 12

$\$$ 7. Wahrscheinlichkeit der Wiederkehr von Kreignissen . . 14

$\$ 8$. Absoluter Werth der Hoffnung . . . . . . . . . . 16

$\$ 9$. Relativer Werth derselben . . . . . . . . . . . 17

$\$ 10$. Beobachtungs-Fehler. . . . . . . . . . 23

II. Abschnitt. Beziehung zwischen der Gröfse der

Beobachtungs-Fehler und der Wahrscheinlichkeit derselbon.

$\$$ 11. Seltenheit seln grolser Fehler . . . . . . . . 28

$\$$ 12. Vermnlassung der Fehler . . . . . . . . . .

$\$ 13$. Bildung derselben durch unendlich viele elementî̉re Fehler $\$ 32$

$\$ 14$. Wahrscheinliclikeit der verschiedenen Fehler . . . . 33

\$15. Uebereinstimmung dieses Gesetzes mit den Resultisten, wenn ouch nur wenige elementăre Fehler angenommen werden . . . . . . . . . 39

\$ 15. Vereinfichung des Ausdrucks . . . . . . . . . 41

III. Abschnitt. Die Methode ler kleinsten Quadrace.

\$ 17. Dis kleinste Fehler-(quadrat. . . . . . . . . . . 47

$\$ 18$. Bedingungs-Gleichungen . . . . . . . . . . . . 49

$\$ 19$. Beispiele der Anwendung . . . . . . . . . . . . $\$ 2$

$\$ 20$. Summirung der Producte . . . . . . . . . . . . 56

$\$ 21$. Berechnung der Unbekinnten . . . . . . . . . . 63

$\$ 22$. Unformung der gegelonen Gleichungen . . . . . 65

\$23. Gewichte der einzelnen Beobachtungen . . . . . . e'

IV. Abschnitt. Der wahrscheinliche Fehler.

$\$ 24$ Der mittlere Fehler . . . . . . . . . . . . . . 73

$\$ 25$. Das mittlere Fehler-Quudrat . . . . . . . . . . . 75,

\$26. Der wahrscheinliche Beoluchtungs-Fehler . . . . . . 77

$\$ 27$. Wahrscheinlichkeit hestimnuter Felıler . . . . . . . 79 
$\$ 28$. Wahrscheinlichkeit derselben zwischen bestimmten Grenzen

$\$ 29$. Vertheilung der Fehler . . . . . . . . . . . 84

$\$ 30$. Wahrscheinlichkeit der berechneten Constanten . . . . 89

$\$$ 31. Frmittelung der wahrscheinlichen Fehler derselben . . 97

\$ :32. Zusammenstellung der Ausdrücke . . . . . . . . . 98

$\$$ 33. Wahrscheinliche Fehler der Producte etc. . . . . . 103

$\$ 34$. Wahrscheinlichkeit bestimmter negativer Feller . . . 107

\section{Abschnitt. Beispiele der Anwendung.}

\$.5. Beobachtungen, im Allgemeinen . . . . . . . . . 111

$\$ 36$. Auffindung des Gesetzes einer Erscheinung . . . . . 114

$\$$ 37. Auffindung der Ursache einer Frscheinung . . . . . 126

$\$$ 38. Beutheilung der Festigkeit des kisens . . . . . . . 197

s 39. Sicherheit der Messung von Winkeln und Linien . . . 145

$\$ 40$. Lösung der Pothenot'schen Aufgalue, wemn mehr, als drei

Festpunkte benutzt werlen . . . . . . . 150

\section{Abschnitt. Anwendung der Wahrscheinlichkeits- Rechnung auf das Nivelliren.}

$\$ 41$. Ursachen der Felıler beim Nivelliren. . . . . . . . 158

\$42. Die üblichen Nivellir-Instrumente . . . . . . . . . 161

$\$$ 43. Ungenauigkeit derselluen . . . . . . . . . . . . 163

$\$ 44$. Unrichtigkeit derselben . . . . . . . . . . . . 167

$\$ 45$. Krimmung der Fidoberfläche und Strahlenbrechung . . 176

\$ 46. Mangel an Dentlichkeit . . . . . . . . . . . . 179

$\$ 47$. Die beweglichen Tibleaus . . . . . . . . . . 181

$\$ 48$. Wahrscheinlicher Febler bein Gebranch der Canalwage. 183

$\$ 4$ 4. Prüfung der Libelle mit Fermohr . . . . . . . . . 185

$\$$ 50. Visirlatten und Bezeichnung dersell,en . . . . . . . 188

$\$$ 51. Beschreibung eines gröl'sern Nivellements . . . . . . 191

$\$$ 5i. Wahrscheiuliche Fehler desselben . . . . . . . . . 196

$\$ 53$. Trigonometrische Nivellements . . . . . . . . . 202

\section{Anhang.}

A. Quadrat-Tabelle . . . . . . . . . . . . . 209

B. 'Tabelle der relativen Waluscheinlichkeit der Fehler . . . 216

C. Tabelle der Wahrscheinlichkeit des Ueberschreitens verschiedener Fehlergrenzen. . . . . . . . . . 216 
I. Abschnitt.

\section{Hauptsitze der Wahrscheinlichkeits-Rechnung.}

\section{$\S 1$.}

"Gäbe es einen Verstand, "sagt L a pl a c e," der alle Krïfte kennt, welche in einem gewissen Zeitpunkt die Natur beleben, so wie alle gegenseitigen Beziehungen der Wesen in ihr, und wäre derselbe fälig, diese gegebnen Grölsen in Rechnung zu stellen, so würde er die Bewegung der Himmelskörper, wie die der leichtesten Staubflöckchen in demselben analytischen Ausdruck umfassen. Für ilın wäre niclits ungewils, Vergangenheit und Zukunft stïnden klar vor seinen Augen! In der Entwicklung der Astronomie hat der menschliche Geist sich zu einem schwachen Abbild dieses Verstandes erhoben."

Doch nicht nur die leblose Natur, sondern auch die belebte, und selbst die denkenden Wesen in ihr folgen nur bestimmten Kräften. Jeder Entschlufs und jede That wird durch gewisse innere oder äufsere Eindrücke veranlafst. Die Geschicke der Völker, wie der einzelnen Menschen, sind die nothwendige Folge vorangegangener Begebenheiten und Auffassungen.

In der eigentlichen Bedeutung des Worts giebt es sonach keinen $Z$ ufall. Wird jedoch ein Ereignils durch Ursachen herbeigeführt, die uns entweder ganz unbekannt sind, oder deren Zusammenhang und Wirksamkeit wir nicht so vollständig zu fassen und zu verfolgen vermögen, dals wir ihr Resultat, oder eben jenes Ereignifs vorher bestimmen können, so ist es für uns eben so räthselhaft, als wenn es vom Zufall abhinge, und wir nennen es $z$ u fällig.

Werfen wir einen Würfel auf, so wird die Lage, die er nnnimmt, oder die Seite, die nach oben gerielıtet bleibt, allein durch 
Aen Stofs bedingt. den wir ihm ertheilen. Wären wir im stande, das Maafs dieses Stofses mit Rücksicht auf das Auffallen auf den Tisch genau zu berechnen, und könnten wir die Bewegung unsrer Hand eben so scharf abmessen, so würde es keine Schwierigkeiten haben, jede beliebige Seite des Würfels erscheinen zu lassen. Beides ist aber nicht möglich, denn theils sind die meclınischen Verhältnisse zu verwickelt, als dafs wir sie verfolgen künnten, theils aber läfst sich der Schwung und die Richtung, die wir dem Wïrfel ertheilen, nicht genau genug abmessen. Die geringste Vermehrung der Kraft, die unserm Gefühl schın entgeht, verändert wesentlich die Verhältnisse und veranlafst ein andres Resultat. Wir führen in diesem Fall selbst das Ereignifs herbei, ohne es nach unserm Willen darstellen zı können und die Art seines Eintreffens vorher zu sehn. Es ist daher für uns $z$ u fällig.

Wird der Würfel nur einmal aufgewosfen, so kann man keine der sechs Seiten desselben mit grölserer Wahrscheinlichkeit, als eine andre erwarten. Benutzt man dagegen zwei Würfel, so sind zwar wieder bei jedem derselben die sechs Seiten in gleichem Grade wahrscheinlich und da bei jeder Lage des einen Würfels der zweite sechs verschiedne Lagen annehmen kann, so entstehn daraus sechs und dreifsig gleich mögliche Fälle. Berïcksichtigt man aber nur die Summe der Augen der nach oben gekehrten Seiten, so sind nur noch elf verschiedne Fälle möglich, die Anzahl der Augen ist nämlich $2,3,4,5,6,7,8,9,10,11$ oder 12 . Diese Fitle sind aber keineswegs gleich wahscheinlich, denn von jenen sechs und dreilsig Lagen giebt

$\begin{array}{llc}\text { eine } 2 & \text { Angen } \\ \text { zwei } & 3 & - \\ \text { drei } & 4 & - \\ \text { vier } 5 & \text { - } \\ \text { fiinf } & 6 & - \\ \text { sechs } 7 & \text { - } \\ \text { fünf } 8 & \text { - } \\ \text { vier } 9 & - \\ \text { drei } 10 & - \\ \text { zwei } 11 & - \\ \text { und eine } 12 & -\end{array}$


Der wahrscheinlichste Wurf ist demnach sieben, und die unwahrscheinlichsten sind zwei und zwölf. In den Kinderspielen wird diese Verschiedenheit beriicksichtigt, indem für die beiden letzten Würfe die grölsten Gewinne, für sieben Augen dagegen kleine Verluste ausgesetzt sind.

Aehnliche Resultate ergeben sicl,, wenn man eine gröfsere Anzahl von Wiurfeln benutzt. Der wahrscheinlichste Wurf ist immer das Product aus der Zahl der Würfel in die Durchschnittszahl der Augen auf' allen Seiten jedes Wiìfels. Der gewöhnliche Spielwiirfel hat sechs Seiten, worauf 1 bis 6 , also zusammen 21 Augen sich belinden. Die Durchschnittszahl der letztern beträgt $3^{1} / 2$, also der wahrscheinlichste Werth der Summe der geworfenen Augen ist bei zwei Würfeln gleich 7 , bei vier gleich 14 u. s. w.

Untersucht man ferner, wie viele unter den gleich wahrscheinlichen Fällen eine Anzahl von Augen darstellen, welche sich nur wenig von dem wahrscheinliclısten Wurf entfernen, so gelangt man noch zu einem andern wichtigen Resultat. Diese Abweichung sei beispielsweise dem siebenten Theil des wahrscheinlichsten Werthes gleich, alsdann giebt es bei einem Würfel nur zwei Würfe, nämlich 3 und 4 , in denen diese Grenze nicht überschritten wird. Die Zahl der günstigen Fälle ist also gleich dem dritten Theil oder 0,333 der sechs möglichen Fälle. Bei \% wei Würfeln sind 6,7 und 8 diejenigen Würfe, die nicht melır; als um den siebenten Theil von der Mittelzahl oder von $7 \mathrm{ab}$ weichen. Die Anzahl der sämmtlichen Combinationen betriigt $6.6=36$, und davon geben, wie man sich leicht überzeugen kann, 16 jene drei Zahlen. Das Verhältnils der günstigen Würfe stellt sich also nunmehr auf $16: 36$ oder es ist 0,444 . Bei drei Wïrfeln wird dieses unter Beibehaltung derselben Grenze 104 : 216 oder 0,482 , bei vier Würfeln $676: 1296$ oder 0,522 u. s. w.

Man ersieht hieraus, dafs bei einem Wurf mit vier Würfeln oder was dasselbe ist, beim viermaligen Aufwerfen eines Würfels, der grölste Theil der gleich möglichen Fiille schon eine Anzalıl von Augen ergielst, die von der mittlern oder der walırscheinlichsten, nicht weiter, als um den siebenten Theil abweichen. In diescr Weise vermindert sich bei fortgesetzter Wiederholung des Spiels der Finflufs des einzelnen zufäligen Wurfs immer melı, und die 
Anzahl der nach oben gekehrten Augen entspricht mit zunehmender Schärfe dem mittlern Werth derselben.

Der Begriff des Wet $\mathrm{t}$ en s erläutert seh" anschaulich diese Verhältnisse. Bei einer richtigen Wette müssen die Gewinne und Verluste im umgekehrten Verhältnils der Wahrscheinlichkeit des Gewinnes zu der des Verlustes stehn. Wettet man z. B., dals beim einmaligen Aufwerfen zweier Würfel zwei gleiche Zahlen erscheinen werden, so führen unter den 36 gleich möglichen Fällen sechs dieses Ereignifs herbei, während es in den übrigen dreifsig nicht eintritt. Die Wahrscheinlichkeit des Gewinns verhält sich also zu der des Verlustes wie 1 zu 5, oder der Gewinn mul's das Finffache des Verlustes betragen.

\section{$\S 2$.}

Die Fehler der Messungen und Beobachtungen sind, wie im Folgenden ausfülırlich nachgewiesen werden wird, zufällige Erscheinungen. Sie treten bei jeder Wiederholung auf's Neue ein, und wenn man auch ihre wahre Gröfse gewöhnlich nicht kennt, so kann man doch aus den Abweichungen bei melurfacher Ausführung derselben Messung auf die Grölse der Fehler schliefsen, und hieraus erkennen, ob das Resultat als hinreichend sicher angesehn werden darf oder nicht. Diese Wiederholungen dienen aber anch noch zur Berichtigung des Resultats. Letzteres setzt sich zusammen ans dem wahren Werth der gesuchten Grölse und aus dem jedesmaligen Beobachtungsfehler, der eben so gut positiv, wie negativ sein kann. Dieser Fehler tritt, so lange er wirklich zufällig ist, und nicht etwa aus constanten Ursachen das Resultat immer in demselben Sinn entstellt wird, ganz verschieden auf. Wie beim fortgesetzten Würfelspiel der wahre mittlere Werth immer schärfer sich zu erkennen giebt, so verliert auch bei fortgesetzter Wiederholung einer Messung der zufällige Fehler der einzelnen Ablesung immer mehr seinen Einflurs auf das Resultat, und letzteres nähert sich mit immer gröfserer Schärfe dem wahren Werth.

Solche vielfachen Wiederholungen oder $R$ e pet i t i o n e $n$ sind indessen, vom Zeitverlust abgesehn, in sofern bedenklich, als im 
Allgemeinen die Aufmerksamkeit sich dabei schwächt, und sonach eine oder zwei Messungen leicht ein besseres Resultat geben, als wenn man deren 10 oder 20 anstellt. Demnächst treten dabej auch wohl, veranlalst durch zahlreiche unmittelbar auf einander folgende Ablesungen des Maalses, constante Irrungen ein.

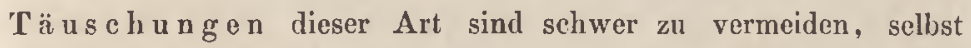
wenn man die Maafse vorsichtig abliest, und alle Einzelheiten der Operation sorgfältig iberwaclit. Vor groben Felılern kann man sich bei einiger Aufmerksamkeit zwar hüten, aber in der Nähe der Grenze des deutlichen Sehıns sind Irrungen nicht zu vermeiden, und dieselben pflegen bei jeder unmittelbar darauf wiederholten Messung in gleichem Sinn sich wieder einzustellen.

Es mag hierbei auf eine Erfahrung hingewiesen werden, dic wohl jeder Leser gemacht hat. In einiger Entfernung bemerkt man eine Inschrift, man sieht deutlich die einzelnen Zeilen, auch die Trennung der Worte, und selbst einige Buchstaben sind kenntlich, das Ganze kann man aber nicht lesen, weil bei dem zu weiten Abstand die Buchstaben noch in cinander fliefsen. Wenn alsdann jemand uns die Inschrift nennt, oder wir dieselbe crrathen, so wird sie plötzlich vollkommen deutlich, und wir sind verwundert, dals wir sie fräher nicht lesen konnten. Im Geiste gestaltet sich die Form der Schrift, diese legen wir tiber das noch unklare Bild und letzteres wird sogleich vollkommen deutlich. Obwohl wir aber nunmehr ganz sicher zu sein glauben, so ist dieses doch keineswegs immer der Fall, und oft bemerken wir, indem wir näher treten, wie selır wir geirrt haben. Das geistige Bild ist wegen seiner Vollständigkeit und Klarheit so vorlıerrschend, dafs wir dic Abweichungen des wirklichen Bildes nicht gewalı worden. In dieser Weise gestaltet sich auch leicht eine Erscheinung anders, als sie wirklich ist, sobald wir vorher schon ein Urtheil darïber uns gebildet lıben, oder wir eine gewisse Form oder ein gewisses Maafs erwarten.

Jedenfalls ist es nothwendig, das ganze Verfahren der Messung, so wie auch die dabei benutzten Instrumente und $A_{p}$ parate einer sorgfältigen $P$ rüf ung zu unterwerfen, um sich zu überzengen, dafs die unvermeidlichen Fehler das Resultat nicht zu sehr entstellen.

Dieser Vorsicht ohnerachtet erreicht man dennoch niemals 
die absolute Sielıerlıcit, rafs der Fehler nicht vielleicht in vinzelnen Fällen die erlaubte Grenze iiberschreitet und sogar sehr grofs wird. Im Folgenden wird gezeigt werden, wie man aus gewissen Proben die Wahrscheinliclıkeit für das Innelıalten gegebener Fehlergrenzen berechnen kann, oder um wieder den Begriff des Wettens einzufïlıren, wieviel man gegen Fins wetten darf, dafs diese Grenzen nicht überschritten werden. Bei gehöriger Aufmerksamkeit und wenn die äufsern Verlüiltnisse nicht gar zu ungiinstig sind, ist beispielsweise für Feldmesser-Arbeiten einc solche Sicherheit leicht zu erreichen, dafs man 999 gregen 1 darauf wetten kann, dals der erlaubte Fehler nicht ïberschritten wird, also dars bei 1000 solcher Messungen dieses nur einmal geschieht. Genïgt dieses nicht, so kann man durch gröfsere Sorgfalt und durch Benutzung besserer Instrumente einen höhern Grad von Genauigkeit erreichıen und sich dadurch vollstiindiger sichern. Dic Wahrscheinlichkeit, dafs in 10000 Fällen nur einmal ein Ereignifs nicht eintritt, oder dufs in diesem Beispiel die vorschriftsmälsige Schärfe der Messung nicht erreicht wird, gilı in gewöhnlichen Jeben wohl schon als volle Sicherheit.

Wenn es befremden sollte, dals die volle Sicherlecit stels unerreichbar bleibt, so muls darauf hingewiesen werden, wie die Wahrscheinlichkeit sehr ungewöhnlicher Ereignisse so geringe werden kann, dals das Eintreten derselben nicht in Jillionen von Jalıren (\$ 13) zu erwarten ist, obwohl sie immer möglich bleiben. In dieser Beziehung ist anzunehmen, dals niemals grofse Fehler olne Verschulden der Beobachter vorkommen, und es rechtfertigt sich daher, für solche denjenigen verantwortlich zu machen, der die Messung ausführte. Geschühlı dieses nicht, so wïrde jede Nachlässigkeit durclı das zufällige Anwachsen der Fehler entschuldigt werden.

\section{$\$ 3$.}

Ys ergieht sich schon aus Vorstehendem, wic mannigfaltig dic Anwendungen der Wahrscheinlichkeits-Rechnung sind. Von grosser Bedeutung sind sie bei Ermittelung der Einsätze für Versicherung gegen Feuersgefahr und andre Schäden, auch hat man sic vielfach benutzt, um bei Lotterien und namentlich auch bei 
complicirten Spielen die Aussicliten auf den erwarteten Gewinn nüher zu priffen. Hiervon wird in der vorliegenden Untersuchung abgesehn, es soll im Folgenden nur gezeigt werden, in welcher Weise man aus Messungen, Beobachtungen und sonstigen Erfahrungen die schärfsten Resultate ziehn und zugleich von dem Grade der Sicherheit derselben sich überzeugen kann. Nichts desto weniger mögen zunächst als Hinleitung diejenigen zelın Hauptsïtze der Wahrseheinliclıkeits-Rechnung mitgetheilt werden, die Laplace aufgestellt hat, ${ }^{*}$ ) und von denen er sagt, dals die ewigen Gesetze der Vernunft und Wahrheit darin ihre Begriindung finden. Jiesen Sätzen habe ich aber einige Erläuterungen und die nöthigen analytischen Entwickelungen beigefügt.

I. Die Wahrscheinlichkeit eines Ereignisses ist das Verluältnifs der Anzahl der Fälle, die dasselbe herbeifïhreu, zur Anzahl aller gleich möglichen Fialle.

Der Ausdruck Wahrscheinlichkeit hat hier eine sehr bestimmte und ganz andre Bedeutung, als in der gewöhinlichen Sprache. So wiirde man z. B. nicht sagen, dafs es walnscheinlich sei, bein einmaligen Aufwerf'en eines Würfols ein Ass zu treffen, nach vorstchender lerklärung giebt es aber dafïir eine bestimmte Wahrscheinlichkeit, und zwar ist dieselbe ein Seclıstel, weil es sechs gleich walırscheinliche Fille giebt, von denen einer dieses Ereignifs herbeiführt. Die Wahrscheinlichkeit, Ass nicht zu werfen, ist gleich fünf Sechstel. Die Summe Beider ist die Gew i fs lı e it, dal's entweder das line oder das Andre eintreten wird. Nach der eingeführten Bezeichnung ist diese Gewifsheit gleich Eins.

II. Der vorstelınde Satz gilt nur, wenn alle einzelnen Fälle gleich möglich oder gleich wahrscheinlich sinct. Findet dieses nicht statt, so mufs man die Wahrscheinlichkeit der särnmtlichen Fïlle mit einander vergleichen und jede in bestimmtem Zahlenwerth ausdrücken. Diese Untersuchung ist oft selır schwicrig und erfordert grofse Sorgfalt und Unbefangenheit. 1)ie Wahrscheinlichkeit des Ereignisses stellt sich alsdann wieder als ein Bruch dar, dessen Nenner die Summe aller in dieser $\Lambda$ rt gefundenen Werthe, der Zähler aber die Summe derjenigen Werthe

*) Essai philosophique sur les probabilites par M. le Marquis de Laplace. 
ențhält, welche sich auf die Fälle beziehn, die das Erejgnil's herbeiführen.

Ein Beispiel wird dieses erläutern. Man wirft eine flache Münze auf, deren Seiten mit Bild und Schrift bezeichnet werden. Es fragt sich, wie grols die Wahrscheinlichkeit ist, in zwei Würfen wenigstens einmal Bild zu werfen. Es giebt alsdann vier gleich mögliche Fälle, nämlich

1. Bild im ersten und im zweiten Wurf,

2. Bild im ersten und Schrift im zweiten,

3. Schrift im ersten und Bild im zweiten, und

4. Schrift in beiden Würfen.

Die drei ersten führen das erwartete Ereignifs herbei, daher ist nach dem obigen Satz die Wahrscheinlichkeit desselben gleich drei Viertel, oder man kann 3 gegen 1 darauf wetten, dafs es eintreten wird.

Der zweite Satz lälst sich gleichfalls hierauf anwenden, man kann nämlich auch drei verschiedene Fälle unterscheiden:

1. Bild im ersten Wurf, wobei die Wette schon gewonnen und das Spiel beendigt ist.

2. Schrift im ersten und Bild im zweiten Wurf und

3. Schrift in beiden Würfen.

Hiernach könnte es scheinen, dafs die Wahrscheinlichkeit nur gleich zwei Drittel wäre. Es ist jedoch klar, dafs die Möglichkeit oder Walısscheinlichkeit des ersten Falls gröfser, als die eines der beiden letzten ist. Jene ist in der That gleich ein halb, während sie für den zweiten und dritten Fall ein Viertel ist. Die Wahrscheinlichkeit für das Erscheinen von Bild in zwei Würfen ist daher wieder

$$
=\frac{\frac{1}{3}+\frac{1}{1}}{1}=\frac{3}{4}
$$

$\$ 4$.

III. Besonders wichtig ist die Frage, wie grofs die Walırscheinlichkeit für das Zusammentreffen mehrerer Ereignis se ist, deren Walırscheinlichkeiten man kennt. Wenn diese Ereignisse von e in ander u n a hä n g i g sind, ist die Wahrscheinlichkeit ihres Zusammentreffens gleich dem Product der Wahrscheinlichkeiten jedes Finzelnen. 
Hat Inan beispielsweise zwei Urnen, in deren jeder schwurze und weilse Kugeln liegen, die man durch das Gefühl von einander nicht unterscheiden kann, so wird es beim Eingreifen immer gleich wahrscheinlich sein, eine oder die andre Kugel zu fassen. In der ersten Urne mögen 25 schwarze und 2 weifse Kugeln liegen, in der zweiten aber 13 sehwarze und 3 weifse. Die Wahrscheinlichkeiten beim einmaligen Ziehn aus jeder der beiden Urnen, eine weifse Kugel zu treffen, sind demnach

$$
\frac{2}{27} \text { und } \frac{8}{16}
$$

und sonach nach vorstehendem Satz, die Wahrscheinlichkeit, bei einmaligem Zuge aus beiden Urnen weifse Kugeln zu fassen, gleich

$$
\frac{2 \cdot 3}{27 \cdot 16}=\frac{1}{72}
$$

Dic Richtigkeit dieser Schlufsfolge ist einleuchtend. Indem nämlich unter den 27 gleich möglichen Fällen beim Eingreifen in die erste Urne nur 2 eine weifse Kugel geben, so ist die Wahrscheinlichkeit dafür gleich 2 dividirt durch 27. Ist aber dieser Zug geschehn, und hat man wirklich eine weifse Kugel gegriffen, so sind beim zweiten Zuge wieder 16 Fälle gleich wahrscheinlich, von denen nur 3 gïnstig sind. Die Wahrscheinlichkeit dafür stellt sich daher im Ganzen auf

$$
\frac{2}{27} \cdot \frac{3}{16}=\frac{1}{72}
$$

Was für diese Zalılen bewiesen, gilt aber augenscheinlich auch für alle andern.

Die Walırscheinlichkeit, womit die mehrmalige Wiederholung desselben Freignisses unter gleichen Umständen erwartet werdeu darf, ist hiernach gleich der Walırscheinlichkeit des einmaligen Eintretens dieses Ereignisses erhoben zu der Potenz, deren Exponent die Anzahl der erwarteten Wiederholungen ausdrïckt. Die höhern Potenzen eines ächten Bruchs werden aber immer kleiner, woher die mehrmalige Wiederholung eines an sich leicht möglichen Ereignisses doch bald sehr wenig walırscheinlich wird.

Laplace schliefst hieran die folgenden Bemerkungen. Eine Thatsache sei durch zwanzigmaliges Wiedererzälılen ïberliefert worden. Wenn alsdann auch die Glaubwürdigkeit jeder Mit- 
theilung gleich 0,9 wäre, so wïrde die der schlielslichen Ueberlief'erung doch nur 0,9 zur zwanzigsten Potenz oder gleich 0,1216 oder weniger als ein Achtel sein. Diese auffallende Verminderung der Wahrscheinlichkeit kann man sehr passend mit der abnehmenden Dentlichkeit der Gegenstände vergleichen, die man durch mehrere Glasscheiben sieht. Die einzelne Scheibe lïlst kaum eine Undentlichkeit bemerken, wenn es aber melirere sind, so wird das bild bald unklar und leicht ganz unkenntlich. Die Geschichtschreiber pflegen diese Entstellung nicht sonderlich zu beachten, wenn sie von Zeiten sprechen, die viele Generationen zuriickliegen, und gewifs wïrden manche historischen Ereignisse, die man als sicher ansieht, wenigstens sehr zweifelhat't er'scheinen, wenn man sie einer solchen Prüfung unterwerfen wollte.

In den rein mathematischen Wissenschaften sind die entferutesten Folgerungen noch eben so sicher, wie die Grundsätze, von denen man ausgegangen ist. Bei Anwendung der Analysis auf' physikalische Gegenstïnde geht die Walıscheinlichkeit der zum Grunde gelegten Voraussetzungen auf alle Folgerungen ïber. In den historischen Wissenschaften leitet man dagegen jetle Folgerung nur auf eine walrscheinliche Art aus den vorlergehenden Sätzen all. Welche Sorgfalt man daher auch anwenden mag, um Täuschungen zu vermeiden, so wächst die Grölse des inöglichen Fehlers doch mit jedem Schritt, und für entfernterc Folgerungen dieser Art wird die Wahrscheinlichkeit sehr geringe.

\section{$\S 5$.}

IV. Wenn zwei Ereignisse von cinander abh ä ngig sind, so ist die Walr'scheinlichkeit des Zusammentreffens beider gleich dem Product aus der Wahrscheinlichkeit des ersten Ereignisses in die Wahrscheinlichkeit, dafs nach dem Eintreten desselben das $z$ weite noch erfolgen wird.

Hätte man z. B. drei Urnen, von denen man wiifste, dafs eine nur schwarze und zwei nur weifse Kugeln enthalten, und würste man nicht, in welcher die schwarzen sich befinden, so würde die Wahrscheinlichkeit, dafs dieses bei der Urne $A$ der Fall wäre, gleich ein Drittel sein. Die Aufgabe lälst sich indessen auch nach vorstehndem Satz lösen, indem man fragt, 
wie wahrsclueinlich es ist, in den beiden andern Lrnen l' und C' die weilsen Kugeln zu finden. Die Wahrscheinlichkeit, dufs die Urne $B$ weilse Kugeln enthält, ist gleich zwei Dritteln. Hat man aber eine weifse aus ilır gezogen, so bleibt nur noch zweifelhaft, ob $A$ oder $(Y$ die schwarzen enthält. Fïr beide Urnen ist die Walırscheinlichkeit gleich grofs, also fïr jede ein halb, dahor diejenige, dafs in $B$ und $C$ weifse Kugeln liegen, gleich

$$
\frac{2}{3} \cdot \frac{1}{2}=\frac{1}{3}
$$

Hier zeigt sich der linflufs frïherer lireignisse aul spätere. Die Wahrscheinlichkeit, in der Urne $C$ weisse Kugeln zu finden. war Anfungs gleich zwei 1)rittel, sic wird aher gleich ein halh, sobald man sich iiberzeugt hat, dal's in $B$ weilse Kugeln liegen, und sie wïre zur Gewifsheit odes gleich Eins geworden, wenn man in $B$ die schwarzen gefunden hätte. Aus dieser Betrachtung ergiebt sich der folgenile Satz:

$V$. Wenn ein erwartetes bireignils theils von einem bereits eingetretenen und theils noch vom Zufall abhaingt, so ist die Wahrscheinlichkeit dieses Zufalls gleich der Wahrscheinlichkeit resselben Ereignisses ohne Rïcksicht auf das schon eingetretene, dividirt durch die nachträglich ermittelte Wahıscheinlichkeit, womit das friihere Ereignifs erwartet werden durfte.

In letzten Beispiel war dic Walı'scheinlichkeit, bei dem ersten Zuge die weifsen Kugeln zu treffen, gleich zwei Drittel, und diejenige, in zwei Zügen weifse Kugeln zu fussen, oder was dasselbe ist, die sclıwarzen erst in der dritten Urme zu finden, gleich ein Drittel. Wenn daler das erste lieignifs bereits eingetreten ist, oder die erste Zieliung ergeben hat, dal's in der einen Urne weifse Kugreln liegen, so ist nach vorstehndern Satz die Wahrsclıeinlichkeit, im folgenden Zuge wieler weilse Kugeln zu greifen, gleich ein Drittel dividirt durch zwei Drittel, also ein lialb.

Oft fragt man, ob bei ganz zufälligen Ereignissen, wobei keine Beziehung zul den frülern stattfindet, die Vergangenheit von Einflufs auf die Zukunft sei. Dieses ist nicht der Fall. So ist es höchst unwahrscheinlicl, dals beim Aufwerfen einer flachen und ganz symmetrisch geformten Münze zehnmal nach einander 
die Bildseite sichtbar sein wird. Nach Satz III ist die Wahrscheinlichkeit dafür nur 1 dividirt durch 1024 , oder man kann vor dem Beginn des Spiels 1 gegen 1023 wetten, dafs dieses nicht der Fall sein wird. Wenn man aber bereits neunmal hinter einander Bild geworfen hat, so bleibt der letzte Wurf hicrvon ganz unabhängig, und die Wahrscheinlichkeit dafür, dafs er Bildseite geben wird, ist wie bei dem ersten Wurf gleich ein halb, weil keine Rückwirkung der frühern Ereignisse auf die folgendeu denkbar ist.

Bei wiederholtem und vorwiegendem Erscheinen von einer der beiden Seiten kann man jedoch vermuthen, dafs in der Münze selbst die Ursache hiervon zu suchen, und die Miinze nicht gleichmälsig geformt sei. Wäre dieses aber der Fall, so würde auch in Zukunft derselbe Wurf der vorherrseliende bleiben. Eben so ist das Glück, welches manche Personen in allen Lebensverhältnissen haben, gemeinhin die Folge ihrer Geschicklichkeit.

\section{$\S 6$.}

Hieran knüpft sich die Frage, wie man ans beobachteten Erscheinungen auf deren Ursachen schliefsen kann. Offenbar ist jede Ursache, der man ein Ereignifs zusclıreiben darf, um so wahrscheinlicher, mit je gröfserer Wahrscheinlichkeit dieselbe, wenn sie wirklich vorhanden wäre, das Ereignifs herbeiführen würde. Der Satz lautet daher:

VI. Die Wahrscheinlichkeit für eine der verschiednen möglichen Ursachen ist ein Bruch, dessen Zähler die Wahrscheinlichkeit ist, womit diese Ursache das Ereignifs herbeifiihrt, und dessen Nenner sich aus der Summe aller Wahrscheinlichkeiten in Betreff der sïmmtlichen möglichen Ursachen zusammensetzt. Sind aber diese Ursachen an sich nicht gleich wahrscheinlich, so mufs man jede Wahrscheinlichkeit, mit der sie das Ereignifs herbeiführt, mit der Wahrscheinlichkeit der Ursache selbst, sowohl im Zähler wie im Nenner multipliciren.

Man pflegt regelmälsig wiederkehrende Er $\mathrm{s} c$ heinungen besondern Ursachen zuzuschreiben. Oft glaubt man sogar, dafs Erscheinungen, die sich in eigenthümlicher Weise oder in einer gewissen Regelmärsigkeit darstellen, weniger wahr- 
scheinlich sind, als andre, dals z. B. beim Aufwerfen einer symmetrisch gestalteten Münze nicht so leicht zehnmal nach einander die Bildseite fallen könne, als irgend eine andre vorher bestimmte Reihenfolge, worin Bild und Schrift wechseln. Dieses ist aber nicht der Fall. Die regelmäfsigen Combinationen ereignen sich vielmelır nur deshalb so selten, weil ilher so wenige sind. An sich ist der Wurf 10 mal Bild eben so wahrscheinlich, wie etwa zuerst 1 mal Schrift, sodann 3 mal Bild, 2 mal Schrift, 1 mal Bild, $1 \mathrm{mal} \mathrm{Schrift}$ und endlich 2 mal Bild. Dieser Wurf erscheint aber ganz unregelmälsig, woher er nicht beachtet, vielmehr zur grofsen Anzahl der anscheinend gesetzlosen gerechnet wird.

Eben wegen dieser verschwindend kleinen Anzahl solcher ungewölınlichen Erscheinungen erregen dieselben den Verdacht, dafs sie nicht zufällig sich gebildet haben, sondern absichtlich herbeigeführt sind. Sehn wir z. B. die Lettern $E U R O P A$ in dieser Reihenfolge neben einander stehn, so urtheilen wir gleich, dafs sie nicht durch Zufall so gefügt wurden. An sich ist dieses Zutreffen aber eben so leicht möglich, wie irgend ein andres, wobei ein vorher bestimmtes Wort dargestellt würde, das sich vielleicht nicht aussprechen läfst und in keiner uns bekannten Sprache vorkommt. Indem aber das Wort Europa eine allgemein bekannte Bedeutung hat, so ist es ohne Vergleich viel wahrscheinlicher, dafs die Lettern absichtlich so gestellt wurden, als dals der Zufall sie zusammengefügt habe. Im letzten Fall würde diese Ursache, nümlich der Zufall, nur mit der Wahrscheinlichkeit

$$
0,000000005233=\frac{1}{191102976}
$$

diese Combination herbeigefïhrt haben, vorausgesetzt, dafs nicht mehr als 24 verschiedenartige Lettern in gleicher Anzahl im Setzkasten gelegen hätten. Es ist daher höchst unwalrscheinlich, dafs diese Ursache die Zusammenstellung veranlafst habe.

Wir sind gewohnt, die Erscheinungen, die um uns vorgehn, in gewöhnliche und ungewöhnliche oder aufserordentliche einzutheilen. Die Anzahl der letzten ist vergleichungsweise zn der der ersten gemeinhin verschwindend klein, wenn sie daher vorkommen, so wird immer der Verdacht angeregt, dals sie nicht z ufüllig eingetreten sind. Laplace bemerkt dabei, 


\section{$-14-$}

wie in gleicher Weise auch Zeugenaussagen, welche aufserordentliche Ereignisse bestätigen, besorgen lassen, dås sie auf 'Täuschıng oder Uebertreibung berulin.

\section{$\$ 7$.}

VII. Die Wahrscheinlichkeit eines kü $\mathrm{nftigen}$ Ereignisses findet man, wenn man für das bereits friiher beobachtete Eintreffen desselben Ereignisses die Wahrscheinlichkeit jeder möglichen Ursache desselben mit der Wahrscheinlichkeit multiplicirt, womit diese Ursache das Ereignifs auch in Zukunft herbeiführen kann. Die Summe dieser Producte drückt die Wahrscheinlichkeit des kïnftigen Eintreffens aus.

Wenn z. B. in einer Urne zwei Kugeln liegen, deren Farben unbekannt sind, so kann es sich treffen, dafs man während einer Reihe von Zïgen, wobei die untersuchte Kugel jedesmal wieder hineingeworfen wird, immer dieselbe Kugel farst, und daher die zweite nicht gezogen ist. Sobald man zweimal nach einander eine weifse Kugel gefafst hat, fragt es sich, wie grofs die Wahrscheinlichkeit sei, dafs der dritte $Z$ ug gleichfalls eine weifse geben werde. Man kann alsdann nur zwei Voraussetzungen machen, nämlich entweder ist die eine Kugel weifs, und die andre von andrer Farbe, oder beide Kugeln sind weifs. Nach der ersten Voraussetzung ist die Wahrscheinlichkeit des bereits eingetretenen Ereignisses oder das zweimalige Treffen der weifsen Kugel gleich ein Viertel, nach der zweiten ist sie 1. Wendet man hierauf den Sutz VI an, und betrachtet beide Vorausset\%ungen als mïgliche Ursachen, so ist die Wahrscheinlichkeit der ersten Ursache

$$
\frac{\frac{1}{6}}{1+\frac{1}{4}}=\frac{1}{5}
$$

und die der zweiten

$$
\frac{1}{1+\frac{1}{4}}=\frac{4}{5}
$$

Nach der ersten Voraussetzung ist die Wahrscheinlichkeit, beim dritten Z/ug wieder eine weirse Kugel zu fassen, gleich ein halb, nach der zweiten gleich eins. Multiplicirt man nun diesc Walırscheinlichkeiten mit denen der Voraussetanngen, so ist die 
Wahrscheinlichkeit für das Wiedererscheinen einer weifsen Kugel beim dritten Zuge

$$
\frac{1}{2} \cdot \frac{1}{5}+1 \cdot \frac{4}{5}=\frac{9}{10}
$$

Wenn die Wahrscheinlichkeit des einfachen Ereignisses unbekannt ist, so kann man dafür alle Werthe von 0 bis 1 einfïhren. Die Wahrscheinlichkeit einer jeden solchen Voraussetzung, geschlossen aus dem bereits erfolgten Eintreten des Ereignisses ist nach dem Satze VI gleich einem Bruch, dessen Zähler die Walırscheinlichkeit des Ereignisses unter dieser Voraussetzung, und dessen Nenner die Summe der Walırscheinlichkeiten der sämmtlichen möglichen Voraussetzungen ist. Multiplicirt man alsdann einen jeden dieser Brüche mit der Wahrscheinlichkeit. womit die betreffende Voraussetzung die Wiederholung des Ereignisses erwarten lärst, und summirt diese Producte, so ist dieses die Walrscheinlichkeit der Wiederkehr. In der analytischen Behandlung stellt sich das Resultat dieser anscheinend schwierigen Untersuchung sehr einfach dar.

Ein Ereignifs sei $n$ mal eingetreten. Die unbekannte Wahrscheinlichkeit des einmaligen Eintretens unter Voraussetzung einer gewissen Ursache sei $\mu$, alsdann ist die Wahrscheinlichkeit, dais unter derselben Voraussetzung das Lreignifs $n$ mal eintritt, gleich

$$
\mu^{a}
$$

und nach Satz VI ist die Wahrscheinlichkeit dieser Voraussetzmng

$$
\frac{\mu^{n}}{\left[\mu^{n}\right]}
$$

indem die Parenthese [] die Summe aller ähnlichen Glieder von $\mu=0$ bis $\mu=1$ bezeichnet. Unter Beibehaltung des Werthes $\mu$ ist die Wahrscheinlichkeit, dafs nach dieser Voraussetzung das Ereignifs auf"s Nene eintreten werde, gleich $\mu$. Die Wahrscheinlichkeit, womit nach allen :̈hnlichen Voraussetzungen dieses zu erwarten ist, wird daher

$$
=\frac{\mu \cdot \mu^{n}}{\left[\mu^{n}\right]}+\frac{\mu^{\prime} \cdot \mu^{\prime n}}{\left[\mu^{n}\right]}+\frac{\mu^{\prime \prime} \cdot \mu^{\prime \prime} n}{\left[\mu^{n}\right]}+\cdots=\frac{\left[\mu^{n+1}\right]}{\left[\mu^{n}\right]}
$$

Multiplicirt man Zähler und Nenner mit $d$, und nimmt darant' Rücksicht, dafs $\mu$ in diesen summen alle möglichen Wahr- 
scheinlichkeiten ausdrücken, also alle Werthe von 0 bis 1 :nnehmen soll, so ist

$$
\left[\mu^{n}\right] d \mu=\int \mu^{n} \cdot d \mu=\frac{1}{n+1} \mu^{n+1}
$$

also innerhalb der Grenzen 0 bis 1

$$
=\frac{1}{n+1}
$$

Eben so findet man

$$
\left[\mu^{n+1} d \mu\right]=\frac{1}{n+2}
$$

Die gesuchte Wahrscheinlichkeit ist daher gleich

$$
\frac{n+1}{n+2}
$$

Fragt man z. B., mit welcher Wahrscheinlichkeit man am nächsten Morgen die Wiederkehr des Tageslichts erwarten darf, nachdem dieses zufolge historischer Nachrichten während 5000 Jahıren regelmälsig eingetreten ist, so wäre $n$ gleich der Anzahl dieser Erfahrungen, also 1826250 und die gesuchte Wahrscheinlichkeit gleich

\section{$\frac{1826251}{1826252}$}

Man könnte also 1 gegen 1826251 wetten, dafs am nächsten Morgen das Tageslicht wiederkehren wird. Diese Wahrscheinlichkeit wird aber zur vollen Gewifsheit, wenn man den Zusammenhang der Erscheinung mit den Gesetzen der Mechanik beachtet, wobei man sich leicht überzeugt, dafs nichts die Drehung der Erde plötzlich hemmen kann.

$\S 8$.

Das Wort Hoffnung, das nach gewöhnlichem Sprachgebrauch dic Erwartung günstiger Lreignisse ausdrückt, hat in der Wahrscheinlichkeits-Rechnuug eine andre sehr bestimmte Bedeutung.

VIII. Die Hoffnung ist nämlich das Product aus dem Vortheil eines gewissen Ereignisses multiplicirt in die Walrsclieinlichkeit des Eintretens dieses Ereignisses. Wenn die Hoff- 
nung aber auf verschiedne Art in Erfüllung gehn kann, so ist sie gleich der Summe der Producte aus der Wahrscheinlichkeit iedes dieser Ereignisse in die Grölse des dadurch herbeigefülırten Vortheils. Zum Unterschied ron einem andern Begriff; worin einige fremdartige Umstände berücksichtigt werden, nennt man die vorstehend bezeichnete Grölse die mathematis che $\mathrm{H}$ offn ung.

Beispielsweise sei verabredet, dafs jemand 3 Thaler erhält, wenn er bei einmaligem Aufwerfen der Münze die Bildseite triff, und 6 Thaler, wenn er zuerst Schrift und darauf Bild wirft. Die Wahrscheinlichkeit des ersten Falls ist $1: 2$, die des zweiten $1: 4$ und die betreffenden Gewinne sind 3 und 6 . Dic Hoffnung ist also

$$
3 \cdot \frac{1}{2}+6 \cdot \frac{1}{4}=3
$$

Der entsprechende Einsatz mülste also bei richtiger Anordnung des Spiels 3 Thaler betragen.

IX. Wenn unter den zufâlligen Ereignissen einige vor theilhaft, andere nachtheilig sind, so ist die Hoffnung gleich der Differenz zwischen der Summe der ersten Producte und der Summe der Producte ans den Verlusten in die Wahrscheinlichkeiten desselben. Ist die zweite Summe gröIser, als die erste, so verwandelt sich der wahrscheinliche Gewinn in Verlust, oder die Hoffnung in Besorgnifs.

Man mufs sich stets bemühn, die Verhältnisse des Lebens so einzurichten, dafs die letzte Summe die erste nicht übersteigt. Zur richtigen Schätzung der Gewinne und Verluste und der Wahrscheinlichkeiten beider gehört aber vorzugsweise volle Unbefangenheit, und demnächst auch Erfahrung und gesundes Urtheil. Man darf sich dabei weder Vorurtheilen, noch Täuschungen durch Furcht oder Hoffinung hingeben, eben so wie auch keiņem Traum von persönlichem Gliick, womit viele Menschen ihrer Eigenliebe schmeicheln.

\section{$\S 9$.}

Die beiden letzten Sätze fïhren zuweilen zu Folgerungen. deren Erklärung nicht leiclit gewesen ist. Es werde beispielsweise 
wieder die Münze aufgeworfen, deren beide Seiten mit gleicher Walırscheinlichkeit zu erwarten sind. Wenn man die Gewinne in der Art verabredet, dals der Spieler 2 'Thaler erhält, wenn er das erste Mal Bild wirft, 4 Tlıaler, wenn dieses erst im zweiten Wurf geschieht, 8 Thaler, wenn erst der dritte Wurf Bild zeigt, und so fort, so ist die mathematische Hoffnung jedes Wurfs gleich einem Thaler, und die ganze Hoffnung für $n$ Würfe gleich $n$ Thaler. Eben so grofs müfste der Einsatz sein, folglich auch unendlich gro@s, wenn keine Grenze gesetzt würde, wobei das Spiel aufhört, falls fortwälırend die Schrift-Seite geworfen würde. Es wird indessen kein vernünftiger Mensch sein Vermögen in dieser Weise anf das Spiel setzen, noch auch eine mäfsige Summe daran wagen, weil der Verlust des gröfsten Theils vom Einsatz mit grofser Sicherheit zu erwarten, der entsprechende Gewinn aber zu unwahrscheinlich ist.

Der reelle Vortheil, den man allein berücksichtigen muls, hängt von vielen Umständen $a b$, die man oft nicht sicher in Rechnung stellen kann, der wichtigste unter diesen ist aber gewils die Grörse des eignen Vermögens. Augenscheinlich hat ein Thaler für den Millionär einen viel geringern Werth, als für einen armen Spieler, und der mögliche Gewinn einer Summe, die dem ganzen oder halben Vermögen gleich kommt, ist nicht cutfernt mit dem Nachtheil eines eben so grofsen Verlustes zu vergleichen. Man darf sich also nicht in ein Spiel einlassen, wobei das eine und das andre mit gleicher Wahrscheinlichkeit zu erwarten ist. Bei dem Gewinn und Verlust mufs man daher die absoluten und relativen Werthe unterscheiden. Von den letztern allein liaingen dic Frwartungen $a b$, und diese nehmen nur jene absoluten Werthe an, wenn das Vernögen des Spielers im Vergleich zu den Gewinnen und Verlusten sehr grofs ist. Ein allgemein gïltiger Ausdruck für die relativen Werthe lärst sich nicht angeben, doch dïrfte in den meisten Fällen der folgende, von Daniel Bernouilli anfgestellte Satz mit dem Urtheil des gesunden Mensehenverstands ïhereinstimmen.

X. Der relative Werth einer unendlich kleinen Summe ist gleich dem absoluten Werth derselben dividirt durch das Vermügen der dabei betheiligten Person. Es wird dabei vor:ansgesetzt, dafs jeder Mensch einiges Vermögen besitzt, und dieses 
niemals bis auf Nichts herabsinkt. In der That sind selbst für den Aermsten die Erträge seiner Arbeit oder auch seine Hoffnungen gleichsam die Zinsen seines Besitzthums.

Das Vermögen sei gleich Eins, und in Theilen desselben ausgedrückt sei $A$ der mit der Wahrscheinlichkeit $a$ erwartete absolute Gewinn. Alsdann ist nach dem vorstehnden Satz der relative, oder nach Laplace's Ausdruck der moralische Werth eines selhr kleinen Gewinnes gleich

$$
\frac{d A}{1+A}
$$

daher die Hoffnung auf den Gewinn $A$

$$
a \int \frac{d A}{1+A}=\log \text { nat }(1+A)^{a}+C
$$

Die Constante ist aber gleich Null, weil für $A=0$ auch $\log (1+A)=0$ ist.

Dieses ist die moralische Hoffnung, während die absolnte nach dem VIII. Satz $=a A$ war.

Wenn in gleicher Weise noch andre Gewinne $B, C \ldots$ mit der Wahrscheinlichkeit $b, c \ldots$ zu erwarten sind, so stellt sich die Summe derselben durch den Ausdruck

$$
\begin{aligned}
& \log (1+A)^{a}+\log (1+B)^{b}+\log (1+C)^{c}+\ldots \\
= & \log \left[(1+A)^{a} \cdot(1+B)^{b} \cdot(1+C)^{c} \ldots\right]
\end{aligned}
$$

dar. Zur nähern Ermittelung dieser Hoffnung bezeiclıne man ihren reellen Werth durch $x$, der ihr aber nicht mit Walrseheinlichkeit, sondern mit Gewirsheit zukommt. Alsdann ist

$$
\int \frac{d x}{1+x}=\log (1+x)=\log \left[(1+A)^{\alpha} \cdot(1+B)^{b} \ldots\right]
$$

und man erhält, wenn man auf beiden Seiten von den Logarithmen zı den Zahlen übergelit

$$
x=(1+A)^{a} \cdot(1+B)^{b} \cdot(1+C)^{c} \cdots-1
$$

Es sei verabredet, dafs nach $n$ Würfen das Spiel aufhört, und der Spieler 2 Thaler erluält, wenn gleich beim ersten Wurf die Bildseite erscheint, 4 Thaler, wenn dieses beim zweiten, 6 Thaler, wenn es zum ersten mal beim dritten geschieht u. s. w.

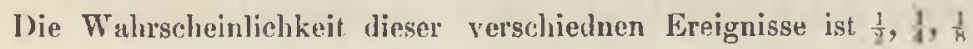


u. s, w. Die Anzahl der Factoren des ersten Gliedes ist aber gleich $n$. Erscheint nun die Bildseite zum ersten mal

beim 1. Wurf, so ist $A=2$ und $a=\frac{1}{2}$

$$
\begin{aligned}
& \text { 2. - - }-B=4-b=\frac{1}{4} \\
& \text { 3. - }-C=8-a=\frac{1}{8}
\end{aligned}
$$

II. S. w.

Der Einsatz muls, um dem Gewinn in seiner wahren Grölse zu entsprechen $=n$ sein. Nimmt man nun etwa an, dals das Vermögen des Spielers 200 Thaler beträgt und drïckt man die Gewinne in Theilen des Vermögens aus, so ist

$$
x=(1,01)^{\frac{1}{t}} \cdot(1,02)^{\frac{1}{t}} \cdot(1,04)^{\frac{1}{6}}, \ldots-1
$$

Hiernach bereclınet sich die Aussicht aut den moralischen Gewinn, in Theilen des Vermögens ausgedriickt $(=x)$ oder in Geldwerth $(=x)$ und zieht man hiervon den Einsatz $(=n)$ ab, so ist der wirkliche Gewinn $(=h)$ jedesmal negativ. Man hat nämlich, wenn das Spiel spätestens nach $n$ Würfen beendigt sein soll,

\begin{tabular}{r|c|c|c} 
für $n$ & $x$ & $x^{\prime}$ & $h$ \\
\hline 1 & 0,004984 & 0,997 & $-0,003$ \\
2 & 0,009974 & 1,995 & $-0,005$ \\
3 & 0,014937 & 2,987 & $-0,013$ \\
4 & 0,019830 & 3,966 & $-0,034$ \\
5 & 0,024571 & 4,914 & $-0,086$ \\
6 & 0,029026 & 5,805 & $-0,195$ \\
7 & 0,033010 & 6,602 & $-0,398$ \\
8 & 0,036340 & 7,268 & $-0,732$ \\
9 & 0,038912 & 7,782 & $-1,218$ \\
10 & 0,040756 & 8,150 & $-1,850$ \\
11 & 0,041981 & 8,396 & $-2,604$ \\
12 & 0,042722 & 8,544 & $-3,456$ \\
13 & 0,043237 & 8,647 & $-4,353$ \\
14 & 0,043519 & 8,704 & $-5,296$ \\
15 & 0,043681 & 8,736 & $-6,264$
\end{tabular}

Die moralische Aussicht auf Gewinn ist also jedesmal kleiner, als der Einsatz, und der Verlust wird selrr bedentend, wenn eine gröfsere Anzalıl von Wïrfen verabredet wird. 
Jener Ausdruck fïr $x$ zeigt aber, dafs wenn die erwarteten Gewinne $A, B, C \ldots$ vergleichungsweise zum Vermögen des Spielers selır klein sind, dafs man alsdann ilure zweiten, wie auch die hïhrern Potenzen, und eben so die Producte $A B, A C, B C \ldots$ gleich Null setzen darf, und hieraus ergiebt sich

$$
\begin{aligned}
x & =(1+a A)(1+b B)(1+c C) \ldots-1 \\
& =a A+b B+c C+\ldots
\end{aligned}
$$

Die moralische Hoffinung ist daher in diesem Fall eben so grol's, wie die absolute und entspricht dem Kinsatz.

$\Lambda$ us Vorstehndem ergiebt sich noch, dars in jedem spiel, wenu auch die Einsïtze den Gewinnen entsprechen, die Verluste immer etwas emptindlicher sind, als die eben so wahrscheinlichen und eben so grofsen Gewinne. In viel höherem Grade ist dieses aber bei solchen Spiclen der Fall, wo die Einsätze sogar die mathematische Holfnung iibersteigen, wie bei allen Spielbanken, weil dieselben einen gewissen Vortheil sich sichern müssen.

Aus dem Satz $\mathrm{X}$ ergiebt sich noch, dafs man bei unvermeidlichen Gefahren nicht sein ganzes Vermögen von einem Zulall abhängig machen darf, man es vielmehr vertheilen muls, danit die zufälligen Verluste nicht zu grols werden. Ist das Vermögen aber an sich zu unbedeutend, um es bei dieser Vertheilung noch vortheilhaft anlegen zu können, so thut man wolıl, mit andern l'ersonen, die in gleicher Verlegenheit sind, in Verbindung zu treten. Hierauf berultt der moralische Werth der Versicherungs-Gesellschaften. In vollem Maals tritt ein solcher jedoch nur ein, wenn das ganze cigne Vermögen, oder ein grofser Theil davon durch dasselbe zufällige Ereignifs verloren werden kann. Lälst sich dieses vermeiden und kann man selbst eine so vielfache Theilung vornehmen, dafs die möglichen Verluste nur unbedeutend bleiben, so sprechen manche Gründe dafür, die gegenseitige Versicherung zu unterlassen. So pflegt der Rheder, dem eine gröfsere Anzahl von Seeschiffen gehört, dieselben bei keiner Gesellschaft zu versichern, indem die Prämien, die er diesen zahlen mülste, den Werth der wahrscheinlichen Verluste etwas übersteigen. Diese Differenz beruht theils auf den nothwendigen Verwaltungskosten, theils aber auch darauf, dals die Walırscheinlichkeit der Verluste für alle Theilnehmer nicht dieselbe ist, viel- 
mehr gut ausgeriistete und tüchtig bemannte Schiffe seltner Scluden nehmen, als andre. Der reelle und vorsichtige Besitzer vieler Schiffe findet es daher angemessner, diese in einem besondern Conto bei sich selbst zu versichern.

Indem man sich durch Versicherungen solcher Art vor grofsen Verlusten schützt, so tiberträgt man das unvermeidliche Risico auf eine Gesellschaft, deren Vermögen viel gröfser ist, als das des Einzelnen, bei der also Verluste und Gewinne sich ausgleichen. Wie sehr diese Einrichtung sich rechtfertigt und als wohlthütig angesehn werden muls, so kommt doch nicht selten anch das Gegentheil vor, indem grofse Capitalisten, um ihr Conto sogleich sicher abzuschliefsen, sich mit Speculanten einlassen, die bei weit geringerem Vermögen die zufälligen Verluste und Gewinne gegen gewisse Abfindungs-Summen ïbernehmen. Dieselben verstehn sich aber hierzu nur, wenn die mathematische Hoffnung überwiegend grofs ist, sie also melır Aussicht nuf Gewinn, als auf Verlust haben. Ein solcher Vortheil gebührt auch dem Unternelımer als Vergütung für die Besorgung des Geschüfts. Bctrachtet man dagegen den moralischen Werth, den die zufälligen Gewinne und Verluste für den Unternehmer bei seinem beschränkten Vermögen lıaben, so überzeugt man sich leicht, dafs er das Risico nur tragen kann, wenn ihm aufser jenem bereits erwähnten, noch ein neuer bedentender Vortheil zugesichert wird. Dieser Vortheil sei gleich $x$ und der Gewinn sei $A$, der mit der Wahrscheinlichkeit $a$ zu erwarten ist, während mit derselben Wahrscheinlichkeit auch ein Verlust $A$ eintreten kann. Endlich sei $m$ das Vermögen des Unternehmers. Hiernach ist

$$
x=-1+\left(1+\frac{A}{m}\right)^{a} \cdot\left(1-\frac{A}{m}\right)^{a}
$$

oder der Geldwerth der entsprechenden Entschädigung ist

$$
m-m\left(1-\frac{A^{2}}{m^{2}}\right)^{a}
$$

Vernachlässigt man dabei die höhern Potenzen des zweiten Gliedes in der Parenthese, so verwandelt sich dieser Ausdruck in

$$
\frac{a A^{2}}{m}
$$

woraus sich ergiebt, dafs diese letzte Vergütung im umgekehrten 
Verhältnils zum Vermögen des Unternehmers steht, der Aermere also zu gröfsern Forderungen, als der Reichere berechtigt ist.

Die Hoffnung, dafs der Unternehmer das Risico wirklich trugen wird, ist indessen, wie die Erfahınng zeigt, nur begründet, so lange die Verluste geringfügig bleiben. Stellen sie sich dagegen in bedeutender Grölse ein, so kann der Unternehmer dieselben nicht decken, weil ilım die uöthigen Mittel fehlen, andern Theils werden aber auch in solchen Fällen, namentlich bei Bauten, die der Staat, oder eine Communal-Verwaltung an einen Entrepreneur iibertrïgt, bei ungünstigem Erfolge jedesmal fïr die Erstattung der Verluste Billigkeitsgrïnde geltend gemacht, die gemeinhin niclit unberücksichtigt bleiben, solvald der Nachweis gefuilırt werden kunn, dafs die Verluste ohne eignes Verschulden eingetreten sind. Diese Uebertragung des IRisicos auf einen Einzelnen ist ein Gliicksspiel, wobei der Banherr, oder der Stuat, vorweg auf den Gewinn in günstigen Chancen verzichtet, aber dennoch die grölsem zufälligen Verluste tràgen mufs.

Glücksspiele dieser $A$ rt sind olme Zweifel liöchst unvortheilhaft und dennoch wird niclit selten, und in manchen Staten sogar regelmïlsig, darauf eingegangen. Vorzugsweise geschieht dieses wohl in der Absiclit, schon vor dem Beginn eines Baues den Kostenbetrag desselben ganz bestimmt bezeichnen zu können, zuweilen glaubt man auch andre Griinde daftir geltend machen zu müssen. Jedenfalls ist es aber für den Sttat, als den gröfsten Capitalisten, immer am vortheillaftesten, wenn er das Risico siclı selbst vorbehält, weil alsdann die möglichen Gewinne und Verluste sich wirklich ausgleichen. Nur solche Arbeiten, deren Ausdehnung sich bestimmt vorherselın läfst und die von keinen Zufäligkeiten abhängig sind, eignen sich zu Entreprisen und noch mehr zu Accorden, und zwar unmittelbar mit den Arbeitern, die sie ausführen.

\section{$\S 10$.}

Von grofser Bedentung ist die Anwendung der Walırscheinlichkeits-Rechnung auf Beobachtungen, und hiervon wird im Folgenden allein die Rede sein. Jede Messung ist, wie bereits erwähnt, mit zufalligen Fehlern behaftet, wenn sie aber oft wieder- 
holt wird, so lassen sich diese Fehler nicht nur in gewissen Grade beseitigen, sondern sie geben anch Gelegenheit zu bcurtheilen, welche Sicherheit die gewonnenen Resultate laben.

Die Beobachtungsfehler riihren zuweilen, und namentlich bei mangelhafter Uebung im Gebrauch der Instrumente und Apparate, von der falschen Aufstellung und unrichtigen Belıandlung der letztern, oder von groben I r ungen im Ablesen der Marse her. Sie können alsdann leicht ïberaus grol's werden und folgen nicht mehr den Gesetzen der Walırscheinlichkeits-Rechnung, dic tïr jede einzelne Beobachtung gleiche Fehler-Ursachen voraussetzt. Bei unvorsichtiger Benutzung der Instrumente sind zuweilen auch sämmtliche Messungen mit gewissen constanten Fehlern, wic etwa mit Collimations-Fehlern behaftet, die also durch Vergleichung der einzelnen Ablesungen sich nicht zu erkenuen geben, während viclleicht dic Uebereinstimmung derselben sogar einen hohen Grad von Genauigkeit vermuthen läfst. Auch von Fehlern dieser Art, die also nicht mehr zufällig sind, ist hier nicht die Rede, sondern nur von solchen, die nach gehöriger Berichtigungr der Instrumente und bei voller Aufmerksamkeit und Uebung im Messen sich nicht vermeiden lassen. Ob diese Fehler positiv oder negativ ausfallen, und wie grofs sic sein werden, lüist siclı weder durch blofse Ueberlegung, noch durch Rechnung vorhersehn. Sie sind also zufällige Erschein un gen und den Gesetzen des Zufalls unterworfen.

Die Instrumente oder Mels-Apparate sind stets in gewissem Glade ungenau und mangelhaft. Die Schärle der Einstellung und Ablesung ist begrenzt, und eben so ist das Mrafs oder die Theilung mit gewissen Fellern behaftet, die selbst durch die sorgfältigste Prüfung nur bis zu einem gewissen Grade festgestellt und zur Berichtigung der Ablesung beseitigt werden können. Endlich sind auch unsere Sinue nicht vollkommen. Selbst das schärfste Auge, von allen Mitteln der Optik unterstützt, kann nur bis zu einer näheren oder entfernteren Grenze die Erscheinungen verfolgen, während die kleineren Maafse, die jenseits derselben liegen, nicht mehr sicher zu erkennen sind.

Hiernach sind alle Beobachtungen mit gewissen Fehlern behaftet, die von der Eigenthümlichkeit der Erscheinung, so wie von der Giite der dabei benutzten Instrumente und von der 
Geschicklichkeit und Aufmerksamkeit des Beobuchters ablıängen. Es giebt aber jedesmal bei wiederholter Messung, wiihrend die iufsern Einwirkungen dieselben bleiben, oder von ihren Aender'ungen Rechnung getragen wird, und wenn jene groben Irrungen vermieden werden, von denen bereits die Rede war, einen g e w is s e n Grad von Genauigkeit, den man dabei erreicht, oder die Fehler treten in derselben Weifse auf, wie andre Lirscheinungen, die von älınlichen Zufälligkeiten abhängeu. Sie folgen also den Gesetzen der Wahrscheinlichkeits-Rechnung, in gleicher Weise, wie dieses beim Würfelspiel, orler beim Ziehn von I,ousen geschieht.

Die Methoden dieser Rechnung lehren zunächst die wahrscheinliclısten Werthe der unbekannten Constanten aus Beobachtungen zu tinden, die sämmtlich mit zufälligen Fehlern derselben Art behatet sind. Dabei wird aber vormugesetzt, dals die $\Lambda$ nzahl der Beobachtungen gröfser als die der Unbekannten ist. Wäron beide einander gleich, so wïrde man zwar ganz bestimmte Resultate erlralteu, die judoch von den Beobachtungsfehlern im vollsten Maufse entstellt sind, indem einc Ausgleichung der letztern in diesem Fall nicht eintreten kann. Ist die Anzahl der Unbekannten kleiner, als die der Messungen, so lassen sich fiir jene keine Werthe finclen, welche die sämmtlichen Beobachtungen in aller Schürfe darstellen, aber wohl solche, die einer Ausgleichung der Fehler nach den Gesetzen des Zufalls entsprechen, und sonach die wahrscheinlichsten und zugleich anch richtiger sind, als jene, die aus Peobachtungen berechnet wurden, deren Anzall eben so grofs, wie die der Unbekannten war.

Vergleicht man demnächst die einzelnen Messungen mit denjenigen Werthen, welche sich durch linführung der in dieser Art gefundenen Unbekannten darstellen, so lassen die Differenzen zwischen beiden erkennen, welchen Grad der Wahrscheinlich. ke it sowohl die Messungen selbst, als auch die daraus hergeleiteten Resultate haben. Diese Untersuchung ist insofern von der höchsten Bedeutung, als sie zu einer richtigen Wïrdigung der gewonnenen Resultate fülıt. Die zuweilen sehr willkürlichen und zum Theil sogar augenscheinlich unrichtigen Lehrsätze in manchen ErfahrungsWissenschaften, würden nicht aufgestellt sein, wenn ilore Erfinder die Sicherheit der vermeintlichen Entdeckung einer vorurtheilsfreien und methodischen Prüfung unterworfen, und die gefundenen 
Resultate als ungiiltig granz unterdlüickt, oder als lö̈chst zweifelhaft bezeichnet hätten, sobald diese sich nicht mit grol'ser Wahrscheinlichkeit annähernd als richtig lıerausstellten.

Endlich fülıren die Methoden der Wahrscheinlichkeits-Rechnung auch bei Vergleichung verschiedener Hypothesen zu cinem sichern Urtheil über dieselben. In vielen Fiillen ist nämlich der Zusammenhang der einzelnen Wirkungen, welche eine Erscheinung veranlassen, so complicirt, dals es nicht gelingt, denselben theoretisch zu verfolgen. Es bleibt alsdann nur iibrig, gewisse Hypothesen einzuführen. Wenn diese aber gleiche Berechtigung haben, so entsteht die Frage, welche von ihnen durch die vorliegenden Beobachtungen am meisten bestïtigt wird.

Fin Beispiel wird dieses Verhältnifs klar machen. IDic Bewegung des Wassers in cyliudrischen Rölıren ist vergleichungsweise eine sehr einfaclic Ersclıeinung, es ist aber bisher noclı nicht geglückt, sie gelı̈rig aufzuklären. In einer Röhre ist die Geschwindigkeit des hindurchströmenden Wassers augenscheinlich von der Iruckliöhe abhängig. Bei uns wird gewöhnlich vorausgesetzt, dafs diese Druckhöhe dem Quadrat der Geschwindigkeit des Wassers proportional sei, in Frankjeich nimmt man dagegen an, die Druckhölıe sei der Summe zweier Glieder gleich, von denen das eine die erste und das andre die zweite Potenz der Geschwindigkeit zum Factor hat. Wolt $\mathrm{m}$ an maclite schou frïher darauf aufmerksam, dafs die ilım vorliegenden Beobachtungen sich ziemlich befriedigend darstellen, wenn man die Drucklïlıe der $1^{3} / 4$ ten Potenz der Geschwindigkeit proportional setzt. In älnolicher Art hat man in neuster Zeit verschiedentlich versucht, andre Exponenten zu finden, die den Beobachtungen noch melır entsprechen. Es sind also sehr verschiedne Hypothesen aufgestellt worden, denen man, so lange der walıre Zusammenlıang unbekannt ist, mit gleichem Rechte noch viele andere hinzufügen könnte. Die Wahrscheinlichkeits-Rechnung lehrt nun das Criterium, woran man erkennt, welche von diesen Hypotliesen den vorliegenden Beobachtungen sich am schärfsten anschliefst. Sie bietet aufserdem auch Gelegenheit zu beurtheilen, ob diese wahrscheinlichste Hypothese als die richtige angeselın werden darf, oder ob sie nur innerhalb gewisser Grenzen giiltig ist. Wenn nämlich die Differenzen zwischen den beobachteten und den nach dieser 
Hypothese berecheten Werthen ganz zuffillig laald positiv, hald negativ ausfallen, so darf man sie als Beobuclitungs-Fehler anselun, wenn sie dagegen, nach der Grölse der Variabeln geordnet, sich in gleichem Sinn regelmälsig verändern, also entweder grölser, oder kleiner werden, so ist dieses ein sichres Zeichen, dafs die zum Grunde gelegte Hypothese nur innerhalb gewisser Grenzen als zutreffend angesehn werdeu darf, dals sie aber keineswegs die Erscheinung vollständig darstellt.

Es ergiebt sich hieraus, welchen wesentlichen Nutzen die Walırscheinlichkeits-Rechnung bietet, so oft man aus Messungen und Beobachtungen sichre Resultate ziehn will. 


\section{Abschnitt.}

\section{Beziehung zwischen der Gridiso der Beohathtungsfehler und der Wahrscheinlichkeit ihres Vorkommens.}

\section{$\$ 11$.}

Die Gesetze, denen die Beobachtungsfehler unterliegen, ergeben sich, wenn man auf die F ehler-Q uelle n zurïkgeht.

Indem die Beobachtungs-Fehler, wie vorstehnd gezeigt ist, zutällig sind, so können sie die Resultate eben so leicht vergröfsern, wie verkleinern, sic lassen sich auch nicht berichtigen, so lange die Messung nicht wiederholt, oder in ander Weise geprifft ist. Der wahrscheinlichste Werth einer nur einmal gcmelsnen Grölse ist derjenige, den man gerade gefunden hat. Ist dagegen die Messung ein- oder melırmals wiederholt, so kaun dic dauerude Wiederkehr desselben zufalligen Fehlers eben so wenig eintreten, wie man beim wiederholten Aufwerfen eines richtigen Würfels immer dieselbe Seite wieder erwarten darf, es werden vielmelır diejenigen Abwechslungen sich zeigen, die eben den 'Lufall charakterisiren, und die bei vielfacher Wiederholung zuletzt dazu dienen, den Finfluls der constanten Ursachen von denen des Zufalls zu trennen, und sonach die letztern aus dem Resultat immer mehr zu entfernen.

Wenn man dieselbe Grölse vielfach gemessen und sich dabei bemültt hat, nicht nur durch unmittelbare Ablesung des Maafses, sondern auch über die Theilung ljinaus, also durch Schätzung das Resultat jedesmal möglichıst sclıarf auszudrücken, so werden die gefundnen Unterschiede allein von jenen zufälligen Fehlern herrïhren. Die Abweichungen von dem mittlern Werth sind aber nicht nur durch das Zeichen von einander verschieden, in. 
dem sie bald positiv, bald negativ ausfallen, sondern sie stellen sich auch in ihrer absoluten Grölse sehr abweichend dar. Zuweilen verschwinden sie ganz, sie können aber alle Abstufungen bis zu ih'en gröfsten Werthen einnehmen. Bei vielfachen Wiederholungen ist indessen die Anzahl der Abweichungen zwischen je zwei gleich weit entfernten Grenzen nicht gleich gro@s, vielmehr kommen kleinere Abweichungen jedesmal häufiger vor, als grölsere. Wenn man zum Beispiel eine Linie von $\check{0} 0$ Ruthen Länge mit der Kette wiederholentlich mifst, indem man jedesmal die Stellen, wo die Kettenstäbe eingesetzt wurden, unkenntlich macht, so wird wohl keine Abweiclıng von melurerea Fufsen vorkummen, Unterschiede von einigen Zollen oder noch kleinere werden sich aber ım so häuffiger wiederholen, je geringer sie sind. Eben so wird man beim wiederholten Messen eines Winkels viel häufiger Abweichungen von einigen Minuten, als von ganzen Graden finden. Dasselbe geschieht bei allen Messungen und Beobachtungen. Hiernach ist es wahrscheinlicher, einen kleinern, als einen grölsern Felıler zu begehn, oder es findet bei jeder Beobachtungs-Art zwischen der Grölse des Fehlers und der Walırscheinlichkeit seines Vorkommens eine gewisse Beziehung statt. Die Wahr$\mathrm{scheinlichkeit}$ eines gewissen Fehlers ist sonach eine Function seiner Gröfse, die positiven und negativen Fehler sind aber gleich wahrscheinlich, wenn man, wie vorausgesetzt wird, constante Fehler-Ursachen vermeidet.

Zur Darstellung des analytischen Ausdrucks dieser Function oder der Beziehung zwischen der Grölse des Fehlers und der Wahrscheinlichkeit seines Vorkommens soll hier ein Weg gewählt werden, der im Gebiet der Wahrscheinlichkeits-Rechnung keineswegs ungewöhnlich, der aber zu diesem Zweck früher nicht benutzt war. Er gewährt den Vorzug einer grofsen Anschaulichkeit. und führt ohne fremdartige Hypothesen zum Ziel, während er zugleich nur solche Vorkenntnisse in Anspruch nimmt, die ziemlich allgemein verbreitet sind.

\section{$\S 12$.}

Der Beobachtungsfehler ist im Allgemeinen niemals die Folge einer einzelnen Ursache, er setzt sich vielmehr aus einer grofsen 
Anzahl verschiedner Fehler zusammen, die sowohl von allen Theilen des Meisapparats, wie auch von allen Einzelheiten bei Benutzung desselben herrühren. Wird zum beispiel eine Linie von der Länge einer Viertel-Meile gemessen, so mufs die Kette hundertmal ausgespannt werden, und jeder Fehler beim einmaligen Ausspannen hat Einflufs auf das Resultat. Der Fehler des letzteru ist die algebraische Summe dieser partiellen Fehler, oder die Differenz zwischen der Summe der positiven und negativen. In gleicher Weise kann man aber auch schon den Fehler beim einmaligen Ausspannen der Kette in eine grofse Anzahl entfernterer Fehler zerlegen. Die Länge der Kette wird nämlich von Zeit zu Zeit mit dem Etalon verglichen. Man spannt sie zu diesem Zweck auf ebnem Boden aus, und überzeugt sich, dais die Kettenstäbe von Mitte zu Mitte wirklich 5 Ruthen von einander entfernt sind. Ist ihr Abstand gröfser oder kleiner, so bringt man die erforderliche Berichtigung an. Wenn aber beim fernern Gebrauch die einzelnen Glieder eine andre Lage annehmen, oder wenn der Boden weniger eben ist, als er bei der Probe war, oder die Kette schärfer oder schwächer angezogen wird, oder die Temperatur eine andre ist, oder überlanpt irgend welche veränderten Umstände eintreten, so werden offenbar eine sehr grolse Anzalıl Abweichungen eingefülırt, deren algebraische Summe schon den Fehler der einzelnen Kettenlänge bildet. Auch bei WinkelMessungen und überhaupt bei jerler Art von Messung findet dasselbe statt, woher es keineswegs eine unbegrïndete Voraussetzung ist, vielmehr aus der nïhern Betrachtung des ganzen Verfahrens beim Gebrauch und bei der Anfertigung des Mefsapparats sich schon erklärt, dafs der Fehler jeder Messung sich aus einer sehr grofsen Anzahl von clementären Fehlern zusammensetzt. Diese Anzahl vergröfsert sich aber immer mehr, je weiter man anf die entfernteren Fellerquellen zurückgeht.

Jeder Beobachter und eben so auch jeder Mechaniker, der den Apparat anfertigt, ist benuiht, constante Fehler zu vermeiden, die clas Resnltat der Messung jedesmal vergrïisern, oder jedesmal verkleinern. Hierher gehört schon die erwähnte Prüfung der Kette durch das Ftalon, und in älnnlicher Art wird der vorsiclıtige Beobachter nie versäumen, diejenigen Prüfungen vorzunehmen, worlurch er sich äherzengen kann, dal's sein Instrument 
den nöthigen Grad von Richtigkeit hat, oder aber er wird die nicht zu beseitigenden Fehler ermitteln und die entsprechende Berichtigung in das Resultat einführen. Iis folgt hieraus, dafs jeder noch bleibende Fehler ein zufälliger ist, und daher eben so leicht positiv, wie negativ sein kann. Die Wahrscheinlichkeit für einen positiven Werth desselben ist daher eben so grofs, wie für einen negativen.

Wenn diese Vornussetzungen als in sich begründet anerkannt werden, so könnte doch die Annalıme, dals es für jede Messung unendlich viele und zwar gleich grofse, elementäre Fehler giebt, Bedenken erregen. Indem man aber bei jeder Fehlerquelle noch auf entferntere Ursachen derselben zurückgehn kann, und es hierbei in der That keine Grenze giebt, so wird auch diese Voraussetzung nicht unpassend erscheinen, man $\mathrm{mufs}$ sie aber machen, wenn man die Beobachtungsfehler allgemein auffassen und nicht etwa eine bestimmte Art von Beobachtungen untersuchen will. Im letzten Fall liefse sich allerdings das Zusammentreffen einer mälsigen Anzahl partieller Fehler und zwar von verschiedner Grölse denken, aber die Feststellung der Verhältnisse würde immer sehr willkürlich bleiben, und die gefundnen Resultate würden nur auf diese Art der Messung Anwendung finden.

Die der folgenden Untersuchung zum Grunde liegende Hypothese lautet demnach:

"Der Beobachtungsfeliler ist die algebraische Summe einer unendlich grofsen Anzahlelementärer Fehler, die alle gleichen Werth haben und eben so leicht positiv, wie negativ sein kännen."

Diese Voranssetzung führt durch einfache Betrachtungen zu Iem Ausdruck, der die Wahrscheinlichkeit des Iintretens der Fehler von verscliedner Gröfse bezeichnet, und zwar stimmt derselbe genau mit demjenigen ïberein, den zuerst $G$ a u $f$ s herleitete, intem er annahm, dufs bei wiederholter Messung einer einfachen Gröfse das arithmetische Mittel der wahrscheinlichste Werth sei. 'T lo mas Young hatte dagegen einer Untersuchung über die Wahrscheinlichkeit der Beobachtıngsfehler schon eine Hypothese zum Gruncle gelegt, die der hier gewählten sehr ähnlich ist. Die Resultate, zu deuen er gelangte, beschränkten sich indessen nur anf einige Vorsichts-Maafsregeln bein Beobachten, ohne zu eines 
Methode zu führen, nach welcher die wahrscheinlichsten Werthe sicher dargestellt werden konnten*). Später hat Bessel sowohl unter Annahme einer einzigen, wie mehrerer Fehler-Quellen und unter der Voraussetzung, dafs jeder Fehler eben so leicht positiv, wie negativ sein kann, jenes von Gau fs aufgestellte Gesetz, unabhängig vom aritımetischen Mittel hergeleitet**). Der dabei verfolgte Weg bietet indessen grö̂sere Schwierigkeiten, woher er sich für die hier beabsichtigte, möglichst einfache Begründung nicht eignet.

\section{$\S 13$.}

Nach vorstehnder Auffassung ist der Beobachtungsfehler gleich der Differenz zwischen den Summen der in unendlicher Auzahl auftretenden positiven und negativen elementären Fehler, von denen jeder eben so leicht positiv, wie negativ sein kann. Das Verhältuifs ist also genau dasselbe, als wenn in einer Urne eine gewisse Anzahl schwarzer und eben so viele weifse Kugeln liegen und man wiederholentlich eine herauszieht, die man aber, nachdem man sie gesehn, wieder hineinwirft, damit immer eben so viele schwarze wie weilse Kugeln in der Urne bleiben. Es fragt sich, mit welcher Walırscheinlichkeit man bei einer grofsen Anzahl von Zügen verschiedne Differenzen zwischen den schwarzen und weirsen Kugeln erwarten darf.

Bei jedem einzelnen Zuge ist es eben so wahrscheinlich, eine schwarze, wie eine weifse Kugel zu fassen. Wenn man also nur einmal eingreift, so ist die Wahrscheinlichkeit für jede gleich ein Halb und die Summe dieser beiden Wahrscheinlichkeiten ist eins, oder die Gewilsheit, dals man entweder eine schwarze, oder eine weilse Kugel ziehn wird.

Indem die sclıwarzen Kugeln mit $S$, die weifsen mit $W$ bezeichnet werden, sind bei zwei Ziehungen vier Fälle gleich wahı'scheinlich, nämlich

\section{$S S, S W, W S$ und $W W$}

die Wahrscheinlichkeit eines jeden also gleich ein Viertel. Wenn

*) Remarks on the probabilities of error in physical observations. Philosophical Transactions for 1819.

**) Schu u acher's Astronomische Nachrichten. Bd. 15. Altona 1838 
man aber die Reihenfolge der schwarzen und weilsen Kugeln unbenchtet läfst, und nur die Anzahl derselben berïcksichtigt, so fallen die $S W$ und $W S$ zusammen, und die Walırscheinlichkeit einer solchen Ziehung ist gleich ein laalb.

Bei der dritten Ziehung und noch mehr bei jeder folgenden werlen die Unterschiede in den Werthen der Wahrscheinlichkeit ler verschiednen Combinationen immer gröfser, und immer weniger darf man erwarten, nur scliwarze oder nur weilse Kugeln zu fassen. Zieht man hundert mal eine Kugel aus jener Urne, so ist diese Wahrscheinlichkeit nur noch 1 dividirt durch die hundertste Potenz von 2 , oder 1 dividirt durch

\section{6 .}

Um diese geringe Wahrscheinliclıkeit zu versinnlichen, wälle man das Aufwerfen von hundert Münzen, statt des hundertmaligen Zielıns aus der Urne, weil letzteres zu zeitraubend sein würde. Die Wahrscheinlichkeit für das gleichzeitige Erscheinen von allen Schrift- oder allen Bildfüichen ist aber eben so grols, wie für jene 100 schwarzen Kugeln. Wenn man in jeder Secunde einmal die Münzen aufwerfen könnte und ununterbrochen das Spiel fortsetzte, so wiirde man in einem Jahre doch nur 31567600 Würfe machen, es wäre also durchaus nicht zu erwarten, dafs man die sämmtlichen Bildflächen träfe. Aber selbst wenn alle menschlichen Bewohner der Erde oder 1000 Millionen Menschen mit derselben Schnelligkeit und ohne Unterbrechung Tag und Nacht hindurch dieses Spiel trieben, so würde dennoch nicht etwa in einem Jahr oder in einem Jahrhundert ein solcher Wurf vorkommen, sondern man könnte nur erwarten, oder 1 gegen 1 darauf wetten, dafs in allen diesen Spielen erst in 43 Millionen mal Millionen Jahren einmal die Bildfïchen aufgeworfen werden. Dieses wäre also eine Begebenheit, die freilich möglich, deren Wahrscheinlichkeit aber so geringe ist, dals man nach menschlichen Begriffen nur sagen kann, sie tritt niemals ein.

\section{$\S 14$.}

Bei fortgesetztem Ziehn der Kugeln aus der Urne, die immer eben so viele schwarze, wie weifse enthält, sind schon nach zwei Zügen zwei Gruppen möglich, die sich nicht durch die 
Anzahl, sondern nur durch die Reihenfolge der $S$ und $W$ von einander unterscheiden. Diese verbinden sich zu einer, wenn man auf die Reihenfolge nicht Riicksicht nimmt. Noch mehr geschieht dieses bei drei, vier und weiteren Ziehungen, wobei immer mehr gleich wahrscheinliche Fïlle zu einer Gruppe sich vereinigen. Indem die Wahrscheinlichkeit solcher Combinationen der Anzahl der darin enthaltenen, an sich gleich walırscheinlichen Fälle proportional ist, so kommt es dauraf an, diese Anzahl zu finden. Dieses geschieht selır einfach durch Vergleichung der auf einander folgenden Ziehungen mit den Zahlen-Coefficienten der Glieder eines Binomiums, dessen Exponent mit der Anzalıl der Zielıungen übereinstimmt. Wie in letzteren jedesmal die Anzahl der gleich wahrscheinlichen Fälle sich verdoppelt, so geschieht dieses auch mit den Gliedern des Binomiums $a+b$, so lange man dabei auch die Reihenfolge der Factoren beachtet. Wie dort zu jeder bereits dargestellten Gruppe einmal ein $S$ und sodann ein $W$ hinzutritt, so wird hier jedem Gliede der Factor $a$ und der Factor $b$ zugefïgt

$(a+b)^{1}=a+b$

$(a+b)^{2}=a a+b a+a b+b b$

$(a+b)^{3}=a a a+b a a+a b a+b b a+a a b+b a b+a b b+b b b$ u. 8 , w.

Bei dieser genau übereinstimmenden Zusammensetzung fallen von diesen Grupıen auch in gleicher Weise melırere zusammen, sobald man von der Reihenfolge der $a$ und $b$ absieht. Ein Unterschied zwischen jenen Kugeln und diesen Gliedern findet nur in so fern statt, als hier die $a$ und $b$ als Factoren auftreten, während dort die $S$ und $W$ nur gezällt werden, und die Differenz dieser Zahlen den Beobachtungs-Fehler darstellt. Die Anzalıl der gleich wahrscheinlichen Glieder, die zu einer Gruppe vereinigt sind, ist der Wahrscheinlichkeit des Eintreffens einer solchen proportional.

Wenn man $n$ mal in die Une greift, worin immer eben so viele schwarze, wie weifse Kugeln liegen, so entsprechen die herausgezogenen Kugeln einer gleichen Anzahl elementärer Felıler. Es ist aber nothwendig, dafs man auch beide Farben in gleicher Anzalıl greifen, und dadurch den Beobachtungsfehler gleich Null darstellen kann. Die Anzahl der Ziehungen mufs also eine gerade $Z$ ahl $l$ sein. Die Anzahl ler verschiedenen müglichen 
Gruppirungen olıne Rücksicht auf die Reihenfolge der schwarzen und weirsen Kugeln ist aber $n+1$. Man kann nämlich ziehn $n S$, oder $(n-1) S+W$, ferner $(n-2) S+2 W$, und so fort bis $S+(n-1) W$ und endlich auch $n W$. Die Anzahl der gefilsten $S$ und $W$ ist immer gleich $n$. Eben so ist auch im Binomium $(a+b)$, erhoben zur $n$ ten Potenz, die Anzahl der Glieder gleich $n+1$, und die Summe der Exponenten von $a$ nnd $b$ in jedem Giliede gleich $n$.

Der Beobachtungs-Fehler bildet sich hiernach aus der Differenz der Anzalıl der positiven und negativen elementären Fehler, die sämmtlich gleich grols sind, und deren Anzahı jedesmal $n$ ist. Wenn alle positiv sind, also gar keine negativen grezogen werden, ist die Differenz zwischen beiden oder der Beobachtungs-Fehler gleich $+n$, und im entgegengesetzten Fall, wenn man nur negative gegriffen hat, gleich $-n$. Dieses sind die beiden grölsten Fehler, die eintreten können. Zwischen diesen liegen aber noch $n-1$ Gruppen, die sowohl positive, als negative Einheiten enthalten. Aus den Differenzen von diesen bilden sich die Beobachtungsfeller. Derselhe ist bei $n-1$ positiven und 1 negativen gleich $n-2$, bei $n--2$ positiven und 2 negativen gleich $n-4$ und sofort, indem die Differenz stets um zwei elementãre Fehler sich vermindert, bis sie gleich Null wird. Dieses geschieht in der mittelsten Gruppe und von hier ab bilden sich die negativen Differenzen, die wieder immer um zwei elementäre Felıler anwachsen, bis sie schliefslich gleich $-n$ werden.

Diese verschiedenen Gruppen, welche die möglichen Beobachtungs-Fehler darstellen, sind keineswegs gleich walrscheinlich. Die Anzahl der gleich wahrscheinlichen Gruppen, wobei auch dic Reihenfolge der positiven und negativen Elemente berïcksichtigt wird, ist gleich 2 zur $n$ ten Potenz erhoben. Diese vertheilen sich aber ganz übereinstimmend mit den Zahlen-Coefficienten der Binomial-Glieder in jene $n+1$ Gruppen.

Der Coeficient des mittlern Gliedes des Binomiums, in welchem die Exponenten von $a$ und $b$ gleich sind, ist bekanntlich

$$
\frac{n}{1} \cdot \frac{n-1}{2} \cdot \frac{n-2}{3} \ldots \frac{\frac{1}{2} n+2}{\frac{1}{2} n-1} \cdot \frac{\frac{1}{2} n+1}{\frac{1}{2} n}
$$

I) Fe Factoren sind besonders geschrieben, um leicht erkennen zII lassen. dafs sie sämmtlich unächte Brïche, also gröfser als 1 sind. 
Indem aber in zweiten Gliede des Binomiums der Factor $n$ allein den Coefficient bildet und in jedem folgenden der Reihe nach der nächste lactor hinzutritt, so ergiebt sich, dals die Wahrscheinlichkeit für das Eintreten derjenigen Combination, welche diese Gruppe darstellt, bis zum mittleren Gliede immer grörser wird. In demselben ist die Anzahl der positiven elementïren Felıler eben so grofs, wie die der negativen, sie heben sich also gegenseitig vollständig auf, oder der Beobachtungsfehler wird gleich Null. Für diesen ist also die Wahrscheinlichkeit grölser, als für alle vorhergehenden, also für jeden positiven Fehler.

Mit den negativen Beobachtungsfehlern verhïlt es sich indessen eben so. Gelit man nämlich zumn folgenden Gliede über, welches einem Beobachtungs-Fehler $=2$ entspricht, so kommt der Factor

$$
\frac{\frac{1}{2} n}{\frac{1}{2} n+1}
$$

hinzu, und dieser verbindet sich mit dem letzten des mittlern Gliedes zum Product $=1$. Beide fallen also fort. Dasselbe geschieht bei dem Hinzutritt eines folgenden Factors, und so auch bei allen übrigen, woraus sich ergiebt, dafs für die sümmtlichen negativen Beobachtungsfehler die Wahrscheinlichkeit mit derjenigen der eben so grofsen positiven übereinstimmt.

Bezeichnet man den Zahlen-Coefficient des mittlern Gliedes, also die relative Wahrscheinlichkeit des Beobachtungs-Fehlers $=0$, mit $a$, so hat man für die verschiedenen Fehler, mögen sie positiv oder negativ sein, die nachstehenden Werthe der relativen Wahrscheinlichkeit

\begin{tabular}{|c|c|}
\hline Fehler & Wahrscheinlichkeit \\
\hline 0 & $a$ \\
\hline 2 & $\frac{\frac{1}{2} n}{\frac{1}{2} n+1} \cdot a$ \\
\hline 4 & $\frac{\frac{1}{2} n}{\frac{1}{2} n+1} \cdot \frac{\frac{1}{2} n-1}{\frac{1}{2} n+2} \cdot a$ \\
\hline 6 & $\frac{\frac{1}{2} n}{\frac{1}{2} n+1} \cdot \frac{\frac{1}{2} n-1}{\frac{1}{2} n+2} \cdot \frac{\frac{1}{2} n-2}{\frac{1}{2} n+3} \cdot a$ \\
\hline$q$ & $\frac{\frac{1}{2} n}{\frac{1}{2} n+1} \cdot \frac{\frac{1}{2} n-1}{\frac{1}{2} n+2} \ldots \ldots \ldots \cdot \frac{\frac{1}{n} n-\frac{1}{2} q+1}{\frac{1}{2} n+\frac{1}{2} q} \cdot a$ \\
\hline$q+2$ & $\frac{\frac{1}{2} n}{\frac{1}{2} n+1} \cdot \frac{\frac{1}{2} n-1}{\frac{1}{2} n+2} \ldots \ldots \ldots \frac{\frac{1}{2} n-\frac{1}{2} q+1}{\frac{1}{2} n+\frac{1}{2} q} \cdot \frac{\frac{1}{2} n-\frac{1}{2} q}{\frac{1}{2} n+\frac{1}{2} q+1} \cdot a$ \\
\hline
\end{tabular}


Bezeichnet man dic Wahrscheinlichkeit des Fehlers $q$ mit $v v_{2}$ und die des nächsten Fehlers $q+2$ mit $w^{\prime}$, so hat man

$$
\begin{gathered}
w^{*}-w=\left(\frac{\frac{1}{2} n-\frac{1}{2} q}{\frac{1}{2} n+1 q+1}-1\right) w \\
=-\frac{2 q+2}{n+q+2} \cdot w
\end{gathered}
$$

Bisher war nur voransgesetzt, dals $n$ eine ganze und zwar eine gerade Zahl sei, jetzt kommt es aber darauf an, zu untersuchen, wie die Verhältnisse sich gestalten, wenn aus den obigen Grïnden $n$ nicht nur als eine sehr grofse, sondern um den Resultaten allgemeine Gültigkeit zu geben, sogar als un e n d li ch grofse $\mathrm{Z}$ ahl angesehn werden mufs. In diesem Fall wird die Anzahl der Beobachtungs-Fehler und eben so die der Werthe ihrer Wahrscheinlichkeit unendlich grofs, und weun man die Fehler als Abscissen, die Wahrscheinlichkeit derselben aber als Ordinaten aufgetragen denkt, so treten die letatern unmittelbar an einander und ihre Endpunkte bilden eine continuirliche Curve, welche die Beziehung zwischen den Fehlern und delen Wahrscheinlichkeit anschaulich macht. Da es aber ganz heterogene Grölsen sind, so kommt es auf die Walıl des Maalsstabes für diese und jene nicht an.

Den Beobachtungs-Fehler $q$ bezeichne man hiernach mit $x$ und seine Wahrscheinlichkeit $w$ mit $y \cdot w^{\prime}-w$ ist alsdann $d y$, während die Gröfse $n$, welche dem gröfsten möglichen, also cinem unendlich grofsen. Fehler gleich ist, unverändert beibehalten wird. Gegen $n$ verschwindet daher der Fehler $q$, und gegren diesen wieder der unendlich kleine elementïre Fehler, der gleich 1 war. Hiernach verwandelt sich der letzte Ausdruck in

$$
d y=-\frac{2 x y}{n}
$$

Bei dieser Unformung ist der wirkliche Beobachtungs-Fehler $q$ vergleichungsweise zum gröfsten denkbaren Fehler $n$ (der nicmals vorkommt, weil seine Wahrscheinlichkeit gleich Null ist) als unendlich klein, und zugleich in Beziehung zum einzelnen elementären Fehler als unendlich grofs angesehn. Hierin liegt kein Widerspruch, da der Begriff une $n d \mathrm{l} i \mathrm{ch}$ niemals absolut, sondern immer nur relativ aufgefarst wird und nichts Andres, 
als überwiegend grofs oder ï berwiegrend klein bedeutet. So werden vielfach Quadrate und höhere P'otenzen kleiner Brïche gleich Null gesetzt, wiewohl sie bestimmte Werthe liaben. Auch im gewöhnlichen Leben wiederholt sich diese Auffassung. Findet man etwa, dals der hundertste Theil einer angekauften Waare felllt, so wird man meist diese Differenz nicht beaclıten. Man setzt also vergleichungsweise gegen luundert die Einheit gleich Null, oder was dasselbe ist, vergleichungsweise gegen lins hundert gleich unendlich grofs.

Es düfte auffallend erscheinen, dafs in der letzten Gleichung das Differenzial nur an der linken Seite erscheint. Die Wahrscheinlichkeit des Fehlers $x$ ist indessen nur vergleiclıungsweise gegen die der andern Fehler angegeben, an sich ist sie unendlich klein. Die Summe der unendlich vielen $y$, welche die Wahrscheinlichkeit aller zahllosen Fehler, von $x=-\infty$ bis $x=+\infty$ angeben, würde erst gleich 1 sein, oder die Gewifsheit ausdrücken, dafs irgend einer dieser Fehler, der auch Null sein kann, cintreten mufs. In der graphischen Darstellung läfst sich die Summe der sämmtlichen Ordinaten der Curve, oder aller y nur in der Fläche der Curve wiedergeben. Da nun das einzelne $y$ ein Theil derselben sein soll, eine Fläche sich aber nicht a us Linien, sondern nur a us Flächen-Elementen zusammensetzt, so muls $y$ als ein solches angesehn werden. Es verwandelt sich also in $y d x$, oder vielmelır, da nach vorstehender Herleitung die Fehler $x$ immer um 2 Einheiten wachsen, in $2 y d x$. Man hat sonach

$$
\begin{gathered}
\frac{d y}{y}=-\frac{4}{n} x d x \\
\log \text { nat } y=-\frac{2}{n} x^{2}+C
\end{gathered}
$$

fïr $x=0$ wird aber $y=a$ oder gleich der grölsten Ordinate also

$$
C=\log \text { nat } a
$$

$$
\begin{gathered}
\log \text { nat } \frac{y}{a}=-\frac{2}{n} x^{2} \\
y=a e^{-\frac{2+x x}{n}}
\end{gathered}
$$

oder

wo $c$ wie gewölnnlich die Grundzahı der natürlichen Logarithmen oder 2,71828 bedeutet. 
Der Nenner $\frac{1}{2} n$ im Exponent steht, wic im Folgenden gezeigt werden soll, in einfacher Beziehung zu $a$, woher eine dieser beiden Grörsen ausscheiden kanu. Zuvor ist es aber nöthig nachzuweisen, dafs schon unter Voraussetzung einer selır geringen Anzahı elementärer Fehler die Walırscheinlichkeit der verschiednen Beobachtungsfehler sehr nahe dieselben Werthe annimmt.

\section{$\S 15$.}

Der vorstelınden Untersuchung liegt die Voraussetzung zum Grunde, dals die Anzahl der elementären Fehler, durch deren zufälliges Zusammentreffen die Beobachtungs-Fehler sich bilden, nnendlich grofs ist. Es lärst sich aber leicht nachweisen, dals auch eine kleine Anzahl von gleich grofsen el ementären Fehlern zu Beobachtungs-Fehlern sich gruppirt, deren Wahrscheinlichkeit in überraschender Weise jenem Gesetz sich anschliefst. Man greife zehn mal in die Urne, oder dic Anzalil der betreffenden gleich grofsen elementären Felıler, die eben so leicht positiv, wie negativ eintreten, beschränke sich anf zehn. Der Beobachtungs-Fehler $x$ kann alsdann 21 verschiedne Werthe annehmen, indem er entweder gleich Null ist, oder positiv oder negativ sich auf $1,2,3$ u. s. w. bis 10 stellt. Die Walırscheinlichkeit, dafs er $=0$ ist, sei gleich $a$, und in dieser Einheit drücke man die Wahrscheinlichkeit der zwanzig andern Fehler aus. Diese reduciren sich aber auf 10, da positive und negative Beobachtungs-Feller gleich wahrscheinlich sind.

Aus den Binomial-Coefficienten ergiebt sich

$$
\begin{aligned}
& \text { für } x=1 \quad \frac{y}{a}=0,90909 \\
& =2 \quad=0,68182 \\
& =3 \quad=0,41958 \\
& =4 \quad=0,20979 \\
& =5 \quad=0,08392 \\
& =6 \quad=0,02622 \\
& =7 \quad=0,00617 \\
& =8 \quad=0,00103 \\
& =9 \quad=0,00011 \\
& =10 \quad=0,00001
\end{aligned}
$$


Berechnet man aus diesen Werthen der relativen Wallrscheinlichkeit die entsprechenden Fehler $x$ nach der Formel

$$
x=\sqrt{-\frac{n}{2} \cdot \log \text { nat } \frac{y}{a}}
$$

wobei $n=20$ ist, weil 21 positive und negative Fehler-Gruppen vorkommen, so findet man die Felıler und die Abweichungen derselben von einander:

\begin{tabular}{r|r|r} 
& $x$ berechnet & Differenz \\
\hline 0 & 0,0000 & \\
1 & 0,9764 & 0,9764 \\
2 & 1,9571 & 0,9807 \\
3 & 2,9471 & 0,9900 \\
4 & 3,9518 & 1,0047 \\
5 & 4,9780 & 1,0262 \\
6 & 6,0340 & 1,0560 \\
7 & 7,1330 & 1,0990 \\
8 & 8,2945 & 1,1605 \\
9 & 9,5558 & 1,2613 \\
10 & 11,0123 & 1,4565
\end{tabular}

Es ergiebt sich hieraus, dals die Felıler, die zu diesen Werthen von $\frac{y}{a}$ gehören, wie nach dem Gesetz für unendlich viele clementäre Fehler, ungefähr in gleichen Abständen liegen. Die gröfsern Abweichungen treten erst ein, wenn die Wahrscheinlichkeit der Beobachtungsfehler sehr geringe wird. Die Zunahme stellt sich aber für den grölsten Theil der Reilıe ungefälır auf 1 . Setzt man dalıer nach einander $x$ gleich $1,2,3$ und berechnet man die zugehörigen $y$ nach der Formel

$$
\frac{y}{a}=e^{-\frac{2 \cdot x x}{y}}
$$

so findet man 


\begin{tabular}{|c|c|c|c|}
\hline$x$ & $\frac{2 \cdot x x}{n}$ & $\frac{y}{a}$ & Abweichu \\
\hline 1 & 0,1 & 0,90484 & $-0,00425$ \\
\hline 2 & 0,4 & 0,67032 & $-0,01150$ \\
\hline 3 & 0,9 & 0,40657 & $-0,01301$ \\
\hline 4 & 1,6 & 0,20190 & $-0,00789$ \\
\hline 5 & 2,5 & 0,08209 & $-0,00183$ \\
\hline 6 & 3,6 & 0,02733 & $+0,00111$ \\
\hline 7 & 4,9 & 0,00744 & $+0,00127$ \\
\hline 8 & 6,4 & 0,00166 & $+0,00063$ \\
\hline 9 & 8,1 & 0,00030 & $+0,00019$ \\
\hline 10 & 10,0 & 0,00005 & $+0,00004$ \\
\hline
\end{tabular}

Die Abweichungen der auf diese Art berechneten von den aus den Binomial-Coefficienten hergeleiteten Wahrscheinlichkeiten, welche die vierte Spalte angiebt, sind nur an zwei Stellen etwas grörser, als 1 Procent. Wollte man also die Curve, welche diese zehın elementären Fehler darstellen, mit derjenigen der unendlich vielen vergleichen, so müiste man die Zeichnung schon in gröfserem Maafsstabe ausführen, um die Abweichungen noch kenntlich zu machen. Wenn man daher auch nur eine sehr mälsige Anzahl elementärer Felıler voraussetzt, so ergielıt sich daraus schon überaus nahe dasselbe Gesetz, wie aus jenen unendlich vielen.

\section{$\S 16$.}

Der $\$ 14$ gefundene Werth für die Wahrscheinlichkeit eines Fehlers $x$ enthält $a$ oder das grölste $y$ als Factor, daher sind die sämmtlichen $y$ diesem gröfsten Werth oder a proportional. Daraus ergiebt sich, dafs auch die Fläche der ganzen Curve, welche die Gewifsheit des Vorkommens irgend eines Fehlers bezeichnet, und daher gleich 1 ist, auch der grölsten Ordinate proportional sein muls. Man hat daher, wenn $c$ einen noch unbekannten Factor darstellt

$$
1=c a \text { oder } c=\frac{1}{a}
$$


Die absolute Wahrscheinlichkeit des Fehlers $x=0$, die nunInelır mit a bezciclinet werden mag, ist

$$
\begin{aligned}
& a= \frac{1}{2^{n}} \cdot \frac{n(n-1)(n-2) \ldots\left(\frac{1}{2} n+2\right)\left(\frac{1}{2} n+1\right)}{1 \cdot 2 \cdot 3 \ldots\left(\frac{1}{2} n-1\right) \frac{1}{2} n} \\
& \text { oder } \quad c=2^{n} \frac{1 \cdot 2 \cdot 3 \ldots\left(\frac{1}{2} n-1\right) \frac{1}{2} n}{n(n-1)(n-2) \ldots\left(\frac{1}{2} n+2\right)\left(\frac{1}{2} n+1\right)}
\end{aligned}
$$

Fiilırt man für $u$ nach und nach die Werthe $2,4,6,8 \ldots$ ein, so ergiebt sich

$$
\text { fuir } \begin{array}{rlrl}
n & =2 & c & =2^{2} \cdot \frac{1}{2} \\
n & =4 & c & =2^{4} \cdot \frac{1 \cdot 2}{4 \cdot 3} \\
n & =6 & c & =2^{6} \cdot \frac{1 \cdot 2 \cdot 3}{6 \cdot 5 \cdot 4} \\
n & =8 & c & =2^{8} \cdot \frac{1 \cdot 2 \cdot 3 \cdot 4}{8 \cdot 7 \cdot 6 \cdot 5}
\end{array}
$$

und so fort. Man bemerkt sogleich, dals jeder folgende Werth fïr $c$ sich aus dem vorhergehenden, der zu $n-2$ gehört, sich dadurch bildet, dafs der Factor

$$
2^{2} \cdot \frac{\frac{1}{2} n \cdot \frac{1}{2} n}{n(n-1)}=\frac{n}{n-1}
$$

hinzukommt.

Gelıt man zu den Quadraten über, so mufs der zu $n-2$ gehörige Werth von $c^{2}$ mit

$$
\frac{n \cdot n}{(n-1)(n-1)}
$$

multiplicirt werden, um den zu $n$ gehörigen darzustellen. Man hat nämlichı

$$
\text { für } \begin{aligned}
n & =2 \ldots c^{2}=\frac{2}{1} \cdot 2 \\
n & =4 \ldots c^{2}=\frac{2 \cdot 2 \cdot 4}{1 \cdot 3 \cdot 3 \cdot 4} \\
n & =6 \ldots c^{2}=\frac{2 \cdot 2 \cdot 4 \cdot 4 \cdot 6}{1 \cdot 3 \cdot 3 \cdot 5 \cdot 5} \cdot 6 \\
n & =8 \ldots c^{2}=\frac{2 \cdot 2 \cdot 4 \cdot 4 \cdot 6 \cdot 6 \cdot 8}{1 \cdot 3 \cdot 3 \cdot 5 \cdot 5 \cdot 7 \cdot 7} \cdot 8
\end{aligned}
$$


und so fort. Die Werthe von $c^{2}$ sind hier in der Art geschinieben, dafs sic aus einem Bruche und einem Fuctor besteh.n. Der Factor hinter dem Bruch ist stets gleich $n$, sobald dieses aljer um 2 wächst, so tritt ein neuer Factor in den Bruch, nämlich

$$
\frac{(n-2) n}{(n-1)(n-1)}
$$

lıinzu und derselbe nähert sich, wenn $u$ grölser wird, immer mehr der Einheit, und $c^{2}$ nimmt endlich einen constanten Werth an und wird gleich 1,57080. Dieses ist aber die Länge des Quadranten für den Radius 1. Man hat also

$$
c^{2}=\frac{1}{2} \pi n \text {. }
$$

Die Herleitung dieses von Wallis angegebenen Ausdrucks für $\frac{1}{2} \pi$ diirfte manchen Lesern unbekannt sein, woher die nachstehnde Mittheilung sich rechtfertigen wird. Man hat

$$
\int \frac{z^{m} d z}{\sqrt{\left(1-z^{2}\right)}}=-\frac{1}{m} z^{m-1} V\left(1-z^{2}\right)+\frac{m-1}{m} \int \frac{z^{m-2} \cdot d z}{\sqrt{\left(1-z^{2}\right)}}
$$

Man kann sonach dieses Integral auf ein undres von gleicher Form zuriickführen, in welchem der Exponent um 2 Linheiten kleiner ist. Jenachdem der letztere gerade oder ungerade ist, bleibt er anch in den abgeleiteten Integralen gerade oder ungerade. Beide Fälle müssen besonder's behandelt werden.

Wenn $m$ eine ungerade $Z$ a hl $l$ ist, so enthalten die nach und nach gefundnen Glieder, die nicht unter dem Integral-Zeichen stehn, nur gerade Potenzen von $z$. Man hat

$$
\begin{aligned}
& \int \frac{z d z}{\sqrt{\left(1-z^{2}\right)}}=-V\left(1-z^{2}\right)+C \\
& \int \frac{z^{3} \cdot d z}{\sqrt{\left(1-z^{2}\right)}}=-\left(\frac{1}{3} z^{2}+\frac{2}{3}\right) V\left(1-z^{2}\right)+C \\
& \int \frac{z^{5} \cdot d z}{\sqrt{ }\left(1-z^{2}\right)}=-\left(\frac{1}{5} z^{4}+\frac{4}{3.5} z^{2}+\frac{2.4}{3.5}\right) V\left(1-z^{2}\right)+C \\
& \int \frac{z^{7} \cdot d z}{\sqrt{ }\left(1-z^{2}\right)}=-\left(\frac{1}{7} z^{6}+\frac{6}{5 \cdot 7^{4}}+\frac{4.6}{3.5 .7} \cdot z^{2}+\frac{2.4 \cdot 6}{3.5 .7}\right) V\left(1-z^{2}\right)+C
\end{aligned}
$$

und so fort. 
Wenn $m$ dagegen e ine gerade $\mathrm{Zahl}$ is $t$, so führt die Integration zu trigonometrischen Functionen. Der einfacheren Bezeichnung wegen setze man

$$
\operatorname{arc}(\sin =s)=\varphi
$$

Man hat alsdann

$\int \frac{d z}{\sqrt{\left(1-z^{2}\right)}}=\varphi+C$

$\int \frac{z^{2} d z}{V\left(1-z^{2}\right)}=-\frac{1}{2} z V\left(1-z^{2}\right)+\frac{1}{2} \varphi+C$

$\int \frac{z^{4} \cdot d z}{V\left(1-z^{2}\right)}=-\left(\frac{1}{2} z^{3}+\frac{1.3}{2.4} z\right) V\left(1-z^{2}\right)+\frac{1.3}{2.4} \varphi+C$

$\int \frac{z^{6} d z}{\sqrt{ }\left(1-z^{2}\right)}=-\left(\frac{3}{4} z^{5}+\frac{1.5}{4.6} z^{3}+\frac{1.3 .5}{2.4 .6} z\right) V\left(1-z^{2}\right)+\frac{1.3 .5}{2.4 .6} \varphi+C$

und so fort.

Sucht man nun für die sämmtlichen Integrale die Werthe innertalb der Grenzen $z=0$ und $z=1$, also von $\varphi=0$ bis $\varphi=\frac{1}{2} \pi$, so bleibt jedesmal nur ein Glied übrig.

Dieses ist

$$
\begin{aligned}
\text { für } m=0 \ldots=\frac{1}{2} \pi & \text { für } m=1 \ldots=1 \\
\text { - } m=2 \ldots=\frac{1}{2} \cdot \frac{1}{2} \pi & -m=3 \ldots=\frac{2}{3} \\
\text { - } m=4 \ldots=\frac{1.3}{2.4} \cdot \frac{1}{2} \pi & -m=5 \ldots=\frac{2.4}{3.5} \\
\text { - } m=6 \ldots=\frac{1.3 .5}{2.4 .6} \cdot \frac{1}{2} \pi & -m=7 \ldots=\frac{2.4 .6}{3.5 .7} \\
\text { - } m=8 \ldots=\frac{1.3 .5 .7}{2.4 .6 .8} \cdot \frac{1}{2} \pi & -m=9 \ldots=\frac{2.4 .6 .8}{3.5 .7 .9}
\end{aligned}
$$

und so weiter. Die Werthe sind einander so gegenüber gestellt, dafs. $m$ auf der rechten Seite um eine Einheit gröfser ist, als auf der linken. $m$ und $m+1$ nähern sich aber um so mehr, je gröfser $m$ wird, und werden einander gleich, wenn $m$ unendlich grofs ist, in diesem Fall sind auch diese Integrale sich gleich. Beide haben alsdann bestimmte Zahlenwerthe angenommen, weil die jedesmal hinzukommenden Factoren 


\section{-45
$\frac{m-1}{m}$}

hei grofsem Werthe von $m$ gleichfalls 1 geworden sind.

Man hat sonach

$$
\frac{1.3 \cdot 5 \cdot 7 \cdot 9 \ldots}{2 \cdot 4 \cdot 6 \cdot 8 \cdot 10 \ldots} \cdot \frac{1}{2} x=\frac{2 \cdot 4 \cdot 6 \cdot 8 \cdot 10 \ldots}{3 \cdot 5 \cdot 7 \cdot 9 \cdot 11 \ldots}
$$

oder

$$
\frac{1}{2} \pi=\frac{2 \cdot 2 \cdot 4 \cdot 4 \cdot 6 \cdot 6 \cdot 8 \cdot 8 \cdot 10 \cdot 10 \ldots}{1 \cdot 3 \cdot 3 \cdot 5 \cdot 5 \cdot 7 \cdot 7 \cdot 9 \cdot 9 \cdot 11 \ldots}
$$

Aus ol,iger Herleitung ergab sich

$$
c^{2}=\frac{1}{2} \pi n
$$

und da

$$
1=a c
$$

so folgt

$$
a=\frac{1}{\sqrt{ } \pi \cdot \sqrt{\frac{1}{2} n}}
$$

und wenn dieser Werth der gröfsten Ordinate in den \$ 14 gefundnen Ausdruck für $y$ eingeführt wird, so wirl

$$
y=\frac{1}{\sqrt{ } \pi \sqrt{\frac{1}{2} n}} \cdot e^{\frac{-2 . x \pi}{\pi}}
$$

Dieses stimmt genan mit dem von Ganfs gegebenen Ausdruck überein, derselbe ist, wenn die Bezeichnungen $x$ und $y$ eingeführt werden,

$$
y=\frac{h}{\sqrt{\pi}} e^{-h h, x x}
$$

Ein Unterschied bestelit nur darin, dafs $\sqrt{\frac{1}{2} n}$ durch $\frac{1}{h}$ ausgedrïckt ist*). Gauls sagt, $h$ sei eine Constante, welche man als das Maafs der Schärfe der Beobachtungen ansehn könne. Er fïgt dabei die Bemerkung hinzu, dieses Resultat entspreche in einer Bezielıung nicht dem wirklichen Vorkommen der Beobachtungsfehler. So lange nämlich die Grölse derselben sich noch bezeichnen lasse, solle für sie noch eine gewisse Wahrscheinlichkeit vorhanden sein, während doch sehr grofse Beobachtungsfehler niemals gemacht werden. Für die Praxis sei dieses ohne Bedeutung, da bei gröfsern Fehlern die Wahrschein-

*) Theoria motus corporum coelestium. Hamburg 1809. Pag. 212. 
lichkeit derselben schnell abnimmt. Fs liege auch in der Natur der Sache, dafs eine bestimmte Grenze der Fehler sich nicht angeben lasse.

Der ersten IIerleitung dieses Gesetzes liegt nach dem erwähnten Werk die Voraussetzung zum Gruncle, dafs das aritlmetische Mittel der wahrscheinlichste Werth einer mehrfach gemefsnen Gröfse sei. Encke beschränkte 1834 diese Voraussetzung noch dahin, dals man nur annehmen dürfe, aus zwei Beobachtungen sei der mittlere Werth der wahrscheinliclıste*). Gaufs latte dagegen. 1823 jeden Beweis dieses Satzes für enthehrlich erklärt**).

*) Astronomisches Jahrbuch für 1834.

**) 'Theoria combinationis observationm erroribus minimis obnoxiae Göttingen 182:. 


\section{Abschnitt. \\ Die Methode der kleinsten Quadrate.}

\section{$\S 17$.}

In vielen Fällen ergeben die Messungen oder Beobachtungen nnmittelbar das gesuchte Resultat. Dieses geschieht, wenn es sich nur um die Auffindung einer einzigen unbekannten Grölse handelt, wie zum Beispiel wenn die Entfernung zweier P'unkte von einander gemessen wird. Auch solche Messung ist jedesmal mit einem gewissen Fehler behaftet, woher die Wiederholungen im Allgemeinen verschiedne Resultate geben.

Häufig ist dagegen die Erscheinung, die man beobachtet, von mehreren Grölsen oder Kräften abhängig, deren Einflufs man kennt, so dals man die Ablängigkeit der Erscheinung von denselben analytisch ausdrücken kann. Alsdann treten die Unbekannten, die das Maafs des Einflusses bezeichnen. als Factoren, oder in andrer Form auf. Sollte aber die Art der Einwirkung unbekannt sein, so mufs man verschieine Hypothesen versuchen und für jede den betreffenden Ausdruck mit den Beobachtungen vergleichen.

Um das Vorkommen mehrerer Unbekanten durch ein Beispiel zu erläutern, mag wieder auf die Bewegung des Wassers in Röhren zurückgegangen werden. Nach der von Prony aufgestellten Theorie rührt der Widerstand des Wassers theils von einem gewissen Anhaften an die Rölrenwand und theils von der Reibung her. Dabei wird vorausgesetzt, dals der erste Widerstand der ersten Potenz, die Reibung dagegen dem Quadrat der Geschwindigkeit proportional sei. Der zur Bewegung erforderliche Druck ist hiernach

$$
h=r \cdot c+s \cdot c^{2}
$$


wo $h$ die Druckhöhe, $c$ die Geschwindigkeit des Wassers in der Rülıre und $r$ und $s$ die gesuchten unbekannten Factoren sind. Durch jede einzelne Beobachtung ist der zun jedesmaligen $h$ gehïrige Werth von $c$ gegeben.

Ist nur eine Beobachtnng angestellt, so erhält man auch nur eine Bedingungs-Gleichung, aus der sich beide Unbekannte nicht berechnen lassen. Aus zwei Beobaclitungen, oder allgemein, wem die Anzalı der Beobachtingen eben so grols ist, als die der Unbekannten, kann man die Werthe der letztern zwar in voller Schärfe bestimmen, aber die Resultate sind durch die unvermeidlichen Beobachtungsfehler entstellt, über deren Größse, so wie über ihren Einflufs man sich kein Urtheil bilden kann, so lange jede Controlle fehlt.

Der dritte Fall tritt endlich ein, wenn die Anzalıl der Beobachtungen grölser, als die der Unbekannten ist. Man kann bei zwei Unbekannten dieselben aus je zwei beliebig gewällten Beobachtungen berechnen, aber bei einer andern Wahl erhält man eben wegen der Beobachtungsfehler andre Resultate, und es bleibt unentschieden, welche von diesen die richtigeren sind. Es entsteht die Frage, wie man die Beobachtungen am vortheilhaftesten $7 .$, verbinden hat, um die wahrscheinlichsten Werthe darzustellen. Diese Aufgabe löst die Wahrscheinlichkeits-Rechnung und zwar durch die Methodederkleinsten Quadrate.

Nach obiger Herleitung ist bei irgend einer Beobachtungsart die Walhrscheinlichkeit eines Fehlers

$$
y=\frac{1}{\sqrt{ } \pi \sqrt{2} n} \cdot e^{-\frac{2 \cdot x x}{\pi}}
$$

und in gleicher Weise drücken sich auch bei derselben Beobachtungsart die Wahrscheinlichkeiten $y^{\prime}, y^{\prime \prime}, y^{\prime \prime} \ldots$ für die Fehler $x^{\prime}, x^{\prime \prime}, x^{\prime \prime \prime} \ldots$ aus.

In $\S 4$ ist gezeigt worden, dafs die Wahrscheinlichkeit des Zusammentreffens zweier, von einander unabhängiger Ereignisse dem Product aus der Wahrscheinlichkeit des ersten in die des zweiten gleich ist. Betrachtet man noch ein drittes Ereignifs, so ist dieses als das zweite zu betrachten, nachdem die beiden ersten schon verbunden sind, und der Satz dehnt sich also dahin aus, dals die Wahrscheinlichkeit des $Z$ usammentreffens 
jeder beliebigen Anzali von Ereignissen, die von einander unabhängig sind, dem Product der Wahrscheinlichkeiten aller einzelnen gleich ist. Die Wahrscheinlichkeit des Zusammentreffens der Fehler $x, x^{\prime}, x^{\prime \prime}, \ldots$ ist also

$$
y \cdot y^{\prime} y^{\prime \prime} \ldots=\frac{1}{\sqrt{x} \sqrt{\frac{1}{2} n}} e^{\frac{-x z-x^{\prime} x^{\prime}-x^{\prime \prime} x^{\prime \prime}-\ldots}{1 / 9 n}}
$$

Man sucht diejenige Wahrscheinlichkeit, die unter allen die gröfste ist, und diese stellt sich augenscheinlich heraus, wenn

$$
x x+x^{\prime} x^{\prime}+x^{\prime \prime} x^{\prime \prime}+\cdots
$$

ein Minimum wird, oder we n $\mathrm{n}$ die $\mathrm{Summe}$ der $Q$ u ad rate der übrig bleibenden Fehler ein Kleinstes ist.

Dieser Lehrsatz ist schon an sich von grofser Wichtigkeit, indem er sicher erkennen lärst, welche Hypothese über die $\mathbf{A b}$ liängigkeit der Erscheinungen von gewissen constanten Factoren sich an die Beobachtungen am besten anschliefst, er gewälrt aber auch die wesentliche Erleichterung der Rechnung, dafs man nicht durch versuchsweise Einführung verschiedner Werthe der Constanten die passendsten aufsuchen darf, sondern man diese fiir das zum Grunde gelegte Gesetz der Frscheinung aus den Beobachtungen direct berechnen kann.

\section{$\S 18$.}

Der einfachste Fall stellt sich dar, wenn die beobachtete Grölse $k$ der Summe verschiedner Glieder gleich ist, von denen jedes eine gemessene Grölse oder eine Function derselben a ls F a ctor enthält, während die gesuchten Constanten die andern Factoren dieser Glieder sind. In der Gleichung

$$
k=a r+b s+c t+\ldots .
$$

kennt man die Grölsen $k, a, b, c \ldots$ gesucht werden $r, s, t . \ldots$

Sollte zu dieser Summe noch ein Glied kommen, das keine Unbekannte zum Factor luat, so kann man dieses sogleich von $k$ abzielın, wodurch der Ausdruck wieder die angegebne Form annimmt. Von der Behandlung andrer Ausdrücke, worin etwa eine der Unbekannten als Exponent erscheint, oder sonst sich nicht so einfach darstellt, wird später die Rede sein.

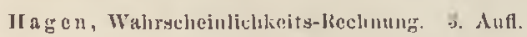


Zur Erläuterung mag noch hinzugefügt werden, dafs nach dem im vorigen Paragraph gewählten Beispiele $k=h, a=c$, $b=c^{2}$ und $t=0$ sein würde, weil nach der zum Grunde gelegten Hypothese die Drucklıöhe sich nur aus zwei Gliedern zusammensetzt, von denen das eine die erste und das andre die zweite Potenz der Geschwindigkeit zum Factor hat.

$k$ ist nicht in aller Schärfe beobachtet, vielmehr enthält es noch den Beobachtungsfehler $x$, so dafs es sich in $k+x$ verwandelt. Man hat also

$$
x=-k+a r+b s+c t+\cdots
$$

und in gleicher Art hat man für die äbrigen Beobachtungen die Fehler

$$
\begin{aligned}
& x^{\prime}=-k^{\prime}+a^{\prime} r+b^{\prime} s+c^{\prime} t+\ldots \\
& x^{\prime \prime}=-k^{\prime \prime}+a^{\prime \prime} r+b^{\prime \prime} s+c^{\prime \prime} t+\ldots
\end{aligned}
$$

und so fort. Die Anzahl dieser Gleichungen ist eben so grofs, als die der Beobachtungen.

Indem nun

$$
x x+x^{4} x^{2}+x^{\prime \prime} x^{\prime \prime}+\ldots=\mathbf{\Sigma}
$$

ein Minimum sein soll, so muls das Differenzial davon gleich Null sein, daher

$$
0=d \mathbf{\Sigma}=x d x+x^{\prime} d x^{4}+x^{\prime \prime} d x^{\prime \prime}+\ldots
$$

Man liat aber

$x d x=(-k+a r+b s+c t+\ldots)(a d r+b d s+c d t+\ldots)$

und in gleicher Weise die Ausdrücke fïr die übrigen Fehler $x^{\prime}, x^{\prime \prime} \ldots$.

Die gesuchten Constanten sind von einander unabhängig, daher lörst sich die Gleichung

$$
d \mathbf{\Sigma}=0
$$

in so viele Gleichungen auf, als es Unbekannte giebt, nämlich

$$
\begin{aligned}
& \frac{d \Sigma}{d r}=0 \\
& \frac{d \Sigma}{d s}=0 \\
& \frac{d \Sigma}{d t}=0
\end{aligned}
$$


und so fort. Führt man nun die Multiplication des Ausdrucks liir $x d x$ wirklich aus, so hat man

$$
\begin{aligned}
x d x= & (-k a+a a \cdot r+a b \cdot s+a c \cdot t+\ldots) d r \\
& +(-k b+a b \cdot r+b b \cdot s+b c \cdot t+\ldots) d s \\
& +(-k c+a c \cdot r+b c \cdot s+c c \cdot t+\ldots) d t \\
& +\ldots
\end{aligned}
$$

Ganz übereinstimmende Ausdrïcke erhält man für $x^{\prime} d x^{\prime}$, $x^{\prime \prime} d x^{\prime \prime}, \ldots$ wobei nur $k, a, b, c \ldots$ sich in $k^{\prime}, a^{\prime}, b^{\prime}, c^{\prime} \ldots$ so wie in $k^{\prime \prime}, a^{\prime \prime}, b^{\prime \prime}, c^{\prime \prime} \ldots$ u. s. w. verwandeln. Man erlält alsdamn durch Summirung der Glieder, die $d r$ zum Factor haben,

$$
\begin{aligned}
0=\frac{d \mathbf{\Sigma}}{d r}= & -\left(k a+k^{\prime} a^{t}+k^{\prime \prime} a^{\prime \prime}+\ldots\right) \\
& +\left(a a+a^{\prime} a^{\prime}+a^{\prime \prime} a^{\prime \prime}+\ldots\right) r \\
& +\left(a b+a^{\prime} b^{\prime}+a^{\prime \prime} b^{\prime \prime}+\ldots\right) s \\
& +\left(a c+a^{\prime} c^{\prime}+a^{\prime \prime} c^{\mu}+\ldots\right) t \\
& +\ldots
\end{aligned}
$$

In gleicher Weise stellen sich die Ausdrïcke für $\frac{d \Sigma}{d s}$ und $\frac{d \Sigma}{d t}$ dar, und wenn man die Summe der gleichartigen Producte durch die Parenthese [] bezeichnet, so erhält man die Bedingungsgleichungen

$$
\begin{aligned}
& 0=-[k a]+[a a] r+[a b] s+[a c] t+\ldots \\
& 0=-[k b]+[a b] r+[b b] s+[b c] t+\ldots \\
& 0=-[k c]+[a c] r+[b c] s+[c c] t+\cdots
\end{aligned}
$$

u. $8, \mathrm{w}$.

Die Anzahl dieser Gleiclungen ist eben so grofs, als die der Constanten oder der unbekannten Grölsen $r, s, t, \ldots$ Die Werthe der letzten lassen sich also in aller Schärfe finden und sind die wahrscheinliclısten, weil sie die kleinste Summe der Fehler-Quadrate darstellen *).

*) Diese Gleichungen wurden zueist von Legendre in den Nouvelles inéthodes pour la détermination des orbites des cométes. Paris 1806 bekannt gemacht. Der Verfasser empfiehlt sie aber nur, weil er sie als besonders bequem und in sofern auch als sicher ansieht, weil dabei sehr grofse Abweichungen von den Beobachtungen vermieden werden. Gauls hatte dieselbe Methode indessen schon 1795 benutzt, und leitete sie 1809 in der Theoria motus corporum coelestium, wie vorstehend erwähnt, aus dem Gesetz über das Vorkommen der verschiednen Fehler her. 


\section{$\S 19$.}

Um zu zeigen, wie diese Ausdrücke zu benutzen sind, und um zugleich auf einige Umstïnde aufmerksam 211 machen, die leicht überselın werden dïrften, mögen einige Zalılen-Beispiele dienen, und zwar zunächst ein solches, das sich auf den einfachsten Fall bezieht, worin nämlich nur e ine Un bekannte gesucht wird.

Es sei die Riclitung einer Grenze zwischen zwei Grund stücken festzustellen, von der man weifs, dafs sie von einem noch sicher erkennbaren Punkt in gerader Linie sich hingezogen habe. In der Nähe dieser Linie finden sich auch einige Punkte, von denen man voraussetzen darf, dafs sie in der Grenze selbst oder doch sehr nahe an derselben gelegen laben. Die Lage dieser Punkte bestimme man durch rechtwinklige Coordinaten, indem die Abscissen-Linie durch jenen sichern Festpunkt gelegt, und von demselben ab die Entfernungen in irgend einem Maafs gezählt werden. Man tinde für dieselben

$$
\begin{aligned}
& \text { - bei } x=14,2 \ldots y=0,42 \\
& =37,5=1,35 \\
& =64,0=2,67 \\
& =96,1 \quad=3,92 \\
& =136,7 \quad=5,33 \\
& =152,4 \quad=6,04
\end{aligned}
$$

Lïgen diese Punkte sämmtlich in einer durch jenen Festpunkt gezogenen geraden Linie, so würden sich die Ordinat. an die Gleichung

$$
y=r x
$$

scharf anschliefsen und jeder Punkt wïrde für

$$
r=\frac{y}{x}
$$

denselben Werth ergeben. Dieses ist indessen nicht der Fall und es kommt daher darauf an, die wahrscheinlichste Richtıng dieser Linie zu bestimmen, das heifst derjenigen, bei der die Summe der Quadrate der Abweichungen von den Beobachtungen ein Minimum wird. 
Indem nur eine Unbekannte gesucht wird, so braucht man anch nur eine Bedingungsgleichung, nämlich

also

$$
\begin{gathered}
0=-[k a]+[a a] r \\
r=\frac{[k a]}{[a a]}=\frac{[x y]}{[x x]}
\end{gathered}
$$

Berechnet man dic Producte $x y$ und $x x$ und summirt sic, so findet man

und

$$
\begin{aligned}
& {[x y]=2253,3} \\
& {[x x]=56852}
\end{aligned}
$$

woraus sich ergiebt

$$
r=0,039635
$$

Durch Einführung dieses Werthes in die Gleichung

$$
y=r x
$$

findet man für die obigen $x$ die entsprechenden $y$, so wic dic Differenzen derselben gegen die gemefsnen $y$ und die Quadrate clieser Differenzen.

$\begin{array}{crr}y & \text { Differ. } & \text { Quadr. } \\ 0,56 & -0,14 & 0,020 \\ 1,49 & +0,14 & 0,020 \\ 2,54 & -0,13 & 0,017 \\ 3,81 & -0,11 & 0,012 \\ 5,42 & +0,09 & 0,008 \\ 6,04 & 0,00 & 0,000\end{array}$

Die Summe der Quadrate ist 0,077 .

Man könnte leicht vermuthen, diese Aufgabe liefse sich leichter lösen, wenn man für jede zusammen gehörige Messung $y$ durch $x$ dividirt, und aus den so gefundenen Werthen für $r$ das arithmetische Mittel nimmt. Dieses ist indessen keineswegs begriundet, und man iiberzeugt sich leiclıt, dass alsdann die Summe der Fehlerruadrate bedeutend gröfser wird. Die in dieser Weise berechneten Werthe von $r$ sind in der ersten Spalte der nachstelınden Tabelle angegeben. Das arithmetische Mittel derselben beträgt 0,03778 , und wenn man unter Zugrundelegung dieses Werths von $r$ dic zu den verschiednen $x$ gehörigen $y$ sucht, so ergeben sich diese, wie sie in der zweiten Spalte angegeben sind. Die Tabelle 


\section{$-54--$}

enthialt ferner die Differenzen gegen die gemelisnen $y$, und die Quadrate derselben

\begin{tabular}{c|c|c|c}
$r$ & $y$ & Diff. & Quadr. \\
\hline 0,02958 & 0,54 & $+0,12$ & 0,014 \\
0,03600 & 1,42 & $+0,07$ & 0,005 \\
0,04172 & 2,42 & $-0,25$ & 0,062 \\
0,04079 & 3,63 & $-0,29$ & 0,084 \\
0,03899 & 5,17 & $-0,16$ & 0,025 \\
0,03963 & 5,76 & $-0,28$ & 0,078
\end{tabular}

Die Summe der Quadrate der übrigbleibenden Feller stellt sich dabei auf 0,268 , ist also dreimal so grofs, wie früher.

Wenn man eine Gröfse, also etwa eine Linie, wiederholentlich gemessen und wegen der unvermeidlichen Beobachtungsfehler jedesmal ein andres Resultat gefunden liat, so entsteht wieder die Frage, welches das wahrscheinlichste sei. Unter Beibehaltung der frühern Bezeichnung ist das gesuchte $r$ jedesmal dem durch den Beobachtungsfehler $x$ entstellten Maals $k$ gleich, also

$$
x=r-k
$$

Der Factor $a$ ist aber in diesem Fall gleich 1, also $[a a]=$ $m$, wenn die Messung $m$ mal wiederholt wurde. Hiernach erhält man den Ausdruck

$$
r=\frac{[k]}{m}
$$

Der wahrscheinlichste Werth ist also das arithmetische Mittel aus allen einzelnen Messungen. In dieser Weise begründet sich durch das allgemeine Gesetz diejenige Voraussetzung, die sonst der Herleitung desselben zum Grunde gelegt wurde.

Werden zwei Unbekannte $r$ und $s$ gesucht, welche in dem Ausdruck

$$
k=a \cdot r+b \cdot s
$$

enthalten sind, so hat man die beiden Bedingungs-Gleichungen

und

$$
\begin{aligned}
& 0=-[k a]+[a a] r+[a b] s \\
& 0=-[k b]+[a b] r+[b b] s
\end{aligned}
$$

Sollte hier wieder einer der Factoren $a$ oder $b$ gleich 1 sein, so fällt er in den Producten fort und die betreffende Summe [ac] oder $[b b]$ wird gleich $m$ oder gleich der Anzahl der Beobachtungen. 
Um ein Beispiel für die Berechnung mehrerer Unbekannten mitzutheilen, sei wieder die wahrscheinlichste Lage einer geradlinigen Grenze zu ermitteln, für die es aber keinen ganz sichern Festpunkt giebt, in welcher vielmehr nur vier Stellen annähernd ilıre Lage bezeichnen. Man messe in der Nähe eine beliebig gewählte Abscissen-Linie und verbinde diese durch rechtwinklige Ordinaten mit jenen vier Punkten. Man finde

$$
\text { fuir } \begin{array}{rlrl}
x & =0 & y & =3,5 \\
& =88 & & =5,7 \\
& =182 & & =8,2 \\
& =274 & & =10,3
\end{array}
$$

Die gerade Linic, die an diese Punkte sich möglichst anschliefsen soll, ist gegeben durch die Gleichung

$$
y=r+x s
$$

Vergleicht man diese mit der obigen Formel

$$
k=a r+b s
$$

so ist

$$
\begin{aligned}
& k=y \\
& a=1 \\
& b=x
\end{aligned}
$$

Zur liestimmung der walurscheinlichsten Werthe von $r$ und $s$ hat man daher die beiden Bedingungungs-Gleichungen

$$
0=-[y]+[1] r+[x] s
$$

und

$$
0=-[x y]+[x] r+[x x] s
$$

Bildet man die einzelnen Producte nach den durch die Messung gefnndnen Gröfsen, und summirt man dieselben, so ergiebt sich

$$
\begin{aligned}
{[y] } & =27,7 \\
{[1] } & =4 \\
{[x] } & =544 \\
{[x y] } & =4816,2 \\
{[x x] } & =115944
\end{aligned}
$$

Man hat sonach die beiden Bedingungs-Gleichungen

$$
\begin{gathered}
27,7=4 \cdot r+544 \cdot s \\
4816,2=544 \cdot r+115944 \cdot s
\end{gathered}
$$


und hieraus ergielst sich

$$
\begin{aligned}
& r=3,525 \\
& s=0,025
\end{aligned}
$$

Die gesuchte wahrscheinlichste Grenze ist demnach für dasselbe Coordinaten-System durch die Gleichung

$$
y=3,525+0,025 \cdot x
$$

\begin{tabular}{|c|c|c|c|c|}
\hline & $\stackrel{y}{b}$ berechnet & $\stackrel{y}{y}$ & Fehler & $\begin{array}{l}\text { Fehler } \\
\text { Quadrat }\end{array}$ \\
\hline ür $x=0$ & 3,525 & 3,500 & $+0,025$ & 0,000625 \\
\hline$=88$ & 5,725 & 5,700 & $+0,025$ & 0,000625 \\
\hline$=182$ & 8,075 & 8,200 & $-0,125$ & 0,015625 \\
\hline$=274$ & 10,375 & 10,300 & $\begin{array}{c}+0,075 \\
\text { Summe }\end{array}$ & $\begin{array}{l}0,005625 \\
0,022500\end{array}$ \\
\hline
\end{tabular}

gegeben. Berechnet man hiernach fïr die obigen $x$ die zugehörigen y und vergleicht diese mit den gemelsnen $y$, so ergiebt sich

Die Summe der Quadrate der übrig bleibenden Fehler beträgt also 0,0225 und ist geringer, als wenn man irgend eine andre gerade Linie gewählt hätte *).

\section{$\S 20$.}

Die Anwendung der Methode der kleinsten Quadrate erfordert uicht selten ausgedehnte Rechnungen, die um so umfangreicher und zeitraubender sind, je melır Beobaclitungen vorliegen, und je grö[ser die Anzahl der gesuchten Factoren ist. Um diese Arbeit auf das zulässig geringste Manfs zu beschränken, ist besonders zu beachten, dafs es ganz zwecklos wäre, die Rechnungen mit einer Schärfe auszuführen, die weit über die Sicherheit der Beobachtungen hinausginge. Wïrren letztere, wie dieses in vielen Fällen geschieht, von der Art, daís man die Werthe von $k$, $a$, 6... bei sorgfältiger Messung nur in drei oder vier Ziffern

*) Wie man durch graphische Darstellung und unter der Voraussetzung, dals grolse Fehler viel unwahrseheinlicher sind, als kleine, ungefähr zu gleichen Resultaten gelangt, ergiebt sich aus manchen Aufsätzen von Lambert in dessen „Beiträgen zum Gebrauch der Mathematik. Berlin 1763" und besonders aus der Abhandlung: "Theorie der Zuverlässigkeit der Beobachtungen und Versuche." 
bezeichnen künnte, und man wollte die Producte derselben logaritlımisch bestimmen, so wäre es durchaus unpassend, siebenstellige Tafeln zu benutzen. Die viel bequemeren fünfstelligen, und in vielen Fällen selbst vierstellige, sind meist volıstïndig genügend. Tralles bemerkte einst, der Mangel an mathematiseher Bildung gebe sich durch nichts so auffallend zu erkennen, als durch die übertriebne Schärfe in den Zahlenrechnungen.

Sobald die Producte $k a$, $a a, a b \ldots$ gefunden sind und man summirt dieselben, so gelangt man zu gröfsern Zahlen, welche ans mehr Ziffern bestehn. Indem diese als Factoren oder in andrer Art mit einander verbunden werden, mufs man oft zu gröfsern Tafeln greifen, um ihre Werthe sicher auszudrücken. Dieses ist um so mehr geboten, als nunmelır Subtractionen nöthig werden, wobei nicht selten beide Zalılen einander sehr nahe gleich sind, und sonach die Differenzen, auf die es eben ankommt, als überaus klein sich hernusstellen. Bei weniger Schärfe der Rechnung könnte es alsdann leicht geschelın, dafs cin gesuclter Factor unter negativem Zeichen sich darstellt, der wirklich positiv ist. Welchen Gral der Sicherheit das Resultat aber hat, ergiebt sich, indem man die wahrscheinlichen Fehler ermittelt, wovon im folgenden Abschnitt die Rede sein wird.

Es dïrfte für manche Leser von Nutzen sein, noch darauf aufmerksam gemacht zu werden, wie diese Bechnungen bequem und übersichtlich anzuordnen sind. Man schreibe, am besten auf liniirtem Papier die beobachteten Werthe der $k, a, b \ldots$ etwa nach der Grörse von $l$ geordnet, in besondere Spalten unter einander, so dafs jede Zeile in den verschiednen Spalten sich auf dieselbe Beobachtung bezieht. Die folgenden Spalten enthalten die Logarithmen, und je zwei Logarithmen, die man auf einen Blick iibersielt, lassen sich leicht addiren oder subtrahiren. Man gewöhne sich dabei aber, diese Operationen nicht von der rechten nach der linken Seite, wie sonst geschieht, sondern umgekehrt von links nach rechts, also in derselben Richtung, wie man schreibt, auszuführen. Bei mangelnder Uebung und namentlich wenn die Zahlen nicht unmittelbar neben einander stehn, gewährt die Benutzung eines Zirkels, den man in der linken Hand hält, einige Erleichterung. Derselbe wird soweit geöffnet, dafs seinc Spitzen unter diejenigen Ziffern treffen, die summirt werden sollen, 
während ein Blick auf' die folgenden leiclıt erkennen lärst, ob noch eine Einheit hinzuzufïgen ist. Vielfach kommt es auch vor, dal's Logarithmen oder Zahlen bei sämmtlichen Beobachtungen, also in der ganzen Spalte, um eine gleiche Zahl vergröfsert oder vermindert werden sollen. Alsdann schreibt man diese auf' ein besonderes Blättelien (eine Visitenkarte) und indem man dasselbe naclı und nach iiber oder unter jede Zahl schiebt, kann man die Summen oder Differenzen wieder in die betreffenden Spalten schreiben, von denen jede mit der besondern Ueberschrift versehn ist. Bei einiger Uebung im Rechnen braucht man nicht alle diese Zahlen einzutragen, man kann beispielsweise die Summen zweier Logarithmen unmittelbar zum $\Lambda$ ufsuchen der betreffenden Zahlen benutzen, ohne sie aufzuschreiben. Solten aber etwa einfache Multiplicationen nöthig sein, wobei man die betreffenden Factoreu besonders aufschreiben mufs, so geschielıt dieses anf einem losen Blättchen Papier.

Bei solcher Behandlung der ganzen Rechnung in tabellarischer Form gewinnt man nicht nur eine leichte Uebersicht derselben, wodurch oft etwaige Rechnungsfehler sich schon zu erkennen geben, sondern die Controle wird auch selır erleichtert, und iiberdies stelın alle Producte oder Zahlen, die man summiren soll, unmittelbar unter einnnder.

Bei Berechnung der Quadrate und Producte aus den gegebnen Werthen von $k, a, b \ldots$ ist indessen die Benutzung der Logaritlımen-Tafeln in sofern unbequem, als man dabei immer von den Zahlen anf die Logarithmen und sodann wieder auf die Zahlen iibergelın mufs. Bessel schlug daher vor*), diese Rechnung allein mit Hïlfe der Quadrat-'Tabellen auszuführen. Man kann aus diesen unmittelbar die Quadrate $a a, b b, \ldots$ entnehmen, doch wäre dieser Vortheil von wenig Bedentung, wenn man zur Darstellung der Producte $a b, a c, \ldots$ noch die Logarithmen-Tafeln benutzen mürste.

Dieses lärst sich indessen vermeiden, indem auch die Producte sich aus denselben Tabellen ergeben. Man hat nümlich

$$
a b=\frac{(a+b)^{2}-a^{2}-b^{2}}{2}
$$

*) In Schumacher's astronomischen Nachrichten. Nr. 399. Band XVII 1840. Seite 225. 
Die Qundrate von $a$ und $b$ gebraucht man schon zur Darstellung ihrer Summen, und sonacls lindet man bequem das Procluct $a b$, sobald man noch $(a+b)^{2}$ aufschlägt. Fïr $k a$ ist das Verhältnifs freilich ein andres, insofern das Quadrat von $k$ in jenen Gleichungen nicht vorkornmt. Um $k a$ zu finden, mufs man die Quadrate von $k$ und von $(k+a)$ suchen. Diese MehrArbeit ist indessen nicht berleutend, und gewährt schliefslich noch den Vortheil einer sichern Controlle der ganzen R e chn ung.

Solche Erleichterung der Rechnung wïrde nicht eintreten, wenn man fïr jede einzelne Beobachtung die Producte $a b, k n, \ldots$ entwickeln müfste, dieses ist aber nicht nothwendig. Unter Beibehaltung der oben gewählten Bezeichnung für die Summen hat man nämlich

$$
[a b]=\frac{[(a+b)(a+b)]-[a a]-[b b]}{2}
$$

Man summirt also unmittelbar die einzelnen Quadrate uud berechnet aus den Summen derselben, die grofsentheils schon in jenen Bedingungs-Gleichungen vorkommen, die Summe der Producte $a b$.

Was die erwälınte schliefsliche Controle betrifft, so braucht man nur die Quadrate von

$$
k+a+b+c+\cdots
$$

aus den Tabellen zu entnehmen und die Summe derselben mit den bereits ermittelten Summen zu vergleichen. Diese Summe ist nämlich

$=[k k]+[a a]+[b b]+\cdots 2([k a]+[k b]+\cdots+[a b]+[a c]+\cdots)$

Stellt sich hierdurch jene Summe wirklich dar, so ergiebt sich daraus, dafs nicht nur die einzelnen Quadrate und Producte richtig berechnet sind, sondern dafs auch in den sämmtlichen Summationen kein Fehler vorgekommen ist.

Die Erleichterung und Sicherheit der Rechnung in dieser Weise fand Bessel so grofs, dals selbst in dem Fall, wenn die Größsen $k, a, b, \ldots$ durch Logarithmen gegeben waren, er von diesen auf die Zahlen überging und die Quadrat-Tabellen benutzte. 
Mun findet vielficcl in ten Taschenbüchern für Ingenioure und in andern Handbiichern (Quadrat-Tabellen mitgetheilt, dieselben sind indessen fïr den vorliegenden Zweck nicht bequem eingerichtet, auch nicht mit den Differenzen versehn, die man doch zur Berechnung der zwischenliegenden Werthe braucht. Hierzu genügen aber schon die ersten Differenzen, da die zweiten constant sind.

In der im Anhang beigefügten Tabelle $A$ sind die Quadrate, wie die dazugehörigen Zahlen in Form von Decimalbrüchen ansgedrïckt, weil sie bei den in Rede stehnden Rechnungen am häufigsten als solche vorzukommen pflegen. Es ist aber sehr leicht, sie auch in ganze Zahlen oder in noch kleinere Briche zu verwandeln, indem das Komma in gleichem Sinn nach rechts oder links verstellt wird, jedoch in der Art, dafs man dasselbe in den Quadraten doppelt so weit verschiebt, als in den Zahlen. So ist beispielsweise das Quadrat von 7,777 nach der Tabelle gleich 60,481 . Von 77,77 würde es daher $6048,1 \ldots$ von 0,7777 dagegen $0,60481, \ldots$ von 0.07777 wieder 0,0060481 und so fort.

Die Angabe der Quadrate ist auf drei Decimalstellen beschränkt, wiewohl durch Hinzufügung der vierten Stelle ihre Werthe in voller Schärfe auszudriicken gewesen wären. Ich habe dieses indessen unterlassen, weil nicht leicht solche Genauigkeit erforderlich sein dïrfte, und eine zu weit ausgedehnte Tabelle weniger bequem ist.

Ein Zahlenbeispiel mag die Berechinung der Producte mittelst der Quadrat-Tabelle erlikutern. Line gemefsne Grö̊se $l$ sei von einer Variabeln $e$ in der Art abhïngig, dafs

$$
k=r e+s c^{2} \text {. }
$$

Dic constanten Factoren $r$ und $s$ sollen aus den Beobuchtungen bestimmt werden. Vergleiclit man diesen Ausdruck mit der $\$ 18$ angegebnen allgemeinen Form, so ist

$$
\begin{aligned}
& a=e \\
& b=e^{2}
\end{aligned}
$$

und da nur zwei Glieder vorkommen, so braucht man auch nur $a a, b b, a b, l a$ und $k b$ für jede Beobachtung zu berechnen. 
Die Messungen haben ergeben

$$
\text { liir } \begin{array}{rlrl}
r & =0,33 & l i & =2,51 \\
& =1,04 & & =5,23 \\
& =1,32 & & =6,12 \\
& =2,06 & & =7,97 \\
& =2,60 & & =8,81 \\
& =3,14 & & =9,10 \\
& =3,82 & & =8,26 \\
& =4,13 & & =8,04
\end{array}
$$

Die Werthe von $b=c^{2}$ und $b b=e^{2} \cdot e^{2}$ findet man unmittelbar in der Tahelle.

$$
\begin{array}{rlrl}
b=a a= & 0,109 & b b= & 0,01 \\
& =1,082 & & =1,17 \\
& =1,742 & & =3,03 \\
& =4,244 & & =18,01 \\
& =6,760 & & =45,70 \\
& =9,860 & & =97,22 \\
& =14,592 & & =212,92 \\
& =17,057 & & =290,94 \\
{[b]=[a a]} & =55,446 & {[b b]} & =669,00
\end{array}
$$

Der erste Werth $b b$ könnte genauer angegeben werden, die gröfsere Schärfe wäre jedoch ohne Zwweck, weil die letzten Werthe von $b b$ nur in Hunderttheilen der Einheit ansgedrïckt sind. Selbst diese letzte Decimal-Stelle dürfte vernachlässigt werden, da die Untersuchung der wahrscheinlichen Fehler, wovon im Folgenden die Rede sein wird, ergiebt, dais die Beobachtungen niclıt den Grad der Genauigkeit besitzen, mit dem die Rechnung hier geführt ist. Man iiberzengt sich auch leicht, dås für diese Beobachtungen, von denen keine bis auf ein Tausendtheil ihres Werthes genau angegeben ist, schion Tafeln von weniger Stellen genügt hätten, wodurch die Rechnung erleichtert wäre.

In derselben Art findet man

$$
\begin{aligned}
{[k k] } & =427,92 \\
{[(k+a)(k+a)] } & =777,38 \\
{[(k+b)(k+b)] } & =2011,6 \\
{[(a+b)(a+b)] } & =1098,3
\end{aligned}
$$


Hieraus kann man nach der bezeichneten Methode leicht die Summen der Producte darstellen, nämlich

$$
\begin{aligned}
& {[a k]=\frac{[(k+a)(k+a)]-[k k]-[a a]}{2}=147,01} \\
& {[b k]=\frac{[(k+b)(k+b)]-[k k]-[b b]}{2}=457,33} \\
& {[a b]=\frac{[(a+b)(a+b)]-[a a]-[b b]}{2}=186,92}
\end{aligned}
$$

Wenn man alsdann behufs der Controle noch die Quadrate der Summen von $k$, $a$ und $b$ berechnet, so findet man

$$
[(k+a+b)(k+a+b)]=2734,88
$$

die obigen Quadrate und Producte ergeben dagegen

$$
[k k]+[a a]+[b b]+2([a k]+[b k]+[a b])=2734,89
$$

Die Uebereinstimmung beider Zahlen ist zufällig gröfser, als man erwarten konnte, woher die Rechnung in allen Theilen richtig ist.

Aus den gefundnen Summen

$$
[a a],[b b],[a b],[a k] \text { und }[b k]
$$

kann man nun nach den Bedingungs-Gleichungen $(\$ 18)$ die

\begin{tabular}{|c|c|c|c|c|}
\hline$\epsilon$ & k berechnet & $k$ beobachtet & Differenz & Quadrat \\
\hline 0,33 & 1,86 & 2,51 & $-0,65$ & 0,422 \\
\hline 1,04 & 5,15 & 5,23 & $-0,08$ & ,006 \\
\hline 1,32 & 6,16 & 6,12 & $+0,04$ & ,002 \\
\hline 2,06 & 8,12 & 7,97 & $+0,15$ &, 023 \\
\hline 2,60 & 8,87 & 8,81 & $+0,06$ &, 004 \\
\hline 3,14 & 9,04 & 9,10 & $-0,06$ & ,004 \\
\hline 3,82 & 8,45 & 8,26 & $+0,19$ &, 036 \\
\hline 4,13 & 7,86 & 8,04 & $-0,18$ &, 032 \\
\hline
\end{tabular}
wahrscheinlichsten Werthe der Unbekunnten berechnen. Man findet darnacl

$$
\begin{aligned}
r & =5,9723 \\
s & =-0,9851 \\
\text { also } k & =5,9723, e-0,9851 \cdot e^{2}
\end{aligned}
$$

Wenn man nunmehr für $e$ die gemefsnen Werthe einfiihrt, so sind die $k$ : 
Man darf die vorstehnden Differenzen nicht als die wirklichen Beobachtangsfehler anselın, indem die für $r$ und $s$ gefundnen $W$ erthe nicht die wahren, sondern nur die walırscheinlichsten sind. Es wird später gezeigt werden, wie man aus diesen Differenzen auf' die Grölse der wirklichen Beobachtungs-Fehler schliefsen und die wahrscheinlichen Fehler der gefundnen Constanten $r$ und $s$ berechnen kann.

Vergleicht man die Differenzen unter sich, so könnte man leicht vermuthen, dafs die starke Abweichung der ersten Beobachtung, die also an sich selır unwahrscheinliclı ist, durch andre Werthe von $r$ und $s$ vermindert werden könnte. Dieses ist jedoch lier nicht der Fall, weil die zum Grunde gelegte Gleichung die Bedingung enthält, dal's für $e=0$ auch $k=0$ ist. Hiernach mufs angenommen werden, dafs die erste Messung mit einem starken Feller behaftet ist, der bei der geringen Gröfse von $e$ und $l$ sich auch erklärt.

Man darf, so lange man eines Irrthums sich nicht bewufst ist, eine abweichende Beobachtung nicht als falsch anselin und sie deshalb a usschlief'sen. Allerdings geschielit dieses niclıt selten, doch rechtfertigt es sich keineswegs, denn eines Theils sind möglicher Weise die unter einander übereinstimmenden Beobachtungen weniger richtig, als die abweichende, sodann aber wird auch bei solchem Verfihhren die Sicherheit des Resultats gröfser dargestellt, als sie wirklich ist. Die Täuschung, die man durch Verschweigen von Messungen begeht, lälst sich eben so wenig entschuldigen, als wenn man Messungen fälschen oder fingiren wollte.

\section{$\S 21$.}

Eine zweite Frleichterung der Rechnung bezieht sich auf die Auffindung der Constanten $r, s \ldots$ nachdern die Summen jener Quadrate und Producte $a k t, b b \ldots k a, a b, a c \ldots$ bereits dargestellt sind. Im Jahr 1810 deutete Gaufs in einem Brief an Bessel dieses Verfalıren bereits $a n,{ }^{*}$ ) doch mag dasselbe hier in

*) Briefwechsel zwischen Gaufs und Bessel. Leiprig 1880. Seite 129. 
der Art wiedergegeben werden, wie Bessel in seinen Vortrigen es mittlieilte, und wie es auch besonders bequem ist, namentlich wenn man eine gröfsere Anzahl von Constanten zı bestimmen lıat.

Die Bedingungs-Gleichungen

$$
\begin{aligned}
& {[k a]=[a a] r+[a b] s+[a c] t+[a d] u+\ldots} \\
& {[k b]=[a b] r+[b b] s+[b c] t+[b d] u+\cdots} \\
& {[k c]=[a c] r+[b c] s+[c c] t+[c d] u+\cdots}
\end{aligned}
$$

11. 8. w.

deren Anzalıl jedesmal eben so grofs ist, wie die der Unbekannten, genïgen zwar zur Berechnung der Werthe von $r, s$, $t \ldots$. da jedoch dieselben Factoren $[a b],[a c]$ u. s. w. in den verschiednen Gleichungen sich wiederholen, so bietet sich hierdurch Gelegenheit zum bequemeren Eliminiren der einzelnen Glieder. Die erste Gleichung, wie die zweite entlualt den Coefficient [alo], die erste nnd die dritte den Coefficient $[a c]$ und so fort. Multiplicirt man daher die erste mit

$$
[a b]
$$

so wird der Coefficient von $r$ gleich $[a b]$ und hei der Subtraction dieser Gleichung von der unveränderten zweiten fällt das Glied fort, welches $r$ zum Factor hat. Multiplicirt man lierauf wieder die erste Gleichung mit

$$
\frac{\lceil a c\rceil}{\lfloor a a]}
$$

und subtrahirt dieselbe von der dritten, so erhïlt man eine zweite Gleichung, in der gleichfalls das Glied mit dem Factor $r$ verschwunden ist. In dieser Art ergeben sich aus den früheren Bedingungs-Gleichungen, deren Anzahl $=\mu$ war, nunmehr $\mu-1$ Gleichungen, die aber auch nur $\mu-1$ Unbekannte enthalten. Der wesentliche Vortheil dieses Verfahrens beruht darauf, dafs man nur die Logaritlımen der Coefficienten von den Gliedern der ersten Gleichung, also der $[k a],[a a],[a b], \ldots$ aufzuschlagen braucht, weil die sämmtlichen tibrigen Gleichungen bei der Elimination der Constanten $r$ in ihren Zahlenwertlıen benutzt werden können.

Nach Beendigung dieser ersten Operation hat man die folgenden Bedingungungs-Gleichungen 


$$
\begin{gathered}
-65- \\
\left.\left([k b]-\frac{[k a][a b]}{[a a]}\right)=(\mid b b]-\frac{[a b][a b]}{[a a]}\right) s+\left([b c]-\frac{[a b][a c]}{[a c]}\right) t \\
+\left([b d]-\frac{[a b][a d]}{[a a]}\right) u+\ldots \\
\left([k c]-\frac{[k a][a c]}{[a a]}\right)=\left([b c]-\frac{[a b][a c]}{[a a]}\right) s+\left([c c]-\frac{[a c][a c]}{[a a]}\right) t \\
+\left([c d]-\frac{[a c][a d]}{[a a]}\right) u+\ldots \\
\left([k d]-\frac{[k a][a d]}{[a a]}\right)=\left([b d]-\frac{[a b][a d]}{[a a]}\right) s+\left([c d]-\frac{[a c][a d]}{[a a]}\right) t \\
+\left([d d]-\frac{[a d][a d]}{[a a]}\right) u+\ldots
\end{gathered}
$$

Man bemerkt, dafs auch lier auf der rechten Seite das zweite Glied der ersten Gleichung denselben Coefficient hat, wie das erste der zweiten, eben so auch das dritte Glied der ersten Gleichung und das erste der dritten 11 . s. f. Es ergiebt sich auch aus der Bildung dieser Coefticienten der Grund dieser Erscheinung. Sobald man daher die in die Parenthesen eingeschlossenen Differenzen berechnet hat, kann man in gleiclıer Art, wie früher, die ersten Glieder, die den Factor s enthalten, beseitigen, während man allein von den Zahlen-Coefticienten der ersten Gleichung die Logarithmen aufzuschlagen braucht. In dieser Weise setzt sich die Rechnung fort, indem die Anzalıl der Unbekannten sich jedesmal um eine vermindert, bis endlich nur die letzte in einer Gleichung übrig bleibt, deren Werth man alsdann berechnen kann. Aus rliesem ergeben sich abel nach den vorhergehenden Gleichungen auch die andern Unbekannten und in den verschiednen Gleichungen bietet sich reichlich Gelegenheit die Rechnung zu controlliren.

I) Anwendung dieser Methode wirl später in einem Beispiel nüher nacligewiesen werlen.

\section{$\$ 22$.}

Die bisher den Beohachiıngen zum Grunde gelegte Gleichung

$$
k=a r+b s+c t+\ldots
$$

worin die Unbekannten als einfache Factoren in don verschiednen Gliedern vorkommen, stellt sich keineswegs in allen Fällen dar, 
doch lassen sich jedesmal auch andre Ausdrïcke auf diese Form zur ï ckführen.

Sollte ein Glied das Product oder den Quotient $z$ weier Unbekannten enthalten, von denen die eine noch in einem andern Gliede auftritt, so hindert nichts, dieses Product oder diesen Quotient zunächst als eine einfache Unbekannte anzuselın, die sich zerlegen läfst, sobald man den Werth der darin enthaltenen zweiten L'nbekannten berechnet hat. Hätte man z. B.

$$
k=a \cdot r s+b \cdot s
$$

so würde man die walırscheinlichsten Werthe von $r s$ und $s$ suchen, und alsdann den ersten dureh den zweiten dividiren.

Zuweilen kommt dieselbe Unbekannte in vers chiednen Potenzen vor. Alsdann empfichit es sich, einen Näherungswerth dafür einzuführen und die Verbesserung desselben als die gesuchte Unbekannte anzuselın. Hat man zum Beispiel die Gleichung

$$
k=a r^{h}+b r+c s
$$

so setze man

$$
r=R+\varrho
$$

$R$ ist der Näherungswerth und $\varrho$ die unbekannte Verbesserung desselben. Letztere mufs gegen den ersten so klein sein, dafs ilıre höheren Potenzen vernachlässigt werden dürfen. Alsdann ist

$$
r^{h}=R^{h}+h \cdot R^{h-1} \cdot \varrho
$$

und man erhült, indem man die bekannten Glieder vor das Gleichheits-Zeichen stellt,

$$
k-a R^{h}-b R=\left(a h R^{h-1}+b\right) \varrho+e s
$$

Die Unbekannten $\varrho$ und $s$ sind alsdann durch diese UTmformung einfache Factoren geworden, wie in der frühern Gleichung. Sollte sich schliefslich für $\varrho$ ein so grofser Werth ergeben, dafs dessen zweite Potenz nocl, nicht vernachlässigt werden darf, so bleibt nur ïbrig nunmelr $R+\varrho$ als den Näherungswerth anzuselın und $r=(l i+\varrho)$ - $\varrho^{\prime}$ zu setzen, und in gleicher Weise die Verbesserung $e^{\prime}$ zu berechnen.

Zuweilen sind die Verhältnisse, unter denen eine Erscheinung eintritt, so verwickelt, dals man nicht weifs, in weleher Potenz man eine der gegebnen Grïfsen in den Ausdruck einfuibren soll, 
und es kommt alsdann darauf an, den walırscheinlichsten Werth des Exponenten zu finderı. Der einfachste Fall dieser Art wäre die Gleichung

$$
k=r \cdot a_{x}
$$

wobei sowohl der Coefficient $r$, wie der Kxponent $s$ gesucht wird. Durch Uebergang zu den Logarithmen erfolgt die Umbildung sehr einfach in der Art, dafs beide Unbekannte in verschiednen Gliedern als Coefficienten erscheinen, nämlich

$$
\log k=\log r+\log a \cdot s
$$

Alsdann kann man nach der Metlıode der kleinsten Quadrate sowohl $r$, wie $s$ unmittelbar berechnen. Diese Umformung verbietet sich indessen, wenn noch ein zweites Glied hinzutritt, wie etwa

$$
k=r \cdot a^{s}+b \cdot t
$$

Abgesehn hiervon darf' man nicht unbeachtet lassen, dafs bei Benutzung des logarithmischen Ausdrucks nicht sowohl die Summe der Quadrate der Feller von $k$, sondern die der Fehler der Logarithmen derselben ein Minimum wird, und dadurch die kleineren Werthe von $h$, fïr welche die Differenzen der Logarithmen am gröfsten sind, überwiegenden Einflufs gewinnen. Ist die Anzahl der Beobachtungen nur geringe, so kann man diesem Uebelstand dadurch begegnen, dals man für die vorliegenden Werthe von $k$ die Differenzen der Logarithmen zweier zunächst stehender Zahlen aufsucht, und im umgekehrten Verhältnifs derselben den Beobachtungen verschiedne Gewi chte beilegt, wovon im folgenden Paragraph die Rede sein wird. Bei einer gröfsern Anzalıl von Beobaclitungen ist dieses Verfahren indessen so miilısam, dals man davon absehn muls.

Am passendsten ersclıcint es, den durch die logaritlımische Rechnung, oder auch aus einzelnen Beobachtungen direct gefundnen lixponent als Nïherungswertlı anzusehn und die Verbesserung desselben zn berechnen.

Nach dem Taylorsclien Lehrsatz ist

$$
f(x+h)=f_{x}^{*}+h \cdot d f_{x}^{*}+\frac{h^{2}}{1,2} d^{2} f_{x}^{*}+\ldots
$$


Das dritte Glied nebst allen folgenden fällt aber fort, wenn 7 so klein ist, dafs man die höheren Potenzen gleich Null setzen kann. Man hat ferner

$$
d a^{s}=a^{s} \cdot \log \text { nat } a \cdot d s
$$

also ist

$$
a^{s+o}=a^{s}+a^{s} \log \text { nat } a \cdot \sigma
$$

folglich, wenn $S$ der angenommene Näherungswerth von $s$, und $\sigma$ die Verbesserung desselben ist,

$$
k=a^{s} r+a^{s} \log \text { nat } a \cdot r \sigma+b t
$$

Die drei Unbekannten sind alsdann $r, r \sigma$ und $t$ und der Ausdruck hat diejenige Form, welche die unmittelbare Anwendung der Methode der kleinsten Quadrate gestattet. Es darf aber kaum daran erinnert werden, dals der natiirliche Logarithmus einer Zahl gleiclı dem Briggeschen ist multiplicirt mit 2,3025, wofür man gewöhnlich 2,3 setzen darf. Auch müissen die Logarithmen von ächten Brüchen nicht mit der decadischen Ergänzung versehn, sondern als negative Zahlen dargestellt werden.

Der Berechnung von $\sigma$ nach dem vorstelinden Ausdruck tritt zuweilen eine Schwierigkeit entgegen, die auf diesem Wege jede weitere Annäherung unmöglich macht. Die zweite Unbekannte ist nämlich nicht $\sigma$, soudern $r \sigma$, und wenn $r$ sehr grofs ist, so muls $\sigma$ schon überaus klein oder die Annäherung sehr weit getrieben sein, damit das Quadrat und die höhern Potenzen von $r \sigma$ vernachlissigt werden dürfen. Es kann sogar leicht geschehn, dafs dieser Versuch zur 1)arstellung des passendsten Werthes von $s$ zum Gegentheil führt und man dadurch von der Wahrlıeit sich noch weiter entfernt.

Seln wichtig ist indessen hierbei die Erfahrung, dafs die Fxponenten gewöhnlich einfache Zahlen oder einfache ichlite orler unïchte Brïclıe sind. Wenn daher die logaritlımische Rechnung z1 Decimalbrüchen mit vielen Ziffern fühıt, so sind diese auf' einfache Werthe zurïckzufülıren. Es empfiehlt sich alsdann, nicht nur die wahrscheinlichsten Werthe der Exponenten, sondern auch die wahrscheinlichen Fehler dieser Werthe nach $\$ 30$ zu ermitteln und mit Berïcksichtigung dersellen die Vereinfachung anszufühıren.

Jedenfulls giebt es alıer noch eine sehr sichre Probe fiir die Wahl eines kxponenten. Ist man nïmlich zweifelhaft, ob diesel 
oder jener der passendere sei, so darf man nur unter Annalune des einen und des andern die Rechnung durchfïhhren und fïr beide die $\Lambda$ bweichungen von den beolachteten Werthen $l i$ zum Quadrat erheben. Derjenige Exponent ist alsdann der passendere, bei dem die Summe der Quadrate der lelıler die kleinere ist.

\section{$\S 23$.}

Die vorstehend entwickelte Methode zur Auffindung der wahrscheinlichsten Werthe der Unbekennten berulht auf der Voraussetzung, dal's die Wahrseheinlichkeit der sianmtlichen Fehler der zum Grunde gelegten Beobachtungen gleich grofs oder dufs in allen Messungen der Werth von $\frac{1}{2} u=r$ in der Gleichung

$$
y=\frac{1}{\sqrt{x} \cdot \sqrt{\nu}} e^{-\frac{x x}{v}}
$$

derselbe bleibt, dafs also abgesehn von der zuf̈älligen Grö fs e der Fehler, nicht ein 'Tlıeil der Messungen schärfer ist, oder ein genaueres Resultat erwarten lärst, als ein andrer. Diese (Xleichmaifsigkeit lindet oft nicht statt, wenn auch die BeobachtungsArt dieselbe ist.

So kommt es bei hydraulischen Messungen nicht selten vor, dafs in derselben Beobachtungs-Reihe die grofsen Geschwindigkeiten und grofsen Druckhöhen wegen der schwierigen Messung nicht so genau sind, wie die kleinern. Wenn in jenem Beispiel $b$ die Drnckhöhe ist, $a$ und $b$ dagegen gewisse Functionen der Geschwindigkeit sind, so hängen die Summen der Producte und lotenzen vorzugsweise von diesen überwiegend grofsen, aber am wenigsten sichern Beobachtungen ab, und die genauern Messungen, die sich auf die kleinern Geschwindigkeiten bezichn, verlieren dagegen grolsentheils ibren Einflufs. Jene Bedingung wird also in điesem Falle keineswegs erfïllt, vielmehr ist die Wahrscheinlichkeit eines gleich grofsen Beobachtungs-Fehlers sehr verschieden.

Oft lälst sich eine Ausgleichung dadurch herbeifïhren, dafs man in jeder Beobachtung alle gegebnen Grō̂sen durch eine derselben dividirt, also etwa statt

$$
k=a r+b s
$$


die Gleichung

$$
\frac{k}{a}=r+\frac{b}{a} s
$$

wählt. Hierdurch gelingt es zuwcilen, allen Messungen ungefiilır gleichen Werth zu geben und den iiherwiegenten Einflufs cinzelner aufzuheben. Nichts desto weniger darf man Aenderungen dieser Art nicht willkürlich einführen, vielmchr ist jedesmal eine sorgfältige Ueberlegung erforderlich, ob die Wahrscheinlichkeit der Fehler von $\frac{k}{a}$ in den verschiednen Beobacbtungen annälıernd dieselbe ist. Auch darf dabei nicht unbeaclitet bleiben, dafs in diesem Fall wieder nicht die Summe der Quadrate der Beobachtungs-Felıler, sondern die der Quotienten ein Minimum wird. Es ist daher nöthig, die Zulässigkeit solcher Umformung auch in dieser Bezichung zu prïfen.

Vielfach kornmt es darauf an, aus selır verschiedenartigen Beobachtungen, die an sich keineswegs mit gleicher Schärfe angestellt sind, Resultate zu zielın. Man darf' alsdann augenscheinlich niclit allen gleichen Werth beilegen, man inufs vielmehr den Werth der einzelnen Messungen zu bestimmen, oder wenigstens zu schätzen versuchen, und ihn angemessen in Reclınung stellen. Wenn es sich z. B. um Winkelmessungen handelt, wobei verschiedne Instrumente benutzt wurden, von denen theils einzelne Minuten, theils aber nur je 10 Minuten abgelesen werden konnten, so dïrfen diese keineswegs als gleich berechtigt angesehn werden.

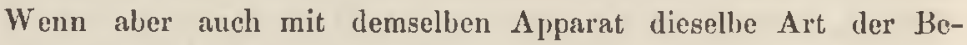
obaclitung unter verschiednen Umständen mehrfuch wiederholt wircl, so geschicht es oft, dals dic iufsern Einwirkungen auffallend günstig, oder besonders ungünstig sind, und man sogleiclı die Uebcrzengung gewinnt, dafs die Beobachtungen sehr verscliedne Werthe laben.

Die genaue Ermittlung dieser Werthe oder der Ge wi clite der einzelnen Beobaclitungen ist unbedingt sehr scliwierig und erfordert jedenfulls grofse Sorgfult und volle Unbefingenheit. Besonders mufs man sich liäten, aus der Uebereinstimmung einiger Beolhachtungen unter sich auf die besondre Schärfe derselben zu schliefsen, oder andrerseits denjenigen allen Werth abzusprechen oder gar kein Gewicht beizulegen, welche grofse Abweichungen 
zeigen. In diesem Fall würde man keineswegs das walırscheinliclıste, sondern nur ein solches Resultat darstellen, welches sich an diejenigen Beobachtungen anschliefst, die zufallig mit einander ïbereinstimmen. Bei dem verschiedenartigen Auftreten der Fehler kann es leicht geschehn, dafs gerade diejenige Messung, welche von den übrigen am stärksten abweicht, zur Berichtigung des Resultats wesentlich beiträgt. Man muls daher unbedingt den Grundsatz befolgen, dafs keine Messung oder Reobachtung ron der Rechnung ausgeschlossen werden darf, wenn man nicht sclion, während sie gemacht wurde, bemerkte, dafs sie nicht richtig oder doch sehr zweifelhaft sei.

Dagegen rechtfertigt es sich nicht nur, sondern es ist aluch nothwendig, denjenigen Beobachtungen einen gröfsern oder geringern Werth beizulegen, von denen man mit Rücksicht auf :iufsere Umstinde sich überzengt hat, dals sie bedeutend sichrer oder weniger sicher sind, als die übrigen. Um zu zeigen, in welcher. Weise dieses geschieht, ist es nöthig, den Begriff des wah recheinlichen Beobachtungs-Fehlers schon zum Grunde zu legen, von dem später eingehend dic Rede sein wird. Man verstelit darunter einen Felıler von solcher Grïfse, dufs derselbe bei vielficher Wiederholung der Messung von allen Fehlem, sowolll positiven, wie negativen, die dabei vorkommen, eben so oft iiberschritten, wie nicht erreicht wird. Auch mufs linzugefügt werden, dafs, wemn dieser wahrscheinliche Fehler $=\omega$ atus " gleich sichern Beobachtungen hergeleitet ist, dafs alsilann der wahrscheinliche Fehler des arithmetischen Mittels aus diesen Beobachtungen gleich ist $(\S 30)$

$$
\frac{w}{\sqrt{\mu}}
$$

Weifs man nun, dafs beispielsweise in einer Reilie von Beobachtungen fiir eine oder mehrere derselben der wahrscheinliche Fohler nur halb so grols, als der der Uebrigen ist, so ergiebt sich aus Vorstehndem, dals diese besonders scharfen Beobachtungen denselben Werth haben, als wenn sie mit der Schärfe der andern viermal gemacht wären. Sie sind also viermal in Rechnung zu stellen. Im Allgemeinen ergiebt sich aber, dafs wenn der walırscheinliche Fehler der Mehrzahl der Beobachtungen gleich $\omega$, derjenige von einzelnen aber $m \omega$ ist, wobei 
m. sowohl eine ganze Zahl, wie ein ächter Bruch sein kann, dal's man alsdann diese Beobachtungen $\frac{1}{m \cdot m}$ mitl in Rechnung zu stellen hat. Mit diesem Bruch sind also die friiher mit $k, a, b \ldots$ bezeichneten $W$ erthe zu multipliciren und in die Summen der l'roducte $k a, l i b, a a, a b \ldots$ einzuführen. Wenn aber einer der Factoren $a, b \ldots=1$ ist, so darf man nicht unterlassen in die Anzahl der Beobachtungen statt der Einheit eben diesen Bruch $z u$ setzen.

Schliefslich mufs erwälnt werden, dafs die Bestimmung des Werthes von $m$ wohl niemals mit grofser Schärfe ausgefiilırt werden kann und meist nur auf Schiitzung berulit. Man wird daher zur Untersuchung der Gewiclite der einzelnen Messungen sich nur entschliefsen, wenn dieselben wesentlich verschieden sind. 


\title{
IV. Abschnitt.
}

\section{Der wahrocheinliohe Fehler.}

\author{
$\$ 24$.
}

Obwohl nach den vorstehend entwickelten Gesetzen die Fehler, die bei jeder Messung vorkommen können, zwischen denselben Grenzen, nämlich zwischen Null und positiv oder negutiv Unendlich liegen, so ist dennch die Sicherheit der verschiednen Beobachtungs-Arten sehr verschieden. Mit einem bessern Instrument und bei grölsrer Uebung wird man ohne $Z$ weifel richtiger messen, als im entgegengesetzten Fall. l)ie Schärfe jerler Beohnchtungs-Art ist in dem (\$ 16) entwickelten Ausdruck fiir die Wahrscheinlichkeit des Vorkommens cines gewissen Fehlers $x$ durch $n$ gegeben. Dic eigentliche Bedeutung von $n$ war aber die Anzahl der unendlich vielen theils positiven, theils negativen elementären Fehler, aus deren Verbindung die BeobachtungsFehler entstehn.

Ferner ist nachgewiesen, dafs zwischen diesem $u$ und der Wahrscheinlichkeit, dafs der Fehler gleich Null sei, die mit $\iota$ bezcichnet wurde, eine sehr einfache Bezichung besteht. Man könnte sonach diese Wahrscheinlichkeit, oder wie oben gezeigt ist, die gröfste Ordinate der Curve zum Maafs der Schärfe der verschiednen Beobaclitungs-Arten wählen. Hierzu sind aber andre charakteristische Fehler mehr geeignet, insofern sie aus einer mäfsigen Anzahl von Messungen mit grölsrer Sicherheit sich ermitteln lassen.

Am einfachsten erscheint es, hierzu den mittle r $\mathbf{n}$ e hle r $=m$ zı wählen, also die Summe der sämmtlichen Fehler dividirt durch ihre Anzalıl. Macht man die Voraussetzung, dal's 
wirklich alle verschiednen Feller vorkommen, oder dal's dic Anzahl der Beobachtungen unendlich grofs ist, so ist die Wahrscheinlichkeit, einen Fehler zu begehn, der zwischen den Grenzen $x$ und $x+d x$ liegt, $y d x$. Dieser Ausdruck bezeichnet nach vorstelınder Annahme aber auch die Anzahl der Feliler von dieser Gröfse. Die Anzahl der gesammten Fehler ist demnach

$$
=\int y d x, \text { von } x=-\infty \text { bis } x=+\infty
$$

Dio Su m me der Felıler ist aber gleich der Summe der l'roducte jedes Fehlers in dic Walıscheinlicllkeit seines Vorkommens, also

$$
=\int y x d x
$$

und zwar wieder innerlaalb derselben Grenzen.

Das Integral von $y d x$ ist der Flächeninhalt der ganzen Curve, also gleich 1 , das Integral von $y x d x$ dagegen ist, wenn man wieder $\frac{1}{2} n$ durch $v$ bezeichnet, fïir diese

$$
\begin{aligned}
& =\frac{1}{\sqrt{ } \pi \cdot \sqrt{v}} \int e^{-\frac{s x}{y}} x d x \\
& =-\frac{\sqrt{v}}{2 \sqrt{x}} e^{-\frac{x x}{v}}
\end{aligned}
$$

Der Werth dieses Integrals ist

$$
\begin{array}{rrr}
\text { für } x=0 & \text { gleich } & -\frac{\sqrt{v}}{2 \sqrt{v}} \\
\text { und für } x=\infty & 0 \\
\text { also von } 0 \text { bis } \infty & =\frac{\sqrt{v}}{2 \sqrt{ } x} \\
\text { und von }-\infty \text { bis }+\infty & =\frac{\sqrt{\nu}}{\sqrt{ } x}
\end{array}
$$

Bei der Division durch die Anzalıl der Fehler oder durch 1 andert sich nicht der Werth und man hat sonach den mittlern Fehler $m$

$$
m=\frac{\sqrt{\nu}}{\sqrt{\pi}}=0,56419 \cdot V^{\nu}
$$


Indem man diesen Werth von $m$ statt $x$ in den Ausdruck

$$
y=\frac{1}{\sqrt{\pi} \cdot V^{\nu}} e^{-\frac{x \pi}{v}}
$$

cinfühlıt, so erhailt man die Wahrscheinlichkeit des mittlern Felılers

$$
y=0,72738 \text {. } \iota
$$

während $a$ wicder die größste Ordinate der Curve ist, und die Walırscheinlichkeit bezeiclınet, dal's der Beobachtungsfehler gleich Null sei.

Wenu dagegen nicht alle Fehler, sondern nur eine beschränkte Anzahl derselben vorkommt, so ist die wahırscheinlichste Voraussetzung, dals diese nach Matalsgabe ilırer Wahrscheinlichkeit sich vertheilen. Liegen daher $\mu$ Beobachtungen vor, so ist die Summe der betreffenden Fehler gleich

$$
\mu \int y x d x
$$

die Auzahl derselben ist aber gleich $\|$ und folglich der mittlere Fehler $m$ eben so grof's, wie frïher. Dieses geschieht jedoch nur, wenn in der mälsigen Anzahl von Beobachtungen die Fehler wirklich dem Vorhältnifs ihrer Wahrscheinliclikeit entsprechend vertheilt sind. Gröfsre Fehler sind aber seltner als kleinere und kommen vielleicht hier gar nicht vor, wolıer der walıe mittlere Fehler sich nicht richtig herausstellt. Liegen mehr Beobachtungen vor, so vermindert sich zwar dieser Uebelstand, aber vortheilhaft ist es unbedingt, cinen andern charakteristischen Fehler zu suchen, dessen Werth aus einer geringen Anzalhl von Messungen mit gröfsserer Sicherheit sich lerleiten lälist.

\section{$\S 25$.}

Demnïchist künnte man die $W$ urzel at s dem mittlern $\mathrm{Fe}$ hleryuad a $\mathrm{t}$ als solchen charakteristischen Fehler ansehn. Mau quadrirt nämlich alle Fehler, summirt die Quadrate, und dividirt ihre Summe durch die Anzahl der Fehler. Dieser Quotient ist das mittlere Fehlerquadrat, das durch $q q$ bezeichnet werden mag. Hiernach hat man, unter der Voraussetzung, dafs alle Fehler wirklich vorgekommen sind

$$
q q=\frac{\int y x^{2} d x}{\int y d x}
$$


und zwar erstrecken sich beide Integrale von - $\propto$ his $\dagger \infty$. Der Nenner ist alstann wieder $=1$ und man hat

$$
q q=\frac{1}{\sqrt{x} \cdot \sqrt{v}} \int e^{-\frac{x x}{v}} x^{2} d x
$$

Durch Ausfïlırung der partiellen Integration tindet man

$$
q q=\frac{\sqrt{\nu}}{2 \sqrt{ } x}\left(-e^{-\frac{x x}{v}} x+\int e^{-\frac{x x}{v}} d x\right)
$$

Das erste Glied in der Parenthese

$$
-e^{-\frac{x x}{v}} \cdot x=-\frac{x}{e^{\frac{x x}{v}}}
$$

verwandelt sich dit

$$
\epsilon=1+\frac{z}{1}+\frac{z^{2}}{1 \cdot 2}+\frac{z^{3}}{1 \cdot 2 \cdot 3}+\cdots
$$

ist, in

$$
-\frac{x}{1+\frac{x x}{y}+\frac{1}{2}\left(\frac{x x}{y}\right)^{2}+\frac{1}{6}\left(\frac{x x}{y}\right)^{5}+\ldots}
$$

und der Werth dieses Ausdrucks ist für $x=0$ gleich Null. für $x=\infty$ aher gleichfalls Null. Das erste Glied faltt sonach innerhalb dieser Grenzen fort. Das zweite Glied in der Parenthese ist

$$
\int e^{-\frac{x x}{v}} d x=\sqrt{x} \cdot V^{v} \int y d x
$$

man hat also

$$
q q=\frac{1}{2} v \int y d x
$$

Jieses Integral ist innerhalb derselben Grenzen gleich 1, und man erhält schfiefslich

$$
\begin{aligned}
q q & =\frac{1}{2} \nu \\
q & =\sqrt{\frac{1}{2}} \cdot V^{\nu} \\
& =0,7071068 \cdot \sqrt{ } \nu
\end{aligned}
$$

und wenn man die Wahrscheinlichkeit dieses Fehlers $q$ wieder durch die grölste Ordinate $a$ ausdrïckt, so ergiebt sich

$$
y=0,60653 \cdot a
$$

Der Fehler $x=q$ nimmt in der Curve eine sehr markirte Stelle ein, nänlich diejenige, wo die abwärts gckehrte Krümmung 
in die entgegengesetzte übergeht, oder wo die Neigung am grö́sten ist. Die Neignng ist nämlich

$$
\frac{d y}{d x}=-\frac{2}{v \sqrt{v} \cdot \sqrt{x}} e^{-\frac{x x}{r}} \cdot x
$$

und wenn man diesen Ausdruck differenzirt und das Differenzial gleich Null setzt, so ergiebt sich

$$
2 x^{2}=v
$$

oder

$$
x=\sqrt{\frac{1}{2}} \cdot v^{\nu}
$$

also ibereinstimmend mit dem Werth von $q$.

\section{$\S 26$.}

Fs giebt endlich noch einen sehr wichtigen charakteristischen Fehler, nämlich den wahrscheinlichen Fehler. Derselbe bezeichnet diejenige Grenze, die von den sämmtlichen sowohl positiven, wie negativen Fehlern eben so oft überschritten, wie nicht erreicht wird. Nennt man diesen Fehler $w$, so muls das Integral

$$
\int y d x \text { von } x=0 \text { bis } x=w
$$

ehen so grofs sein, wie dasselbe von

$$
x=w \text { bis } x=\infty
$$

Indem nher beide Schenkel der Cuve symmetriseh und die ganze vom ilir eingeschlofsne Fliiche $=1$ ist, so folgt die Bedlugung, dafs dieses Integral zwischen $x=0$ und $x=w$ glpich ein V'iertel ist. Zur einfacheren Bezeichnung setze man

$$
\begin{aligned}
\frac{x}{\sqrt{v}} & =t \\
x & =t \sqrt{v} \text { und } d x=\sqrt{v} \cdot d t
\end{aligned}
$$

Man hat alsdaun nach $\$ 16$

$$
\int y d x=\frac{1}{\sqrt{x}} \cdot \int e^{-1 t} d t
$$

aber

$$
e^{-11}=1-\frac{t^{2}}{1}+\frac{t^{4}}{1 \cdot 2}-\frac{t^{6}}{1 \cdot 2 \cdot 3}+\cdots
$$


Fìr die vorstelind angegebnen Grenzen erhält man nach Ausführung der Integration, indem

$$
\begin{gathered}
\frac{1}{4} \sqrt{ } x=0,4431135 \\
0,4431135=t-\frac{1}{3} t^{3}+\frac{1}{10} t^{5}-\frac{1}{62} t^{7}+\frac{1}{216} t^{9}-\frac{1}{1320} t^{11}+\frac{1}{1050} t^{13}-\ldots
\end{gathered}
$$

Eine Constante kommt nicht hinzu, da für $t=0$ jedes Glied gleich Null ist. Es kommt darauf an, denjenigen Wertl von $t$ zu finden, der dieser Gleichung entspricht. Indem man versuchsweise verschiedne Werthe für $t$ einfülırt, findet man schliesslich

\section{$\left.t=0,4769364^{*}\right)$}

Von der Richtigkeit dieser Zahl kann man sich überzeugen, wenn man sie in die vorstehnde Reihe einfïhrt. Hieraus ergiebt sich nun der wahrscheinliche Felıler

$$
w=0,4769364 \cdot \sqrt{v}
$$

und die Wahrscheinlichkeit dieses Fehlers vergleichungsweise zur gröfsten Ordinate ist

$$
y=0,79654 \cdot a
$$

Aus der Vergleichung dieser drei charakteristischen Fehler $m, q$ und $w$ ergiebt sich schon, dals der letzte vor den beiden andern den Vorzug hat, dafs er der kleinste ist. Seine Walıscheinlichkeit $y$ hat also den gröfsten Werth, er liegt den am häufigsten vorkommenden Fehlern am nächsten, und kann sonach auch am sichersten aus diesen berechnet werden.

Seine Gröfse wïrde indessen ziemlich unsicher bleiben, wenn man dieselbe nur in der Art ermitteln wollte, dafs man die sï̈mmtlichen Felıler, olıne clarauf Rücksicht zu nelınen, ob sie positiv oler negativ sind, nach ihrer Grölse ordnete, und denjenigen als den wahrscheinlichen ansähe, der die mittlere Stclle einuimmt. lis leuchtet ein, dafs dabei keine gleichmäfsige Berieksichtigung der sämmtliclıen Fehler erfolgt, vorzıgsweise nur desjenigen der an dieser Stelle steht. Wenn aber eine gerade $\Lambda_{n}$ \%ahl von Fehlern vorläge, so liefse sich kein bestimmter Werth dafiir angeben und man könnte vielmehr nur Grenzen bezeichnen, die vielleicht weit aus cinander liegen. Weit sichmer ist es, das

*) In der Ahhandlung ïber den Olbers'schen Kometen hat Bessel einen directen Weg zur Berechnung von $t$ angegeben. 
mittlere Fehler-Quadrat zu bestimmen und von diesem zum walırscheinlichen Fehler überzugehn.

Der aus den Fehlerrynadraten hergeleitete cliarakteristische Fehler war

$$
\eta=0,7071068 \cdot v \nu
$$

und der wahrscheinliche Fehler

$$
v=0,4769364 \cdot V^{y}
$$

man hat daher

$$
w=0,6744900 \cdot q
$$

Man quadrire also die zwischen den Beobachtungen und der Rechnung gefundenen Differenzen, summire diese Quadrate, dividire sie durch ihre Anzahl, und ziehe aus dem Qnotient die Wurzel, die alsdann gleich q ist. Dieses mit 0,67449 multiplicirt giebt den gesuchten wahrscheinlichen Beobachtungs-Fehler $w$.

Geht man beispielsweise auf die $\$ 20$ mitgetheilten Beobaclitungen zurïck, so sind die Differenzen der berechneten Resultate gegen die gemefsnen nach ihrer Gröfse geordnet

$$
\begin{array}{llll}
0,04 & 0,06 & 0,06 & 0,08 \\
0,15 & 0,18 & 0,19 & 0,65
\end{array}
$$

Man würde also unmittelbar nur entnehmen können, dafs der walırscheinliche Fehler zwischen 0,08 und 0,15 liegt. Dabei wäre aber noch die sehr starke Abweichnng 0,65 ganz unbeachtet geblieben. Berücksichtigt nuan dagegen die Fehlerquadrate, deren Summe 0,529 ist, findet man

und

$$
\begin{aligned}
q & =0,257 \\
w & =0,173
\end{aligned}
$$

\section{$\S 27$.}

Der wahrscheinliche Fehler eignet sich vorzngsweise zur Li in heit des $M$ a a $f$ ses, worin die Fehler der Beobaclitungsreihen gemessen werden. Die Fläche jener (Murve, deren Abscissen die Fehler, und deren Ordinaten die zugehörigen Wahrscheinlichkeiten darstellen, ist gleich 1. Führt man nunmehr als Iängenmaals für die Abscissen den wahrscheinlichen Fehler ein, so lassen sich die Ordinaten in bestimmten Zalılenwerthen ausdrücken, und 
dieses gilt auch von den durch sie begrenzten Flächen. Das Letztere ist besonders insofern von grofser Wichtigkeit, als sich aus diesen Flächen unmittelbar entnehmen lärst, mit welcher Wahrscheinlichkeit man das Vorkommen von Fehlern erwarten darf, die gewisse Vielfache, oder irgend welche aliquote Theile des walırscheinlichen Fehlers sind.

Indem die Flächen nach der Methode der mechanischeu Quadratur berechnet werden, so muls man zuerst die Ordinaten in geringen Abständen bestimmen. Dieses ist auch schon nothwendig, um ein anschauliches Bild von der Form der Curve zu gewinnen. Man hatte

dagegen war

$$
y=\frac{1}{\sqrt{\pi} \cdot V^{y}} e^{-\frac{x x}{y}}
$$

$$
w=0,476936 \cdot v \nu
$$

und indem

$$
w=1
$$

gesetzt wird, ergiebt sich

$$
v=4,396224
$$

Man kann hiernach für jedes beliebige $x$, das zugehorige y berechnen, und am leichtesten geschieht dieses logarithmisch.

$$
\log y=-\log (\sqrt{ } \pi \cdot V \nu)-\frac{x x}{y} \log e
$$

Die Berechnung des ersten, constanten Gliedes macht keine Schwierigkeit, um aber das zweite Glied zu finden, mul's man nochmals zu den Logarithmen übergehn. Das zweite Glied ist nämlich die Zahı, die zu

$$
\log x x-\log \nu+\log \log e
$$

geliört. Die beiden letzten Glieder sind hier constant, und unan lomucht, also nur $\log x x$ wiederlolentlich anfisschlagen.

Beispielsweise werde dasjenige $y$ gesuclıt, das zı $x=4,4$ gehört. Man hat alsdann

$$
\begin{aligned}
e= & 2,718282 \\
\log e= & 0,434294 \\
\log \log e= & 9,637784 \\
& =-0,362216 \\
\log v & =0,643079 \\
\log \log e-\log v & =-1,005295
\end{aligned}
$$


Ferner

nnd

$$
\log \gamma \nu=0,321540
$$

$\log V \pi=0,248575$
$\cdot \log V \nu \cdot V \pi=0,570115$

Dieses sind dic vorbereitenden Rechnungen, von denen man bei Restimuung aller ? Gebrauch macht.

ist.

$$
\begin{aligned}
& \text { Fũr } x=4,4 \\
& \log x=0,643453 \\
& \log x x=1,286906 \\
& -\log n+\frac{\log \log e=-1,005295}{x x} \\
& \log \log e v=0,281611 \\
& \log e^{\frac{x x}{v}}=1,91254
\end{aligned}
$$

also

endlich

$$
\begin{aligned}
\log e^{-\frac{x x}{v}} & =8,08746 \\
\log V \pi \cdot V y & =0,57011 \\
\log y & =7,51735
\end{aligned}
$$

\section{$y=0,0032912$}

Die Tabelle $B$ im Anlange entlält die in dieser Weise berechneten relativen $W$ ahrscheinlichkeiten $W$ der Fehler $x$. Da die Anzahl der möglichen Fehler unendlich grofs ist, so ist die Wahrscheinlichkeit, dafs der Fehler in aller Schürfe eine vorlier bestimmte Grörse erreichen wird, jedesmal gleich Null, dennoch haben diese unendlich kleinen Walırscheinlichkeiten, wenn man sie unter einander vergleicht, sehr verschiedne Werthe, und diese bezeichnet die mitgetheilte Tabelle. In derselben sind die $W^{r}$ von $x=0$ bis $x=8$. $w$ berechnet, indem die $x$ in der Einheit des wahrselıeinlichen Felılers $w$ gemessen, oder durch ihr Verhältnifs zu diesen ausgelriickt sind. Wine weitere $\Lambda$ usdehnung der Tabelle war entbehrliclı, da die Wahrscheinlichkeit des Fehlers $8 w$ schon unter den zwanzigmillionsten Theil der Wahrscheinliclıkeit des Fehlers $x=0$ herabgesunken ist.

In dieser Tabelle wachsen die $x$ um $0,1 . w$, und den betreffenden Wertlien von $W$ sind die ersten und zweiten Differenzen beigefügt. 1)ie dritten Differenzen sind meist so geringe, dafs sie unbeachtet bleiben durften, wollte man sie aber benutzen, so ist 
es leicht, sie ans den zweiten zu entnehmen und dadurch mit noch gröfserer Schärfe den Werth von $W$ für einen dazwischen liegenden Fehler $x$ zu bestimmen. Beispielsweise suche man diesen fiir $x=1,1763$,

Die Tabelle ergiebt fuir $x=1,1$

$$
\begin{aligned}
W & =0,204339 \\
D 1 & =-0,010416 \\
D 2 & =-0,000304 \\
D 3 & =+0,000111
\end{aligned}
$$

Nach den bekannten Regeln der Interpolation ist der $z 11 x+m$ gehörige Werth $W^{\prime}$

$$
W^{\prime}=W+m \cdot D 1+\frac{m \cdot m-1}{1 \cdot 2} \cdot D 2+\frac{m \cdot m-1 \cdot m-2}{1 \cdot 2 \cdot 3} D 3+\ldots
$$

Indem die $x$ in der Tabelle sich nicht um 1 , sondern nur um 0,1 ändern so ist im vorliegenden Fall

$$
m=0,763
$$

und man findet hiernach

$$
\begin{aligned}
& W=\quad 0,204339 \\
& -0,007947 \\
& +0,000027 \\
& \begin{array}{r}
+0,000006 \\
=\quad 0,196425
\end{array}
\end{aligned}
$$

Fis muls noch darauf aufmerksam gemacht werden, dafs die Schärfe, mit der die Rechnung hier ausgeführt worden, wohl in

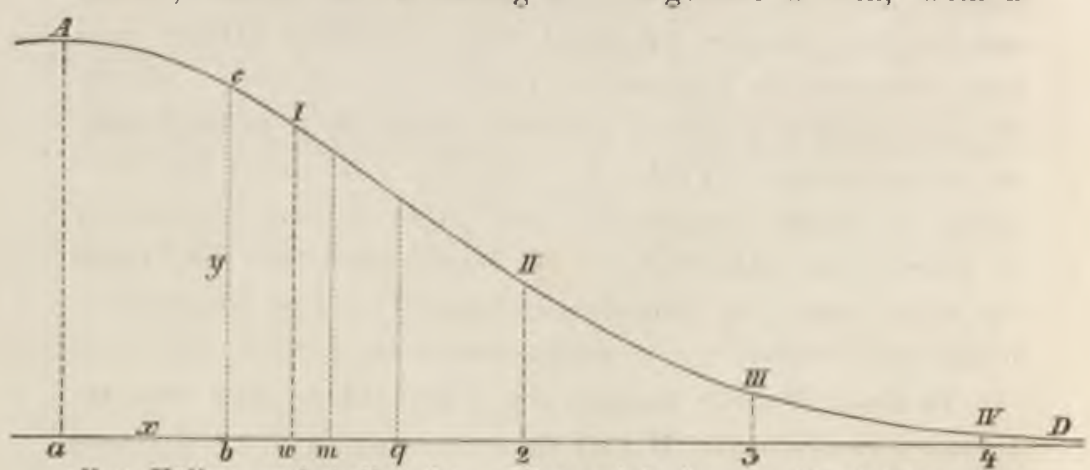

allen Fällen entbehrlich ist. Man wird immer die letzten drei und vielleicht sogar vier Decimalstellen der Werthe von $W$ un- 
heachtet lassen dürfen. Es kam bei Aufstellung der 'Tabelle nur darauf an, dieselbe recht weit auszudehnen, wobei die letzten Decimalstellen allein ïbrig blieben.

Stellt man diese Werthe von $W$ als Ordinaten dar, während die $x$ die Abscissen sind, so bildet sich eine Curve, deren Zug die vorstelınde Figur in der einen Hälfte zeigt, wälırend der linkseitige Schenkel, der sich auf die negativen Fehler bezieht, ganz symmetriseh mit diesem sich gestaltet. Der Scheitelpunkt in $A$ entspricht dem Fehler $x=0$. Die Abscisse $a w$ ist der wa h r scheinliche Fehler, so wiə $a 2, a 3 \ldots$ die Vielfachen desselben, $a m$ dagegen ist der mittlere Fehler und $a q$ die Wurzel aus dem mittlern Feliler-Quadrat.

\section{$\$ 28$.}

Die Flächen $\int y d x$ lassen sich nunmelır durch $\mathrm{m}$ e $\mathrm{ch}$ h a $\mathrm{n}$ is $\mathrm{ch} \mathrm{e}$ Quadratur leicht aus den Werthen von $y$ herleiten. Dabei pflegt man gewölınlich grö[sere Flächen, die durch eine Reihe von Ordinaten gegeben sind, zusammenzufussen. Im vorliegenden Fall ist es aber Aufgabe, jeden einzelnen Abschnitt zwischen zwei zunäclsst liegenden Ordinaten zu berechnen, und dalıer empfiehlt es sich, diese kleinen Theile zu bestimmen, und sie demnächst zu summiren. In solcher Art werden die Resultate auch etwas genauer, indem die Aenderung der Differenzial-Quotienten in jeder einzelnen Ordinate berïcksichtigt wird.

Der Ausdruck für die Flïche zwischen zwei zunächst stehnden Ordinaten $y$ und $y^{\prime}$, die zu den Abscissen $x$ und $x^{\prime}$ gehören, ist bekanntlicl, wenn

$$
x^{\prime}-x=\delta
$$

gesetzt wird,

$$
\int y d x=\frac{1}{2}\left(y+y^{\prime}\right) \delta-\frac{1}{x^{2}}\left(\frac{d y^{\prime}}{d x}-\frac{d y}{d x}\right) \delta^{2}
$$

oder wenn zugleich die negativen Fehler berïcksichtigt werden, also die kleine Fläche sich verdoppelt

$$
\int y d x=\left(y+y^{\prime}\right) \delta-\frac{1}{6}\left(\frac{d y^{\prime}}{d x}-\frac{d y}{d x}\right) \delta^{2}
$$


Man hat alser nach $\$ 14$ wenn $\frac{1}{2} n=\nu$ gesetzt wird

$$
\frac{d y}{d x}=-2 \frac{x y}{y}
$$

und

$$
\frac{d y^{\prime}}{d x}=-2 \frac{x^{\prime} y^{\prime}}{y}
$$

Da ferner die Ordinaten in Abständen von 0,1 bereelinet sind, so hat $\delta$ gleichfalls diesen Werth, und die gesuchte Fliche ist

$$
\int y d x=0,1\left(y+y^{\prime}\right)+\frac{0,01}{3 y}\left(y^{\prime} x^{\prime}-y x\right)
$$

oder wenn man für $v$ den Zahlenwerth einführt

$$
=0,1\left(y+y^{\prime}\right)+0,00075823\left(y^{4} x^{\prime}-y x\right)
$$

Die Werthe von $y$ und $y^{\prime}$, die zu den Fehlern $x$ und $x^{\prime}$ gehören, werden unmittelbar aus der Tabelle $B$ im Anhang entnommen, wodurch diese Rechnung ïberaus einfach wird. Die so gefundnen kleinen Flächen werden alsdann zu der Summe aller vorhergehnden, bis zu $x=0$, addirt. Diese Summen bezeichnen die Wahrscheinlichkeit, dafs ein Fehler nicht grölser, als $x$ werden, oder dafs er zwischen den Grenzen $-x$ und $+x$ bleiben wird. Gewöhnlich fragt man aber nach der Wahrscheinlichkeit des Gegentheils, nämlich ob er diese Grenzen überschreiten wird, und die Antwort hierauf' ergiebt sich aus der Gewifsheit, oder ans der Wahrscheinlichkeit $=1$, dafs der Fehler diese Grenzen entweder überschreitet, oder innerhalb derselben bleibt. Man erhält also die Wahrscheinlichkeit für grörsere Fehler, indem man jene Summen von 1 abzieht. Die Tabelle $C$ im Anhange enthält in der mit $W$ überschriebnen Spalte diese Wahrscheinlichkeiten für die im Verhältnil's zım wahrscheinlichen Felıer ausgedrückten Felıler $x$. Auch sind derselben, soweit es nöthig war, die ersten, zweiten und dritten Differenzen beigefïgt.

\section{$\S 29$.}

Aus dieser Tabelle $C$ lälst sich unmittelbar entnehmen, mit welcher Walırscheinlichkeit man erwarten darf, dals ein Beobachtungsfehler ein gewisses Vielfache des walırscheinlichen 
Fehlers nicht iibersteigen wird. So ist zum Beispiel diese Wahrscheinlichkeit für das Dreifache des wahrscheinlichen Fehlers gleich 0,043. Man kann demnach

oder ungefihir

\section{7 gegen 43}

\section{2 gegen 1}

wetten, dafs der Fehler das Dreifache des wahrscheinlichen Fehlers nicht überschreitet.

Die Wahrscheinlichkeit für das Ueberschreiten der Grenze $x=0$ ist gleich Lins angegehen, also als $\mathrm{G} \mathrm{e}$ wifsheit. Dieses erklärt sich ıladurch, dals die Wahrscheinlichkeit eines Fehlers, der in aller Schärfe gleich Null ist, eben so wie jedes andern vorher bestimmt bezeichneten Fehlers immer der Quotient von Eins dividirt doch unendlich bleibt. Die ersten Differenzen (l)1) bezeichnen die Wahrscheinlichkeit des Vorkommens von Fehlern $z$ wischen den betreffenden, um 0,1 von einander entfernten Grenzen. Beispielsweise ist die Wahrscheinlichkeit für das Vorkommen von Fehlern zwischen 0,6 und 0,7 gleich 0,048878 .

In gleicher Weise berechnen sich die Einsïtze, die man daraul verwetten kann, dals der einzelne Heobachtungs-Fehler gewisse Vielfache von $v$ nicht ïbersteigen. Nämlich

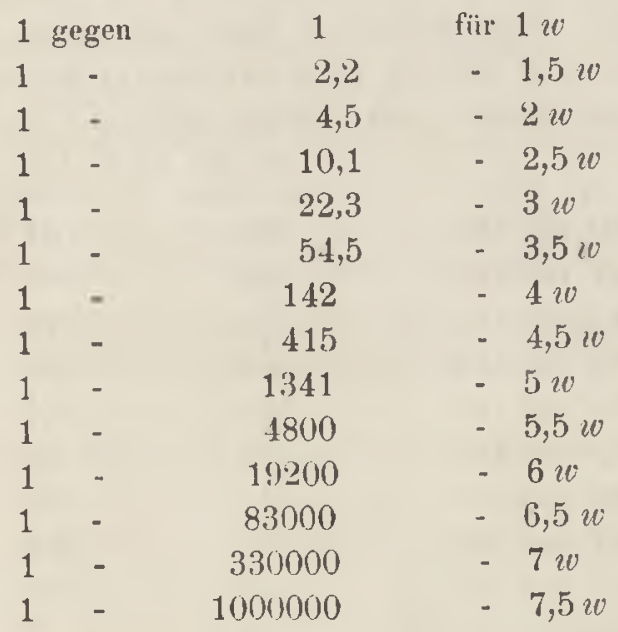

Aulserdem zeigt diese Tabelle auch, in welchem Verlı̈̈ltnifs die Felıler sich nach ihrer Gröfse vertheilcn, oder wie die Anzahl derselben bei zunehmender Gröl'se 
innerlalb je zwei gleich weit entfernter Grenzen sich vermindert. Ilierdurch wirl Gelegenlıeit geboten, die Richtigkeit der Tabelle und der ganzen vorgetragnen 'Theorie der Fehler durch die liffuhrung zu prüfen. Ls kommt nämlich nur darauf an, diese Zalılen mit einer grölsern Reihe von Beobachtungen zu vergleichen.

Bui Gelegenheit der Bestimmung des wahrseheinlichen Fehlers von Bradley's Beobachtungen hat Bessel Vergleiche dieser Art imgestellt*), und nachgewiesen, dafs die wirklichen Fehler sich in der That sehr übercinstimmend mit diesen Gesetzen gruppiren. Beispielsweise mögen hier die Fehler der geraden Aufsteigumg der Sonne gegen die Hauptsterne im kleinen Hunde und im Aller angeführt werden.

470 Beobachtungen dieser Art waren angestellt und aus der Vergleichung derselben unter sich ergab sich der wahrscheinliche Fehler der einzelnen Messung gleich 0,2637 Zeitsecunden. Indem liese Gröfse als Einlıeit angenommen wird, lassen sich nach der erwähnten Tabelle die Verhältnilszahlın der Fehler berechnen, die gewisse aliquote Theile oder Vielfache des wahrscheinlichen Fehlers überschreiten. Man kann die Grenzen auch in Secunden ausdrïcken, dieses hat Bessel gethan und die relative Anzahl der Fehler gesucht, die unter $0,1 \ldots 0,2 \ldots 0,3$ Secunden und so weiter fallen. Durch Subtraction wurde sodann die Anzahl der Fehler zwischen 0 und 0,1 ferner zwischen 0,1 und 0,2 Secunden und so weiter ermittelt, und es ergab sich

$\begin{array}{ccc}\text { zwischen } & \begin{array}{c}\text { Anzahl der Feliler } \\ \text { werechnet }\end{array} & \begin{array}{c}\text { wirklich } \\ 0,0 \text { und } 0,1\end{array} \\ 0,1 \text { und } 0,2 & 85 & 94 \\ 0,2 \text { und } 0,3 & 78 & 88 \\ 0,3 \text { und } 0,4 & 64 & 78 \\ 0,4 \text { und } 0,5 & 49 & 58 \\ 0,5 \text { und } 0,6 & 35 & 36 \\ 0,6 \text { und } 0,7 & 24 & 26 \\ 0,7 \text { und } 0,8 & 16 & 14 \\ 0,8 \text { und } 0,9 & 9 & 10 \\ 0,9 \text { und } 1,0 & 5 & 7 \\ 1 \text { Secunde } & 5 & 8\end{array}$

*) Fundamenta astronomiae. Seite 20. 
Die Uebereinstimmung dieser Zahlen zeigt deutlich, wie der Zufall, sobald vielfache Wiederholungen stattfinden, den Gesetzen der Wahrscheinlichkeits-Rechnung folgt.

lis mag noch in einem andern Beispiel das Zutreffen dieser Gesetze nachgewiesen werden. Dasselbe bezieht sich freilich nicht ant' Beobachtungs-Feliler, aber doch auf eine e be e s s o z uf f̈̈ ll $\mathrm{i}$ ge Erscheiu ung, die sich in besimmten Zahlenwerthen ausdrïicken lälst. Aus vielfachen Wiederholungen kann man nämlich den normalen Werth mit grofser Wahrscheinlichkeit bestimmen und die jedesmalige Abweichung von diesem ist dem Beobachtungsfehler vergleichbar. Es wird dafür ein Beispiel gewählt, dals jeder Leser in allen Einzelheiten leicht verfolgen und von der Richtigkeit der nachstehnden $\Lambda$ ngaben sich selbst iiberzeugen kann.

Eine solche ganz zufällige Erscheinung ist unter andern die Wiederholung eines gewissen Buchstaben. Am häufigsten wird diss $c$ gebraucht, daher empfiehlt es sich, dieses zu wählen. In kytelweins Handbuch der Mechanik und Hydraulik und zwar in der ersten Ausgabe von 1801 zähle man die in jeder Zeile der Vorrede enthaltenen $e$ mit Einschlufs der Diphtongen $\ddot{a}$, $\ddot{o}$ und $\ddot{u}$, damit man etwas grö̊sere Zahlıen erhält. Die eingezogenen und alggebrochenen Zeilen bleiben aber unberücksichtigt, weil sie kürzer sind als die übrigen, und duher auch eine geringere Anzahl der $e$ in ihnen zu vermuthen ist. Man findet alsdann 110 ganze Zeilen und darin wieterholt sich der Buchstabe $e 886 \mathrm{mal}$, durchschnittlich kommt er sonach in jeder Zeile $8,06 \mathrm{mal}$ oder sehr nahe $8 \mathrm{mal}$ vor.

Die Abweichungen von dieser Anzatıl sind

\begin{tabular}{|c|c|c|}
\hline 26 & mal & gleich \\
\hline 43 & - & - \\
\hline 24 & - & - \\
\hline 11 & - & - \\
\hline 4 & - & - \\
\hline & - & - \\
\hline & - & - \\
\hline
\end{tabular}

Die Summe der Quadrate dieser Abweichungen beträgt 374, das 
mittlere Feliler'quadrat ist also $3,40=q q$, folglich $q=1,8.44$ und die wahrscheinliche Abweichung

$$
\begin{aligned}
w & =0,6745 \cdot q \\
& =1,244
\end{aligned}
$$

Die 'Tabelle $B$ im Anhange ist für den wahrscheinlichen Fehler $=1$ berechnet, man mufs also die Grenzwerthe der $x$, die man sucht, durch 1,244 dividiren. Die Abweichungen von der normalen Anzahl sind immer ganze Zahlen, daher fallen diese Grenzwerthe auf die Mitte zwischen je zwei Zahlen. Man findet nun fiir

$$
\begin{array}{lll}
x=\frac{0,5}{1,244}=0,402 & \int y d x=0,223 \\
x=\frac{1,5}{1,244}=1,206 & & =0,584 \\
x=\frac{2,5}{1,244}=2,010 & & =0,825 \\
x=\frac{3,5}{1,244}=2,814 & & =0,942 \\
x=\frac{4,5}{1,244}=3,617 & & =0,985 \\
x=\frac{5,5}{1,244}=4,421 & & =0,997
\end{array}
$$

Der erste Werth bezeichnet die Verhältnifs-Zahl derjenigen Fehler, die kleiner als 0,5 also gleich Null sind, der zweite der-

\begin{tabular}{|c|c|c|c|}
\hline \multirow{3}{*}{ Abweichung } & & \\
\hline & & berechinet & wirklich \\
\hline & $=0$ & 24,5 & 26 \\
\hline & $=1$ & 39,7 & 43 \\
\hline & $=2$ & 26,5 & 24 \\
\hline & $=3$ & 12,9 & 11 \\
\hline & $=4$ & 4,8 & 4 \\
\hline & $=5$ & 1,3 & 0 \\
\hline & ber 5 & 0,3 & 2 \\
\hline
\end{tabular}
jenigen, die kleiner als 1,5 also kleiner als 2 sind. Zieht man den ersten von dem zweiten ab, so findet man die relative Anzahl der Fehler von der Grö̈se 1, und diese mit der Anzahl der Beobaclitungen also der Zeilen oder mit 110 multiplicirt, ergiebt die ahsolute Zahl dieser Abweichungen. In derselben Art vertährt man mit den iibrigen Werthen, und man erliält schliefslich die nachstehnde Anzahl der Abweichungen von verschiedner Gröfse. 
Die Lebereinstimmung ist auch hier der geringen Auzahl ron Abzihlungen unerachtet, durchaus befiriedigend.

\section{$\$ 30$.}

In gleicher Weise, wie die Schärfe der einzelnen Beobachtungen durch den wahrscheinlichen Fehler derselben bemessen wird, lassen sich aus diesen auch die wa hrehein $\mathrm{ichen}$ Fehler der daraus berechneten Constanten herleiten. Hierdurch allein gelangt man aber zu einem richtigen Urtheil über die Sicherheit der gewonnenen Resultate. Wenn man zum Beispiel nach der Methode iler kleinsten Quadrate den Werth der Constante $r$ gleich 0,5 gefunden hätte, ihr wahrscheinlicher Fehler aber 0,7 wäre, so dürfte man noch nicht 1 gegen 1 wetten, dals die zum Grunde gelegte Gleichung wirklich das Glied $a r$ enthält, es wäre sogar wahrscheinlicher, dafs nur in Folge der zufälligen Reobachıtungs-Felıler ein bestimmter Werth fuir $r$ sich herausstellte, als dals das Glied $a r$ in der Frscheinung begriindet ist.

Die wahrscheinlichsten Werthe cler unbekannten Constanten $r, s, t, \ldots$ für welche die Summe der Quadrate der tibrig bleibenden Fehler ein Minimum ist, können leicht in der Art sich herausstellen, dafs diese Summe sich wenig ïndert, wenn die Constanten andre Werthe annehmen, indem einige sie vergrïlsern, andre sie verkleinern. In diesem Fall wären die gefundnen Werthe, wenn auch die wahrscheinlichsten, dennosh wenig sicher. Hierüber gewinnt man aber ein bestimmtes Urtheil, wenn man die wahrscheinlichen Fehler der berechneten Constanten kennt.

Die betreffende Untersuchung mag auf die Fälle beschränkt bleiben, worin nicht melır als drei unbekannte Constanten nach der Methode der kleinsten Quadrate berechnet sind. Das Verfahren zur Ermittelung der wahrscheinlichen Fehler derselben bleibt sich aber ganz gleicl, wenn ihre Anzalıl eine gröfsere ist, es wird hier nur davon abgesehn, weil die Ausdrïcke, zu denen man dabei gelangt, sich viel complicirter darstellen. Dazu kommt auch noch, dafs in den Ingenieur-Wissenschaften wohl nicht leicht eine Aufgabe vorliegen dïrfte, welche die Berechnung von vier oder von noch melır Constanten forderte.

Dic gefundnen wahrscheinlichsten Werthe von $r, s$ und $t$ sind nicht die richtigen, sondern mit den Felılern $\varrho, \sigma$ und $\tau$ 
behaftet, daher die waliren Werthe $r+\varrho, s+\sigma$ und $t+t$ : Der wirkliche Fehler jeder einzelnen Beobachtung, der mit $x$ bezeichnet wird, ist dalıer

$$
\begin{aligned}
x^{\prime}= & -k+a(r+\varrho)+b(s+\sigma)+c(t+\tau) \\
= & (-k+a r+b s+c t)+(a \varrho+b \sigma+c \tau) \\
x^{\prime} x^{\prime}= & (-k+a r+b s+c t)^{2} \\
& +2(-a k+a a \cdot r+a b \cdot s+a c \cdot t) \varrho \\
& +2(-b k+a b \cdot r+b b \cdot s+b c \cdot t) \sigma \\
& +2(-c k+a c \cdot r+b c \cdot s+c c \cdot t) \tau \\
& +(a a \cdot \varrho+a b \cdot \sigma+a c \cdot \tau) \varrho \\
& +(a b \cdot \varrho+b b \cdot \sigma+b c \cdot \tau) \sigma \\
& +(a c \cdot \varrho+b c \cdot \sigma+c c \cdot \tau) \tau
\end{aligned}
$$

Das erste Glied dieses Ausdruckes ist niclits Andres, als das Quadrat der Differenz zwischen der beobachteten Grölse $k$ und dem Werthe derselben, der sich durch Einführung der wahrscheinlichsten Werthe $r, s, t$ in die zum Grunde gelegte Bedingungs-Gleichung ergab. Diese Differenz wurde frülıer mit $x$ bezeiclinet.

Zur nähern Untersuchung der folgenden Glieder berechne man die Summen, die sich darstellen, indem die entsprechenden Ausdrücke für alle einzelnen Beobaclitungen entwickelt werden. Man erhält alsdann unter Beibehaltung der frühern Bezeichnung

$$
\begin{aligned}
{\left[x^{\prime} x^{\prime}\right]=[x x] } & +2(-[a k]+[a a] r+[a b] s+[a c] t) \varrho \\
& +2(-[b k]+[a b] r+[b b] s+[b c] t) \sigma \\
& +2(-[c k]+[a c] r+[b c] s+[c c] t) \tau \\
& +\left([a a]+[a b] \frac{\sigma}{\varrho}+[a c] \frac{\tau}{\varrho}\right) \varrho \varrho \\
& +\left([a b] \frac{\varrho}{\sigma}+[b b]+[b c] \frac{\tau}{\sigma}\right) \sigma \sigma \\
+ & \left([a c] \frac{\varrho}{\tau}+[b c] \frac{\sigma}{\tau}+[c c]\right) \tau \tau
\end{aligned}
$$

Das zweite, dritte und vierte Glied dieses Ausdrucks enthält in der Parenthese genau dieselben Werthe, die zur Darstellung der kleinsten Fehlerquadrate gleich Null gesetzt wurden. Diese Glieder fallen also fort, und die drei letzten vereinfachen sich, wenn man die Bezeichnungen $R, S$ und $T$ einführt, nämlich 


$$
\begin{gathered}
-91- \\
R=[a a]+[a b] \frac{\sigma}{\varrho}+[a c] \frac{\tau}{\varrho} \\
S=[a b] \frac{\varrho}{\sigma}+[b b]+[b c] \frac{\tau}{\sigma} \\
T=[a c] \frac{\varrho}{\tau}+[b c] \frac{\sigma}{\tau}+[c c]
\end{gathered}
$$

Die vorstehnde Gleichung wird daher

$$
\left[x^{\prime} x^{\prime}\right]=[x, x]+R \cdot \varrho \varrho+S \cdot \sigma \sigma+T \cdot \tau \tau
$$

Un den wahrscheinlichen Fehler der ersten Constanten $r$ zu finden, verändere mun den Werth derselben um $\varrho$, und untersuche, welche Aenderungen die andern Constanten dadurch erfahren, oder wie gro[s $\sigma$ und $\tau$ sein müssen, damit die Summe der übrig bleibenden Fehler-Quadrate wieder ein Minimum wird.

Der einzelne Beobachtungsfehler ist

$$
x^{\prime}=-k+a(r+\varrho)+b(s+\sigma)+c(t+x)
$$

Nuchldem man für $\varrho$ einen bestimmten Werth angenommen hat, sind nur noch die beiden $\Lambda$ enderungen $\sigma$ und $\tau$ unbekannt, und weun man die Bezeichnung einfülırt

$$
-K=-k+a(r+\varrho)+b s+c t
$$

so loigt

$$
x^{\prime}=-K+b \sigma+c \tau
$$

Dieser Ausdruck, der nur noch die beiden Unbekannten $\sigma$ und $\imath$ enthält, wird wieder nach der Methode der kleinsten Quadrate behandelt. Die Bedingungs-Gleichungen dafür sind

$$
\begin{aligned}
& 0=-[K b]+[b b] \sigma+[b c] \tau \\
& 0=-[K c]+[b c] \sigma+[c c] \tau
\end{aligned}
$$

Man hat aber

$$
-[K b]=-[k b]+[a b] r+[b b] s+[b c] t+[a b] \varrho
$$

und da die Summe der vier ersten Glieder gleich Null war, so ist

und eben so findet man

$$
-[K b]=[a b] \varrho
$$

$$
-[K c]=[a c] \varrho
$$

Jene Bedingungs-Gleichungen verwandeln sich daher in

$$
\begin{aligned}
& 0=[a b] \varrho+[b b] \sigma+[b c] \tau=S \sigma \\
& 0=[a c] \varrho+[b c] \sigma+[c c] \tau=T \tau
\end{aligned}
$$


Man sucht die Verbesserungen $\sigma$ und $\tau$, die nicht gleich Null sind. Hieraus ergiebt sich, dals in dieser Untersuchung, die sich auf die Ermittelung des Werthes von $\varrho$ bezieht, sowohl $S$ wie $T$ gleich Null sein müssen.

Aus den vorstehnden beiden Bedingungs-Gleichungen findet man

und

$$
\frac{\sigma}{\varrho}=\frac{[a c][b c]-[a b][c c]}{[b b][c c]-[b c][b c]}
$$

$$
\frac{x}{e}=\frac{[a b][b c]-[a c][b b]}{\mid b b] \mid c c]-\mid b c]|b c|}
$$

Fïhrt man diese Werthe in den obigen Ausdruck für $R$ ein, so erhält man

$R=\frac{[a a][b b][c c]+2[a b][a c][b c]-[a a][b c][b c]-[b b][a c][a c]-[c c][a b][a b]}{[b b][c c]-[b c][b c]}$

$R$ ist sonach allein von den bekannten Groisen $a, b$ und $c$ abliängig, und in dem Ausdruck für die Summe der Fehlerquadrate kommt nur noch die Unbekannte $\varrho$ vor, nämlich

$$
\left[x^{\prime} x^{\prime}\right]=[x x]+R \cdot \varrho \varrho
$$

Die Wahrscheinlichkeit für das Zusammentreffen der versclicdenen Fehler $x$ ist aber gleich dem Product aus den entsprechenden Wahrscheinlichkeiten $y^{\prime}$, und wenn man dieses Product mit $Y$ bezeichnet, so lat man

$$
\begin{aligned}
Y & =\frac{1}{\sqrt{\pi \cdot V \nu}} e^{-\frac{\left[x^{\prime} x^{2}\right]}{\nu}} \\
& =\frac{1}{\sqrt{\pi} \cdot \sqrt{\nu}} e^{-\frac{\mid r x]}{\gamma}} \cdot e^{-\frac{n}{v} \varphi \vartheta}
\end{aligned}
$$

Der erste Exponent von e bezieht sich auf die Abweiclıungen der Beohachtungen von denjenigen Werthen, dic unter Zugrundelegung der wahrscheinlichisten Werthe von $r, s$ und $t$ bereclinet waren. Dieser Exponent ist sonach bekannt, und setzt man

so ist

$$
\frac{1}{\sqrt{\pi} \cdot \sqrt{\nu}} e^{-\frac{[x x]}{\nu}}=F
$$

$$
Y=F \cdot e^{-\frac{k}{r} e s}
$$

Die Wurzel des mittlern Fehlerquadrats der Beoba e li tu $n$ gen wurde mit $q$ bezeichnet. In gleicher Weise sei 
$q(r)$ die Wurzel aus dem mittlern Fehlerquadrat der Constante $r$. Die Sum me aller Fehlerquadrate erhält man, wenn man das Quadrat jedes möglichen $\varrho$ mit der Walırseheinlichkeit seines Vorkommens multiplicirt, und diese Producte summirt.

Diese Summe ist

$$
\int Y \varphi^{2} d e
$$

die Anzahl der Fehlerquadrate ist aber gleich der Summe der Wahrscheinlichkeiten ihres Vorkommens, oder

$$
\int Y d \varphi
$$

Beide Integrale sind von $\varrho=-\infty$ bis $\varrho=+\infty$ z.n nehmen, daher das mittlere Fehlerquadrat

$$
q(r) q(r)=\frac{\int Y \varrho^{2} d \varrho}{\int Y d \varrho}
$$

wobei der constante Factor $F$ ans dem Zähler und Nenner fortfiilt. Indem man nunmehr für $Y$ wieder dessen Werth einführt, so ergielot sich

$$
q(r) \cdot q(r)=\frac{\int e^{-\frac{n}{r} e \varrho} \cdot \varrho^{2} d \varrho}{\int e^{-\frac{n}{r} e \varrho} d \varrho}
$$

Setzt man aber zur einfachern Bezeichnung

$$
\frac{R}{v} \varrho \varrho=z z
$$

so findet man

$$
q(r) \cdot q(r)=\frac{\nu}{R} \frac{\int e^{-z t} \cdot z^{2} d z}{\int e^{-x x} \cdot d z}
$$

die partielle Integration ergiebt

$$
\int e^{-s} \cdot z^{2} d s=-\frac{1}{3} e^{-z} \cdot z+\frac{1}{2} \int e^{-z} \cdot d z
$$

Das erste Glied ist wieder gleich Null, wenn man $e^{-n}$ in jene Reilıe auflöst und den Werth derselben innerhall, der Grenzen 
von $z$ oder $\varrho=0$ his $z$ oder $\varrho=t \infty$ sucht. Das zweite Glied aber ist halb so grofs, als der Nenner. Man erhält dahıer

$$
q(r) \cdot q(r)=\frac{\nu}{2 R}
$$

folglich

$$
\begin{aligned}
q(r) & =\frac{1}{V R} \cdot V \frac{v}{2} \\
& =\frac{1}{V R} \cdot q
\end{aligned}
$$

wo $q$, wie oben die Wurzel des mittlern Quadrats der Beo bach tungs - Fehl er bezeichnet.

liben so kann man auch $w(r)$ oder den wahscheinlichen Fehler von $r$ finden. Derselhe ist nämlich demjenigen @ gleich, welches unter Beibehaltung der vorstehnden Bezeichnung der Bedingung entspricht, dafs

$$
\int_{0}^{\varrho} y d \varrho=\int_{\varrho}^{\infty} y d e
$$

Setzt man nunmehr

$$
V R \cdot \varrho=z
$$

so verwandelt sich das Integral in

$$
\frac{1}{\sqrt{R}} \int e^{-\frac{2 x}{x}} \cdot d z
$$

Dieser Ausdruck entspriclıt wieder genau demjenigen, welcher zuır Bestimmung des wahrscheinlichen Beobachtungs-Fehlers diente. Die Bedingung wird daher auch hier erfült, sobald man

oder

$$
z=0,4769364 \cdot v v
$$

$$
\varrho=0,4769364 \cdot V \frac{\nu}{R}
$$

setzt. Der wahrscheinliche Beobachtungs-Fehler $w$ war aber gleich $0,4769364 \cdot V n$, daher ist

$$
w(r)=\frac{1}{V R} w
$$

Dieser wahrscheinliche Feller der Constante $r$ ist zugleich der Werth der früher eingeführten unbekannten Verbesserung $\varrho$, man hat also auch

$$
\varrho=\frac{1}{\sqrt{R}} w
$$


Was die wahrscheinlichen Fehler der andern Constanten $s$ und $t$ betrifft, so findet man dieselben in gleicher Weise, wobei aber in Beziehung auf $v(s)$ sowolıl $R$ wie $T$ und in Beziehung auf $w(t)$ wieder $R$ und $S=0$ zu setzen sind. Man hat also beispielsweise für $v(s)$ die drei Bedingungs-Gleichungen

$$
\begin{aligned}
0 & =[a a] \varrho+[a b] \sigma+[a c] \tau \\
S \sigma & =[a b] \varrho+[b b] \sigma+[b c] \tau \\
0 & =[a c] \varrho+[b c] \sigma+[c c] \tau
\end{aligned}
$$

Aehnlich gestalten sich die Ausdrücke für $w(t)$. Man kann die wahrscheinlichen Fehler aber auch unmittelbar aus den vorstehnden Ausdrücken ableiten, indem man in Bezug auf $s$ die Werthe von $a$ und $b$ und in Bezug auf $t$ die Werthe von $a$ und $c$ gegen einander vertauscht.

Man bemerkt sogleich, dafs der Zähler von $R$ in seinen fünf Gliedern aus den drei gegebnen Grörsen $a, b$ und $c$ sich gleichmälsig zusammensetzt, woher er auch in den Ausdriicken für $S$ und $T$ unverändert bleibt.

Der Nenner von $R$ war

$$
[b b][c c]-\mid b c][b c]
$$

derselbe wird daher

und

$$
\begin{aligned}
& \text { für } S \ldots[a a][c c]-[a c][a c] \\
& \text { für } T .[a a][b b]-[a b][a b]
\end{aligned}
$$

In gleicher Weise, wie der wahrscheinliche Fehler der Constante $r$

$$
w(r)=\frac{1}{\sqrt{R}} \cdot w
$$

war, so findet man anch

und

$$
\begin{aligned}
& w(s)=\frac{1}{\sqrt{S}} \cdot w \\
& w(t)=\frac{1}{\sqrt{T}} \cdot w
\end{aligned}
$$

$w$ bedeutet aber den wahrscheinlichen Beobachtungsfehler, den man nach \$ 26 aus der Summe der Fehlerquadrate ermittelt.

Die vorstelnde Untersuchung bezog sich auf den Fall, dafs drei constante Factoren gesucht wurden. Giebt es deren nur zwei, so wird man von der Gleichnng

$$
k=a r+b s
$$


ausgelın, und alle Glieder, die in den so eben entwickelten Formeln $c$ als Factor entlalten, fallen fort. Um den wahrscheinlichen Fehler von $r$ zu finden, hat man daher die beiden Bedingungs-Gleichungen

und

$$
\begin{aligned}
& R \varrho=[a a] \varrho+[a b] \sigma \\
& 0=[a b] \varrho+[b b] \sigma \\
& R=\frac{[a a][b b]-[a b][a b]}{[b b]}
\end{aligned}
$$

nlso

fiir" w(s) dagegen

und

$$
0=[a a] \varrho+[a b] \sigma
$$

folglicl

$$
S \sigma=[a b] \varrho+[b b] \sigma
$$

und schliefslich

$$
S=\frac{[a a][b b]-[a b][a b]}{[a a]}
$$

$$
\begin{aligned}
& w(r)=\frac{1}{\sqrt{R}} w \\
& w(s)=\frac{1}{\sqrt{S}} w
\end{aligned}
$$

Wenn endliclı nur eine Constante oder Unbekannte vorkommt, also auch $b=0$ wird, oder das zum Frunde gelegte Gresetz durch

$$
k=a \cdot r
$$

ausgedrückt wird, so hat man nur die einzige PeelingungsGleichung

$$
R=[a a]
$$

und alsdann ist der wahrscheinliche Felıler von $r$

$$
w(r)=\frac{1}{V[a a]} \cdot w
$$

Wenn aher $a=1$, also eine einfache Messung $n$ mal wiederholt ist, so ergieltt sich

$$
w(r)=\frac{1}{\sqrt{m}} w
$$

Aclınliche Untersuchungen ïber die Sicherheit der nach der Methode der kleinsten Quadrate gefundnen Constanten wurden zuerst von Gaufs in den oben ( $\$ 16$ ) angeführten Schriften bekannt gemacht, doch bestimmte derselbe die Wahrscheinlichkeit 
der gefundnen Werthe in andrer $\Lambda \mathrm{rt}$, indem er ihnen vergleichungsweise zur Wahrscheinlichkeit der einzelnen Beobachtungen gewisse Gewichte beilegte. Die Ermittelung der wahrscheinlichen Fehler der nach der Methode der kleinsten Quadrate berechneten constanten Factoren rïlırt aber von Bessel her.

\section{$\S 31$.}

Die vorstehend entwickelten Ausdrücke setzen voraus, dals man clie wahren Werthe der gemel'snen Gröfsen $k$ kennt, deren Abweichungen von den Beobachtungen die Fehler darstellen. Wirklich kennt man aber nur die wahrscheinlichsten W e r the der Constanten $r, s, t \ldots$ und aus diesen kann man daher nur die wahrscheinlichsten, keineswegs aber die wahren Werthe von $k$ ableiten und mit den Beobachtungen vergleichen. Nachsthende selir einfache Retrachtung zeigt aber, wie man die Summe. der Quadrate der wirklichen Beobachtungsfehler findet.

In vorigen Paragraph wurde der Ausdruck

$$
\left[x^{\prime} x^{\prime}\right]=[x x]+R \varrho \varrho+S \sigma \sigma+T \tau \tau
$$

dargestellt, worin $x^{\prime}$ die wahren Fehler, $x$ dagegen die Abweiclungen der Beobachtungen von den nach der Methode der kleinsten Quadrate hergeleiteten walırscheinlichsten Werthen von $l_{i}$ bezeichnen. Fs wurde daselbst auch nachgewiesen, dafs

und eben so

$$
\varrho=\frac{1}{\sqrt{R}} \cdot q
$$

$$
\begin{aligned}
\sigma & =\frac{1}{\sqrt{S}} q \\
\tau & =\frac{1}{\sqrt{V}} q
\end{aligned}
$$

Jedes der drei letzten Glieder im Ausdruck für [ $\left.x^{\prime} x^{\prime}\right]$ verwandelt sich daher in $q q$, und wenn $\mu$ Constanten vorkommen, hat man

$$
\left[x^{2} x^{\prime}\right]=[x x]+\mu \cdot q q
$$

$\left[\begin{array}{ll}x^{\prime} & x^{\prime}\end{array}\right]$ ist aber die Summe der wirklichen Fehlerquadrate, also gleich dem Product aus dem mittlern Fehlerquadrat in die Anzahl der Beobachtungen, die gleich $m$ ist, also

$$
m \cdot q q \cdot=[x x]+\mu \cdot q q
$$

If agen, Wahracheinlichkcitg-Rechnung. 3. Aufl. 
folglich

$$
q q=\frac{[x x]}{m-\mu}
$$

und hieraus der wahrscheinliche Beobachtungsfehler

$$
w=0,674490 \sqrt{\frac{[x x]}{w-\mu}}
$$

$[x x]$ ist aber die Summe der Quadrate der Abweichungen der berechneten von den beobachteten Werthen $k$, also eine bekannte Grölse.

Diese selır wichtige Vervollständigung der Untersuchung über die Beobachtungsfehler und über die Sicherheit der daraus gezogenen Resultate machte $\mathrm{Bessel}$ in der Abhandlung über den Olbersschen Kometen bekannt*).

\section{$\S 32$.}

Da für manche Leser eine Zusammenstellung der analytischen Ausdrücke erwünscht sein dürfte, nach welchen man sowohl die wahrscheinlichsten Werthe der Constanten, wie auch die wahrscheinlichen Fehler derselben und der Beobachtungen unmittelbar berechnen kann, so lasse ich eine solche nachstehend folgen.

Die beobachtete Erscheinung oder das Resultat der Messung ist von einem oder mehreren Umständen abhängig, über deren Einwirkung auf Frstere man bestimmte Voraussetzungen macht. Unbekannt ist alsdann nur das Maafs dieser Einwirkung und dieses soll eben durch die Beobachtung festgestellt werden. Sonach ist die beobachtete Gröfse $k$ gleich einem oder mehreren Gliedern, von denen jedes das Product der Wirksamkeit einer von diesen Ursachen $a, b, c \ldots$ mit dem noch unbekannten constanten Factor $r, s, t \ldots$ enthält. Man geht sonach jedesmal von dem Ausdruck

$$
k=a r+b s+c t+\ldots
$$

aus. Sollte rechts vom Gleichheitszeichen noch ein Glied einzuführen sein, das nur aus einer bekannten Gröfse besteht, so ist dieses sogleich mit $k$ zu verbinden, woher die Form sich dadurch nicht

*) Abhandlungen der Berliner Akidemie der Wissenschaften für 1812 und 1813. 
ändert. In welcher Weise man aber die Unbekannten einfülıren muls, wenn sie an sich nicht als einfache Factoren auftreten, ist $\S 22$ gezeigt worden.

Bei Anwendung der in Rede stehnden Rechnungsart handelt es sich immer um den Fall, dafs die Anzahl der Beobachtungen gröfser, als die der Unbekannten ist und man erhält die wahrscheinlichsten Werthe der Unbekannten, wenn man sie aus den nachstehnden Bedingungs-Gleichungen berechnet.

$$
\begin{aligned}
& {[k a]=[a a] r+[a b] s+[a c] t+\cdots} \\
& {[k b]=[a b] r+[b b] s+[b c] t+\cdots} \\
& {[k c]=[a c] r+[b c] s+[c c] t+\ldots}
\end{aligned}
$$

u. s. w.

Die Anzahl dieser Gleichungen ist jedesmal eben so grofs, wie die der gesuchten Factoren $r, s, t \ldots$ man kann also die Werthe derselben hiernach berechnen. Die Parenthesen [] bezeichnen aber die Summen der gleichnamigen Producte, die aus allen einzelnen Beobaclitungen sich ergeben, z. B.

$$
[k a]=k a+k^{\prime} a^{\prime}+k^{\prime \prime} a^{\prime \prime}+\cdots
$$

In Allgemeinen mufs sogleich darauf aufmerksam gemacht werden, dafs wenn eine der bekannten Grölsen $a, b, c \ldots$ also etwa $a$ gleich 1 wäre, dafs alsdann $[a a]=m$ oder der Anzahl der Beobachtungen gleich wird. Dabei verwandelt sich auch $[a k]$ in $[k]=k+k^{\prime}+k^{\prime \prime}+\ldots$ und dasselbe geschieht bei den andern Summen, die $a$ als Factor enthalten. Sollten aber die Gewichte der einzelnen Beobachtungen so verschieden sein, dafs man diese nicht gleichmärsig behandeln darf, wovon $\$ 23$ die Rede war, so mufs man die abweichenden Beobachtungen beispielsweise zweimal, oder im Allgemeinen mehrfach, wie ihr gröfseres oder geringeres Gewicht dieses verlangt, in Rechnung stellen. Dabei kann es augenscheinlich leicht geschehn, dafs die Anzahl der Beobaclitungen oder $m$ sich nicht als ganze Zahl darstellt.

Der einfachste Fall ist der, dafs nur ein unbekannter Factor $r$ vorkommt, oder dafs man von der Gleichung

$$
k=\alpha r
$$

ansgeht. Man findet alsdann den wahrscheinlichsten Werth von $r$

$$
r=\frac{[a k]}{[a a]}
$$


und wenn hiernach aus den gemefsnen $a$ die betreffenden Werthe von $k$ berechnet und mit den wirklich beobachteten verglichen werden, so stellen sich dabei gewisse Differenzen $x, x^{\prime}$, $x^{\prime \prime}$... heraus, die man zur zweiten Potenz erhebt und summirt. Der wahrscheinliche Beobachitungsfehler ist alsdann

$$
w=0,67449 \sqrt{\frac{[x x]}{m-1}}
$$

indem $m$ die Anzalıl der Beobachtungen ausdrückt. Der wahrscheinliche Fehler der berechneten Constante $r$ ist aber

$$
w(r)=w \sqrt{\frac{1}{|a a|}}
$$

fiir den Fall, dafs $a=1$ wäre, würde man erhalten

$$
\begin{aligned}
r & =\frac{[k]}{m} \\
w & =0,67449 \sqrt{\frac{[x x]}{m-1}}
\end{aligned}
$$

und

$$
w(r)=v \sqrt{\frac{1}{m}}
$$

Wenn $z$ wei u n bekannte Constanten vorkommen, also

$$
k=a r+b s
$$

ist, so gelten die zwei Bedingungsgleichungen

und

$$
\begin{aligned}
& {[k a]=[a \quad a] r+[a b] s} \\
& {[k b]=[a b] r+[b \quad b] s}
\end{aligned}
$$

Es ergelıen sich daraus die wahrscheinlichsten Werthe von $r$ und $s$

und

$$
\begin{aligned}
& \left.r=\frac{[k a][b b]-[k b][a b]}{[a} a\right][b b]-[a b][a b] \\
& \left.s=\frac{[k b][a a]-[k a][a b]}{[a} a\right][b b]-[a b][a b]
\end{aligned}
$$

ferner ist der wahrscheinliche Beobachtungsfehler, wenn $x$ wieder die Differenz zwischen den hiernach berechneten und den beobachteten $k$ bezeichnet,

$$
v=0,67449 \sqrt{\frac{[x x]}{m-2}}
$$


und die wahrscheinlichen Fehler von $r$ und $s$ findet man unter Zugrundelegung der $\S 29$ ermittelten Werthe von $R$ und $S$

und

$$
\begin{aligned}
& w(r)=w \sqrt{\frac{[b b]}{[a a][b b]-[a b][a b]}} \\
& w(s)=w \sqrt{\frac{[a a]}{[a a][b b]-[a b][a b]}}
\end{aligned}
$$

Um diese Rechnungen möglichst bequem auszuführen, schreibe man die vorher ermittelten Summen der Producte

$$
[k a] \ldots[b b] \ldots[a a] \ldots[k b] \ldots[a b]
$$

unter einander, und die Logarithmen derselben daneben. Man lat alsdann den Vortheil, dafs jedesmal zwei unter einander stehende Logarithmen zu summiren sind. Der Nenner $[a a][b b]$ $-[a b][a b]$ wiederholt sich aber vier mal.

Wenn $a=1$ ist, hat man

$$
\begin{aligned}
r & =\frac{[k][b b]-[k b][b]}{m \cdot[b b]-[b][b]} \\
s & =\frac{m \cdot[k b]-[k][b]}{m \cdot[b b]-[b][b]} \\
w & =0,67449 \sqrt{\frac{[x x]}{m-2}} \\
w(r) & =w \sqrt{\frac{[b b]}{m[b b]-[b][b]}} \\
w(s) & =w \sqrt{\frac{m[b b]-[b][b]}{m}}
\end{aligned}
$$

Sobald drei constante Factoren gesuclit werden, man also von der Gleichung

$$
k=a r+b s+c t
$$

ausgeht, hat man die Bedingungs-Gleichungen

$$
\begin{aligned}
& {[k a]=[a a] r+[a b] s+[a c] t} \\
& {[k b]=[a b] r+[b b] s+[b c] t} \\
& {[k c]=[a c] r+[b c] s+[c c] t}
\end{aligned}
$$

Die Unbekannten lassen nach dem ( $(21)$ angegebenen Verfalıren sich leichter finden, will man sie aber nach bestimmten analytischien Formeln berechnen, so empfiehlt es sich, in diese 
gewisse einfache Bezeichnungen für solche Combinationen einzuführen, die sich mehrfach wiederholen. Hiernach sei

$$
\begin{aligned}
& \alpha=[a a][b c]-[a b][a c] \\
& \beta=[b b][a c]-[a b][b c] \\
& \gamma=[c c][a b]-[a c][b c] \\
& \alpha^{\prime}=[b b][c c]-[b c][b c] \\
& \beta^{\prime}=[a c][c c]-[a c][a c] \\
& \gamma^{\prime}=[a a][b b]-[a b][a b]
\end{aligned}
$$

Demnächst sei noch

$$
M=[a a][b b][c c]+2[a b][a c][b c]-[a c][b c][b c]-[b b][a c][a c]-[c c][a b][a b]
$$

oder wenn man die vorstehnden Bezeichnungen einführt,

$$
M=\frac{\alpha \alpha^{\prime}+\beta \gamma}{[b c]}=\frac{\beta \beta^{\prime}+\alpha \gamma}{[a c]}=\frac{\gamma \gamma^{\prime}+\alpha \beta}{[a b]}
$$

Stimmen diese letzten Werthe unter sich überein, so ergiebt sich lieraus die Richtigkeit der vorhergehnden Rechnung.

Die gesuchten Unbekannten sind alsdann

$$
\begin{aligned}
& r=\frac{1}{M}\left([k a] \alpha^{\prime}-[k b] \gamma-[k c] \beta\right) \\
& s=\frac{1}{M}\left(-[k a] \gamma+[k b] \beta^{\prime}-[k c] \alpha\right) \\
& t=\frac{1}{M}\left(-[k a] \beta-[k b] \alpha+[k c] \gamma^{\prime}\right.
\end{aligned}
$$

Von der Richtigkeit dieser Werthe überzeugt man sich, wenn man sie in jene drei Bedingungs-Gleichungen fiir $[k a],[k b]$ und $[k c]$ einfülırt und rnit den betreffenden Factoren multiplicirt. Werden alsdann die Glieder nach den Factoren $[k a],[k b]$ und $[k c]$ geordnet, so heben sie sich grörstentheils auf, und die Gleichungen werden identisch : $[k a]=[k a], \ldots$

Der wahrscheinliche Beobachtungsfehler ist ferner

$$
w=0,67449 \sqrt{\frac{[x x]}{m-3}}
$$

und die wahrscheinlichen Fehler der drei Constanten stellen sich in sofern sehr einfach dar, als die $\S 30 \mathrm{mit} R, S$ und $T$ bezeichneten Ausdrïcke nichts andres sind, als $M$ dividirt durch $\alpha$, 
$\beta^{\star}$ und $\gamma^{\prime}$. Man hat sonach die wahrscheinlichen Fehler der drei Constanten

$$
\begin{aligned}
& w(r)=w \sqrt{\frac{a^{\prime}}{M}} \\
& w(s)=w \sqrt{\frac{\beta^{\prime}}{M}} \\
& w(t)=w \sqrt{\frac{\gamma^{\prime}}{M}}
\end{aligned}
$$

Im Folgenden wird die Auflösung melırerer Aufgaben mitgetleilt werden, in welchen die wahrscheinlichsten Werthe von drei Unbekannten sowie auch die wahrscheinlichen Fehler derselben berechnet sind.

\section{$\S 33$.}

Hüufig wiederholt sich die Aufgabe, den wahrscheinlichen Fehler einer Function verschiedner Grölsen zu ermitteln, deren wahrscheinliche Fehler man kennt. Sind diese Gröfsen von einander, oder sämmtlich von einer entfernteren abhängig, so lassen sie sich auf eine einzige zurückführen, in vielen Fällen sind sie aber unabhängig von einander und hiervon soll allein die Rede sein.

$p$ sei eine Function von $r, s, t \ldots$ Die wahrscheinlichen Fehler von diesen seien bekannt, derjenige von $p$ werde gesucht

$$
p=f(r, s, t \ldots)
$$

Insofern $r, s, t .$, ganz unabhängig von einander sind, hat man

$$
d p=\varphi \cdot d r+\chi \cdot d s+\psi \cdot d t+\ldots
$$

wo $\varphi, \chi$ und $\psi$ die betreffenden Differenzial-Quotienten bedeuten. Indem $r$ um $d r$ wächst, ändert sich $p$ um $\varphi d r$, und die Wahrscheinlichkeit, dafs ein Fehler von dieser Grölse eintritt, ist

$$
y=\frac{1}{\sqrt{x} \cdot \sqrt{\nu}} e^{-\frac{\varphi d r-\varphi d r}{\nu}}
$$

Eben so ist die Walırscheinlichkeit des Fehlers $\chi d s$, den die Aenderung der zweiten Unbekannten veranlalst,

$$
y^{\prime}=\frac{1}{\sqrt{\pi} \cdot \sqrt{v}} e^{-\frac{x^{d s}-x^{d s}}{r}}
$$




\section{$-104$}

und so weiter. Die Wahrscheinlichkeit für das Zusammentreffen dieser Aenderungen in den Werthen von $r, s, t \ldots$ also auch für die Aenderung von $p$ in $p+d p$ ist dalıer

$$
y \cdot y^{\prime} \cdot y^{\prime \prime} \ldots=\frac{1}{\sqrt{\pi} \cdot V^{\nu}} e^{-\frac{\varphi d r \cdot \psi d r+x^{d s} \cdot \chi_{d s}+\psi d t \cdot \psi d \ell+\ldots}{\nu}}
$$

Unter der Voraussetzung, dafs die wahrscheinlichen Fehler von $r, s, t \ldots$ nur klein sind, kann man dieselben statt $d r, d s, d t \ldots$ einführen. Aus vorstelındem Ausdruck ergiebt sich alsdann, welche Aenderung dadurch im Werthe von $p$ veranlalst wird, oder wie grofs der entsprechende, also der wahrscheinliche Fehler von $p$ ist. Unter Beibehaltung der frühren Bezeichnung liat man demnach

$$
v(p)=\sqrt{\varphi^{2} \cdot w(r)^{2}+\chi^{2} \cdot w(s)^{2}+\psi^{2} \cdot w(t)^{2}+\cdots}
$$

Um ein Beispiel der Anwendung dieses Satzes zu geben, mag untersucht werden, wie grofs der wahrscheinliche Fehler eines Productes ist, wenn man die wahrscheinlichen Fehler der Factoren kennt.

folglicl

$$
\begin{aligned}
p & =r \cdot s \\
d p & =s d r+r d s
\end{aligned}
$$

also

$$
\varphi=s \text { und } \chi=r
$$

Gesetzt dafs

$$
w(r s)=\sqrt{s^{2} \cdot w(r)^{2}+r^{2} \cdot w(s)^{2}}
$$

$$
\begin{aligned}
& r=7,22 \text { und } w(r)=0,62 \\
& s=5,47 \text { und } w(s)=0,35
\end{aligned}
$$

so wïrde der wahrscheinliche Fehler des Productes

$$
w(p)=4,23
$$

sein, während der wahrscheinlichste Werth von $p$ oder $r s$ gleich

$$
39,493 \text { ist. }
$$

Dieses Beispiel beantwortet die oft angeregte, und nicht selten unrichtig gelöste Frage, wie grofs der wahrscheinliche Fehler einer Fläche ist, wenn man die wahrscheinlichen Fehler der lineären Messungen kennt. Wäre etwa ein Quadrat gemessen, dessen Seiten $=r$ mit dem wahrscheinlichen Fehler $=\varrho$ behaftet sind, so würde hiernach der wahrscheinliche Fehler der Fläche $=\varrho \sqrt{ } 2 \operatorname{sein}$. 


\section{$-105-$}

Ist einer der Factoren, zum Beispiel $r$, eine bestimmt gegebene Grörse, also etwa ein Zahlen-Coefficient, so ist $w(r)$ gleich 0 , folglich

$$
w(r s)=r \cdot w(s)
$$

Kennt man den wahrscheinlichen Fehler des Productes und zugleich den des einen Factors, so ergiebt sich der des andern

$$
w(r)=\frac{1}{s} \sqrt{w(r s)^{2}-r^{y} \cdot w(s)^{2}}
$$

Ls darf kaum erwähnt werden, dals in den vorstelınden Ausdriicken der Exponent 2 sich nicht auf die in Parenthese eingeschlofsenen GröIsen, sondern auf die wahrscheinlichen Fehler derselben bezieht.

Man kann ferner durch den vorstehnden Ausdruck den wah rscheinlichen Fehler einer Summe von Gliedern finden, deren wahrscheinliche Fehler man kennt.

$$
p=r+s+t+\ldots
$$

also

$$
w(p)=\sqrt{w(r)^{2}+w(s)^{2}+w(t)^{2}+\cdots}
$$

Dieses führt zur Bestimmung der Sicherheit einer Längenmessung, die sich aus einzelnen und zwar gleich grofsen partiellen Messungen zusammensetzt. Wenn beispielsweise die 5 Ruthen lange Kette, $m$ mal ausgespannt, also eine Länge von $5 m$ Ruthen gemessen ist, und der wahrscheinliche Fehler jedes Kettenschlages gleich $w$ ist, so ist der wahrscheinliche Fehler in der Messung der ganzen Linie übereinstimmend mit $\S 30$ gleich

$$
w \sqrt{ } m
$$

also keineswegs der Länge der Linie proportional.

Man kann auch umgekehrt aus den Abweichungen in der wiederholten Messung der ganzen Linie auf den wahrscheinlichen Fehler des einzelnen Kettenschlages oder der zum Grunde liegenden Längen-Einheit schliefsen.

Man habe beispielsweise zehn mal nach einander dieselbe Linie gemessen und die gefundnen Maalse bis auf ein Hunderttheil der Ruthe abgelesen 


\begin{tabular}{lcc} 
gemefsne Länge & $\begin{array}{c}\text { Abweichung } \\
\text { vom Mittel }\end{array}$ \\
92,65 Ruthen & $+0,14$ & Quadrat \\
92,47 & $-0,04$ & 0,020 \\
92,55 & $+0,04$ & 0,002 \\
92,31 & $-0,20$ & 0,002 \\
92,43 & $-0,08$ & 0,040 \\
93,01 & $+0,50$ & 0,006 \\
92,52 & $+0,01$ & 0,250 \\
92,49 & $-0,02$ & 0,000 \\
92,29 & $-0,22$ & 0,000 \\
92,38 & $-0,13$ & 0,048 \\
Mittel 92,51 & & 0,017 \\
\hline
\end{tabular}

Der wahrscheinlichste Werth ist das arithmetische Mittel, also in diesem Beispiel 92,51 Ruthen, und die Summe der Quadrate der Abweichungen von demselben oder

$$
[x x]=0,385
$$

dieselbe mufs (nach § 31) durch die Anzahl der Messungen weniger der Anzahl der Unbekannten, also durch $10-1=9$ dividirt werden, um das mittlere Fehlerquadrat darzustellen. Folglich

$\begin{array}{rlrl} & \text { oder } & q q & =0,0428 \\ \text { und } & q & =0,207 \\ w & =0,139\end{array}$

Dieses ist der wahrscheinliche Fehler der Messung der ganzen Linie, die 92,51 Ruthen lang ist. Der wahrscheinliche Fehler für die Länge einer Ruthe wird nach der letzten Darstellung gefunden, wenn man jenen durch $\sqrt{92,51}=9,62$ dividirt. Er ist daher 0,0145 und für eine Kettenlänge oder 5 Ruthen gleich $0,0145 \sqrt{ } / 5=0,0324$ Ruthen.

Häufig kann man den wahrscheinlichsten Werth einer Unbekannten nicht unmittelbar, vielmelır nur den einer Function derselben berechnen. Für diese findet man nach Vorstehndem anch leicht den wahrseheinlichen Fehler und es entstelt die Frage, wie grofs ein solcher für die Unbekannte selbst ist. Zur Beantwortung dieser Frage braucht man nur den wahrscheinlichen Fehler der Function zu dieser zu addiren und aus der Summe beider die Unbekannte aufs Neue zu berechnen. Der Unterschied gegen ihren frühern Werth ist alsdann ihr wahrscheinlicher Fehler. 
Beispielsweise habe man gefunden als wahrscheinlichsten Werth

$$
\log m=1,4784
$$

hieraus ergiebt sich

$$
m=14,055
$$

der wahrscheinliche Fehler jenes $\log m$ sei aber 0,0175 . Addirt man diesen zum Logarithmus, so verwandelt sich letzterer in 1,4959 und $m$ wird alsdann 14,112. Der wahrscheinliche Fehler für $m$ ist daher

$$
14,112-14,055=0,057
$$

Hätte dagegen die Rechnung als den wahrscheinlichsten Werth ergeben

$$
\frac{1}{r}=m
$$

und den walrscheinlichen Fehler dieses Resultates gleich $\mu$, so würde der wahrscheinlichste Werth der Unbekannten sein

$$
r=\frac{1}{m}
$$

und der wahrscheinliche Fehler dieses Werthes von $r$

$$
=\frac{1}{m}-\frac{1}{m+\mu}=\frac{\mu}{m(m+\mu)}
$$

\section{$\S 34$.}

Manche Ereignisse, die man in gewisser Beziehung als zufällig ansehn kann, sind von so schädlichen und gefährlichen Folgen, dâfs sie unbedingt verhindert werden müssen, so weit dieses ïberhaupt möglich ist. Die Vorsichts-Maafsregeln, die man zu diesem $Z$ weck ergreift, können indessen auclı äbertrieben werden, wodurch theils unbereclitigte Mehrkosten, theils auch wohl andre Uebelstände herbeigeführt werden. Es entstelt alsdann die wichtige Frage, wo die Grenze liegt, die man erreiclıen muls, die man aber nicht überschreiten darf.

Hierher gehört beispielsweise die Bestimmung der Stärke von Verbandstïcken in Bau-Constructionen. Man geht dabei von Beobachtungen aus, und die Resultate derselben sind um so sicherer, je zahlreicher sie sind, und je vollständiger sie alle Abweichungen 
in der Textur des Materials umfassen, welches beim Bau angewendet werden soll. Diese Beobachtungen geben aber jedesmal verschiedne Resultate, wenn auch anscheinend dasselbe Material untersucht wird, die Verschiedenheit berult aber in diesem Fall nicht auf Beobachtungs-Fehlern, sondern auf dem Mangel an Gleichmäfsigkeit der einzelnen geprïften Stücke. Insofern aber diese Abweiclungen nicht äufserlich zu erkennen sind, so sind sie zufällig, wie die Fehler in den Messungen, und folgen daher denselben Gesetzen. Der Mittel werth oder das arithmetische Mittel aus einer Reihe solcher Beobachtungen ist zwar als der wahrscheinlichste Werth von grolser Bedeutung, er giebt aber keinen Maafsstab für die Abweiclıungen von demselben, also für die gröfsere oder mindere Festigkeit, welche die einzelnen Verbandstücke vielleicht haben. Hierüber kann man sich nur ein sicheres Urtheil bilden, wenn man die Resultate aller Versuche mit jenem Mittelwerth vergleicht und in derselben Art, wie der wahrscheinliche Fehler einer Beobachtungs-Reilıe gefunden wurde, die wahrsheinliche $\mathbf{A b w e i c h u n g ~ s u c h t . ~}$

Man habe beispielsweise eine grölsere Anzahl Eisenstäbe geprüft, die gleichen Querschnitt haben, auch äufserlich keine Verschiedenheit zeigen, und dabei gefunden, dafs sie durchschnittlich unter einer Belastung von 10 Centnern so eben zerreifsen. Die wahrscheinliche Abweichung habe sich aber aus diesen Proben gieich 1 Centner (nach \$ 31 ) ergehen. Fragt man alsrlann, wic stark ein gleicher Stab mit voller Sicherheit belastet werden kanı, wobei er also bestimmt noch nicht zerreifst, so giebt es nach den oben entwickelten Gesetzen dafïr keine Antwort, weil der Fehler oder die Abweichung jede Grenze übersteigen und sogar unendlich grols werden kann, aber die Wahrscheinlichkeit dafür ist unendlich geringe, und eben so wenig, wie man hoffen darf, beim Aufwerfen von hundert Münzen alle hundert Bildseiten $\mathrm{zu}$ treffen, so ist es nach menschlichen Begriffen auch unmöglich, dafs hier eine selı grofse Abweichung eintreten kann, weil die Walıscheinlichkeit einer solchen überaus geringe ist. Lis ist daher notlıwendig, nact sorgfältiger Erwägung der Verhältnisse diejenige $W$ a h r s cheinli c h k e it zu bestimmen, die als genügend oder als $\mathrm{h}$ in reich e n d sicher angeselın werden darf. Setzt man dieselbe z. B. gleich 0,999 oder mit andern Worten, will man des Erfolges so sicher 
sein, dafs man Eins gegen Eins wetten kann, ein Bruch werde unter tausend Fällen nur einmal eintreten, so kann man aus der Tabelle im Anhange $B$ die entsprechende Belastung berechnen.

Obwohl die Art, wie diese Rechnung zu führen, sich schon aus den frühern Herleitungen ergiebt, so ist diese Aufgabe doch in ihren Anwendungen so wichtig, dafs ihre specielle Behandlung sich rechtfertigen wird.

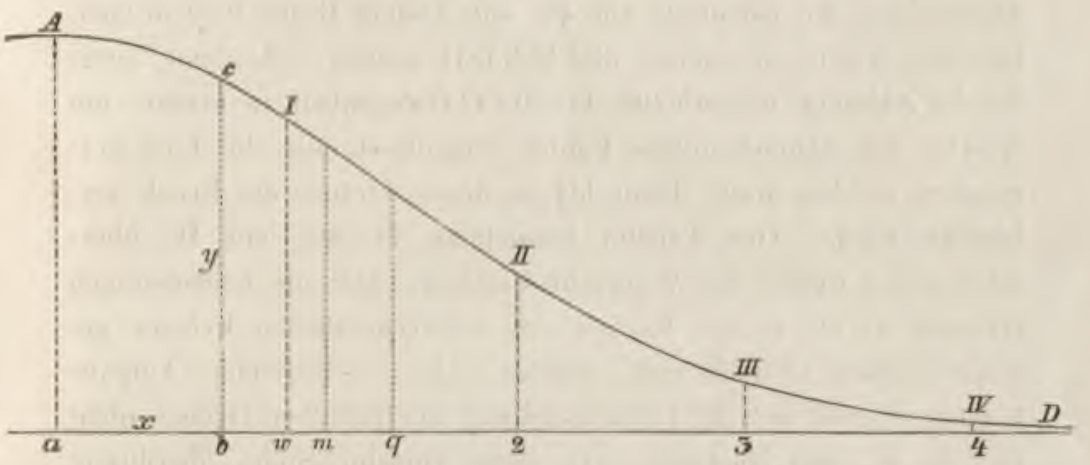

Die ganze von der Curve und der Abscissenlinie begrenzte Fläche, oder $\int y d x$ von $x=-\infty$ bis $x=+\infty$ ist gleich der Gewilsheit, daIs irgend ein Fehler (der auch Null sein kann) eintreten wird, sie ist also gleich 1 . Die halbe Fläche bis zur grörsen Ordinate oder bis zur Mitte ist gleich $\frac{1}{2}$, und bezeichnet die Wahrscheinlichkeit, dals der Fehler negativ, also dafs das Verbandstück schwächer, als der Mittelwerth sein wird. Die Fläche, die von $b c$ oder von der Wahrscheinlichkeit des Fehlers $x$ begrenzt ist und sich bis zu dem unendlich weit entfernten Punkt $D$ erstreckt, stellt die Wahrscheinlichkeit der Ueberschreitung des negativen Fehlers $x$ dar. Es wird also das Verlältnifs der Fläche $c b D$ zur Fläche der ganzen Curve gesucht, und diese Wahrscheinlichkeit ist halb so grofs als die Tabelle $C$ angiebt.

Die gröiste Ordinate $a A$ bezeichnet relativ die Wahrscheinlichkeit des Fehlers $=0$, also die Wahrscheinlichkeit, dafs der Stab die 10 Centner noch so eben trägt. Die Ordinate $w I$ entspricht dem wahrscheinlichen Fehler, der gleich 1 Centner sein sollte, sie giebt also die Wahrscheinlichkeit dafür an, dafs der 
Stab nur $10-1=9$ Centner tragen kann. Eben so die Ordinaten $2 I I, 3 I I I, 4 I V$ die Walırscheinlichkeit dafür, dals er schon mit 8, 7 oder 6 Centnern aufs Aeufserste belastet ist.

Um die erforderliche Sicherheit zu gewinnen, die freilich niemals vollständig erreicht werden kann, mufs man den Werth derjenigen $W$ ahrscheinlichkeit angeben, mit der man den giinstigen Erfolg erwarten will, oder andrerseits die Wahrscheinlichkeit des Mirslingens, die jedenfalls nur ein sehr kleiner Bruch bleiben darf. Derselbe wurde vorstehend gleich 0,001 gesetzt. Alsdann bietet die im Anhange mitgetheilte Tabelle $C$ Gelegenheit zu ersehn, um wieviel der wahrscheinliche Fehler vergrölsert oder die Last vermindert werden mufs, damit bis zu dieser Grenze der Bruch verhindert wird. Die Tabelle bezeichnet in der mit $W$ überschriebenen Spalte die Wahrscheinlichkeit, dafs die beiderseitigen Grenzen $x$, die in der Einheit des wahrscheinlichen Fehlers gemessen sind, überschritten werden. In vorliegender Aufgabe kommt es aber auf die Ueberschreitung der positiven Grenze nicht an, da es ohne Nachtheil ist, wenn einzelne Stäbe überflüssig stark sind. Der Werth der Wahrscheinlichkeit in Betreff der negativen Grenzen ist also nur die Hälfte von dem in der Tabelle angegebnen. Man entnehme daher aus dieser Tabelle dasjenige $x$, welches $W=0,002$ entspricht, da dieses $W$ mit ein Halb multiplicirt 0,001 wird. Indem es hier auf grofse Genauigkeit nicht ankommt, kann man sich mit der ersten Differenz begnügen, und man findet alsdann $x=4,58$. Hiernach mufs der wahrscheinliche Fehler $w$, der gleich 1 Centner war, mit 4,58 multiplicirt werden. Die zulässige Belastung, die dem heabsichtigten Grade der Sicherheit entspricht, ist alsdann

$$
10-4,58=5,42 \text { Centner. }
$$




\title{
V. Abschnitt.
}

\section{Beispiele der Anwendung der Wahrscheinlichkeits- rechnung.}

\author{
$\S 35$.
}

In den physikalischen Wissenschaften, wozu auch die angewandte Mechanik und Hydraulik gehören, hat man oft aus den Beobachtungen nicht nur die Constanten, sondern auch die Gesetze selbst hergeleitet, welche die Erscheinungen bedingen, und nich $\mathrm{t}_{\mathrm{t}}$ selten später für die in solcher Weise gefundnen Gesetze auch allgemein gültige Beweise aufzustellen versucht, wobei jedoch vielfach Mifsgriffe vorgekommen sind. Wenn aber diese Gesetze nur auf Erfahrungen und Beobachtungen beruhn, so haben sie keine allgemeine Gültigkeit, man darf vielmehr ihre Anwendung $\mathrm{nicht}$ über die Grenzen jener Beobachtungen hinaus ausdehnen.

Es entsteht dabei die Frage, ob nan aus Beobachtungen, die in kleinem Marfsstab angestellt sind, auf Erscheinungen im Grofsen schliefsen darf. Nicht selten wird dieses in Abrede gestellt, jedoch vorzugsweise wohl nur in der Absicht, um wissenschaftlichen Untersuchungen überhaupt entgegen zu treten, und den sogenannten praktischen Auffassungen Geltung zu geben. Dafs Beobachtungen im Grofsen selır kostbar und zeitraubend sind, und daher nur selten angestellt werden können, ist an sich klar, dazu kommt aber noch, dafs es überaus schwierig ist, die verschiednen fremdartigen Einflüsse dabei auszuschlief'sen und die Erscheinungen in einfachen Formen darzustellen. Die Erfahrung zeigt auch in der That, dafs man auf 
diesem Wege nicht leicht zu einem branchbaren Resultat gelangt ist, wenn nicht durch sorgfältige Messungen im Kleinen die Verhïltnisse schon vorher aufgeklärt waren, und es sonach nur noch darauf ankam, die bereits bekannten Gesetze und Constanten an den Erscheinungen im Grofsen zu prüfen. Es mag hier auf die im Jahre 1827 in Wien ausgeführten Versuche über den Seitendruck der Erde und den Einsturz von Futtermauern hingewiesen werden, die obwohl mit grofsem Kosten-Aufwande angestellt und sehr vollständig öfentlich bekannt gemacht, dennoch in keiner Beziehung ein brauchbares Resultat gaben, oder zur Aufklärung der Verhältnisse irgend beitragen konnten. Andrer Seits ist die unbegrenzte Kraft, welche die Erde und alle Himmelskörper in ihren Bahnen erhält, nämlich die Schwere, durch das kleine Instrument, den Secunden-Pendel, in lı̈̈chster Schärfe gemessen worden.

Nur bei Beobachtungen mit kleinen Apparaten lassen sich die fremdartigen Einflüsse möglichst beseitigen, oder bei ihrer unvermeidlichen Einwirkung so vollständig erkennen, dafs man von ihnen Reclınung tragen kann. Auch ist es dabei leicht, vielfache Modificationen anzubringen, woraus sich ergiebt, wie bei Aenderungen in der Grölse und Form der Erscheinung die Resultate sich anders herausstellen. Solche Versuche deuten daher schon an, wie die Errscheinung im Grofsen sich gestalten wird, und wenn die gefundnen Gesetze an sich nicht zu begründen sind, also der walıre Zusammenhang noch unbekannt ist, so kommt es nur darauf an, durch Messungen in gröfserem Maafsstabe, die Gültigkeit der bereits gefundnen Gesetze innerhalb weiterer Grenzen zu prüfen, was viel leichter ist, als wenn man auf diesem Wege die Gesetze auffinden wollte.

Die Methoden der Wahrscheinlichkeits-Rechnung lehren, wie man aus Beobachtungen nicht nur die wahrscheinlichsten Resultate ziehn, sondern auch den Grad der Sicherheit dieser Resultate beurtheilen, also die Walirscheinlichkeit berechnen kann, mit der die Gültigheit der gefundnen Gesetze über die Grenze der zum Grunde liegenden Beobachtungen hinaus, noch zu erwarten ist. Man denke die Resultate der Beobachtungen, die im einfachsten Fall nur von einem Argument abhängen, graphisch aufgetragen. Diese Argumente seien die Abscissen, während die beobachteten 
GröIsen als Ordinaten gezeichnet werden. In dieser Weise werden verschiedne Punkte in der Linie gegeben, deren Gleichung man sucht, um für gewisse grölsere Abscissen die Ordinaten berechnen zu können. Wenn die Linie, welche durch die gemelsnen Punkte gezogen wird, sehr nahe als gerade Linie sich darstellt, und die kleinen Differenzen innerhalb der Grenze der unvermeidlichen Beobachtungsfehler liegen, so ist dieses noch kein Beweis dafïr, dafs die Linie, wenn man sie verlängert, noch eine gerade bleiben wird. Das unbekannte Gesetz derselben kann beispielsweise eine Hyperbel bedingen, was sich aber aus den Beobachtungen noch nicht ergiebt, weil diese an einer Stelle liegen, wo die Curve sich nahe an die gerade anschliefst. Nicht leicht wird es sich treffen, dals man mit der Natur iler Curve ganz unbekannt ist, denn gemeinlin führt schon die Betrachtung der mechanischen oder der sonstigen einwirkenden Verhältnisse auf gewisse aufserhalb der Beobachtungen liegende Punkte, so zum Beispiel lassen sich die Werthe derjenigen Ordinaten häufig bestimmt bezeichnen, die zu den Abscissen $=0$ und zu + oder $-\infty$ gehören. Aber wenn dieses Letzte auch möglich ist, so mufs man doch auf die kleinen $\mathrm{Abweichungen} \mathrm{in} \mathrm{den} \mathrm{Beobachtungen} \mathrm{selır}$ aufmerksam sein, und selbst wenn sie die Gröfse der gewöhnlichen Beobaclitungs-Fehler nicht iibersteigen, untersuchen, ob sie regelmärsig fallen, also auf' eine schwache Krümmung der anscheinend geraden Linie hindeuten, die bei weiterer Fortsetzung viel schärfer hervortreten kann. Wie grofs die Wahrscheinlichkeit einer solchen Voraussetzung ist, läfst sich aber nach den vorstehenden Herleitungen jedesmal bestimmt angeben, und man entgeht auf diesem Wege selır sicher der Gefahr, aus dem Gebiete der Wirklichkeit in das der Phantasie zu treten.

Wie grofs diese Gefahr ist, wenn die Regeln der Wahırscheinlichkeits-Reclınung ganz unbeachtet bleiben, zeigen vielfnche Beispicle in unsern Lehrbüchern, namentlich in denen, welche die lydraulik betreffen. Die Sätze, dals das Längenprofil eines Flusses eine Parabel, oder Kettenlinie oder eine andre Curve bildet, würden gewifs nie ausgesprochen sein, wenn man aucl nur eine einzige Beobachtungs-Reihe mit einer solchen Hypothese sorgfailtig verglichen und die übrig bleibenden Fehler untersucht hätte.

Indem die Methoden der Wahrscheinlichkeits-Rechnung in II gen, Wahrseh einliclikeits-Rechumg. 3. Aut, 
solchen Fällen immer auf die Beobachtungs-Fehler zuriickführen, und von der Grölse derselben die Sicherheit der gefundnen Resultate abhängt, so ist die Anwendung dieser Reclinungs-Art auch von unverkennbarem Einflu's auf die B e obachtungs-Kunst. Die Melsapparate verbessern sich eben so, wie die Methoden ihrer Benutzung, und man erreicht bald eine Schärfe und Sicherleit, die bisher unbekannt war und sogar für unmöglich gehalten wurde. Namentlich hat sich dieses in der Astronomie bestätigt, wo gegenwärtig keine Untersuchung angestellt wird, ohne daf's zugleich der Grad der Wahrscheinlichkeit der gefundnen Resultate bestimmt nachgewiesen würde.

\section{$\$ 36$.}

Als Beispiel der Anwendung der Wahrscheinlichkeits-Rech-

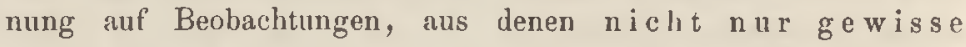
Constanten, sondern aucli das Gesetz hergeleitet werden soll, dem die Erscheinung folgt, wähle ich eine Untersuchung über den Ausflufs des trocknen Sandes durch kreisförmige Oeffinungen im Boden eines Gefälses.

Wie zuerst Hubert Burnand bemerkte, ist die durch kleine Oeffnungen austliefsende Sandmasse von der Druckhöle oder der Höhe der Füllung des Gefälses unablıängig. Dieses erklärt sich durch die starke Reibung, welche der Sand erfïhrt, indem er sich von der iibrigen Masse löst. Die vorliegenden Versuche bestätigten auch, dals bei hoher und niedriger Füllung in gleichen Zeiten stets gleiche Quantitäten abflossen. Nur wenn der hohle Trichter, der sich in der Oberfläche der Schüttung äber der Oeffinung bildet, letztere beinahe erreicht, und die von seinen Wänden herabstürzenden Massen unmittelbar die Oeffnung treflen, wird die Gcschwindigkeit und sonach die Menge des durchfliefsenden Sandes etwas gröfser, bis sie sich sehr bald darauf wieder vermindert, weil die Oeffnung voriibergehend frei wird, oder nicht melır ganz gefïllt ist. Meine Beobachtungen wurden daher jedesmal abgelorochen, sobald der Trichter sich bis auf 1 Zoll der Oeffinung genähert hatte. 
Der Sand den ich benutzte, war ein sehr reiner, vom Seestrande aus auf das dahinter liegende niedrige Ufer aufgewehter Quarzsand. Derselbe bestand aus Körnchen von nahe gleicher Gröfse, doch befanden sich auch einzelne merklich grïfsere darunter, die durch Aussieben entfernt wurden. Der Durclımesser der ïbrig bleibenden war nach mehrfachen Versuchen, indem ich sie reihenweise an einander schob, 0,021 \%oll.

Die Durchfluls-Oeffinungen waren kreisförmig in Messingscheiben ausgedreht, und zwar so, dafs ein scharfer Rand, der naclı oben gekehrt wurde, sie umgab. Ihre Durchmesser mafs ich jedesmal in zwei verschiednen Richtungen mittelst eines mikrometrischen Apparats.

Die Quantitaten des ausfliefsenden Sandes wurden durch sorgtailtigres Abwiegen ermittelt. Unter den austretenden Sandstrahl schob ich nach dem Schlage einer Secunden-Uhr ein Gefäls, und in gleicher Weise wurde dasselbe nach einer bestinmten Zeit wieder zurïckgezogen. Die Vergleichung der in dieser Art aufgefangnen Sandmassen ergab, dals der wahrscheinliche Fehler beim Vor- und Zurïckschicben des Gefiilses noch nicht eine halhe Secunde betrug, und sellost dieser geringe Fehler verminderte sich bei den grölsern Oeffinungen noch bedeutend. lis rïhrte zum 'Theil von den zufalligen Unregelmäfsigkeiten beim Austreten des Sandes lier, die offenbar in den kleinern Oeffinungen am gröfsten waren.

Die Sandmassen $m$ sind nachstehend nicht durch Gewichte, sondern durch den Rauminhalt und zwar in Rheinländischen C'ubikzollen ausgedriickt, indem wiederholentlich das Gewicht gewisser Sand-Volumina, und zwar bei mögliclıst loser Schuittung ermittelt wurde. Die Radien $\varrho$ der Oeffunngen bezichn sich gleichfalls auf Rheinländische Zolle.

In einer Secunde flols durch die Oeffnung vom Radius $\varrho$ die Masse $m$
1) $\varrho=0,05487$
$m=0,00912$
2) $=0,08052$
$=0,02985$
3) $=0,09868$
$=0,05399$
4) $=0,12017$
$=0,095.32$
5) $=0,16784$
$=0,23463$ 
Es kam darauf an, die Beziehung zu finden, in welcher $m$ zu $\varrho$ steht. Z Zu vermuthen war, dafs $m$ durch eine oder verschiedne Potenzen von $\varrho$ ausgedrückt würde, ich versuchte daher zunächst die Formel

$$
m=r \varrho+s \varrho^{2}+t \varrho^{3}
$$

Ein constantes Glied konnte der Ausdruck nicht enthalten, weil offenbar für $\varrho=0$ auch $m=0$ wird. Die Factoren $r, s$ und $t$ sind die zu suchenden Constanten, während die oben (\$ 18) mit $a, b$ und $c$ bezeichneten Factoren hier $\varrho, \varrho^{2}$ und $\varrho^{3}$ sind.

Aus den fünf Beobachtungen findet man die Summen

$$
\begin{aligned}
& {[k a] }=[m \varrho]=0,059065 \\
& {[k b]=\left[m \varrho^{2}\right] }=0,0087325 \\
& {[k c] }=\left[m \varrho^{3}\right]=0,00134369 \\
& {[a a] }=\left[\varrho^{2}\right]=0,061841 \\
& {[a b] }=\left[\varrho^{5}\right]=0,0081113 \\
& {[a c]=[b b]=\left[\varrho^{4}\right]=0,00114796 } \\
& {[b c]=\left[\varrho^{5}\right]=0,000171481 } \\
& {[c c]=\left[\varrho^{6}\right]=0,0000265875 }
\end{aligned}
$$

\begin{tabular}{|c|c|c|c|}
\hline beobachtet & berechnet & Fehler & Quadrate \\
\hline 0,00912 & 0,00879 & $-0,00033$ & 0,0000001089 \\
\hline 0,02985 & 0,03027 & $+0,00042$ & 1764 \\
\hline 0,05399 & 0,05461 & $+0,00062$ & 3844 \\
\hline 0,09532 & 0,09463 & $-0,00069$ & 4761 \\
\hline 0,23463 & 0,23471 & 0,00010 & 100 \\
\hline
\end{tabular}

Wenn man diese Werthe in die Bedingungs-Gleichungen

$$
\begin{aligned}
& {[k a]=[a a] r+[a b] s+[a c] t} \\
& {[k b]=[a b] r+[b b] s+[b c] t} \\
& {[k c]=[a c] r+[b c] s+[c c] t}
\end{aligned}
$$

einführt, so gelangt man am leichtesten durch das $\$ 21$ angegebne Verfahren zur Bestimmung der Constanten und findet

$$
\begin{aligned}
& r=-0,18940 \\
& s=+4,7705 \\
& t=+27,945
\end{aligned}
$$

Hieraus ergeben sich alsdann für die obigen fünf Werthe von $\varrho$ die Sandmassen $m$ 
1)er wahrscheinliche Beobachtungs-Fehler ist daher

$$
0,6745 \sqrt{\frac{0,0000011558}{5-3}}=0,000513
$$

Um die wahrscheinlichen Fehler der drei Constanten zu ermitteln, muls man den Werth der oben mit $M$ bezeichneten Gröfse berechnen. Derselbe ist

\section{$M=0,0000000000003994$}

und hieraus findet man die walirscheinlichen Fehler in der Beftimmung der Constanten

$$
\begin{aligned}
& w(r)=0,027 \\
& w(s)=0,463 \\
& w(t)=1,850
\end{aligned}
$$

Es mufs erwähnt werden, dafs bei dieser Rechnung anfangs zwar die fünfstelligen Logarithmen-'Tafeln vollkommen genïgten, da sie der Schärfe der Messungen entsprachen, dafs aber nach Darstellung der Summen von $k a, k b, l c, a a \ldots$ zur Benutzung siebenstelliger Tafeln ẗbergegangen werden mufste, weil sonst die Differenzen gar zu unsicher geworden wären, und namentlich $M$ als verschwindend klein sich dargestellt laätte.

Für den Fall, dafs man zur Lüsung dieser Aufgabe die gesuchten Constanten nicht durch Elimination finden, sondern dieselben nach jenen Formeln berechnen will, die $\$ 32$ angegeben sind, hat man

$$
\begin{aligned}
& \alpha=+0,00000129312 \\
& \beta=-0,000000073119 \\
& \gamma=+0,0000000188050 \\
& \alpha^{\prime}=+0,00000000111561 \\
& \beta^{\prime}=+0,000000326383 \\
& \gamma^{\prime}=+0,0000051982
\end{aligned}
$$

woraus man wieder die obigen Werthe der $r, s, t$ und der wahrscheinlichen Fehler derselben erhält.

Obwohl die Beobachtungen an den zum Grunde gelegten Ausdruck sich befriedigend anschliefsen, auch die wahrscheinlichen Fehler der Constanten so geringe sind, dafs man nicht annehmen darf, eins oder das andre der drei Glieder könne an sich vielleicht gleich Null sein, und habe nur durch zufälliges Zusammentreffen 
der Jieobachitungs-Fehler einigen Werth erhalten, so begriindet sich doch ein wesentlicher Zweifel gegen die Angemessenheit dieser Form des Gesetzes. Zuniichst läfst sich dieselbe nicht erklären und sodann befremdet das Minus-Zeiclıen des ersten Gliedes.

Hiernach wurde der Versuch gemacht, das erste Glied, das in den letzten Beobachtungen von geringer Bedeutung ist, fortzulassen, also die Form zu wählen

$$
m=s \varrho^{2}+t \varrho^{3}
$$

Indem die Rechnung in gleicher Weise, wie friiher, durchgefulırt wird, findet man als die wahrscheinlichsten Werthe

$$
\begin{aligned}
& s=1,5794 \\
& t=40,350
\end{aligned}
$$

und wenn man hiernach fïr die gemefsnen $\varrho$ die Massen $m$ sucht, so ergeben sich diese, wie auch ihre Abweichungen von den gemefsnen und dic Quadrate derselben

\begin{tabular}{c|c|c}
$m$ & Fehler & Quadrat \\
\hline 0,01142 & $+0,00230$ & 0,0000052900 \\
0,03130 & $+0,00145$ & 0,0000021025 \\
0,05415 & $+0,00016$ & 0,0000000256 \\
0,09283 & $-0,00249$ & 0,0000062001 \\
0,23527 & $+0,00064$ & 0,0000004096 \\
\hline \multicolumn{2}{|c|}{ Summa } & 0,0000140278
\end{tabular}

Dic Summe der Fehler-Quadrate ist sonach 12 mal so grols, als sie friiher war und der wahrscheinliche Beobachtungs-Fehles stellt sich auf 0,00148, während die berechneten Constanten mit nachstehnden wahrscheinlichen Feliern behaftet sind.

$$
\begin{aligned}
& w(s)=0,225 \\
& w(t)=1,479
\end{aligned}
$$

Indem dic mechanischen Verhältnisse der Erscheinung keineswegs so einfach sind, dals sich aus denselben das Gesetz der letztern herleiten lielse, vielmelır eben die Beobachtungen hierzu dienen sollten, so wurde nummehr eine andre Form des Ausdrucks versucht, nïmlich

$$
m=s \cdot Q^{x}
$$

worin wieder zwei Constanten $z$ und $x$ vorkommen. Um diesen Ausdruck aber in die Form zu bringen, welche die Methode der 
kleinsten Quadrate verlangt, und um zugleich einen Nibherungswertl fiir $x$ zu erhalten, der späiter berichtigt worden könnte, ging ich $\mathrm{zu}$ den Jogarithmen iiber.

$$
\log m=\log z+x \cdot \log e
$$

wobei also vergleichungsweise mit jener Gleichung

$$
k=a r+b s
$$

die beiden Unbekannten $r=\log z$ und $s=x$ wurden, die bekannten Grölsen waren aber

$$
\begin{aligned}
& k=\log m \\
& a=1 \\
& b=\log \varrho
\end{aligned}
$$

In Betreff der nunmelır vorzunehmenden Zahlenrechnung mufs darauf aufmerksam gemacht werden, dal's diese Logaritlimen die gewöhnlichen Briggeschen sind, da sie aber sämmtlich zu ächten Briachen gehören, so sincl sie negativ, und man muls sie als solche, also ohne die decadische Frgänzung auschriicken. So ist z. 13. der IJogarithmus von 0,009117

$$
\begin{aligned}
& =7,95985-10 \\
\text { oder } & =-2,04015
\end{aligned}
$$

In dieser Weise werden die in die Reclunnng einzulïilırenten Werthe von $\log m$ und $\log \varrho$ bestimmt. Un dic Producte $k b, l, l$ zul bilken, kann man sich naclı \& 20 der Quadrat-Tabellen im Auhange $A$ bedienen, doch läfst sich die Rechnung anch logarithmisch führen, indem man die gefundnen Logarithmen wieder als Zahlen belıandelt, und die zugehörigen Logarithmen aufschlïgt, also beispielsweise

$$
\begin{aligned}
& \log k=\log \cdot \log m=\log (-2,04015)=0,30966_{n} \\
& \log b=\log \cdot \log e=\log (-1,26067)=0,10060_{n}
\end{aligned}
$$

Das den letzten beiden Zahlen beigefügte $n$ zeigt an, dafs diese Logarithmen zu negativen Zahlen gehören, worauf Riicksicht zu nehmen ist, sobald man zu den letztren wieder iiburgeht. Man findet hiernach

$$
\text { oder } \quad k b=2,5719
$$

$$
\log k b=0,41026
$$

Dieses Product ist positiv, weil beide Factoren negativ sind. 
In gleicher $\Lambda$ rt werden dic sämmtlichen Producte $k b$ berechnet und die Summe derselben, oder $[k b]$ dergestellt, und so auch die andern Summen, wobei die Zeichen stets zu beachten sincl. $a a$ ist aber 1 , also bei 5 Beobachtungen $[a a]=5$.

Die Bedingungs-Gleichungen

$$
\begin{aligned}
& {[k a]=[a a] r+[a b] s} \\
& {[k b]=[a b] r+[b b] s}
\end{aligned}
$$

verwandeln sich alsdann in

$$
\begin{aligned}
-6,48329 & =5 \cdot \log z-5,05583 \cdot x \\
6,94297 & =-5,05583 \cdot \log z+5,24544 \cdot x
\end{aligned}
$$

Mau findet

also

$$
\log z=1,64445
$$

und

$$
\begin{aligned}
& z=44,111 \\
& x=2,9089
\end{aligned}
$$

Hiernach ist

$$
m=44.111 \cdot \varrho^{2,91}
$$

\begin{tabular}{|c|c|}
\hline Fehler & Quadrate \\
\hline$+0,00037$ & 0,00000014 \\
\hline$-0,00088$ & 0,00000077 \\
\hline$-0,00164$ & 0,00000269 \\
\hline$-0,00247$ & 0,00000613 \\
\hline$+0,01073$ & 0,00011513 \\
\hline
\end{tabular}

Berechnet man daraus für die fünf $\varrho$ die Werthe von $\log m$ und vergleicht dieselben mit den Logarithmen der gemelsnen $m$, so schliefsen sie sich an diese selr befriedigend an. Geht man indessen, wie doch die Aufgabe verlangt, zu den Zalılen über, so sind die Abweichungen viel bedeutender. Die Abweichungen und die Quadrate derselben sind im letzten Fall

Hiernach stellt sich der walısscheinliche Beobachtungs-Fehler auf'

$$
w=0,00435
$$

Zur Berichtigung der in dieser Weise gefundnen Unbekannten setze ich den Exponent $x=2,9$, nehme aber an, dals er um die geringe Grölse $\sigma$ noch corrigirt werden mufs, die wieder aus den Beobachtungen zu berechnen ist. Man hat also

$$
m=r \cdot \varphi^{x+o}
$$


Nach dem 'Taylorschen Lehrsat: ist

$$
\varrho^{x+o}=\varrho^{x}+\frac{\sigma}{1} \cdot \frac{d \varrho^{x}}{d x}+\frac{\sigma^{2}}{1 \cdot 2} \cdot \frac{d^{2} \varrho^{x}}{d x^{2}}+\cdots
$$

Indem vorausgesetzt wird, dafs $\sigma$ vergleichungsweise gegen $x$ selır klein ist, so versclıwindet das dritte Glied, wie alle folgenden

$$
d \varrho^{x}=\varrho \cdot{ }^{x} \log \text { nat } \varrho \cdot d x
$$

also

$$
\varrho^{x+o}=\varrho^{x}+\sigma \cdot \varrho^{x} \log \text { nat } \varrho
$$

Hiernach wird die Gleichung, von der man ausgeht

$$
m=e^{x} \cdot r+\varrho^{x} \log \text { nat } \varrho \cdot r \sigma
$$

Die beiden Unbekannten sind alsdann $r$ und $r \sigma$. Die bekannten Factoren dagegen nach der früher gewählten Bezeichnung

$$
\begin{aligned}
& k=m \\
& a=\varrho^{x} \\
& b=\varrho^{x} \log \text { nat } \varrho
\end{aligned}
$$

Für $x$ fiihre ich den so eben gefundnen Nälierungswerth 2,9 ein. Die natiirlichen Logarithmen findet man, wenn man die gewöhnlichen oder die Briggeschen Logarithmen mit log nat $10=2,3025851$ multiplicirt. Beispielsweise mag hier diese Rechnung fï̀r $\varrho=0,05487$ mitgetheilt werden.

$$
\begin{aligned}
\log \varrho & =8,739335-10 \\
& =-1,260665 \\
\log \log \varrho & =0,100600_{n} \\
\log 2,3025851 & =0,362216 \\
\log \log \text { nat } \varrho & =0,462816_{n} \\
\log \text { nat } \varrho & =-2,90280
\end{aligned}
$$

Die beiden Bedingungs-Gleichungen sind $0,0016180164=0,00003851187 \cdot r+0,00007144611 \cdot r \sigma$ $0,003007772=0,00007144611 \cdot r+0,0001335503 \cdot r \sigma$ und man findet hieraus

$$
\begin{aligned}
r & =30,8052 \\
r \sigma & =-6,04019 \\
\sigma & =-0,16908 \\
x+\sigma & =2,73092
\end{aligned}
$$

also

oder

Bereclinet man nunmehr nach dem Ausdruck

$$
m=30,8025 \cdot e^{2,73092}
$$


die ansgeflolsnen Sandmassen, so wie die Differenzen derselben gegen die gemel'snen und die Fehler-Quadrate, so ergiebt sich

\begin{tabular}{c|r|r}
$m$ & Diff. & \multicolumn{1}{|c}{ Quadrate } \\
\hline 0,01111 & $+0,00199$ & 0,000003960 \\
0,03168 & $+0,00183$ & 3349 \\
0,05520 & $+0,00121$ & 1464 \\
0,09454 & $-0,00078$ & 0608 \\
0,23543 & $+0,00080$ & 0640 \\
& & 0,000010021
\end{tabular}

und hieraus der wahrscheinliche Beobachtungs-Fehler

$$
w=0,001233
$$

Die bisherigen Untersuchungen bezogen sich auf die Voraussetzung, dafs die kreisförmigen Oeflnungen, deren Radieu gleich e gemessen waren, in ihrer ganzen Ausdehnung vom Sande durchströmt wiirden. Man darf dieses indessen wohl kaum annelımen, da wahrscheinlich einzelne Körnchen über die Ränder dieser Oeffinungen vortreten, während sie auf dem Boden des Gefïlses noch aufliegen und daher an der Bewegung nicht Theil nehmen. Is bleibt daher zu prüfen, ob die Beobachtungen vielleicht mit gröfsrer Schärfe an ein Gesetz sich anschliefsen, nach welchem die Radien jedesmal un eine gewisse geringe Quantität sich verkleinern. Ich lege hiernach den Ausdruck

$$
m=r(\varrho-x)^{2}
$$

zum Grunde, in welchem die drei unbekannten Grö́sen $1 ; x$ und z vorkommen. Um denselben in der Art umzuformen, wie die Rechnung dieses fordert, mufs man wieder Näherungswertlıe einfïlıren, aber auch hierdurch stellt er sich nicht bequem heraus, und es bleibt daher nur übrig, durch wiederholte Annäherung die passendsten Werthe für $x$ und $z$ zu ermitteln.

Zunächst setze ich demnach voraus, dafs die Sandkörnchen mit ihrem halben Durchmesser, der nach obiger Mittheilung ungefäbr 0,01 Zoll betrïgt. ïber die Oeffnung vortreten. Es sei also $x=0,01$ und der Näherungswerth des Exponenten gleich dem zuletzt gefundnen oder 2,73. Man hat also

$$
m=r(\varrho-0,01)^{2,78+t}
$$


oder, wie oben

$m=(\varrho-0,01)^{2,33} \cdot r+(\varrho-0,01)^{2,33} \cdot \log$ nat $(\varrho-0,01) \cdot r \&$

Nach der Methode der kleinsten Quadrate ergeben sich hieraus die beiden Bedingungs-Gleichungen

$0,001845817=0,0000501467 \cdot r-0,0000962025 \cdot r$ * $-0,003552250=-0,0000962025 \cdot r+0,0001860572 \cdot r z$ und man crhält

$$
\begin{gathered}
r=22,489 \\
r z=-7,4652
\end{gathered}
$$

Dureh Einfiihrung dieser. Werthe in die vorstehnde Gleichung erhält man für die verschieduen $\varrho$ die Sandmassen $m$, sowie die Differenzen derselben gegen die beobachteten, und deren Quadrate

\begin{tabular}{ccr}
$m$ & Diff. & \multicolumn{1}{c}{ Quall. } \\
0,00954 & $-0,00042$ & 0,0000001764 \\
0,03034 & $+0,00049$ & 2401 \\
0,05443 & $+0,00054$ & 1936 \\
0,09449 & $-0,00083$ & 6884 \\
0,23480 & $+0,00017$ & 0289 \\
\multicolumn{2}{c}{ Summe } & 0,0000013274
\end{tabular}

Die Beobachtungen schliel'sen sich also an diesen Ausdruck hedeutend schïrfer, als an den frühern an. Der Werth von z ist $=-0,33194$, also der Exponent von $e-1$

$$
2,73-0,332=2,398
$$

Indem die Exponenten gewöhnlich einfache Zahılen sind, dïrfte man vermuthen, dafs derselbe gleich 2,5 wäre, was sogar durch gewisse Analogien vergleichungsweise mit ausströmendem Wasser wahrscheinlich wird, doch verbietet sich hier diese Aenderung. Der wahrscheinliche Beobnchtungs-Fehler stellt sich nämlich alsdann auf, 0,0004486 , und hieraus ergeben sich die wahrscheinlichen Fehler

$$
\begin{aligned}
& \text { von } r \text { gleich } 0,7053 \\
& \text { von } r s \ldots \ldots 0,3662
\end{aligned}
$$

daher nach $\S 33$ von

$$
\text { \&.... } 0,0125
$$

Jene Aenderung würde also das Acltfaclıe des wahrscheinlichen Fehlers übersteigen, sie ist daher nicht statthaft.

Es kommt nunmelır darauf an zu untersuchen, ob jene willkürlich angenommene Verminderung von $\varrho ~ u m ~ 0,01$ Zoll passend 
gewählt war, oder ob ein andrer Werth dafür den Beobachltungen besser entspricht. Fügt man zu diesem Werth noch die Correction $x$, so liat man unter Einführung des so eben gefundnen Exponenten 2,4

$$
m=(\varrho-0,01+x)^{2,4} \cdot r
$$

oder $\quad m=(\varrho-0,01)^{2,4} \cdot r+2,4(\varrho-0,01)^{1,4} \cdot r x$

wobei also $r$ und $r x$ dic beiden Unbekannten sind, diese findet man, wenn man die drei Factoren $m,(\varrho-0,01)^{2,1}$ und $2,4(\varrho-0,01)^{1,4}$ statt $k, a$ und $b$ in jene Bedingungs-Gleichungen einführt. Letztere sind alsdann

$$
\begin{aligned}
& 0,00348980=0,000179159 \cdot r+0,00306449 \cdot r x \\
& 0,05929431=0,003064487 \cdot r+0,05566189 \cdot r x
\end{aligned}
$$

und man erhïlt

also

$$
\begin{aligned}
r & =21,578 \\
r x & =-0,12274 \\
x & =-0,005688
\end{aligned}
$$

Der Radius der Oeffunng mufs also um 0,01569 vermindert werden.

Berechnet man die Werthe von $m$ und deren Abweichungen von den beobachteten nach der Formel

$$
m=21,578(\varrho-0,00569)^{2,4}
$$

so findet man

\begin{tabular}{c|c|c}
$m$ & Diff. & Quadr. \\
\hline 0,00971 & $+0,00059$ & 0,0000003481 \\
0,03036 & $+0,00051$ & 2601 \\
0,05491 & $+0,00092$ & 8464 \\
0,09544 & $+0,00012$ & 0144 \\
0,23522 & $+0,00059$ & 3481 \\
\hline \multicolumn{2}{c}{ Summ^ 0,0000018171}
\end{tabular}

Die sämmtlichen Ahweichungen sind positiv und hieraus ergiebt sich, dafs die gefundnen Werthe für $r$ und $x$, wenn sie sich auch an die Beobachtungen genügend anschliefsen, doch nicht die richtigsten sind. Dieses rührt allein davon her, dafs der Rechnung nicht der einfache Ausdruck für $m$ zum Grunde gelegt werden konnte, vielmehr die Potenz des Binomiums in eine Reihe 
aufgelöst wurde, von der nur die beiden ersten Glieder berücksichtigt sind, die übrigen aber fortfallen mufsten, obwohl sie nicht verschwindend klein waren. Berechnet man dagegen die Werthe von $m$ aus der Gleichung

$$
m=(\varrho-0,01)^{2,4} \cdot r+2,4(\varrho-0,01)^{1,4} r x
$$

aus der sich jene Werthe von $r$ und $r x$ ergaben, so findet man

\begin{tabular}{c|c|c}
$m$ & Diff. & \multicolumn{1}{c}{ Quadr. } \\
\hline 0,00873 & $-0,00039$ & 0,0000001521 \\
0,02996 & $+0,00011$ & 0121 \\
0,05448 & $+0,00049$ & 2401 \\
0,09495 & $-0,00037$ & 1369 \\
0,23467 & $+0,00004$ & 0016 \\
\hline \multicolumn{2}{|c}{ Summa } & 0,0000005428
\end{tabular}

In diesem Fall schliefsen sich also die Werthe von $m$ bedeutend besser an die beobachteten an, auch sind sie bald grörser und bald kleiner, als die letzten. Das letzte Verfalıren ist jedoch nicht angemessen, weil es darauf ankam, die Sicherheit des einfachen Ausdrucks zu prïfen. Um diesen zu berichtigen, mufs man zu dem gefundnen Radius in gleicher Weise noch eine neue Correction suchen, und indem dieselbe ohne Zweifel viel kleiner ist, als das so eben ermittelte $x$, so werden auch die folgenden Glieder des Binomiums so klein, dafs man sie unbeachtet lassen darf.

Wichtiger ist indessen die Frage, ob die sehr bedeutende Aenderung des Radius $\varrho$ eine wesentliche Aenderung des Exponent 2,4 veranlalst. Dieses ist in sofern nicht wahrscheinlich, als sich schon früher ergab, dafs der wahrscheinliche Fehler dieses Exponenten sehr klein ist. Setze ich voraus unter Benutzung der so eben gefundnen Correction von $\varrho$, dafs der Exponent 2,4 sich um $\sigma$ indert, und suche eben so, wie oben die wahrscheinlichsten Werthe für $r$ und $\sigma$, so ergiebt sich aus der Formel

$$
\begin{gathered}
m=(\varrho-0,01569)^{2,4+\sigma} \cdot r \\
m=(\varrho-0,01569)^{2,4} \cdot r+(\varrho-0,01569)^{2,4} \cdot \log \operatorname{nat}(\varrho-0,01569) \cdot r \sigma
\end{gathered}
$$

und man erhält die beiden Bedingungs-Gleichungen

$$
\begin{aligned}
& 0,00316241=0,0001470160 \cdot r+0,0002900207 \cdot r \sigma \\
& 0,00623724=0,0002900207 \cdot r+0,0005778495 \cdot r \sigma
\end{aligned}
$$


Hieraus findet man

also

$$
\begin{aligned}
r & =21,957 \\
r \sigma & =0,22564 \\
\sigma & =0,01028
\end{aligned}
$$

Der Exponent verändert sich also noch nicht um ein halbes Procent seines Werthes und wird $=2,41$. Berechnet man aber hiernach die Sandmassen $m$ nach dem Ausdruck

$$
m=(\varrho-0,01569)^{2,41}, r
$$

so findet mun

\begin{tabular}{c|r|r}
$m$ & Ditt. & \multicolumn{1}{c}{ Quadr. } \\
\hline 0,00893 & $-0,00019$ & 0,0000000361 \\
0,03006 & $+0,00021$ & 0441 \\
0,05450 & $-0,00051$ & 2601 \\
0,09494 & $-0,00038$ & 1444 \\
0,23488 & $+0,00025$ & 0625 \\
\hline \multicolumn{2}{|c}{ Summa } & 0,0000005472
\end{tabular}

Renutzt man dagegen den zweigliedrigen Ausdruck, aus dem die Unbekannten berechnet wurden, so erhält man beinahe dieselben Werthe für $m$, doch schliefsen sie sich noch etwas schürfer an die beobachteten an, indem die Summe der Fehlerquadrate sich nur auf 0,0000004985 stellt.

Schliefslich mufs erwälnt werden, dafs vorstehende Untersuchung unter so vielseitiger Auffassung und so eingehend mitgetheilt ist, um zu zeigen, mit welcher Sicherheit die Methode der kleinsten Quadrate die Zulässigkeit verschiedner Voraussetzungen beurtheilen lälst. Aufserdem schien es bei dem so hiilufigen Mangel an Uebung in logaritlımischen Rechnungen unch notlıwendig, iiber die zweckmiifsige Ausfïhrung derselben manche Andeutungen beizufügen.

\section{$\S 37$.}

Als zweites Beispiel der Anwendung der WahırscheinlichkeitsRechnung mag ein selır wichtiger Erfahrungs-Satz der Hydraulik nach den vorstehnd entwickelten Gesetzen geprïft werden.

Wenn das $W$ asser in einem geraden und gleichmiifsigen 
Flufsbett oder Canal sich gleichförmig bewegt, so findet eine gewisse Bezielıung zwischen der mittlern Geschwindigkeit $(c)$, dem relativen Gefälle ( $c$ ), dem Flächeninhalt des Querprofils $(q)$ und dem benetzten Umfange des letztern $(p)$ statt. Nimmt man an, dals der Widerstand dem Quadrat der Geschwindigkeit proportional sei, so gelangt man unter den üblichen Voraussetzungen zu dem Ausdruck

$$
c=\gamma \sqrt{\frac{\alpha q}{p}}
$$

wo $\gamma$ die Constante bedeutet, deren Werth aus den Beobachtungen zu bestimmen ist. Chezy war der erste, der diese Formel angab, obwohl das Gesetz, workuf sie berulıt, schon 20 Jalıre früher von Brahms bestimmt ausgesprochen und aus Beobachtungen an Strömen liergeleitet war. ${ }^{*}$ ) Später führten Woltman und Eytelwein denselben Ausdruck statt des höchst complicirten, von Dubuat aufgestellten, wieder ein. Eytelwein fand anfangs unter Zugrundelegung der von Dubuat mitgetheilten Messungen, und zwar auf Rhıinländisches Fufsmaafs redueirt

also

$$
\gamma=90,9
$$

$$
c=90,9 \sqrt{\frac{\alpha q}{p}}
$$

Einige Jalıre später nahm Eytelwein dieselbe Untersuchung nochmals auf, indem er nicht nur die von Iubuat an kleinern Flüssen und Canälen angestellten Beobachtungen, sondern auch diejenigen benutzte, die Brïnings, Woltman und Funk an Rhein, an der Weser und an andern Flüssen gemacht hatten.**) Der Widerstand wurde dabei einem Ausdruck gleichgesetzt, dessen erstes Glied die erste, und dessen zweites Glied die zweite Potenz der Geschwindigkeit zum Factor enthielt, also

$$
\frac{\alpha q}{p}=r c+s c^{2}
$$

*) Vergl. mein Handbuch der Wasserbaukunst. Theil II, Band. I. Dritte Ausgabe, Seite 297.

**) Abhandlungen der königlichen Akademie der Wissenschaften 1813 und 1814. Diese Untersuchung ist anch der dritten Ausgabe von Eytelwein's H:undbuch der Mechanik und Ifydraulik als Anhung loeigefügt. 
und kytelwein fand

$$
c=-0,1057+\sqrt{0,01118+8715,6 \cdot \frac{\alpha q}{p}}
$$

Die beiden Constanten $r$ und $s$ waren dabei aus 91 Gleichungen hergeleitet, welche die gleich grofse Anzahl von Beobachtungen darstellten. Um die wahrscheinlichsten Werthe zu finden, wählte Eytelwein dasselbe Verfahren, dessen sich Prony in einer ähnlichen Untersuchung bedient hatte*), und welches von $L$ a place herrihrte. Bevor nämlich die Methode der kleinsten Quadrate bekannt war, hatte Laplace in der Untersuchung ïber die Gestalt der Erde, die Ansicht ausgesprochen, $\left.{ }^{* *}\right)$ diejenigen Werthe der Constanten seien die wallrscheinlichsten, wobei 1) die algebraische Summe der übrig bleibenden Fehler gleiclı Null und 2) die Summe der sämmtlichen Fehler, wenn alle als positiv angesehn werden, ein Minimum ist. Diese Bedingungen sind wesentlich verschieden von derjenigen, dafs die Summe der Quadrate der übrig bleibenden Fehler ein Minimum sein soll, und namentlich werden dabei die grörsern Felller nicht genïgend beriicksichtigt. Nichts desto weniger wurde das von Eytelwein gefundne Resultat, welches sich nahe an das von Prony ermittelte anschlofs und vor diesem den wichtigen Vorzng latte, dais es zum Theil auf Messungen an grofsen Strömen basirte, ziemlich allgemein angenommen. Lejeune Dirichlet, der damals in Paris studirte, übersetzte auf Prony's Wunsch diese Abliandlungen, und letzterer war selır erfreut, eine iiberraschende Bestätigung des von ihm aufgestellten Gesetzes zu finden. Auch d'Aubuisson ***) begnïgte sich später Kytelwein's Resultate anzuführen. Durch diese schien die Theorie der Kewegung des Wussers in Flufsbetten abgeschlossen.

Bei der Wichtigkeit des Gegenstandes rechtfertigt es sich gewifs, die Werthe der Constanten nach der richtigen Metlode zu berechnen und zugleich zu untersuchen, wie grofs die Wahrscheinlichkeit dieser Resultate ist.

*) Recherches physico-mathématiques sur la théorie des eaux courantes. Paris 1804.

**) Mécanique céleste. Liv. III, art. 39 et 40 .

***) 'I'raité d'hydraulique. Paris 1834, Seite 111. 
Aus der von Eytelwein mitgetheilten Vergleichung der durch Rechnung dargestellten Werthe mit den beobachteten ergiebt sich, dals die Messungen, welche von Funk herrülren, weit weniger übereinstimmen, als die übrigen, obwobl von denselben schon einige gar nicht benutzt waren, weil sie sehr abweichende Resultate gaben. Dafs eine solche Ausschlielsung einzelner Messungen, und zwar nur deshalb, weil sie von den übrigen abweichen, sehr gewagt ist, und leicht grofse Irrthiimer veranlassen kann, ist bereits oben $\$ 23$ nachgewiesen. Jedenfalls aber mufsten die von verschiednen Beobachtern herrührenden Messungen besonders geprüft werden, weil ihre Gewichte sehr versclieden sind.

Von Brünings rühren sechszehn Beobachtungen her, welche aus den Mittheilungen von Wiebeking*) entlehnt sein sollen. Eine nïhere Vergleichung mit diesem Werk zeigte indessen aufser dem Druckfehler in der 59 ten noch eine kleine Unrichtigkeit in der 62 ten Beobachtung, insofern der Umfang $p$ doch grïfser, als die Breite sein mufs. Aufserdem hat Wiebeking siebenzehn Beobachtungen von Brünings mitgetheilt, von denen jedoch eine, nämlich Litt. $\boldsymbol{F}^{\prime}$ olıne Angabe eines Grundes von Eytelwein nusgelnssen ist. Am meisten ijberrascht es aber, dafs Wicbeking das Gefälle dieser Stromstrecken zur Zeit der Messungen. oder $\alpha$, gar nicht angiebt, während Eytelwein dafür bestimmte Werthe eingeführt und diese der Rechnung zum Grunde gelegt hat. Aus Wiebekings Beschreibung dieser Beobachtungen lïist sich nicht entnehmen, dafs die Gefille wirklich gemessen wurden. Der $/$ weck war nämlich nur die Feststellung des Verlïilnisses, in welchem die Wassermenge des obern Rheins zwischen Waal, Leck und Yssel sich vertheilt, wozu die Querschnitte und Geschwindigkeiten genügten. Am Schluss der erwälınten Stelle im Wiebeking'schen Werke werden freilich die Neigungs-Verlältnisse des Rheins und der Wanl im Allgemeinen angegeben, doch beziehn sich diese keineswegs auf die Stellen und die Zeiten, in denen die Profile und die Geschwindigkeiten gemessen wurden, und stimmen aufserdem auch nicht entfernt mit denjenigen überein, die Eytelwein zum Grunde gelegt hat.

*) Allgemeine Wasserbaukunst. Erste Ausgabe 1798. Theil I. Seite $344-388$.

II agen, Wahrscheinllikeits-Rechnung. 3. Auf. 
Woltma ${ }^{*}$ ) spricht gleichfalls von diesen Beobachtungen, die Brünings ilım mitgetheilt hatte, und rühmt die grofse Sorgfalt, womit die Geschwindigkeiten gemessen wurden, dafs aber gleichzeitig die Gefälle ermittelt wären, erwähnt er nicht und sagt vielmehr ausdriicklich, dals es nur Absicht gewesen ,zu wissen, wie sich die Wassermengen dieser verschiednen Flüsse gegen einander verhalten."

Dagegen hat Funk ${ }^{*}$ ) dieselben sechszehn Beobachtungen von Brünings, die Eytelwein benutzte und die gleichfalls aus Wiebeking's Werk entnommen sein sollen, zusammengestellt, und seine Angaben stimmen mit Ausschlufs jenes Iruckfehler's genau mit denen von Eytelwein ïberein. Funk giebt aber auch die relativen Gefälle oder die Neigungs-Quotienten an, welche sieben verschiedne Werthe haben. Woher er diese entnommen, theilt er nicht mit, und da jede andre Vermuthung an sich höchst unwalırscheinlich wäre, so muls man zunächst voraussetzen, er und nach ihm Eytelwein haben von diesen Gefällen auf irgend eine Weise sichere Kenntnils erhalten.

Um aus diesen sechszehn Beobachtungen Resultate zu zielın, mögen dieselben mit rem einfachsten Ausdruck

$$
c=\gamma / \frac{\alpha q}{p}
$$

verglichen werden. Sie sind nachstehend in der Reihenfolge zusammengestellt, wie Funk sie gerrdnet hat, wobei jede der sieben Gruppen die Beobachtnngen umfarst, in denen das relative Gefälle $\gamma$ gleich grofs sein soll. Die letzte Spalte entlält den jedesmaligen Werth von $\gamma$.

$\begin{array}{cccc}\begin{array}{c}\text { Nummer der Beobachtung nach } \\ \text { Funk } \\ \text { Fytelwein }\end{array} & \begin{array}{c}\text { Neigumgs- } \\ \text { (quotient }\end{array} & \gamma \\ 1 & 52 & 7571 & 98,026 \\ 2 & 62 & 7571 & 90,894 \\ 3 & 44 & 9045) & 80,053 \\ 4 & 54 & 9045 & 90,900 \\ 5 & 53 & 4542 & 83,058 \\ 6 & 67 & 4542 & 90,888\end{array}$

*) Beiträge zur hydraulischen Architectur. Band III. Seite $350 \mathrm{tt}$.

**) Beitrïge zur allgemeinen Wasserbaukumst. 1808 Seite 97. 
Nimmer der Beobachtung nach Funk Fytelwein

$\begin{array}{rr}7 & 45 \\ 8 & 55 \\ 9 & 60 \\ 10 & 61 \\ 11 & 34 \\ 12 & 56 \\ 13 & 43 \\ 14 & 50 \\ 15 & 47 \\ 16 & 59\end{array}$

Neigungs-

Quotient

7957

7957

7957

7957

4931

4931

6701

6701

5825

5825 $\gamma$

84,458

100,823

109,165

90,900

86,190

90,892

90,074

90,892

86,632

90,919

Der walırscheinlichste Werth von $\gamma$ oder das arithmetische Mittel aus den vorstehenden ist 90,923. Die Summe der Qnadrate der Albweichungen von demselben ist

$$
[x x]=702,542
$$

daher der wahrscheinliche Reobachtungs-Fehler

$$
\begin{aligned}
w & =0,6745 \cdot \sqrt{\frac{[x x]}{m-1}} \\
& =0,6745 \cdot \sqrt{\frac{702,542}{15}} \\
& =4,6160
\end{aligned}
$$

Pei dieser Gröfse des Beobachtungs-Fehlers ist es ein liijclist wunderbares Zusammentreffen, dafs in jeder der sieben Gruppen und zwar jedesmal in der letzten Beobachtung, die Werthe von $\gamma$ sehr nahe dieselben sind, und sogne bis auf geringe Abweichungen, die im Maximum nur 0,019 betragen, sicll dem bereits früher von Eytelwein eingefülurten Werth $\gamma=90,9$ nähern. Die mittlere Alıweichung beträgt bei diesen Benbachtungen nur 0,0076 , sic ist also noch nicht dem 500 ton Theil des wahrscheinlichen Beobachtungs-Fehlers gleich, sondern nur $0,00165 w$. Für einen Fehler, der innerhalb dieser Grenze bleibt, ist die Wahrscheinlichkeit oder $\int y d x$ nur 0,0000885 , oder man kann 11296 gegen 1 wetten, dafs in der letzten Beobachtung der ersten Gruppe diese Uebereinstimmung sich zufällig nicht darstellen wird. Nun wiederholt sich aijer dieser ganz 
unglaubliche Fall siebenmal nach einander an derselben Stelle, es ist also ein Ereignifs eingetreten, dessen Walurscheinlichkeit der siebenten Potenz jenes kleinen Bruchs gleich ist. Dieselbe driickt sich durch eine Zahl aus, in welcher auf das DecimalKomma zunächst 28 Nullen und sodann die Ziffern 4265 folgen. Dieser Bruch werde durch $\mu$ bezeichnet.

Die Wahrscheinlichkeit für das vorliegende Ereignifs, wenn dasselbe wirklich nur zufällig eintrat, ist demnach unglaublich geringe, und eben deshalb wird der Verdacht rege, dafs es nicht durch Zufall, sondern absichtlich herbeigefiihrt wurde. Indem es an sich sehr unwahrscheinlich ist, dafs Eytelwein, der doch in naher Beziehung zu Funk stand, gar nicht erfahren habe, dafs Letzterer die angegebenen Gefälle nicht aus wirklichen Beobachtungen entnommen, sondern dieselben eben nach der Eytelwein'schen Formel bereclinet habe, so setze man die Wahrscheinlichkeit einer solchen Voraussetzung nur 0,0001 und schliefse (nach \& 6) von dem Ereignifs auf die Ursachen desselhen. Man findet alsdann die Walırscheinlichkeit der ersten Ursache, also des $\mathrm{Z}$ ufalls, gleich

$$
\frac{\mu}{\mu+0,0001}
$$

und die der zweiten, oder der Annalıme, dals die Gefälle berech h e t worden, gleich

$$
\frac{0,0001}{\mu+0,0001}
$$

Beide verhalten sich daher an einander, wie

$$
\mu: 0,0001
$$

oder wic

\section{1 хu 23447000000 Billionen.}

Gewifs giebt es nur wenig Wahrheiten, die mit einer so grolsen Wahrscheinlichkeit sich als solche herausstellen, wie diese zweitc Voraussetzung, und es wäre eine sehr vortheilhafte Wette, wenn man alleg Gold und Silber, welches geprägt und ungeprägt im Umlauf ist, gegen einen Pfennig anf die Behauptung verwetten kïnnte, dafs in der in Rede stehenden Untersuchung die Gefälle 
nicht wirklich gemessen, sondern nach der Eytelwein'schon Formel berechnet wurden.

Is leidet sonach keinen Zweifel, dafs Funk, wahrscheinlich in der Absicht, die Beobachtungen von Brünings zu vervollständigen, nach jener Formel die Gefälle berechnete. Wenn daher Eytelwein hieraus wieder das Gesetz der Bewegung des Wassers herleitete, so konnte dasselbe voll dem früler zum Grunde gelegten nicht bedeutend abweichen, und es mufste auch mit den von Prony gefundenen Resultaten nahe ïbereinstimmen, da auch diese aus denselben wirklichen Beobachtungen hergeleitet waren. Hätte aber Funk für jede einzelne Messung mit grölserer Schärfe die Rechnung geführt, so würde Eytelwein atus diesen Beobaclitungen gefunden haben, dals der Factor der ersten Potenz der Geschwindigkeit gleich Null, und der der zweiten genau derselbe ist, den er früher gefunden hatte, weil aus diesem dic angeblichen Beobachtungen hergeleitet waren.

Was die von Funk an der Weser angestellten Messungen betrifft, so sollte man zwar vermuthen, dafs dieselben wirklich vollstiindig ausgefiilırt wären, insofern der Mittheilung dieser Beobachtungen eine selır ausführliche Beschreibung des WeserNivellements vorangeht. Niclits desto weniger erweckt es sclion Verdacht, dal's bei den verschiedensten Wasserständen die Gefülle immer dieselhen bleiben. Wenn man aber aus diesen cinzelnen Beobachtungen den Coefficient $\gamma$ lierleitet, so bemerkt man auch hier die an sich ganz unwahrscheinliche Figenthümlichkeit, daIs in jeder Reilıe einmal der Eytelwein'sche Cocficient 90,9 vorkommt, und zwar geschieht dieses viermal, nïmlich in den Revilıen, die Funk mit $I, I, K$ und $M$ bezeichnet, wieder in den letaten Beobachtungen, wogegen in der Reilıe $L$, dic nur aus zwej Messungen bestcht, das Gefalle zweimal berechnet, und aus beilen Werthen das Mittel genommen zu sein seheint. In der Reihe $G$ entspricht dagegen das Gefiille demjenigen, das fïr den Wasserstand 10,54 berechnet wurde.

Der Untersuchung Eytelweins sind also grofsen Theils Beobachtungen zum Grunde gelegt, die nicht wirklich gemacht, sondern nur fingirt waren, und unglücklicher Weisc trifft dieser Vorwurf gerade diejenigen, welche sich auf grofse Ströme beziehn, und die daher vorzugsweise wichtig erscheinen. Wenn 
man von diesen absicht, so bleiben nur noch die Beobachtungen von Dubuat und Woltman übrig. Gegen die Glaubwiurdigkeit derselben begriindet sich kein Verdacht, sie beziehn sich aber nur auf kleinere Wasserläufe. Dubuat's Versuche sind sogar in der grol'sen Mehrzahl nur in hölzernen Rinnen angestellt. Wenn auch diese ausgeschlossen werden, so bleiben nur die Messungen im Canal du Jard und im Haine-Flusse übrig, deren Breite 30 bis 45 Fuls betrug*). Es sind im Ganzen 10 Beobachtungen, doch dürfen die beiden ersten nicht berücksichtigt werden, da sie vor der Krautung des Canals angestellt wurden. Die vier Beobachtungen von Woltman beziehn sich dagegen auf kleine Entwäisserungs-Gräben bei Cuxhaven von 8 und 14 Fuls Breite**).

Man könnte auch gegen diese wenigen Messungen noch dus Bedenken erheben, dals die Geschwindigkeiten sowolıl von Dubuat, wie von Woltman nur in der Oberfläche gemessen wurden, also die mittleren Geschwindigkeiten unbekannt sind. Eine Reduction nach irgend einer der verschiednen dafür vorgeschlagenen Regeln wïrde indessen immer sehr zweifelhaft bleiben und aufserdem auch zu keinen erheblichen Aenderungen fülıren. Dazu kommt noch, dafs in so kleinen Canälen und bei so geringer Geschwindigkeit das Wasser in der Oberfläcle jedesmal sich etwas langsamer bewegt, als einige Zolle tiefer, und daher anzunehmen ist, dal's diese Geschwindigkeit sich der mittlern etwas mehr nähert.

In der folgenden Zusammenstellung sind die Beobachtungen von Dubuat durch Arabische und die von Woltman durch Rümische Ziffern bezeichnet und nach den Geschwindigkeiten georduet. Sic sind sämmtlich auf' Rheinländisches Fufs-Maal's reducirt, und zunächst ist aus jeder einzelnen nach der Formel

$$
c=\gamma / \frac{\alpha \eta}{p}
$$

die Constante $\gamma$ bercchnet. Von den in der fïnften Spalte beigefïigten Abweichungen $x$ wird später die Rede sein.

*) Dubuat principes d'hydraulique. II. Volume. Sect. I. partie 8.

**) Beiträge zur Baukunst schiftbarer Canäle. Seite 286 und 287. 


\begin{tabular}{r|c|c|r|c}
\hline Nummer & $c$ & $\frac{\alpha q}{p}$ & $\gamma$ & $x$ \\
\hline 177 & 0,627 & 0,0000590 & 81,68 & $-0,0000120$ \\
179 & 0,672 & 0,0000683 & 81,33 & $-0,0000147$ \\
178 & 0,829 & 0,0000913 & 86,74 & $-0,0000114$ \\
III & 0,895 & 0,0001264 & 79,57 & $-0,0000339$ \\
IV & 0,895 & 0,0001150 & 83,43 & $-0,0000225$ \\
I & 1,019 & 0,0001398 & 86,14 & $-0,0000211$ \\
181 & 1,174 & 0,0001427 & 98,32 & $+0,0000135$ \\
180 & 1,357 & 0,0001634 & 106,20 & $-0,0000435$ \\
II & 1,369 & 0,0002071 & 95,13 & $+0,0000035$ \\
183 & 1,377 & 0,0001587 & 109,26 & $+0,0000540$ \\
184 & 2,740 & 0,0008707 & 92,87 & $-0,0000507$ \\
182 & 3,029 & 0,0009709 & 97,20 & $+0,0000281$
\end{tabular}

Man kann hiernach mit einiger Walrrseheinlichkeit annehunen, dafs $\gamma$ nicht constant ist, sondern bei zunehmender Geschwindigkeit etwas gröfser wirl. Es wurle daher noch der Versuch gemacht, in gleicher Weise, wie Prony und Eytelwein grethan, diese Beobachtungen an den Ausdruck

$$
\frac{\alpha q}{p}=r c+s c^{2}
$$

'unzuschliefsen. bei Anwendung der Methode der kleinsten Quadrate hat man alsdann die beiden Bedingungs-Gleichungen

$$
\left\lceil\frac{c q}{p} \cdot c\right]=\left[c^{2}\right] r+\left[c^{3}\right] s
$$

ind

$$
\left\lceil\frac{\alpha \cdot q}{p} \cdot c^{2}\right\rceil=\left[c^{3}\right] r+\left[c^{3}\right] s
$$

oder durch Einfuihrung der Zahlenwertle aus der vorstehnden Tabelle

$$
\begin{aligned}
& 0,006737=27,847 \cdot r+61,272 \cdot s \\
& 0,017088=61,272 \cdot r+156,158 \cdot s
\end{aligned}
$$

Man findet daraus

$$
\begin{aligned}
& r=0,000008468 \\
& s=0,000106106
\end{aligned}
$$

und wenn man mit Benutzung dieser Werthe für die verschiednen 
Geschwindigkeiten $\frac{\alpha \eta}{p}$ berechnet, so weichen die letztern ron den beobachteten um diejenigen $x \mathrm{ab}$, welche in der vorstelinden Tabelle angegeben sind. Die Summe der Quadrate der Abweichungen beträgt

$$
[x x]=0,000000010954
$$

Hieraus ergielt sich der wahrscheinliche Beobachtungs-Fehler

$$
w=0,000022323
$$

und man findet die wahrscheinlichen Fehler der Constanten $r$ und $s$

$$
\begin{aligned}
& w(r)=0,000006987 \\
& w(s)=0,000002950
\end{aligned}
$$

Es ergiebt sich, dafs die Constante $r$ nur sehr wenig grölser als ihr walırscheinlicher Fehler ist, man hat nämlich annähernd

$$
r=1,2 \cdot w(r)
$$

und man kann daher nur 58 gegen 42 oder 7 gegen 5 wetten, dafs die Constante $r$ nicht Null ist, oder dafs in der zum Grunde gelegten Gleichung überhaupt ein Glied vorkommt, welches die erste Potenz der Geschwindigkeit als Factor enthält.

Diese 12 Beobachtungen, welche unter den 91, die Eytelwein benutzte, allein brauchbar sind, rechtfertigen demnach nur mit einer sehr geringen Wahrscheinlichkeit die Einführung des Gliedes $r . c$ in den früher von Chezy und Woltman benutzten Ausdruck. Das Resultat würde sich freilich anders herausstellen und in höherem Grade die von Prony angegebne Formel bestitigen, wenn man die Beobaclitung Nr. 184, die Dubuat gemaclıt laat, unberücksichtigt lassen dürfte. Ein solches Verfahren wäre indessen nicht gerechtfertigt. Man könnte dasselbe auch erreichen, wenn man nicht die Summe der Quadrate der absoluten, sondern die der relativen Abweichungen zu einem Minimum machen wollte. In diesem Falle würden nämlich die Beobachtungen bei kleinern Geschwindigkeiten, für welche die Abweichungen $x$ sechsmal hinter einander negativ sind, eine grölsere Geltung erhalten. Aber auch hierzu liegt kein Grund vor, weil nicht anzunehmen, dufs diese Messungen mit grölsrer Schlı̈rfe ausgefiilurt sind, als die übrigen, die sich auf grölsre Geschwindigkeiten beziehn. 
$\S 38$.

Sehr wichtig ist die Anwendung der WahrscheinlichkeitsRechnung auf Untersuchungen ïber die Festigkeit der Baumaterialien, wovon schon $\$ 34$ die Rede war. Die Mittelwerthe, die man dabei gewöhnlich allein berïcksichtigt, sind nur in dem Fall als ausreichend anzusehn, wenn zahlreiche Verbandstücke sich gegenseitig so unterstïtzen, dafs die zufällige gröfsre Festigkeit eines Stücks den Bruch eines andern verhindert. Dieses wäre beispielsweise der Fall, wenn eine grolse Last gleichmäIsig an viele Zugstangen gehängt wïrde. Eine, solche Anordnung kommt indessen bei Constructionen wolıl nur selten vor, meist triftt auf jedes Verbandstück ein gewisser Druck oder Zug, und es kommt darauf an, ihm solche Dimensionen zu geben, dafs es mit Sicherheit den nöthigen Widerstand leistet. Der aus Versuchen hergeleitete Mittelwerth bezeichnet nur die walirscheinlichste Grölse der Festigkeit, läfst aber nicht erkennen, mit welcher Wahrscheinlichkeit man gewisse Abweichungen erwarten latr, und welche Verstärkungen man daher anbringen mufs, um letztere unschädlich zu machen. Diese $\mathrm{A}$ bwe ichungen lassen sich aber leicht und sicher aus der Vergleichung der einzelnen Messungen mit dem Mittelwerth erkennen und durch den wahrscheinlichen Fehler ausdrücken. Letzterer ist in diesem Falzwar kein Beobachtungs-Fehler, vielmehr beruht er auf der unvermeidlichen Verschiedenlıeit des Materials, da diese aber wieder zufällig ist, so gelten auch fïr sie die obigen Cresetze.

Der wahrscheinliche Fehler lïlst sich um so sichrer bestimmen, je gröfser die Anzahl der Versuclıe ist, und je vollstäindiger dieselben alle Abstufungen des Materials umfassen, das in der Construction benutzt werden soll. Sind einzelne Stricke so fehlerhaft, dafs sie wegen schlechter Beschaffenlıeit schon bei der $\Lambda$ bnahme verworfen werden, so braucht man die Versuche nicht auf sie auszudehnen, wohl aber kommen häufig verborgne Fehler vor, und diese veranlassen, dafs einzelne Versuche ein besonders ungünstiges Resultat geben. Tritt ein solches ein, so darf dieses keineswers als ungültig vernachlässigt werden, es dient vielmelır wesentlich zur richtigen Bestimmung des wahrsclieinlichen Fehlers. 
Gemeinhin lassen siclı solche Versuche nicht im Grol'sen anstellen, nur bei gewalztem Eisen pflegt man die Elasticität der sämmtlichen Haupt-Verbandstiucke zu prïfen. Die meisten Versuche werden in kleinen Dimensionen gemacht, wobei die vorhandnen Mängel des Materials viel augenscheinlicher hervortreten, und kaum noch ein bedeutender Fehler unbemerkt bleiben kann. Die hieraus abgeleiteten Resultate stellen sich daher im Allgemeinen vergleichungsweise hedeutend giinstiger heraus, als diejenigen, welche die Verbandstücke in ihren vollen Dimensionen ergeben wïrden. Man darf dieses nicht unbeachtet lassen.

Als Baispiel für Untersuchungen solcher $\Lambda$ rt wähle ich die Messungen der absoluten Festigkeit des Eisens, die in der Fabrik von J. C. Harkort auf Harkotten im October 1860 angestell wurden*). Stäbe von Rundeisen etwa 10 Zoll lang und 9 Linien stark wurden auf 2 Zoll Länge cylindrisch abgedreht, so duls hier der Durchmesser $5 / 8$ Zoll oder $7 \frac{1}{2}$ Rheinländische Linien hielt. Die nachstehnde Tábelle giebt die Gewichte in Pfunden an, unter denen die Cylinder zerrissen. Ohne Zweifel wäre es zur Beurtheilung der Festigkeit viel wichtiger gewesen, diejenigen Beobaclitungen zu erfahren, unter welchen die Elasticitäts-Grenze erreicht wird, oder das Eisen sich deuternd verlängert. Dieses liel's sich jedoch bei der sehr geringen Lünge der abgedrehten Cylinder nicht messen, und ich kounte die Untersuchung hierauf' nicht ausdehınen, da mir keine gröfsern Reilıen vou Beobachitungen dieser Art bekanut geworden sind.

Die siebenzehn hier geprüften lisensorten waren aus verschiednen inländischen Fabriken bezogen, die in einer besondern Anlage derselben Zeitschrift zum Theil benannt sind. Das Eisen war im Bruch theils körnig, theils sehnig, und theils war es in Cokesfeurung, theils mit Holzkohlen durgestellt. Die Mittelwerthe dafïr sind wohl verschieden, doch sind diese Unterschiede geringer, als diejenigen, die zuweilen in derselben Fisensorte vorkommen, woher nachstehend die Resultate aller Proben gemeinschaftlich behandelt sind. Dieses war auch nothwendig, um eine grofse Anzalıl von Beobachtungen der Rechnung zum Grunde zu legen.

*) Beilage zu Nr. 22 der Zeitschrift: Berggeist. 1861. 
1)ie erste Spalte bezeichnet die Nunner der Eissensorte, die zweite die des Versuchs, und die dritte das angehängte Gewicht in Pfunden, wobei der Cylinder zerrifs. Der Querschnitt vou diesem mals jedesmal 0,307 Quadrat-Zoll.

\begin{tabular}{|c|c|c|c|c|c|}
\hline 1 & $\begin{array}{l}1 \\
2 \\
3\end{array}$ & $\begin{array}{l}18091 \\
16945 \\
16945\end{array}$ & 10 & $\begin{array}{l}26 \\
27 \\
28\end{array}$ & $\begin{array}{l}21400 \\
21400 \\
20460\end{array}$ \\
\hline 2 & $\begin{array}{l}4 \\
5 \\
6\end{array}$ & $\begin{array}{l}20010 \\
20364 \\
20364\end{array}$ & 11 & $\begin{array}{l}29 \\
30 \\
31\end{array}$ & $\begin{array}{l}21400 \\
20460 \\
20460\end{array}$ \\
\hline 3 & $\begin{array}{l}7 \\
8 \\
9\end{array}$ & $\begin{array}{l}15727 \\
15727 \\
14910\end{array}$ & 12 & $\begin{array}{l}32 \\
33 \\
34\end{array}$ & $\begin{array}{l}16740 \\
17680 \\
17680\end{array}$ \\
\hline 4 & $\begin{array}{l}10 \\
11 \\
12\end{array}$ & $\begin{array}{l}20000 \\
20000 \\
24727\end{array}$ & 13 & $\begin{array}{l}35 \\
36 \\
37\end{array}$ & $\begin{array}{l}19540 \\
19540 \\
17680\end{array}$ \\
\hline 5 & $\begin{array}{l}13 \\
14 \\
15\end{array}$ & $\begin{array}{l}14491 \\
19910 \\
19910\end{array}$ & 14 & $\begin{array}{l}38 \\
39 \\
40\end{array}$ & $\begin{array}{l}14880 \\
13960 \\
15820\end{array}$ \\
\hline 6 & $\begin{array}{l}16 \\
17\end{array}$ & $\begin{array}{l}14855 \\
14491\end{array}$ & 17 & $\begin{array}{l}41 \\
42\end{array}$ & $\begin{array}{l}16740 \\
17680\end{array}$ \\
\hline 7 & $\begin{array}{l}18 \\
19\end{array}$ & $\begin{array}{l}14036 \\
14455\end{array}$ & 18 & $\begin{array}{l}43 \\
44\end{array}$ & $\begin{array}{l}17680 \\
13960\end{array}$ \\
\hline 8 & $\begin{array}{l}20 \\
21\end{array}$ & $\begin{array}{l}16740 \\
17680\end{array}$ & & $\begin{array}{l}45 \\
46 \\
\end{array}$ & $\begin{array}{l}15820 \\
16740\end{array}$ \\
\hline & 22 & 15820 & 19 & 47 & 15820 \\
\hline 9 & $\begin{array}{l}23 \\
24\end{array}$ & $\begin{array}{l}17680 \\
16740\end{array}$ & & $\begin{array}{l}48 \\
49\end{array}$ & $\begin{array}{l}16740 \\
16740\end{array}$ \\
\hline & 25 & 16740 & & & \\
\hline
\end{tabular}

Die lisensorten Nr. 1, 3, 6, 7, 8, 10, 12, 14 und 19 werden als sehnig, Nr. 5 und 18 als halb sehnig und halb körnig und Nr, 2, 4, 9, 11, 13 und 17 als körnig bezeichnet. Die Mittelwerthe dieser drei Gattungen verhalteu siclı zu einander, wie

$$
1: 1,010: 1,162
$$


Man kann daraus schliefsen, dal's das körnige Eisen fester ist, als das sehnige, abel die Sorte $\mathrm{Nr}$. 4, welche nach einer Probe die festeste von allen war, weicht nur sehr wenig von dem sehnigen Eisen Nr. $10 \mathrm{ab}$, und die Festigkeit des halb sehnigen und halb körnigen Eisens ist im Mittelwerthe sehr nahe eben so grofs, wie die des selınigen.

Ferner sind die Sorten Nr. 8, 9 und 17 als HolzkohlenEisen, Nr. 1, 2, 3, 4, 5, 6, 7, 10, 11, 12, 13 und 19 als Cokes-Eisen bezeichnet, wälırend $\mathrm{Nr} .18$ mit Holzkohlen und Cokes bereitet war. Die Mittelwerthe der Festigkeit dieser drei Gattungen verhalten sich, wie

$$
1: 1,034: 0,909 \text {. }
$$

Diese Unterschiede sind theils geringer, theils aber stellen sie sich noch unregelmäfsiger heraus, als die frïher'n.

Dagegen zeigen sich in verschiednen Proben derselben Hiscnsorten Differenzen, die viel grölser, als die vorstehnden sind, so

in der Sorte Nr. 4 20000:24727 $=1: 1,236$

in der Sorte Nr. $5 \quad 14490: 19910=1: 1,374$

Hiemach rechtfertigt es sich gewifs, dafs die sämntlichen Versuche gemeinschaftlich behandelt sind. Die Summe aller Gewichte, unter denen die Cylinder zerrissen, beträgt 864378 I'fl. und die Zahl der Versuche 49. Der mittlere Wertlı der als-

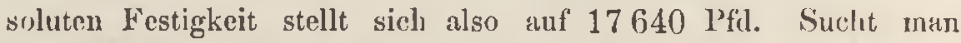
die Differenzen zwischen diesem Werthe und den einzelnen Beobachtungs-Resultaten und quadrirt dieselben, so findet man die Summe der Fehler-Quadrate gleich 286742000 . Hieraus ergiebt sich der wahrscheinliche Fehler gleich 1650 Pfund, er stellt sich also nalie auf 10 P'rocent des ganzen Werths.

Der Quersehnitt der zerifsnen Cylinder mafs 0,307 Quedratzoll, woher 3,26 solcher einen Quadratzoll bilden. Man nimmt gewölınlich an, die Festigkeit sei proportional dem Querschnitt, sie würde daher für einen Stab des hier geprüften Fisens von 1 Quadratzoll Querschnitt im Mittelwerth 3,26.17640=57500 Pfund betragen.

Diese Auffassung ist indessen zweifelhaft. Man vergleiche zwei Stäbe, von denen der Querschnitt des einen $n$ mal so grols, als der des andern ist, und denke ihn aus $n$ Stäben zustmmen 
geschweifst, die mit diesem sowohl in der Stärke, wie in der Textur so genau übereinstimmen, dafs in allen die schwāchern Stellen genau zusammentreffen. In diesem Fall wïrde die Festigkeit beider Stäbe ihren Querschnitten proportional sein. Wenn dagegen jene einzelnen Stäbe, die im Allgemeinen mit einander übereinstimmen, in der Art verbunden sind, wie sie zufällig gefaíst wurden, so dals die schwache Stelle des einen mit der festern des andern zusammenfällt, so wird der Stab verhailtnifsmäfsig eine gröfsre Last tragen, als der einzelne.

Diese Ausgleichung dürfte vorzugsweise bei der Ermittlung des wahrscheinlichen Fehlers zu beachten sein, und zwar in gleicher Weise, wie bei Messung einer Linie durch $n$ maliges Auszielın der Ketten. Eben so wie hier der walırscheinliche Fehler der ganzen Linie zu dem der einzelnen Kettenlänge sich nicht wie $n: 1$ sonder nur wie $V \mathrm{n}: 1$ verhält, so darf man auch annehmen, dafs der wahrscheinliche Fehler in der Bestimmung der Festigkeit des Stabes von 1 Quadratzoll Querschnitt nach vorstelienden Beobachtungen

\section{$1650 \cdot V 3,26=2980$ Pfund}

betragen wird. In gleicher Weise vermindert sich relativ auch wieder der wahrscheinliche Feller für Stäbe, deren Querschnitt mehrere Zolle enthalten.

Dabei kommt jedoch die Frage in Betracht, ob man annehımen darf, dafs Stäbe von verschiednem Querschnitt im äufsern Ansehn die darin vorkommenden Mängel mit gleicher Sicherheit erkennen lassen, oder ob man besorgen muls, dafs stïrkere Stäbe noch als fehlerfrei übernommen und verwendet, wälrend schwächere von derselben Beschaffenheit schon als unbrauchbar erkannt und zurüickgewiesen werden. Diese Besorgnils dürfte sich wohl begrïnden.

Navier *) theilt einige Beobachtungen von Perronet ïber die Festigkeit gewalzter Eisenstiicke von verschiednem Querschnitt mit, die jedoch, wie die nachstelnde Zusammenstellung der mittlern Werthe zeigt, zu keinem Resultat führen. $k$ bezeichnet die Last,

*) Résumé des leçons donnêes ì l'école des Ponts et chaussées. I. Partic \$s 28 und 29. 
in Kilogrammen für jedes Quadrat-Millimeter Querschnitt, wobei der Stab zerrifs, und Q den Querschnitt in Quadrat-Millimetern.

A. Rundeisen

\begin{tabular}{c|c}
$Q$ & $k$ \\
\hline 10,5 & 39,6 \\
7,88 & 55,7 \\
7,62 & 34,8
\end{tabular}

B. prismatisches

\begin{tabular}{c|c}
$Q$ & $j$ \\
\hline 12,9 & 35,9 \\
9,02 & 37,5 \\
6,77 & 50,7
\end{tabular}

Ehen diese Beobachtungen sind auch, soviel bekannt, die einzigen, die mit Stäben von verschiednen Längen angestellt sind, nach denen man also die bisher unbenchtet geblielone, aber liöclist wichtige Frage beantworten könnte, in welcher Beziehung die Lünge cines gleichmälsig geformten Stales zu seiner Festigkeit gegen das Zerreifsen oder das Ueberschreiten der ElasticitätsGrenze steht. Dals eine solche Beziehung vorhanden ist, darf man wohl nicht bezweifeln, indem der Bruch oder das zu starke Auszielnn niemals in allen Theilen des Stabes, sondern meist nur an einer einzigen Stelle eintritt, die zufïlliger Weise die schwächste ist, worin also gewisse Fehler vorkommen, die man iinfserlich nicht hemerkt hatte. Angenscheinlich sind solche Fehler in einem lïngern Stabe zallireicher, als in einem kürzern, es ist daher auch walırscheinlich, dafs einzelne derselben in jenem gröfser sind, als in diesem, und er daher früher zerrissen wird. In welchem Marss die Tragfähigkeit des Stabes bei grüfsrer Lünge desselben sich vermindert, liifst sich im Allgemeinen nicht entscheiden und liängt wohl vorzugsweise von der Sorgfalt seiner Fabrikation ab. Gewifs aber darf man in diesem Fall nicht eine solche Vergröfserung des wahrscheinlichen Fehlers, wie etwa beim Messen einer Linie durch wiederholte Kettenschligge, erwarten, wohei das Resultat gar zu ungïnstig ansfallen wïrde. Aus jenen 49 Beobachtungen, die an den 2 Zoll langen Cylindern angestellt wurden, würde bei dieser Anffassung der wahrscheinliche Fehler für einen $10 \mathrm{Furs}$ langen Stab von gleichem Querschnitt $1650 \cdot \sqrt{60}=12780$ Pfund betragen, und da der Mittelwerth, wobei die kurzen Stäbe zerrissen, 17640 Pfund gefunden war, so wäre es eben so walırscheinlich, dafs der 10 Fuls lange Stal, unter der Last von 4860 Pfund schon zerreifst, 
als dafs er dieselbe noch trägt. Dazu kommt aber noch, dafs in diesem Fall die Ausgleichung der positiven und negativen Fehler gar nicht stattfindet, indem jene oder die zufällige grölsre Stiirke an einzelnen Stellen nicht in Betracht kommt, und es sich nur um die schwächern Stellen handelt.

Hiernach wärden Messungen an Stäben von verschiedner Länge sehr wichtig sein, und wiewohl die von Navier mitgetheilten Beobachitungen sich nur auf die Längen von 3 bis 25 Zoll beschränken, auch wegen der sehr starken Abweichungen höchst unsicher sind, so habe ich sie dennoch berechnet, um zu sehn, ob sie eine Abhängigkeit der Festigkeit eines Stabes von seiner Länge vielleicht andeuten. Es mufs aber erwähnt werden, dafs das Gewicht des Stabes selbst, hier ganz unbeachtet bleiben darf, da es in Vergleich zu seiner 'Tragfähigkeit zu unbedeutend ist.

Das Gewicht, wobei der Stab zerreilst, in Kilogrammen ausgedrïckt und auf ein Quadrat-Millimeter reducirt, ist nachstehend mit $k$ und die Länge der Stäbe in Metern mit 7 bezeichnet.

A. Rundeisen.

\begin{tabular}{c|c}
$k$ & 7 \\
\hline 37,3 & 0,650 \\
55,7 & 0,650 \\
32,1 & 0,650 \\
38,0 & 0,325 \\
36,4 & 0,325 \\
41,4 & 0,162 \\
56,3 & 0,162 \\
37,8 & 0,162 \\
41,6 & 0,081 \\
55,0 & 0,081 \\
33,1 & 0,081
\end{tabular}

B. prismatisches.

\begin{tabular}{c|c}
7 & 7 \\
\hline 35,5 & 0,650 \\
36,7 & 0,650 \\
46,6 & 0,650 \\
47,1 & 0,650 \\
39,8 & 0,325 \\
38,3 & 0,325 \\
51,7 & 0,325 \\
32,7 & 0,162 \\
53,9 & 0,162 \\
35,5 & 0,081 \\
54,3 & 0,081
\end{tabular}

Indem ich die Gleichung

$$
k=r+b s
$$

zum Grunde legte, ergaben sich nach der Methode der kleinsten Qundrute, die Bedingungsgleichungen für $A$

$$
\begin{array}{ll}
464,6=11 \cdot r+3,329 . s \\
\text { und } & 1379=3,329 \cdot r+1,57716 . s
\end{array}
$$


Hieraus folgt

$$
k=43,673-4,748 . b
$$

Fs wird also in der That eine Verminderung der Festigkeit bei zunehmender Länge angedeutet, doch ist dieses Resultat durchaus unsicher, indem der wahrscheinliche Fehler von $s$ nahe das Doppelte des Werthes von $s$, nämlich 8,508 betriigt

Man hat ferner für die Reilıe $B$

$$
472,1=11 \cdot r+4,061 \cdot 8
$$

und

$$
\begin{gathered}
171,56=4,061 \cdot r+2,0725 \cdot s \\
k=44,674-4,755 \cdot s
\end{gathered}
$$

Beide Reihen geben sonach sehr nahe übereinstimmende Resultate, doch ist anch fiir die letzte der wahrscheinliche Fehler des Factors $s=-4,755$ nahe das Doppelte seines Werthes, nämlich 7,437. Es ist daher wahrscheinlich, dafs das dort, wie hier, angedeutete Gesetz nur von den zufälligen $\mathrm{Ab}$. weichungen der Messungen unter sich herrührt.

Indem nach Vorstehndem die Umstände, welche die Festigkeit des Eisens bedingen, so wenig bisher bekannt geworden sind, muls man zur Zeit wohl darauf verzichten, durch methodisches Verfahren diejenigen Dimensionen zu ermitteln, welche einem hestimmten Grade der Sicherheit entsprechen. Es bleibt dalıer nur übrig, in der hisher üblichen Weise, durch mehr oder weniger begründete Zusätze zu den aus Beobachtungen hergeleiteten Mittelwerthen der Festigkeit gegen Unfälle sich zu sichern. Was aber über das Eisen gesagt ist, gilt anch, vielleicht in noch hijherm Grale, für alle Baumaterialien.

Es darf nicht unerwähnt bleiben, dafs die Beseitigung der angedeuteten Mängel gewirs nicht leicht sein wird, aber man wiirde schon viel gewinnen, wenn aus den vielfach angestellten Beobachtungen nicht nur Mittelwertlıe hergeleitet, sondern auch die Abweichungen der einzelnen Messungen berücksichtigt und die wahrscheinlichen Fehler berechnet würden, wonach allein die Sicherlıeit der gefundnen Resultate beurtheilt werden kann. 
$\S 39$.

Es mag noch von der Anwendung der WahrscheinlichkeitsRechnung auf einige der gewöhnlichsten Fälle beim Feld messen die Rede sein.

Man habe in einem Dreieck, das man bei der märsigen Länge seiner Seiten als ein ebnes ansehn kann, die drei Winkel gemessen, aber in Folge der unvermeidlichen Beobachtungs-Fehler sei die Summe derselben nicht, wie sie sein sollte, 180 Grade, sondern um die Grölse $\mu$ geringer, woher die gemelsnen Winkel

$$
a+b+c=180^{\circ}-\mu
$$

Es sind also gewisse Verbesserungen dabei anzubringen, die mit $\alpha, \beta$ und $\gamma$ bezeichnet werden, und deren wahrscheinlichste Werthe man sucht, während man weifs, dafs

folglich

$$
\alpha+\beta+\gamma=\mu
$$

$$
\begin{gathered}
\gamma=\mu-\alpha-\beta \\
d \gamma=-d \alpha-d \beta
\end{gathered}
$$

Die wahrscheinlichste Annahme ist, dals die Summe der Quadrate der Fehler ein Minimum darstellt, woher

$$
2 \alpha d \alpha+2 \beta d \beta+2 \gamma d \gamma=0
$$

und wenn man den gemeinschaftlichen Factor 2 fortlälst und für $\gamma$ und $d \gamma$ die vorstehnden Werthe einfülırt, so ergiebt sich

$2 \alpha d \alpha+2 \beta d \beta+\alpha d \beta+\beta d \alpha-\mu d \alpha-\mu d \beta=0$

Indem $\beta$ und $\alpha$, und sonach auch die Differenziale derselben von einander unablı̈ngig sind, so mufs die Summe der Glieder, die $d \alpha$ als Factor enthalten, an sich gleich Null sein, und dasselbe gilt auch von denen, die $d \beta$ zum Factor haben. Die Gleichung zerfällt also in zwei andre, nämlich

und

$$
2 \alpha+\beta-\mu=0
$$

Hieraus ergiebt sich

$$
\alpha+2 \beta-\mu=0
$$

und

$$
\alpha=\frac{1}{8} \mu
$$

und daraus endlich auch

$$
\beta=\frac{1}{3} \mu
$$

$$
\gamma=\frac{1}{3} \mu
$$

If age n, Wahrscheinlichkeits-Rechnung. 3. Auf. 
Die wahrscheinlichsten Werthe der anzubringenden Verbesserungen erhält man sonach, wenn man die Differenz der Summe der gemelsnen Winkel gegen 180 Grade in drei gleiche Theile zerlegt und jedem Winkel einen solchen Theil zusetzt, oder von demselben abzieht. Dieses Verfahren ist jedoch nur in dem Fall das richtige, wenn man sich bewufst ist, alle drei Winkel mit gleicher Sorgfalt und unter gleich günstigen äufsern Umständen gemessen zu haben. Die Sicherheit der Messung eines Winkels ist im Allgemeinen von der Grörse desselben unablı̈̈ngig, die Verbültnisse sind also wesentlich verschieden von den Längenmessungen, bei denen der wahrscheinliche Fehler mit der Länge zunimmt. Es kann indessen leicht geschehn, dafs einer jener drei Winkel in Folge äufserer Umstände mit bedeutend gröfsrer oder geringerer Genauigkeit, als die andern bestimmt wurde. Dies wäre zum Beispiel der Fall, wenn man von einem Punkte aus sehr nahe gegen die Sonne visiren mufste, und deshalb das Fernrolır oder die Alhidade nicht so scharf einstellen konnte. Man mufs alsdann die Grölse des betreffenden wahrscheinlichen Fehlers vergleichungsweise gegen die der übrigen Messungen schätzen. Wenn also beispielsweise die Genauigkeit in der Bestimmung des Winkels $a$ nur halb so grofs, oder der wahrscheinliche Fehler doppelt so grols erscheint, wie bei $b$ und $c$, so darf man annehmen, dafs die Verbesserungen, welche die erforderliche Ergänzung der Summen zu 180 Grad darstellen sollen, in demselben Verlältnils stehn. Bezeichnet man die Verbefserung für $b$ und $c$ mit $m$, so hat man

$$
a+2 m+b+m+c+m=180^{\circ}
$$

oder

$$
2 m+m+m=4 m=\mu
$$

daraus ergiebt sich

$$
m=\frac{1}{4} \mu
$$

indem $\mu$ wieder die Abweichung der Summe der drei gemefsnen Winkel von 180 Graden ist. Der Winkel $a$ wäre also $u \frac{1}{2} \mu$, und die beiden andern um $\frac{1}{4} \mu$ zu ändern.

Bei Messung der Winkel in den sämmtlichen Eckpunkten eines Polygons treten dieselben Verhältnisse, wie beim Dreieck 
ein. Hat das Polygon $n$ Seiten, so beträgt die Summe der Winkel $(n-2) \cdot 180$ Grade. Ergiebt die Messung dafür einen um $\mu$ gröfsern oder geringern Werth, so wird unter der Voraussetzung einer gleichen Schärfe in allen Messungen die wahrscheinlichste Verbesserung eingeführt, wenn man jedem Winkel den $n$ ten Theil von $\mu$ zusetzt, oder ihn um diese Quantität vermindert.

Häufig kommt es vor, namentlich wenn die Lage des Stationspunktes gegen andre bekannte Punkte bestimmt werden soll, die rings um den Horizont zerstreut liegen, dals man die Winkel zwischen je zweien Punkten mirst. Kommt man dabei wieder an den ersten Punkt, so sollte die Summe der sämmtlichen Winkel 360 Grade betragen. Findet man dabei aber eine Differenz von der Grölse $\mu$, so ist dieselbe gleichmärsig auf alle Winkel zu vertheilen.

Benutzt man dagegen nur eine geringere Anzahl von Punkten, deren Richtungen nicht weit von einander abweichen, so wälılt man gewöhnlich zur Controlle das Verfahren, dafs man zuerst die Winkel zwischen je zwei zunächst liegenden Punkten, und sodann denjenigen zwischen dem ersten und letzten Punkt mifst. Dieser Winkel mülste der Summe der erstern gleich sein, wenn er aber um $\mu$ gröfser oder kleiner ist, so ergeben sich die wahrscheinlichsten Verbesserungen in derselben Art, wie bei den Dreiecks-Winkeln. Gesetzt, dafs es sich nur um 3 Punkte $A$, $B$ und $C$ handelt, und man habe zwischen $A$ und $B$ den Winkel $=a$, zwischen $B$ und $C$ den Winkel $=b, \quad$ zwischen $A$ und $C$ den Winkel $=c$ gefunden, so sollte

$$
c=a+b
$$

sein. Wegen der Beobachtungsfehler ist aber

$$
c=a+b+\mu
$$

Verbessert man nun die drei Winkel $a, b$ und $c$, indem man sie um $\alpha, \beta$ und $\gamma$ vergrölsert, so mufs, um die walırscheinlichsten Werthe darzustellen

$$
\begin{aligned}
& \alpha+\beta=\mu+\gamma \\
& \gamma=\alpha+\beta-\mu
\end{aligned}
$$

oder

$$
\alpha^{2}+\beta^{2}+\gamma^{2}
$$

muls ein Minimum, also das Differenzial dieser Summe gleich $10^{*}$ 
Null sein. Diese Bedingung führt eben so, wie früher zu den beiden Gleichungen

$$
2 \alpha+\beta-\mu=0
$$

und

$$
\alpha+2 \beta-\mu=0
$$

und hieraus findet man

$$
\begin{aligned}
& \alpha=\frac{1}{3} \mu \\
& \beta=\frac{1}{3} \mu \\
& \gamma=-\frac{1}{3} \mu
\end{aligned}
$$

Bei Längen-Messungen ist das Verhältnifs insofern wesentlich ein andres, als der wahrscheinliche Fehler bei längern und kürzern Linien nicht mehr derselbe bleibt, vielmehr bei den erstern gröfser ist, als bei den letztern. $\S 33$ wurde schon nachgewiesen, dafs dieser Fehler gleich $w V a$ ist, wenn $w$ der wahrscheinliche Fehler der Maafs-Einheit und $a$ die Länge der Linie bedeutet.

Beispielsweise sei die Entfernung zweier Punkte $A$ und $D$ sehr genau bekannt, indem sie vielleicht Winkelpunkte einer sorgfältig ausgeführten trigonometrischen Operation sind. Steckt man alsdann in der durch sie gegebnen geraden Linie zwei Zwischenpunkte $B$ und $C$ ab, und mirst mit der Kette die Entfernungen $A B, B C$ und $C D$, die mit $a, b$ und $c$ bezeichnet werden, so sollte die Summe derselben der bekannten Entfernung $A D$ gleich sein. Weicht diese indessen von jener um $\mu \mathrm{ab}$, und ist man überzeugt, dafs der Fehler vorzugsweise in der letzten Messung liegt, indem die frühere vergleichungsweise zu dieser als riclitig angesehn werden kann, so entstelıt die Frage, in welcher Weise man den bemerkten Felıler $\mu$ mit der gröfsten Wahrscheinlichkeit auf die drei kürzern Linien vetheilen soll.

Wenn ein richtiges Maafs benutzt wurde, so sind die Fehler von $a, b$ und $c$ eben so leicht positiv, wie negativ und heben sich daher zum Theil auf. Jenes $\mu$ ist aber nur die Differenz zwischen den positiven und negativen Felılern und gestattet kein Urtheil über die absolute Grörse derselben. Dagegen ist die wahrscheinlichste Voraussetzung, die man unter diesen Verhältnissen machen kann, die Einfülhrung der Bedingung, dafs die anzubringenden Correctionen $\alpha, \beta$ und $\gamma$ den wahrscheinlichen 
Fehlern der einzelnen Linien proportional sind. Man hat alsdann, wenn $w$ der wahrscheinliche Fehler in der Messung der Lüngen-Einheit ist, die wahrscheinlichen Fehler

$$
\begin{aligned}
& \text { von } a \text { gleich } w \sqrt{a} \\
& \text { von } b-w \sqrt{b} \\
& \text { von } c-w \sqrt{c}
\end{aligned}
$$

also

$$
\begin{aligned}
& \alpha=m w \vee a \\
& \beta=m w V b \\
& \gamma=m w \vee c
\end{aligned}
$$

wo $m$ einen unbekannten Factor bedeutet. Aufserdem ist

$$
a+\beta+\gamma=\mu=m v(\sqrt{ } a+\gamma b+\sqrt{ } c)
$$

folglich

$$
m w=\frac{\mu}{\sqrt{a}+v^{b}+V^{c}}
$$

und hicraus ergeben sich die anzubringenden Verbesserungen

$$
\begin{aligned}
& a=\frac{\mu \sqrt{ } a}{\sqrt{a}+\sqrt{b}+\sqrt{c}} \\
& \beta=\frac{\mu \sqrt{b}}{\sqrt{a}+\sqrt{b}+\sqrt{c}} \\
& \gamma=\frac{\mu \sqrt{c}}{\sqrt{a}+\sqrt{b}+\sqrt{c}}
\end{aligned}
$$

Die Zeichen von $\alpha, \beta$ und $\gamma$ sind aber jedesmal einander gleich und so zu wählen, dars dadurch die bemerkte Differenz $\mu$ aufgehoben wird.

Wesentlich verschieden ist das Resultat, wenn die bemerkte Differenz nicht sowohl auf der Verbindung zufälliger Fehler beruht die eben so gut positiv, wie negativ sein köunen, als vielmehr auf einem unrichtigen Maafs, das bei den partiellen Messungen benutzt wurde. In diesem Fall sind die einzuführenden Verbesserungen nicht mehr den Quadratwurzeln der Längen, sondern den Längen selbst proportional, also

$$
\alpha=\frac{\mu a}{a+b+c}
$$

u. S. w. 
$\S 40$.

Von grofser Wichtigkeit ist beim Feldmessen die Lösung der sogenannten $\mathbf{P}$ othe not's che n A f f a b e, wodurch nämlich die Lage eines Stationspunktes bestimmt wird, indem man von clemselben aus die Winkel zwischen andern bekannten Punkten mifst. Geschieht diese Messung mit der Boussole, so genügen schon zwei bekannte Punkte, die nicht mit dem Stationspunkt in derselben geraden Linie liegen. Sobald indessen sich Gelegenheit bietet, noch nach mehreren bekannten Punkten zu visiren, so wird dadurch nicht nur eine sichere Controlle möglich, sondern das Resultat lärst sich auch einigermaalsen berichtigen.

Wenn man nach $n$ P'unkten visirt, so erhält man eben so viele Richtungslinien, welche den unbekannten Stationspunkt schneiden würden, falls keine Fehler vorgekommen wären. 1)a Letztere nicht zu vermeiden sind, so bilden sich im Allgemeinen

$$
1+2+3+4+\ldots+(n-1)
$$

Durchschnittspunkte, die mehr oder weniger aus einander liegen, von denen aber auch einzelne zufällig zusammentreffen können. Geschieht Letzteres, so muls man einem solclıen Doppelpunkt den doppelten Werth der übrigen beilegen.

Die wahrscheinliclıste Lage des Stationspunkts stimmt keineswegs mit dem Schwerpunkt der sämmtlichen Durchschnittspunkte überein, selbst wenn man den letztern gleiche Gewichte beilegt. Dieses würde freilich der Fall sein, wenn alle Festpunkte, nach denen man visirt, gleich weit entfernt wären. I)ie Bedingung ist aher, dals die Summe der Quadrate der Verbesserungen der Winkel ein Minimum sein soll, und da gleiclie Aenderungen der Winkel bei entferntern Festpunkten auf dic Lage des Stationspunktes weit grölsern Einflufs haben, als bei nähern, so mufs man auch die Abstände der Festpunkte beriicksichtigen. Durch eine einfache Construction liifst sich die Aufgabe nicht lösen, wenn man daher keine eingehnde Rechnung anstellen will, so wird man sich mit einer ungefäluen Schätzung begnügen. Man mufs alsdann den Stationspunkt so wählen, dafs kein Winkel eine bedeutende Veränderung erfülırt, vielmehr jede Correction möglichst geringe bleibt, auch hat man vorzugsweise 
die zunächst liegenden Festpunkte zu berïcksichtigen. Diese Regeln sind an sich begründet, vorausgesetzt, dafs die Lage aller Festpunkte mit gleicher Sicherheit gegeben ist.

Sobald es sich um eine genauere Messung handelt, wird man weder die Winkel mit der Boussole messen, noch auch mit geometrischen Constructionen sich begnügen dürfen, vielmehr ist alsdann die Rechnung nicht zu umgehn. Die Methoden, wonach man aus den zwei Winkeln, die zwischen drei ihrer Lage nach bekannten Punkten gemessen sind, den noch unbekannten Stationspunkt bestimmt, dürfen hier nicht wiederholt werden. Es fragt sich nur, wie man die wahrscheinlichste Lage dieses Punktes findet, wenn von ihm aus die Winkel zwischen mehr als drei Festpunkten gemessen wurden. In diesem Fall ist es am bequemsten, zunächst $\mathrm{N}$ äh erungswerthe einzuführen, und alsdann die walırscheinlichsten Correctionen derselben zu ermitteln. Man erreicht dabei den nicht unwesentlichen Vortheil, dafs man die höhern Potenzen dieser Correctionen vernachlässigen kann.

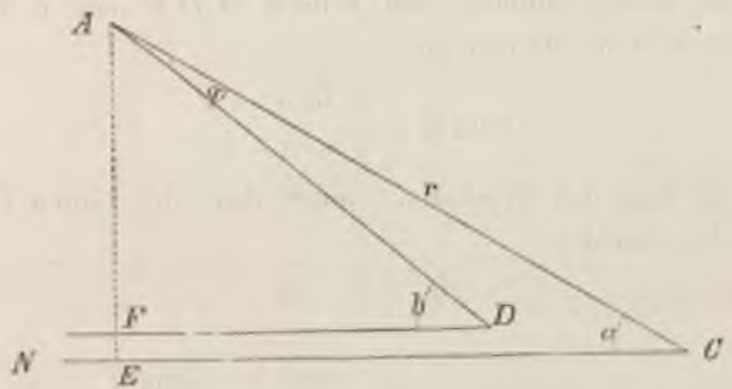

Die Lage der verschiednen Festpunkte ist durch Coordinaten gegeben, die sich auf den Meridian beziehn. Nach beistehnder Figur sei $A$ einer dieser Festpunkte, dessen Coordinaten $x$ und $y$ sind. Als Stationspunkt sei vorläufig $C$ angenommen, dessen Coordinaten $X$ und $Y$. Der gemefsne Azimuthal-Winkel gegen $A$ sei gleich $\beta$, während die Rechnung denselben für den Punkt $C$ gleich $a$ ergiebt. Der Meridian, parallel zur Linie $N C$, liege unterhalb der Figur und der Anfangspunkt der Abscissen auf der rechten Seite derselben.

$$
\begin{aligned}
& A E=y-Y=r \sin a \\
& E C=x-X=r \cos a
\end{aligned}
$$


folglich

$$
\text { tang } a=\frac{y-Y}{x-X}
$$

und

$$
r=\frac{y-Y}{\sin a}=\frac{x-X}{\cos a}
$$

Der aus der Tangente berechnete Winkel $a$ wird von dem gemefsnen Winkel $\beta$ etwas abweichen, und es kommt darauf an, die angenommenen Coordinaten $X$ und $Y$ durch Einführung der Verbesserungen $x^{\prime}$ und $y^{\prime}$ so zu ändern, dafs der Stationspunkt von $C$ nach einem solchen Punkte $D$ rïckt, bei dem der Winkel $\zeta$ die Eigenschaft besitzt, dafs mit Rücksicht auf alle benutzten Festpunkte die Summe der Quadrate $\beta-b$ ein Minimum wird. Aufserdem ist aber auch die Richtung des Meridians für den Stationspunkt noch unsicher, daher ist auch für $\beta$ eine unbekannte Aenderung einzufiihren, die gleich $\psi$ sei. Der wirkliche AzimuthalWinkel ist demnach $\beta+\psi$.

Man drücke nunmehr den Winkel $A D F$ oder $b$ durch die eingeführten Correctionen aus

$$
\tan b=\frac{r \sin a-y^{\prime}}{r \cos a-x^{\prime}}
$$

ferner hat man den Winkel $\varphi$, unter $\operatorname{dem} \operatorname{die}$ Linieu $C A$ und $D A$ sich schneiden

folglich

$$
\varphi=b-a
$$

$$
\operatorname{tang} \varphi=\frac{\operatorname{tang} b-\operatorname{tang} a}{1+\operatorname{tang} b \cdot \operatorname{tang} a}
$$

und nach Einführung des vorstehnden Werthes von tang $b$

$$
\operatorname{tang} \varphi=\frac{x^{\prime} \sin a-y^{\prime} \cos a}{r-x^{\prime} \cos a-y^{\prime} \sin a}
$$

Indem man voraussetzen darf, dafs die Näherungswerthe $X$ und $Y$ nahe die richtigen sind, so sind die Correctionen $x^{\prime}$ und y vergleichungsweise gegen die Linie $r$ versehwindend klein, und man hat dalıer, wenn auch der sehr kleine Winkel of mit seiner Tangente verwechselt wird,

$$
\varphi=\frac{\sin a}{r} x^{\prime}-\frac{\cos a}{r} y^{\prime}
$$


Durch diese Verbesserung wird der berechnete Winkel

$$
b=a+\frac{\sin a}{r} x^{\prime}-\frac{\cos a}{r} y^{\prime}
$$

Der beobachtete Winkel ist aber

$$
\beta+\psi
$$

und da beide einander gleich sind, so hat man

$$
\beta-a=-\psi+\frac{\sin a}{r} x^{\prime}-\frac{\cos a}{r} y^{\prime} \ldots \ldots A
$$

Dieser Ausdruck hat die Form, welche die Anwendung der Methode der kleinsten Quadrate fordert, indem die drei Unbekannten $\psi, x^{\prime}$ und $y^{\prime}$ als Factoren in drei Gliedern auftreten. Ob man aber hiernach unmittelbar die Rechnung vornehmen darf, oder zunächst eine Aenderung einfülıren mufs, hängt von der Art der Winkelmessung ab. Es tritt nämlich ein wesentlicher Unterschied in der Vertheilung der Fehler ein, jenachdem man entweder mit einem Spiegel-Sextant oder einem Repetitions-Kreise die Winkel zwischen je zwei zunächst liegenden Festpunkten mirst, oder ob man an einem Kreise, ohne dic Stellung desselben zu verändern, nach und nach gegen alle Festpunkte visirt und die betreffenden Winkel abliest. Wäre das Erste der Fall, so dürfte man den vorstehnden Ausdruck nicht benutzen, weil der eine Schenkel jedes in die Rechnung einzuführenden Winkels in der Richtung des Meridians liegt, und sonach die Winkel nach den weiter rechts belegnen Festpunkten sich aus den Summen der dazwischen gemefsnen Winkel zusammsetzen. Dabei würden die in den ersten Winkelmessungen vorgekommnen Fehler zu allen folgenden hinzutreten, während der Fehler des letzten Winkels nur einmal in die Rechnung eingeführt wird. Diese $\Lambda$ rt der Messung bedarf daher noch einer Umformung des vorstehnden Ausdrucks.

Zwischen zwei Punkten sei der Winkel $\beta$ gemessen, wälırend die berechneten Azimuthe $a$ und $a^{\prime}$, und die Entfernungen der beiden Festpunkte von dem vorläufig angenommenen Stationspunkte $r$ und $r$ sind. Alsdann ist nach den vorstehnden Entwicklungen der durch Rechnung gefundne Winkel zwischen beiden Punkten gleich

$$
\left(a^{\prime}-a\right)+\left(\frac{\sin a^{\prime}}{r^{\prime}}-\frac{\sin a}{r}\right) x^{\prime}-\left(\frac{\cos a^{\prime}}{r^{\prime}}-\frac{\cos a}{r}\right) y^{\prime} \ldots B
$$


wobei die Correction $\psi$ fortfällt. Der gegen die Messung übrig bleibende Feller ist daher

$$
\beta-\left(a^{t}-a\right)=\left(\frac{\sin a^{t}}{r^{t}}-\frac{\sin a}{r}\right) x^{t}-\left(\frac{\cos a^{t}}{r^{t}}-\frac{\cos a}{r}\right) y^{t}
$$

Hieraus kann man die beiden Unbekannten $x^{\prime}$ und $y^{\prime}$ nach der Methode der kleinsten Quadrate berechnen, indem man sowohl $\beta-\left(a^{\prime}-a\right)$, wie auch die Coefficienten von $x^{\prime}$ und $y^{\prime}$ kennt.

Als Beispiel mag eine Messung mitgetheilt werden, die ich Behufs der richtigen Orientirung einer neuen Hafenkarte einst bei Pillau ausführte. Bessel theilte mir die von ihm festgestellten Coordinaten verschiedner Punkte in der weitern Umgebung von Königsberg mit. Von dem ohnfern der Spitze der FrischenNehrung ausgewählten, etwas erhöhten Stationspunkte aus konnte ich unter diesen benutzen die Thürme von Brandenburg, Heiligenbeil und Braunsberg, so wie auch das Schlors Balga und den Pillauer Leuchtthurm. Letztern wählte ich zum Anfangspunkt der Coordinaten, und es ergaben sich in Bezug auf denselben die Coordinaten der andern Festpunkte, wie folgt:

$$
\begin{aligned}
& \text { Brandenburg } x=-766,55 \quad y=+6087,52 \\
& \text { Balga } \quad=-2548,56 \quad=+1305,80 \\
& \text { Heiligenbeil }=-5286,47=+793,44 \\
& \text { Braunsberg = - 7618,77 }=-1188,43
\end{aligned}
$$

Dabei zühlen die $x$ von Norden nach Süden, und die $y$ von Westen nach Osten. Die Maalseinheit ist die Rheinländische

\begin{tabular}{|c|c|c|c|}
\hline Leuchtthurm & . & . & \\
\hline Brandenburg & . & . & \\
\hline Balga . & . & . & \\
\hline Heiligenbeil & . & . & \\
\hline Braunsberg & & . & . \\
\hline
\end{tabular}
Ruthe.

Ein Katerscher Kreis wurde in dem Stationspunkt aufgestellt, dessen Coordinaten gefunden werden sollten. An dem willkürlich aufigestellten Instrument mals ich die nachstelınden Winkel

Zur Berechnung der Näherungs-Werthe wurden dic nächsten Punkte benutzt, nämlich der Leuchtthurm, Balga und Brandenburg. Aus diesen ergab sich für den Stationspunkt

$$
\begin{aligned}
& X=-192,826 \text { Ruthen } \\
& Y=-125,030
\end{aligned}
$$


Unter den beiden oben erwähnten Berechnungs-Arten mufste die Formel $A$ gewählt werden, weil nicht die Winkel zwischen je zwei nächsten Festpunkten, sondern die Richtung jedes einzelnen gemessen wurde. Die Richtung des durch den Leuchtthurm gelegten Meridians, die aber auch noch der Verbesserung $\psi$ bedarf, ergiebt sich unmittelbar aus den vorstehnden Werthen von $X$ und $Y$, bei jener Aufstellung des Instruments. Nach der vorläufigen Rechnung fiel nämlich der Meridian in den Winkel

$$
213^{0} 57^{\prime} 55^{\prime \prime}, 5
$$

Hiernach sind die fünf beo b a ch teten Azimuthal-Winkel in der obigen Reilıenfolge der Festpunkte

$$
\begin{aligned}
& \beta=32^{\circ} 57^{\prime} 34^{\prime \prime}, 5 \\
& =95^{\circ} 16^{4} 34^{\prime \prime}, 5 \\
& =148^{\circ} 43^{\prime} 34^{\prime \prime}, 5 \\
& =169^{\circ} 46^{\prime} 4^{\prime \prime}, 5 \\
& =188^{\circ} \quad 8^{\prime} 19^{\prime \prime}, 5
\end{aligned}
$$

Die berechneten A z imuthal-Winkel stimmten natürlich für die drei ersten Punkte mit den vorstehnden genau überein, für Heiligenbeil und Braunsberg waren sie dagegen

$$
169^{\circ} 46^{4} 42^{\prime \prime}, 4
$$

und

$$
188^{\circ} \quad 8^{\prime} 57^{\prime \prime}, 8
$$

Die Differenzen $\beta-a$ sind demnach

$$
\begin{aligned}
0,0 & =0,0 \\
0,0 & =0,0 \\
0,0 & =0,0 \\
-37^{\prime \prime}, 9 & =-0,0001838 \\
-38^{\prime \prime}, 3 & =-0,0001856
\end{aligned}
$$

indem die Winkel durch die Länge der Bögen ausgedrückt werden. Da die Berechnung der Winkel $a$ bereits zur Bestimmung der Entfernungen führte, so sind nunmehr alle bekannten Grölsen in der Gleichung $A$ gegeben und vergleichungsweise zu der früher gewählten Formel

hat man

$$
\begin{aligned}
& k=a \cdot r+b \cdot s+c t \\
& k=\beta-a \text { und } r=\psi \\
& a=-1 \quad s=x^{\prime}
\end{aligned}
$$




$$
\begin{array}{ll}
b=\frac{\sin a}{r} & \quad 156- \\
c=-\frac{\cos a}{r} &
\end{array}
$$

Durch Einführung der für die fünf Festpunkte gefundnen Zahlenwerthe ergeben sich die Summen der Producte, welche in den drei Bedingungs-Gleichungen als Factoren auftreten, nämlich

$$
\begin{aligned}
& {[k a]=+0,0003694200} \\
& {[k b]=+0,0000000027910} \\
& {[k c]=+0,000000059439} \\
& {[a a]=+5} \\
& {[b b]=+0,000005666781} \\
& {[c c]=+0,000013479883} \\
& {[a b]=+0,0027306750} \\
& {[a c]=-0,0030040900} \\
& {[b c]=-0,000008758424}
\end{aligned}
$$

Man findet hieraus die drei Unbekannten

$$
\begin{aligned}
& \psi=-0,00020318=41,9 \text { Secunden } \\
& x^{\prime}=+0,60529 \\
& y^{\prime}=+0,33567
\end{aligned}
$$

die Richtung der Nordlinie ist also um 41,9 Secunden melır westlich zu legen, oder sie fällt bei jener Aufstellung des Instruments auf

$$
213^{0} 57^{\prime} 13^{\prime \prime}, 6
$$

Die Coordinaten des Stationspunktes sind

$$
\begin{aligned}
& X=-192,221 \\
& Y=-124,694
\end{aligned}
$$

Berechnet man hiernaclı aufs Neue die Azimuthal-Winkel, so weichen dieselben in den fünf Beobachtungen von den gemefsnen um nachstehnde Winkel ab

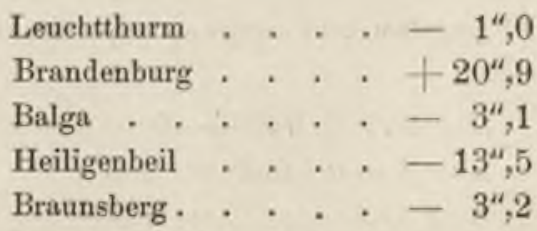


Die Summe der Quadrate dieser Fehler betrügt 639,91 und man findet daraus den wahrscheinlichen Beobachtungs-Fehler

$$
\begin{aligned}
w & =12,065 \text { Secunden } \\
& =0,0000585
\end{aligned}
$$

und die wahrscheinlichen Fehler in den berechneten Constanten

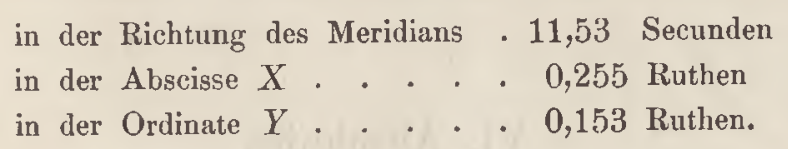




\section{Abschnitt.}

\section{Anwendung der Wahrseheinliehkeits-Rechnung anf das Nivelliren.}

\section{$\S 41$.}

Wenn auch die Anwendung der mitgetheilten Gesetze der Wahrscheinlichkeits-Rechnung auf das Nivelliren überaus einfach ist und dabei keine schwierigen Aufgaben vorkommen, deren Lösung eine besondre Untersuchung fordert, so dürfte es sich doclı empfehlen, in einem speciellen Fall das Verfahren zur Prüfung und Berichtigung, so wie zum angemefsnen Gebrauch der Instrumente eingehend $\mathrm{zu}$ beschreiben und auf verschiedne Umstände aufmerksam zu machen. Hierzu kommt noch, dafs nicht selten von den Nivellements, namentlich wenn sie Behufs hydrotechnischer Anlagen und unter schwierigen Verhältnissen ausgefühn't werden, eine grofse Schärfe gefordert wird, und dabei leicht Fehler und Täuschungen eintreten, welche bei der noch vielfach üblichen Art der Controlle sich gar nicht zu erkennen geben.

In dieser Beziehung erwähne ich, dafs einst für den Unterricht in Wasserbau bei einer Ingenieur-Schule die Aufgabe gestellt war, einen in der Nähe befindlichen Wasserlauf aufuustauen. Zu diesem Zweck wurde ein kleines Nivellement ausgeführt, wobei Maafsstäbe mit beweglichen Tableaux benutzt werden mufsten. Nachdem von der ersten Station vor- und zurückvisirt war, machte ich meine Schüler darauf aufmerksam, dafs es angemessen sei, das Instrument nunmehr etwas zu heben oder zu senken, und zu prüfen, ob auf beiden Seiten gleiche Differenzen sich herausstellten. Trotz alles Winkens und Zurufens war es aber unmöglich, das eine Tableau in die passende Visirlinie zu bringen, 
und als ich den dabei angestellten Mann, der mir als besonders geübt in dieser Handliabung empfohlen war, befragte, ob er die Zurufe nicht verstanden habe, belehrte er mich, dafs bei der zweiten Einstellung die Tafel immer genau an dieselbe Stelle geschoben werden müsse, wo sie früher gestanden hätte, sonst sei die Messung falsch. Seine anerkannte Geschicklichkeit bestand also darin, die Controlle ganz illusorisch zu machen.

Ein solches Verfahren erklärt den wunderbaren Grad von Genauigkeit, die manche Feldmesser zu erreichen glauben. Ich habe Nivellements gesehn, in denen nach den beigefügten Controllen der wahrscheinliche Fehler in jeder Station, auf den Winkel reducirt, nur $1 / 4$ bis $1 / 3$ Secunde betrug. Wenn man aber bei den fest aufgestellten und viel vollkommnern astronomischen Instrumenten nicht leicht eine ganze Secunde verbürgen kann, so beruht diese Uebereinstimmung der Controlle mit der Messung augenscheinlich nur auf Täuschung.

Bei keiner Messung oder Beobachtung darf man sich auf die Zuverlässigkeit der Gehülfen unbedingt verlassen, man mufs vielmehr dafür sorgen, dafs man sie stets sicher controlliren kann, und am vortheilhaftesten ist es, die Anordnungen so zu treffen, dals man die wichtigeren Operationen, also die Einstellungen und Ablesungen, selbst ausführt. Im vorliegenden Fall läfst sich dieses sehr leicht erreichen. Man braucht nur das Tableau zu beseitigen, und die Visirlatte so breit zu machen, dafs sich eine deutliche Theilung darauf anbringen lärst, die man durch das Fernrohr des Instruments unmittelbar ablesen kann.

Dabei wird noch ein andrer sehr wesentlicher Vortheil erreicht. Der Stab soll nämlich senkrecht gehalten werden, wenn man ihn, wie gewölınlich geschieht, auf den Kopf eines vorher eingetriebnen Pfählchens aufstellt. Der Gehülfe bemerkt sehr bald, dafs der Feldmesser, der am Instrument steht, nur ein Urtheil darüber hat, ob der Stab nach der rechten oder der linken Seite geneigt ist, dafs er aber nicht wahrnehmen kann, ob dieses auch in der ihm zugekehrten Richtung geschieht. Eine Zurechtweisung erfolgt also nur, wenn der Stab aus der durch das Instrument gelegten Vertical-Ebene sich auffallend entfernt. Um sich keinen 'Tadel zuzuziehn, stellt sich der Gehülfe hinter den Stab, und weder der Feldmesser, noch der Gehülfe bemerkt es, 
wenn in dieser Ebene der Stab nach vorn oder nach hinten sehr bedeutend von der lothrechten Stellung abweicht.

Endlich mufs der Stab mit dem Tableau auch jedesmal umgedreht werden, sobald man zur nächsten Station ïbergeht. Wenn die Köpfe jener Pfählchen nicht horizontale Ebenen bilden, so kann leicht der Stab, während er umgedreht wird, um einige Linien seine Höhe verändern. Wenn aber der Boden weich ist, also die Pfählehen nicht fest stehn, wie dieses in sumpfigen Wiesen häufig der Fall ist, so bleibt es zweifelhaft, ob nicht der Pfahl beim zweiten Aufstellen des Stabes tiefer eindringt, und sonach die Messung ein Ansteigen des Terrains ergiebt, das in der Wirklichkeit nicht statt findet.

Alle diese Uebelstände lassen sich vollständig vermeiden, wenn die breite Latte auf beiden Seiten übereinstimmend eingetheilt und mit einer eisernen Spitze versehn ist, mit der sie jedesmal fest in den Boden eingestolsen wird. Man bedient sich dabei noch eines Lothes und prüft nach diesem den verticalen Stand in zwei verschiednen Richtungen. Ob die Einstellung der Latte in dieser Beziehung mit hinreichender Genauigkeit erfolgt ist, untersucht der Feldmesser selbst, bevor er dagegen visirt, und wenn dieses geschehn ist, so darf Niemand die Latte berühren, oder sich derselben auch nur nähern, bis vom folgenden Stationspunkte aus die Messung nach diesem Punkt vollständig beendigt ist. Die Ablesung des Maafses an diesen Latten erfolgt aber durch das Fernrohr an der Libelle.

In dieser Weise liabe ich nahe vor funfzig Jalıren sehr ausgedelınte Nivellements ausgeführt. Bei dem General-Nivellement, welches ganz Frankreich umfalst, sind die beweglichen Tableaux nicht mehr zur Anwendung gekommen und dafür die deutlich eingetheilten Visirlatten (mires parlantes) eingeführt, deren wesentliche Vorzüge in der Beschreibung dieses Unternehmens*) erwähnt sind. Bei uns legt man in neuerer Zeit grölsres Gewicht auf die sogenannten trigonometrischen Nivellements, von denen schliefslich die Rede sein wird, und bei welchen die Latten mit oder olne Tableaux ganz umgangen werden.

*) Nivellement général de la France. Notes diverses, par Bourdalouë. Bourges 1864. 
Nach diesen vorläntigen Bemerkungen mögen die beim Nivelliren vorkommenden Fehler näher untersucht, und zwar zunächst die verschiednen Ursachen derselben mit beilïufiger Bestimmung ihres Einflusses ermittelt werden. Später wird die Sicherlıeit, also die Gröfse der wahrscheinlichen Fehler erörtert werden.

\section{$\S 42$.}

Der wesentlichste Theil jedes Nivellir-Instruments bestelıt in der Vorrichtung zur Bildung der horizontalen Abselıenslin i e. Hierzu dient in der Regel eine Flüssigkeit. Diese befindet sich bei den weniger genauen Instrumenten in einer lıorizontalen Röhre, deren beide Schenkel aufwürts gerichtet sind. Bestehn diese aus Glas, so stellen die beiden Oberflächen in ihnen schon die horizontale Ebene dar, und man braucht nur neben denselben zu visiren, $1 \mathrm{~m}$ die horizontale Richtung zu erkennen. Zuweilen lärst man auch in beiden Schenkeln Diopteru schwimmen, dic zwar ein schärfres Visiren gestatten, wobei abcr leicht andre Fehler eintreten. Die erste Vorrichtung ist die gewölnuliche Canalwage, die zweite die Mercurialw a a $\mathrm{ge}$, in der man um das tiefe Eintauchen der Dioptern zu verhindern, die Rölıre mit Quecksilber füllt. I3ei genanern Instrumenten ist dic Flüssigkeit in einer vollstündig geschlofsnen horizontalen Glasrïhre enthalten, die jedoch nicht gan\% gefiillt ist. Lis befindet sich vielnelır darin eine Luftblase, die schon bei schwacher Aendrung der Neigung eine andre Stelle eimninmt, und laher sichrer die Richtung des damit verbundnen Fernrohrs erkennen liifst. I)ieses Instrument, welches mittelst eincr Schrabe horizontal gestellt wird, ist die I, ibelle in it Fernlolir.

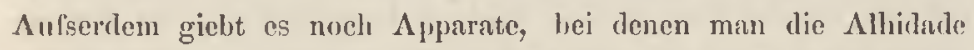
oder das Fernohr frei anflüingt und in der $\Lambda \mathrm{rt}$ nit Gewichten verhindet, dafs die $\Lambda$ bsehenslinie sich horizontal richtet. Diese Vorrichtungen werden heutiges 'Tages wohl nur zu anniliernden Schiitzungen benutzt.

Vitruv beschreibt ein Nivellir-Instrument, das er Chorolates nennt*.) Es bestand ans einem $20 \mathrm{Fufs}$ langen Lineal mit vor-

*) Vitruvii de architcctura. Liber VIII. Cap. VI.

II agen, Wahrseheinlichkeits-Rechume. 3. Aufl. 
tretenden Stifte an beiden Enden, welche dic Visirlinie bezeichneten. Es hingen daran Gewichte, deren Füdlen eine darunter befestigte und mit Marken versehene Latte berïhrten, und liierdurch wurde die horizontale Stellung des Instruments gepriift. Beim Winde pendelten indessen diese Gewichte, und alsdann gois man Wasser in eine an dem Lineal befindliclse Rinne von 5 Fuls Lïnge, 1 Zoll Breite und 1/1/2 Zoll Höhe und berichtigte hiernach die Aufstellung. I)ass man aluer damals schon die Kunst des Nivellirens verstand, ergiebt sich theils aus den antiken Wasserleitungen und vorzugsweise wohl aus dem Stollenbau, der unter Kaiser Claudius zum Ablassen des Fucino-Sees ausgeführt wurde. Dieses Nivellement, durch welches man allein die Ueberzeugung gewinnen konnte, dafs bis zu der gewählten Stelle im Ufer des Liri-Flusses linreichendes Gefälle vorhanden sei, dehnte sich über mehr als drei Viertel Deutsche Meilen aus und mulste über einen zwischenliegenden Bergrücken von nahe $680 \quad$ Fuls Höhe über dem Spiegel dieses Sees fortgefuilırt werden*.)

Sehr zweckmäßsig ist die Anwendung von Fliissigkeiten, um lıorizontale Abselıeuslinien entweder unmittelbar oder mittelbar darzustellen. Man macht dabei freilich die Voraussetzung, dafs die Flüssigkeiten horizontale Oberflächen bilden, also nicht etwa durch Reibung oder andre Umstände verhindert werden, der Kraft der Schwere vollständig zu folgen. Ob dieses in aller Schärfe der Fall ist, lälst sich nicht naclıweisen, und man bemerkt in der That von den dicksten Massen, wie etwa Pech. das bei gewöhnlicher Temperatur langsam eine horizontale Oberfläche annimmt, bis zu Alkohol und Acther eine solche Abstufung in der Beweglichkeit, dafs man die Reibung oder Zäligkeit, die in dem erstern sich augenscheinlich zu erkennen giebt, in gewissem Grade auch bei den letztern voraussetzen dürfte. Jedenfalls sind die Erfolge dieser Hindernisse in den besten Niveaus aber so geringfïgig, dal's sie vergleichungsweise zu den äbrigen unvermeidlichen Fehlern nicht in Betracht kommen.

Unter diesen Fehlem mögen diejenigen, die im Instrument selbst und den zugehörigen Apparaten ihren Grund haben, z11nächst untersucht werden. Das Nivellir-Instrument ist $\mathrm{n} n \mathrm{~g}$ e $\mathrm{n}$ a $\mathrm{u}$,

*) Zeitschrift für Bnuwesen. 1879. Seite 565 . 
insofern die Richtung der Absehenslinie ron manchen Zufälligkeiten abhängt, und bei mehrmaliger Wiederholung der Beobachtung sich verändert. Unrichtig ist es, wenn jene Linie um einen gewissen constanten Winkel sich von der Horizontalen entfernt, und undeutlich, wenn es das hinreichend scharfe Visiren nicht gestattet. Bei den Visirstangen und Tableaus, die der Feldmesser gewöhnlich selbst eintheilt und bezeichnet, lärst sich die erforderliche Richtigkeit und Deutlichkeit leicht erreichen, es bleiben daher hier nur die Fehler der Ungenauigkeit äbrig, und diese entspringen entweder aus der schrägen Aufstellung der Stäbe oder aus der zufälligen oder absichtlichen Verstellung der Tableaus, oder dem Ablesen des Maalses, oder endlich aus dem Eindräcken der Pfählche, auf welchen die Visirstäbe meist aufgestellt werden.

\section{$\S 43$.}

Bei der gewöhnlichen Canalwage kann man als Vernnlassung zu ungenauen Messungen, nächst einer möglichen nicht hinreichend festen Aufstellung oder Sicherung gegen den Wind, wodurch Schwankungen verursacht werden, nur die Anziehung erwähnen, welche die Röhren auf die Oberfliiche des Wassers ausüben. Durch letztere bildet sich der breite dunkle Streif, der in Folge der Brechung der Lichtstrahlen die äufsere Fläche des Glas-Cylinders zu berïhren scheint. Seine Breite vermindert sichı nicht in möglichst dïnnen Glasröhren, weil die Oberfläche des Wassers keineswegs von der ganzen Glasmasse, sondern allein von der innern Oberfäche derselben angezogen und gehoben wird.

Beim Gebrauch der Canalwaagen visirt man bekanntlich längs dieser Streifen in beiden Glasröhren und bestimmt dadurch die horizontale Richtung. Bei gewissen Beleuchtungen sind indessen die Grenzen dieser Streifen nicht deutlich zu erkennen, und die Kunst des geübten Beobachters besteht darin, jedesmal gleiche Stellen an beiden Glasröhren zu treffen. Dieses ist um so schwieriger, als das Auge zugleich nach dem entfernten Tahleau selın mufs, wodurch eine Spannung hervorgel,racht wird, 
die bald crmïdet. Man gewöhnt sich indessen leicht daran, vorzugsweise nur die entferntere Glasröhre und das 'Iableı zı beachten, indem man die IJage des Auges gegen die nächste Röhre nicht verändert, und ein beilïufiger Blick auf dieselbe schon genügt, um sich zu überzengen, dafs das Auge sich in der passenden Höhe wirklich befindet. Auch dadurch, dafs man etwas zurïcktritt, wird das Visiren merklich exleichtert. Mit Verwunderung habe ich mich zuweilen davon ïberzeugt, welche bedeutende Sicherheit bei grofser Vorsicht und Uebung im Gebrauch dieses an sich hüchst mangelhaften Instruments dennoch erreicht werden kann. Nichts desto weniger sind die Ränder, an denell man vorbeiselın muls, keineswegs scharf markirt und dic Breite derselben beträgt etwa $1 \frac{1}{6}$ Jinien. Peginge man den Felıler, dal's man an einer Glasröhre die obere Grenze und an der andern die untere getroffen lätte, so würde dieses bei der Entfermung der Röluren von 4 Fuls eine Abweichung der Visirlinie gegen die Iorizontale von 7 Miuuten, oder auf 5 Ruthen $\Lambda$ bstand von $1 \frac{1}{2}$ Zoll veranlassen. Um soviel wird awar kein vorsichtiger Beobachter irren, wenn aber der Fehler auf 10 Ruthen Läuge lie Grenze von 2,5 Jinien nicht ïbersteigen soll, so ist dieses im $\Lambda$ llgemeinen wohl die Grenze der erreichlnaren Sichiirfe der Messung.

Das Vorhandensein von Lufthlasen in der horizontalen $V$ erbindungsrölıre veranlafst an sich keineswegs einen ungleichen Stand des Wassers in den beiden aufwärts gerichteten Schenkeln.

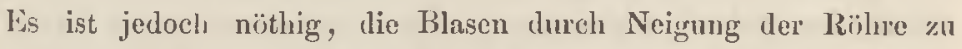
entfernen, hevor man die Messung heginnt, weil dieselben leicht wïhrend der letztern austreten, und darbreh nicht nur Schwankungen veranlal'st, sondern auch beide Oberflichen etwas gesenkt wïrden.

Man hat an der Canalwarge anweilen die Aenderung eingeführt, dafs man nicht unmittelbar an den Glas-Cylindern visirt, somlern zwei Dioptern daran befestigt. Hierdurch verliert. indessen das Instrument diejenige Eigensehaft, durelı die es sich vorzugsweise empfiehlt, nämlich seine Einfachlheit, die Einstellung erfordert alsdann ancl mehr Zeit und der Vortheil ist unbedentend, clem in dem Richten der Dioptern nacl, dem Wasserstand bleibt beinahe dieselbe Unsicherheit, wie im unmittelbaren Visiren, 
und man kann die Dioptern nicht heben oder senken, ohne Bewegungen zu veranlassen, dic wieder neue Umstellungen ertordern.

Was von der Beweglichkeit der Flïssigkeiten gesagt ist, lindet auch auf die Mercurialwa a ge Anwendung, In derselben mufs sich aber nicht nur das Quecksilber in beiden Schenkeln lorizontal stellen, sondern es mufs auch zugleich die darauf sclıwimmenden Elfenbein-Würfel mit den Dioptern bewegen, die sich an die Wrandungen anlelınen, und an denselben olne /weifel einige Reibung erfahren. Ich versuchte bei einem sorgfriltig ausgefiilurten Instrument dieser Art den einen Wiirfel wiederholentlich herabzudricken und nach eingetretener Rulse nach dem 'Tableau zu visiren. Dabei iiberzeugte ich mich, dafs die Genauigkeit der Mercurialwatge bedeutend geringer, als dic der Canalwatge ist.

In der Libelle äufsert sich die Anzichung des Glases unf' die darin eingeschlofsne Flïssigkeit auf äluliche Weise, wie in der (analwage. Auch hier bemerkt man den erwälnten breiten Streif, doch ist derselbe, insofern das Auge in der Eutfernung des rlentlichen Selms, und zwar in gleichem Abstende von beiden Enden der $L_{d}$ uft $\mathrm{l}$ a se, darïber gelaulten wird, in seiner Begrenzung genau zı erkennen. Aulserden wird durch die Anzichnng des Glases die Hlase an beiden Enden abgerundet und erselıeint dalıer un so schïiter begrenzt.

Ist die Grasrölure an einer Seite weiter, als an der andern, so wird offenbar, selbst wenn die innere Flïclıe der obern Gilaswinnt horizontal liegt, die Anzichung an der weitern Seite geringer sein, also die Blase sicl, nacl der entgegengesetzten bewergen. l)ieser Umstand ist jodoch unter iibrigens gleichen Verhältnissen nicht nachtheiligr, denn es kommt nur darauf an, die Iultblase an diejenige Stelle zu bringen, welche der horizontalen Absehenshinic des Fernrohrs entspricht. Der nachtleilige Winflufs einer Rähre von ungleicher Weite tritt erst bei TemperaturVerïnderungen ein, indem alsdann wegen der Ausdelunung oder $V$ erminderung des Volums der tropfbaren Fliissiglicit die Blase? kiirzer oder länger wird, und die beiderseitigen Begrenzungen derselben sich nicht in grleicher Weise verindern.

Die Libelle ist mit dem Fernrohr fest verlunden und diese 
Verbindung wird mittelst Nitellschrauben in der Art berichtigt, dal's die Luftblase gegen die beiderseitigen 'Theilstriche auf der Glasröhre sich gleich weit erstreckt, sobald die A b schenslinie des Fernrohrs horizontal gerichtet ist. Indem nu dieselbe Bedingung auch bei eintretenden 'Temperatur-Veränderungen noch erfüllt werden soll, so mufs die Röhre gleiche Weite haben. Aufserdem ist es aber auch notlıwendig, dafs schon bei geringen Abweichungen des Fernrohrs die Luftblase ihre Stelle merklich verüindert. Hieraus ergiebt sich, dals die Röhre in Innern und zwar an der obern Wand in ihrer Längeneinrichtung nach einem Kreisbogen ausgeschliffen scin mufs, oder' dafs dieser 'Theil der Fläche einen der Länge nacl kreisförmig gekrümmten Cylinder-Mantel darstellt. Der Mittelpunkt der Krïmmung liegt senkrecht unter der Libelle. Entgegengesetzten Falls würde bei der geringsten Abweichung die Luftblase sich sogleich an das Ende der Röhre bewegen, und cine Einstellung derselben wiirde viel schwieriger sein. Der gewählte Krümmungs-Halbmesser bedingt die Empfindlichkeit der Libelle, weil die veränderte Stellung der Blase oder der Ausschlag augenscheinlich dem Product aus der Neigung (im Bogen gemessen) in den Radius gleich ist. Es kommt daher darauf an, diesen Radius passend zu wählen, damit die Emptindlichkeit der Libelle der Schärfe des Fernroh's und dem Zweck des Nivellements entspricht. Ist der Radius zu grofs angenommen, so wird das jedesmalige Einstellen erschwert, auch darf nicht unbemerkt bleiben, dals geringe Unregelmälsigkeiten in der Schleifung bei einem grofsen Radius nachtheiliger hervortreten, als wenn die Krümmung schwächer wïre.

Um die nöthige Genauigkeit mit diesem Instrument zu erreichen, muls das Fern ro hr in einem der Schärfe der Messung entsprechenden Verhältnifs das Bild vergröfsern, besonders aber dieses möglichst deutlich und klar zeigen. Die darin eingespannten $\mathrm{F}$ ä de $n$ müssen feine gerade Linien bilden, sich rechtwinklig durchschneiden und bei der richtigen Lage der Libelle horizontal und vertical gerichtet sein. Ferner mufs die Schraube, womit man das Fernrohr mit der Libelle einstellt, mit feinen Gängen versehn und leicht beweglich sein, olıne 
jedocl, todte Gänge zu haben. Wie fiein indessen diese sichraube atuch geschmitten sein mag, so wird es bei cincen Niveau vou der nötlıigen Empfindlichkeit doch nicht leicht gelingen, kleine Alweichungen im Stande der Luftblase unmittelbar zu beseitigen, vielnehr inufs man sie dadurch aufzuheben suchen, dafs man die Schruube weiter dreht, als nöthig ist, und sie gleich darauf wieder etwas zuriickdrelit. Die Bewegung, dic man darstellen soll, ist zu geringe, als dal's sie sich der Schraube geben liefse, wohl aber läfst sie sich durch dic Dilferenz zweier gröfsern entgegengesetzten Bewegungen einfiiluren. Man erlangt leicht dic nöthige Uelungr, um in dieser Weise nach wenigen Versuchen dic Luftblase zum scharfen Einspielen zu bringen, wälırend dieselbe, wenn man sie unmittelbar einstellen wollte, abwechselnd naclı der einen und der andern Seite ausschlagen wïrde.

\section{$\S 44$.}

Die aus der Unrichtigkeit des Instruments entspringenden Felıler haben ihre Ursache in der Zusammensetzung desselben und hängen nicht mehr von zufälligen Umständen ab. Wenn man daher die Beobachtungen unter gleichen äuðsern Verlältnissen wiederholt, so treten diese Fehler in gleichem Sinne stets wieder suf, man kann aber durch gewisse Vergleiche oder sonstige Prüfungen ihre Gröfse ermitteln, und sie sonach aus dem Resultat entfernen. Ein Fehler dieser Art ist beispielsweise in einern Winkel-Mefsinstrument der Collimations-Felıler, der jedesmal dem abgelesenen Winkel zugesetzt, oder von demselben in Abzug gestellt werden murs.

Die Hülfsmittel, welche dem Künstler bei Anfertigung der Instrumente zu Gebote stehn, werden in der Regel von denjenigen an Schärfe übertroffen, die man später zur Prïfung der Richtigkeit anwenden kann, auch treten meist gewisse Veränderungen mit der Zeit ein, so dafs eine solche Prüfung und Feststellung der Fehler vor dem Gebrauch jedes Instruments nothwendig ist. Für den aufmerksamen Beobachter ist daher im Allgemeinen jedes Instrument mit gewissen Fehlern behaftet. Dieselben lassen sich in manchen Fällen nie vollständig beseitigen, 
wenn gleich Vorrichtungen zu diesem Zweck angebracht sind. weil diese nicht mit derselben Schärfe, welche die späterc Controlle hat, in Wirksamkeit gesetzt werden können. Dazu kommt aber noch, dafs man sein Instrument nicht oft veründern mag. So wird zum Beispiel kein Astronom seine Uhr sogleicl stellen, wenn die Beobachtungen zeigen, dafs sie ein wenig vorgelıt. Die bei unverändertem Instrument eintretenden $\mathrm{Ab}$ wcichungen gestatten ïber ihre jedesmalige Grölse auch ein sichreres Urtheil, und geben daher Gelegenheit, das Resultat vollstiindiger zu berichtigen, als wenn man das Instrument selbst jedesmal berichtigen wollte. Von den Fehlem diescr Art mufs stets Rechnung getragen werden, wenn man nicht, wie oft möglich ist, die Messungen so einrichtet, dafs diese Fehler den Einfluls anf das Resultat verlieren.

Die Can a l wa a ge giebt die Höhen-Unterschiede unrichtig an, wenn der eine der beiden Glas-Cylinder weiter ist, als dler andre, und zwar geschieht dieses in zweifacher Weise. Zunächst soll die Absehenslinie beim Vorwärts - und Riickwärts-Visiren unverändert bleiben. Dieses ist aber nicht der Fall, wenn bei lem Rückwärts - Einstellen die beiden ungleichen Cylinder nicht eben so weit gefüllt bleiben, wie sie früher waren, was doch beinalıe nie geschielit, weil auf die verticale Stellung der I)rehungs-Aclise meist wenig Aufmerksankeit verwendet wird. I Iiereuf kommt es auch in andrer Bezichung nicht an. Wenn aber der weitere Cylinder bei der Drehung etwas gesenkt oder gehoben wird, so stellt sich das gremeinschaftliche Niveau anch etwas tiefer oder höher, als es friiher war, weil die Wassermenge, die in ihn eine gewisse llibhe derstellt, kleiner ist, als dicjenige, die in den andern Cylinder dieselbe Sonkung veranlafst. Der hieraus entspringende Fehler phlegt indessen nicht von Bedeutung zu sein, indem gemeinlin nur eine geringe Drehung erforderlich ist.

Der Mangel an Uebereinstimmung in der lichten Weite der beiden Glasröhren veranlafst aufserlem aber auch einen geringen Unterschied in der Höhenlage des Wasserstandes in denselben. Die sogenante Capillar-Attraction äulsert sich freilich in weitern Röhren nur in selr' geringem Maalse, aber dennoch ist nicht anzunehmen, dafs sie in ilınen ganz verschwindet. In 
cler engern erhebt sich das Wasser etwas höher, als in der weitern, man visirt also nicht lıorizontal, vielmehr in einer Richtung ansteigend und in der andern abfallend. Wenn aber auf jeder Station die Canalwarge in gleicher Richtung aufgestellt wird, so lıeben diese geringen Fehler sich nicht auf, sondern summiren sich. Ls ist daher nöthig, darauf zu achten, dals beide Rülıren inöglichst gleiche lichte Weite haben.

Hei der Mercurialwa ge ist die Visirlinie durch die auf dem Quecksilber schwimmenden Dioptern gegeben und augenscheinlich nimmt sio eine falsche Richtung an, wenn eine Diopter etwas tiefer sich stellt, als die andre. Dieses gesehicht, wenn schon ursprünglich lierbei eine Unrichtigkeit statt fund, orler wenn später durch Vermehrung oder Verminelerung des Gewichts eine solche cintritt. Eiue Vorrichtung zum Berichtigen ler Dioptern fehlt aber, da man jede nicht dringend gebotene Melurbelastung der Elfenbein-Wiirfel vermeiden mufs, weil diese sonst, wïluem sie auf dem Quecksilber schwimmen, die horizontale Stollung verlieren wïrden. Jei diesem Instrument ist es daluer dringend gelioten, jedesmal dieselbe I)iopter dem Auge zuzukehren, also heim Rïckwärts -Visiren das granze Instrument unzudlelı. $\Lambda$ lsdann treten in beiden Richtungen dieselben Feliler ein und helen sich sonach grofsentheils gengenseitig auf:

Die Libelle in Fernrolir pflegt immer mit den nöthigeu Vorrichtungen zur Berichtigung verselın zu sein, wodurch die constanten Fehler, wenn auch nicht ginz aufigehohen, doch wenigrstens sehr vermindert werden kömnen. Dils V erlabren bei dieser Herichtigung, welches man gewöhnlich empfielit, und füir welehes die Instrumente auch eingerishtet zu sein fflegen, ist indessen keineswegs bequem ind sicher.

Auf das Fermohr, welches mit der Libelle fest verbunden ist, sind meist zwei stiirkere Ringe anfgelïthet, deren ïulsere Flïchen cylindrisch abgedreht sind, und welche gleiche l)urchmesser haben. Diese Cylinder rulı in zwei gleichen, gabelförmigen Lagern. In clas Fernrolır sind feine Fäden eingespannt, welche die Visirlinie bezeichnen. Gewöhnlich sinel zwei dergleichen vorhanden, von denen der eine vertical und der andre horizontal gerichtet ist. Diese Fïden sind an einen IRing 
befestigt, den man mittelst vier kleiner Schuraben in Fernrohr etwas verstellen kann.

Das Verfalıren bei der Prïfung und Bericlitigung bezicht siclı zunächst auf die Richtung der Visirlinie gegen die Aclsse des Ferniohrs, oder vielmelır gegen die gemeinschaftliche Achse jener beilen Cylinder, auf denen das Fernrohr ruht, und sodann auf' die Stellung des Niveaus zu dieser Achse.

Ob die Visirlinic des Fernoln's, also die Absehenslinie, welche durch den $\mathrm{Kr}$ eupunkt der beiden Fï den gegeben ist, mit der Achse der beiden Cylinder îbereinstimmt, ergiebt sich aus der Drehung des Fernrohrs um seine Achse, während es auf beiden Lagern ruht. Man richtet das Fermrohr so, dafs jener Kreuzpunkt einen recht scharf markirten Gegenstand trilft, und sieht nun zu, ob während der 1)rehung dieser Gegrenstand fortwährend von dem Kreuzpunkt geschnitten wird, oder ob letzterer einen kleinen Kreis beschrcibt. Im ersten Fall befinden sich die Fäden an der richtigen Stelle, im zweiten dagegen niclıt, und man muls alsdann den erwälınten Ring, in welchen sie eingespannt sind, so verstellen, dars jene Bedingung crfïllt wird. Diese Berichtigung ist aber sehr schwierig. Beim Irehn des Fernrohrs bemerkt man zwar, in welcher Richtung die Verstellung erfolgèn muls, um welche Winkel aber die einzelnen Schrauben zu drehn sind, ist unbekannt, daher wird bei dem ersten Versuch keineswegs der beabsichtigte Zweck erreicht, vielmehr ergiebt sich beim Wiedereinlegen und Drehn des Fernrohrs, dafs man entweder die Fäden noch nicht genïgend verstellt, oder sie bereits über die beabsichtigte Stelle hinans verschoben hat. Fs sind also vielfache Versuche nothwendig, bis endlich die Verbesserung nahe genug erreicht ist.

Jeder dieser Versuche ist zeitraubend und erfordert einige Handfertigkeit. Es genügt nämlich keineswegs, eine Sclnaube anzuziehn, sondern man mufs auch die gegentiberstehende zuvor etwas gelöst haben, und selbst die beiden andern, senkrecht gegen diese gekehrten Schrauben dürfen nicht so fest angezogen sein, dafs sie die Verstellung des Ringes in der ersten Richtung verhindern. Hat man endlich das $K_{l}$ euz in solche Lage gebracht, dafs es beim Drclın des Rolurs stets denselben Punkt deckt, so 
ınïsen noch die sïmmtlichen vier Schrauben fest gestellt werden, um jede spittere zubillige Verrickung des Ringes zu verhindern. Hiorbei treten aber schr leicht wieder auffallende Aenterungen cin, dio auf's Neue aufgehoben werden müssen. Diese ganze Operation wird noch wesentlich daturch erselıwert, dafs der erwähnte Ringr in der ()cular-Röhre sich befindet, und die Schrauben durch die äufsere Röhlıe, die mit der des Objectivs verbunden ist, ïberdeckt werden. Man mufs also jedesmal rlie Ocular-Rölıre wenigstens etwas ausschieben, und bei manchen Instrumenten sogar vollstäudig abschrauben, bevor man zu den Köpf'en der erwähnten vier kleinen Stellschrauben gelangt.

I)ie vorstehend beschriebne Berichtigung bietet liernach so viele Schwierigkeiten, dals sie dem Feldmesser wohl nicht leicht gelingen dürfte, wenn er nicht Geschicklichkeit und Uebung in mechanischen Arbeiten besitat. Gemeinhin pflegt er sich auch nicht hiermit zu befassen, sondern ïberliilst die richtige Einstellung des Fadenkreuzes dem Mechaniker, sobald er bemerkt, dafs der 1) urchschnitt der Fäden auffallend von der DrehungsAchse abweicht.

Dabei kommt indessen noch ein andrer Umstand in Betracht. Die Fïden verdecken nämlich einen Theil des Gesichtsfeldes, und namentlich thut dieses der Durchschnittspunkt beider Fäden, wolıer man denselben nicht leicht zum Visiren benutzt. Damit die Fäden aber nicht reifsen oder schlaff werden, wählt man in den Nivellir-Instrumenten dazu häufig feine Metalldrähte, die unter der Vergrörsrung des Oculars eine bedeutende Dicke haben, also vielleicht ganze /olle verdecken. Gewöhnlich sind auf den Tableaus vier Quadrate dargestellt, nämlich zwei schwarze und zwei weifse, deren Seiten horizontal und vertical gerichtet sind. Sie werden so eingestellt, dafs zwei Quadrate iiber, und zwei unter dem Faden sich befinden; wenn jedoch der dicke Faden die Durchschnittslinie verdeckt, so hat man gar kein Urtheil iiber die richtige Einstellung und es bleibt nur übrig, wie auch gewöhnlich geschieht, das Tableau soweit heben oder senken zu lassen, bis der untere Rand des obern weilsen Quadrats unter, oder del obere Rand des untern so eben über dem Faden sichtbar wird. In dieser Art läfst sich mit grölsrer Schärfe die Einstellung machen, aber alsdann weicht die Richtung der Visir- 
linic von der durch das Fadenkreuz gezognen ab und die beschriehene Berichtigung wird illusorisch.

Jieser Uebelstand läfst sich wesentlich vermindern, wenn man feine Spinnfäden benutzt, die jedoch wonig dauerhaft sind und daher nur angewendet werden dürfen, wenn der Feldmesser selbst im Stande ist, neue einzuzielın. Ein andres Auskunftsmittel, das bei astronomischen Instrumenten oft angewendet wirr, besteht darin, dafs man zwei Parrallel-Fäden sehr nahe neben einander einspannt, und dic Visirlinie durclı die Mitte des kleinen Intervalles bestimmt wird. Durch passende Bezcichnung der 'Tableaus lassen sich indessen auch stärkre Färlen zur schartien Beurtheilung der Hölıenlage benutzen. Ins quadratische Tahleau wird nämlich in derselben Art, wic die im Folgenden beschriobne kleine Marke durch zwei Diagonalen in vier Dreiecke eingetheilt. Jie mit den Spitzen nach oben und nach unten gekehrten färbt Inan schwarz, bie beiden Seiten-Dreiecke dagegen weifs. Alsdann läst sich selı genau auf den letzten beiden erkennen, ob der dunkle Horizontal-Faden, wonu er auch dic Spitzen der I) reiccke rollstiindig iiberdeckt, nnit seiner Mittellinie in diese Spitzen fiillt. 1)er Faden zerschneidet nümlich die Seiten-1)reiecke in zwei obero: und \%wei untere, und diese wie jene mïssen mit ihren innem leken sich gleich weit cinunder nälıen, wenn das 'Tableau gegen den Faden die riclıtige Iöhe hat.

Noch schwieriger ist die Berichtigung der I i be 11 e. Dic dabei zu stellende Bedingung ist zwar selır cinfach, nä̈ulich die darin befindliche Isuftblase soll unverindert dieselbe Stelle wieler eimnohmen, wenn man das Fermolir aushebt und es verkelirt einlegt, so dal's die erwïlnten cylindrisclien linge an Femrobre gegen die gabelförnigen Lager, auf denen sie rulın, verwechselt werden. Das Fernrohr mit der Libelle wircl zu diesen Zweck zunächst durch die an der einen Gabel befindliche Stellschraube soweit geloben oder gesenkt, his die Luftblase die prussende Stelle in der Röhre einnimmt, alsdann legt man das Fernrohr um, so dals die darauf befestigten Ringe auf' den entgegengesetzicn Gabeln aufliegen. Aus der Richtung, in velcher die Blase nammehr ihre Stelle verändert, ergiebt sich leicht, in welelıer Art die Verbindung $z$ wischen der Libelle und dem Fernrolur einer Verbesserung bedarf. Diese Verbesserung darf indessen nur 
die Hälfte des Ausschlags der Blase autheben, während die andre Hiilfte durch die veränderte Stellung der Gabel beseitigt wirl. Lis bedarf wieder vielfacher Versuche, bevor man hiermit annähernd zu Stande kommt, bei empfindlichen Libellen gelingt es aber niemals vollstïndig. Ls kommt niimlich daranf an, dals währenıl des Umlegens die Lager genau ilıren frühern Stand bchalten, also gar keine Bewegung oder Erschütterung im Instrument eintritt, die bei der nothwendigen leichten Beschaffenheit des Stativs schwer zu vermeiden ist. Wie vorsichtig man dabei auch zu Werke gehn mag, so wird jedesmal eine geringe Aenderung eintreten, die bei einer emptindlichen Libelle sich schon zu erkennen giebt. Das Gewiclit der letztern mit dem des Fernrolırs ist vergleichungsweise zu dem des übrigen Theils des Instruments schon zu bedeutend, als dafs dieses sich nicht verstellen sollte, wenn jene Theile abgehoben und wieder anfgelegt werden. Man kann sich hiervon leicht ïberzeugen, wenn mau unit möglichster Vorsicht das Fernrohır wiederholentlich abliebt, und es ummittelbar darauf in derselben Richtung wieder einlegt. Lis ist mir nie gegliickt, alstann die frïhere Stellung der Lufthase zu erhalten, sie zog sich jedesmal, wemn anch nur wenig, so duch schom merklich, nach der einen oder der andern Seite. Wollte man dabei aber noch die Ueberwürfe, oder die gewïlnnlich vorhandnen halben Ringe, welche die kreisförmige Umsehliefsung rollstïndig darstellen, dariiber legen und festschianben, so würde der Ausschlag iibermïisig grols ausfallen.

Ine Methode der Berichtigung, deren ich mich bedient halse, lialst sich mit gröfsrer Sehärfe und weniger Mïhe ausfïituren. Sie berult darutu, dal's man in derjenigen lintfermung, in welcher man nach Maalsgahe der Veryriofserung und Ientlichkeit des Fernrohlı's gewölnnlich zu visiren pflegt, einen P’unkt bezeichnet, der mit der Ocnlar-Oeflinung des nahe richtig eingestellten Fernrolı's in gleicher Ilöhe sielı hefindet. Am lequemsten geschielit dieses, wenn man das Instrument ï ber d e m $R$ a n d e einer. Waserfläche aufstellt, so dafs das Ocular sich schon Iothrecht dariiber befindet. In der erwiilnten lintfernung und «war gleichlalls hereits in das Wasser wird ein Stah senkredht, cingestellt. Nach letzterm richtet man das Fernrolir und stellt es nach der Libelle, wenn diesclhe auch noch nicht vollstïndig 
berichtigt ist, lorizontal. Nunmehr nimmt man einen dünnen und unten zugespitzten Stab, hält denselben unmittelbar an die Ocular-Oeffnung, indem man das Fernrohr möglichst wenig berïhrt, und senkt den Stab soweit, bis er die Oberfläche des Was-

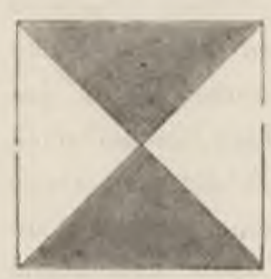
sers trifft. Dieses läfst sich genau erkennen, denn sobald die Beriihrung erfolgt, so hebt sich die Oberfläche neben cler Spitze und die Spiegelung verändert sich sehr auffallend. Die Stelle am Stabe, welche in die Höhe der Mitte der Ocular-Oeffnung trifft, bezeichnet man durch einen Strich mit Blei, und befestigt mittelst Nadeln an den im Wasser stehenden Stab eine etwa 3 Zoll hohe Marke von Papier, die in der nebenstehnden Art bezeichnet ist. Die Mitte dieser Marke, in der die Spitzen der vier Dreiecke zusammenfallen, muls dabei auf den vorher gezognen Strich am Stabe treffen. Dieser Mittelpunkt befindet sich also in der Höhe des Oculars, und wenn man das Fernrohr nach ihm richtet, so hat es die horizontale Stellung eingenommen, und man darf nur die Libelle mittelst der Schrauben so ändern, dafs sie nunmehr auch genau einspielt. Sollte das Fernrohr bei dieser Operation sich etwas verstellen, so kann man es immer leicht gegen die feste Marke wieder einriclıten.

Bei dem Einstellen des Fernrohrs nach der Marke ändert sich freilich seine Richtung gegen den Horizont und sonach hebt oder senkt sich anch die Ocularöfnung, so dafs sie nicht mehr mit jener Marke in gleicher Höhe bleibt. Diese Aenderung ist indessen, wenn es sich nur um kleine Berichtigungen handelt, wie solche während der Arbeit vorkommen, so unbedeutend, dafs sie nur wenige Hunderttheile eines Zolles zu betragen pflegt, also ohne Einflufs ist. Sollte aber zufälig die Libelle eine sehr abweichende Lage angenommen haben, so mufs man nach der ersten Berichtigung und Einstellung die Höle des Oculars nochmals auf die Marke übertragen und nunmelır die Berichtigung vervollständigen. Die Einstellung des Fernrolrrs lïfst sich mit grolser Schärfe ausführen, indem man an dem erwähnten Vortreten der Spitzen der Seitendreiecke äber und unter dem horizontalen Faden mit Sicherheit wahrnehmen kann, ob die Mittellinie des Fadens die gemeinschaftliche Spitze der heiden schwarzen Dreiecke trifft. 
Auch alle übrigen Theile der Operation haben solche Schürfe, dafs in der Berichtigung ein Fehler von 0,1 Zoll für die gewählte Entfernung nicht vorkommen kann. Bedingung ist es dabei aber, dafs stehndes Wasser und zwar im Zustande voller Ruhe vorlıanden ist. Schon bei mälsigem $\mathrm{W}$ inde gelingt diese Operation nicht mehr, und man mufs vollends darauf verzichten, wenn kein kleiner See oder Teich in der Nähe ist. Alsdann wählt man das folgende Verfahren, welches etwas zeitraubender, aber eben so sicher ist.

Man stellt die beiden eingetheilten Visirlatten, von denen später die Rede sein wird, lothrecht und wieder in derienigen Entfernung von einander auf, in der man beim Nivelliren zu visiren pflegt. Hierauf bringt man das Instrument seitwärts neben die eine der beiden Latten, so dafs die Ocular-Oeffnung ein wenig vor die eingetheilte Fläche vortritt, die der anclern Latte zugekehrt ist. Durch Anlaalten eines kleinen Lineals kann man alsdann die Höhe des Mittelpunkts der Ocular-Oeffinung an der Latte ablesen, nachdem das Ferurohr gegen die zweite Latte gerichtet und die Libelle zum Einspielen eingebracht ist. Die Höhe des Oculars an

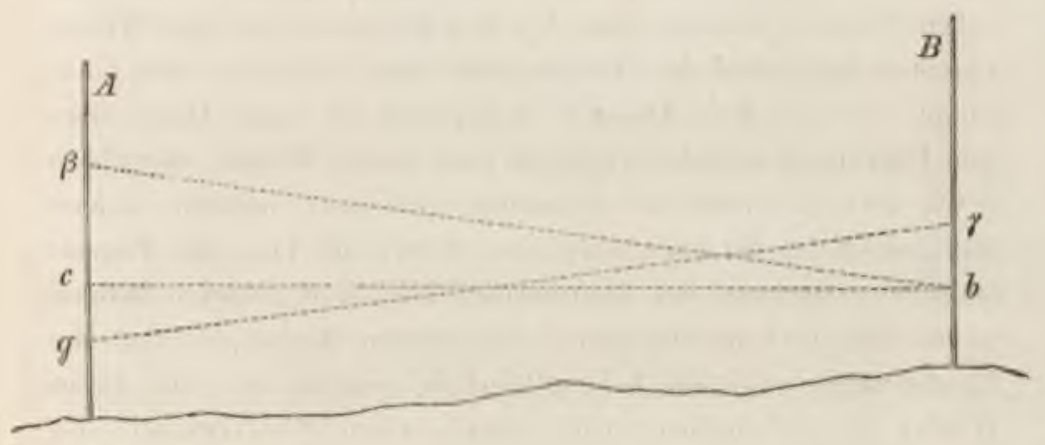

der Latte $A$ sei bei $g$ und man lese durch das so gestellte Fernrolır an der Latte $B$ die Höhe $\gamma$ ab. $\Lambda$ lsdann stellt man das Instrument in gleicher Weise an die Latte $B$ und visirt, naclidem die Libelle gerichtet ist, zurück nach $A$. Hier lese man die Höhe $\beta \mathrm{ab}$, während an der Latte $B$ die Ocular-Oeffnung sich in der Höhe $b$ befindet. Indem nun bei der unveränderten Lage der Libelle gegen das Fernrohr die Linie $g \gamma$ unter demselben 
Wiukel gegen den Horizont geneigt ist, wie $b \beta$, so bilklen sich zwei gleichschenklige Dreiecke, und der l'unkt $\frac{1}{2}(g-+\beta)$ an der Latte $A$ liegt in gleicher Höhe mit $\frac{1}{2}(\gamma+b)$ an der Latte $B$. Wenn man von diesen beiden Höhen $\frac{1}{2}(\gamma--b)$ abzielıt, so bestimmt sich der Punkt $c$ an der Latte $A$, der mit $b$ oder dem Ocular des Instruments bei seiner letzten Aufstellung in gleicher I Hïhe liegt. Das Maals für den Punkt $c$ ist nämliclı

$$
\frac{1}{2}(g+\beta-b-\gamma)
$$

dieses Maals bezeichnet man auf $A$ durclı jene Papiermarke. Aul letztere wird das Fernrolir ron 7 aus gerichtet und dic Libelle soweit verstellt. dals sie bei dieser Richtung des Fernroln's einspielt.

\section{$\$ 45$.}

Was die Krïmmung der Erde und die Strahlenbrechung betrifft, so liilst sich der Einflufs derselben auniihernd nachweisen. Mirst man die Elevation eines entfernten Gegenstandes, z. B. eines hohen Thurms, mittelst eines Vertical-Kíeises, so ist ler Winkel zwischen der Spitze des Thurms und dem Iforizont nicht derjenige, der mit dem Abstande multiplieirt die ganze Hiihe iiber dem Instrument angielut, vielmehr mufs dieser Winkel, der gleich I sci, noch in zweifucher Ijeziehung verbessert werden. Zuerst

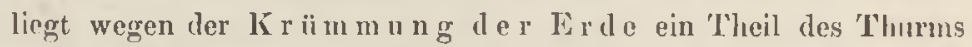
unter dem Horizont des Instruments. Der dazu gehörige Winkel ist ein Chordo-'Tangentenwinkel des grrifsten Kreises, der anf rler Eroberftiche zwischen beiden Punkten gezogen ist, mul dieser Winkel ist bekanntlich gleich dem lıalben ('entriwinkel also) $\frac{1}{2} \varphi$. Wer gemefsue Vierations-Winkel 7 mufs daher um $\frac{1}{2} \varphi$ vergröfsert werden.

Sodann ist die Stralılenbrechung zoll bericksichtigen. Indem der Ijichtstrahl von dem höhern beobachteten l’unkt mach dem tiefer stelınden Instrument aus den diunnern Juftschichten in die dichtern äbergeht, so wirl er gebrochen und krïmmt sich nälırungsweise nuch einem Kicislongen, dessen Radius das Sechsfache 
des Erdradius mifst. Die concave Seite des Strahls liegt wieder abwärts, und es tritt sonach derselbe Fall ein, als wenn man auf einer Kugel, deren Radius das Sechsfache des Erdradius ist, zwischen denselben Punkten die Messung ausgeführt hätte. Der betreffende Centriwinkel ist also gleich $\frac{1}{6} \varphi$, oder der Cliordo-Tangentenwinkel $\frac{1}{12} \varphi$. Dieser Winkel mufs aber von dem ersten abgezogen werlen, weil er wegen der Krümmung des Strahls die Elevation vergröisert.

Der walıre Höhsenwinkel, der mit der Entfernung multiplicirt die richtige Erhebung darstellt, ist also

$$
h+\frac{5}{12} \varphi
$$

Bezeichnet $H$ die Erhebung des gemefsnen Punkts ïber der KugelOberfläche der Erde, $D$ den Abstand des in dieser Fläche stehnden Instruments von jenem Punkt und $r$ den Erdrndius, so ist

$$
H=D\left(h+\frac{5}{12} \varphi\right)
$$

aber

$$
\varphi=\frac{D}{r}
$$

also

$$
H=D\left(h+\frac{5}{12} \cdot \frac{D}{r}\right)
$$

Indem man beim gewöhnlichen Nivelliren keine ElevationsWinkel mifst, vielmehr lıorizontal visirt, so ist $h=0$, und man hat

$$
H=\frac{5}{12} \cdot \frac{D^{2}}{r}
$$

Der Erdradius $r$ mifst im mittleren Breitengrade 1690500 Rheinländische Ruthen, wenn daher alle Gröfsen in diesem Maals ausgedrückt werden, so folgt

$$
H=0,00000024648 \cdot D^{ \pm}
$$

oder wenn $H$ in Zollen, $D$ dagegen in Ruthen gemessen wird,

$$
H=0,0000355 \cdot D^{2}
$$

Hiernach kann man die Correction $H$ wegen Krümmung der Erde 
und Strahlenbrechung leicht berechnen, wenn die Entfernung $D$ ) beknnnt ist. Man findet darnach

$$
\text { fiir. } \begin{aligned}
D & =10 \text { Rutlien } & I I & =0,003 \mathrm{Zoll} \\
& =20- & & =0,014- \\
& =30- & & =0,032- \\
& =40- & & =0,057- \\
& =50- & & =0,089- \\
& =60- & & =0,128- \\
& =70- & & =0,174- \\
& =80- & & =0,227- \\
& =90- & & =0,287- \\
& =100- & & =0,355 .
\end{aligned}
$$

Es ergiebt sich hieraus, dais man bei geringen Entfernungen keine Correction wegen Krümmung der Erde und Strahlenbrechung anzubringen braucht, dieses vielmehr nur bei besonders genauen Nivellements in dem Fall erforderlich wird, wenn man gezwungen ist, das Instrument viel näher an die eine, als an die andre Latte zu stellen. Die erwähnte Correction ist zwar nicht ganz sicher, insoferı die Strahlenbrechung nicht constant ist, sondern nach Maafsgabe der Witterung gröfsre oder kleinere Werthe annimmt, doch dürfte beim gewölmlichen Nivelliren, wo die Entfernungen immer sehr mälsig bleiben, in dieser Beziehung kein merklicher Fehler zu besorgen sein.

Nichts desto weniger mul's man die Aufstellung der Iatten in sehr verschiednen Abständen doch möglichst vermeiden, weil dabei auch die Fehler wegen unvollstïndiger Berichtigung der Libelle in Betracht kommen. Zuweilen sieht man sich dazu gezwungen, namentlich, wenn man eine steile Anlı̈̈lse ersteigt, oder von derselben herabgeht, weil die Latte höher ist, als das Doppelte der Hölie des Instruments, und man um gar zu kurze Stationen zu vermeiden das Instrument von der tiefer stehnden Latte so weit entfernt, dals ihr oberes Ende noch von der Visirlinie getroffen wird. Auch wenn die Richtung des NivellementsZuges nahe mit derjenigen der Sonnenstrahlen und namentlich' bei niedrigem Stande der Sonne nahe zusammenfällt, wird die Mars-Eintheilung auf der Latte beim Visiren gegen die Sonne selır undeutlich, und man ist daher gezwungen, in dieser Richtung nur kurze Entfernungen zu wählen, während dieselben 
auf der andern Seite die passendste Länge behalten. Wiederholt sich diese Ungleichmäfsigkeit mehrfach und zwar immer in gleichem Sinn, so dïrfen die Correctionen nicht unterlassen werden.

Ist das Instrument so berichtigt, dafs die Visirlinie genau horizontal liegt, so milst man an jeder Latte die Höhe zu grols, und die Differenz beider abgelesnen Höhen ist daher um die Differenz beider Correctionen zu verbessern. Wenn dagegen die Berichtigung nach der vorstehend beschriebnen Methode stattgefunden hat, so findet für die dabei gewählte Entfernung keine Correction statt, wohl aber für eine geringere Entfernung eine positive, und für eine gröfsre eine negative. Das Instrument sei auf den Abstand von 40 Ruthen berichtigt, so wird bei einem Abstande der Latte von nur 20 Ruthen die abgelesne Höhe um 0,057 $0,014=0,043$ Zoll vergrörsert werden müssen, und wenn die andre Latte 60 Ruthen entfernt ist, so mufs die Höhe an dieser um $0,128-0,057=0,071$ Zoll vermindert werden. Die Correction in Bezug der beiden Latten ist also gleich der Summe beider partiellen Correctionen oder 0,114 Zoll. Im andern Fall, wenn das Instrument beim Einspielen der Libelle eine horizontale Visirlinie giebt, ist für dieselben Entfernungen die ganze Correction gleich der Differenz derer, die sich auf 20 bis 60 Ruthen beziehn, also $0,128-0,014$, also eben so grofs, wie frïhlıer, oder wieder 0,114 Zoll.

\section{$\S 46$.}

Als dritte Fehler-Ursache beim Nivelliren mufs die U ndentlichkeit des Bildes angefülırt werden. Dieselbe darf man jedoch nur in dem Fall dem Instrument beimessen, wenn dieses mit einem Fernrohr versehn ist, sonst liegt sie in der Unvollkommenheit des menschlichen Auges. In geringen Distanzen veranlarst sie keine bedeutenden Fehler, doch werden diese bei weitern Abständen sehr grofs und können alsdann sogar alle sonstigen Fehler überwiegen. Das deutliche Sehn bedingt dalıer vorzugsweise die Länge der Nivellir-Stationen.

Der Beobachter mufs untersuchen, in welcher Entfernung er mit seinem Fernrolir die Eintheilung anf der Visirlatte noch 
deutliclı erkennen kann. Dabei sind aber manche äufsre Umstände zu berücksichtigen, von denen zum Theil bereits die Relle war. Dahin gehört das Blenden des Sonnenlichts, wenn man bei niedrigem Stande der Sonne nahe gegen dieselbe visirt. Es empfiehlt sich alsdann, von der geraden Richtung abzuweichen und den Nivellements-Zug im Zickzack zu führen, so dafs die einzelnen Linien etwa unter einem halben rechten Winkel von der Hauptrichtung abweichen. Dabei lassen sich die auf beiden Seiten eingetheilten Latten noch so stellen, dafs man vor-, wie rückwärts die Höhen daran ablesen kann. Hierdurch wird vermieden, dafs die Entfernungen sehr verschieden sind, und dieses ist auch in Betreff der Dentlichkeit sehr wichtig. Man hat nämlich die Ocular-Röhre so weit aurgezogen, dafs das Bild in derjenigen Entfernung, in welcher man gewöhnlich mifst, die grölste Schärfe hat. In bedeutend gröfsrer Nähe verschwindet diese Schärfe aber so sehr, dafs ohnerachtet der Nähe, die Ablesung weniger genau wird. Das Verstellen der Ocular-Röhre muls man aber vermeiden, weil dadurch die Absehens-Linie, für welche die Libelle berichtigt ist, leicht verändert werden könnte.

Die Deutlichkeit des Bildes leidet ferner, wenn das ObjectivGlas vou der Sonne beschienen wird, und dieses vermeidet man durch eine leichte Aufsatzröhre, die einige Zoll weit ïber das Fernrohr hinaustritt, und die man nüthigen Falls aus einem Blättchen steifen Papiers darstellt. Diese Röhre gewälırt auch den Vortheil, dafs bei schwachem liegen, wobei die Arbeit noch fortgesetzt werden kann, die 'Tropfen niclit auf das Objectiv fallen und die Deutlichkeit vermindern.

Ilierbei wäre noch zu erwähnen, dafs es bei niedrigem Stande der Sonne sich zuweilen ereignet, dafs das Licht von der mit Oelfarbe angestrichenen Latte gerade nach dem Instrument reHectirt wird, und man alsdann die Fintheilung niclt melir erkennen kann. Durch passende Stellung der Latten, die etwas gedrelit werden, läfst sich dieses freilich leicht vermeiden, nachdem aber bereits die Höhe an der Latte in der vorgehnden Station abgelesen ist, darf keine Veränderung in ihrer Stellung vorgenommen werden, und alsdann bleibt nur übrig, die Latte künstlich zu beschatten, indem der Gehülfe mit einem belaulten $Z_{\text {weige, oder }}$ in andrer Weise das Sonnenlicht abhält. 
$\$ 47$.

Fs hleiben noch die Fehler zu untersuchen, die beim $\Lambda$ ufstellen der Visirstäbe und beim Richten der 'Tab l e a us vorkommen können. Stelın die Stäbe oder Latten nicht senkrecht, so wird an denselben die Höhe jedesmal gröfser gemessen, als sie wirklich ist. In ebnem Terrain heben sich diese Fehler theilweise auf, wenn man jedesmal ungefilir in derselben Höhe der Latten das Maấs abliest. Wird dagegen eine Anhöhe hinauf nivellirt, so hat die schiefe Stellung der hintern Latte gröfsern Einflurs auf das Resultat, als die der vordern, weil das abgelesne Maals ein lïngeres ist. Eine Ausgleichung kann daher in diesem Fall nicht mehr stattfinden. Die Feller, die immer in demselben Sinn vorkommen, summiren sich, und man findet die Anhöhe lıöher, als sie wirklich ist. Dazu kommt noch, dafs man auf unebnem Terrain, wo der Horizont nicht frei ist, durch blofsen Angenschein den lothrechten Stand der Latte nicht beurtheilen kann und in der Schätzung desselben leicht um 15 Grade sich irrt. Wenn der Fehler durchsehnittlich aber auch nur 10 Grucle beträgt, also die Höhen im Verhältnifs von $1: \cos 10^{\circ}$ zu grofs abgelesen werden, so giebt dieses schon einen Fehler von 1 Fufs auf 65 Fufs Höhe.

Wenn die Latte nicht in den Boden fest eingestofsen, sondern nur auf ein Pfălichen aufgestellt und $\mathrm{mit}$ der Hand gehalten wird, so pflegt, wie schon oben bemerkt wurde, ihr lothrechter Stand nur in soweit benrtheilt zu werden, dafs sie nicht stark aus der vom Instrumente ans durch sie gelegten Vertical-Ebene abweicht, während ihre Abweichung in dieser Ebene gan\% unbeachtet bleibt. Zuweilen wählt der Feldmesser die Glasröhren seiner Canalwaage zur Norm und hält mit der strengsten Gewissenlıaftigkeit darauf, dafs der Visirstab in der Ebene gehalten wird, in der die Glasröhren stehn, olıne sich irgend davon zu überzengen, dafs dieses wirklich eine VerticalEbene ist.

Bei den lose aufstehnden Latten wïrde eine kleine daran befestigte Iosen-Libelle wohl der bequemste Apparat zur Controlle in dieser Beziehung sein, wie Bourdalone davon auch in der That Gebrauch gemacht hat. Der Beobachter kann aber 
während des Visirens nicht heurtheilen, ob der Gehïlfe alsdann den Stab richtig hält, und sonach wird hierdurch keineswegs eine grölsere Sicherheit erreicht.

Die feste Aufstellung der Latten ist zur Sicherung gegen diese Fehler dringend geboten. Alsdann liifst sich sehr bequem ein Loth benutzen, welches der Arbeiter bei sich fïhrt, und nach welchem er nach dem jedesmaligen Finstellen in einer und der anclern Richtung den Stand beurtheilen und verbessern kann. Durch dasselbe Mittel prïft aber auch der Ijeobachter selbst die richtige Aufstellung jeder Latte.

Das Aufsetzen des Visirstabes a $\mathrm{f}$ den $\mathrm{K}$ opf e ines vorher eingeschlagnen $\mathrm{kle}$ inen $\mathrm{Pfählchens,} \mathrm{wie} \mathrm{dieses}$ gewöhnlich geschieht, ist noch insofern unsicher, als cin solcher Kopf keine horizontale Ebene bildet, also der Stab bei dem Visiren von der einen Seite leicht etwas hölıer steht, als wenn von der andern Seite dagegen visirt wird. Die hieraus entspringenden Fehler sind indessen im Allgemeinen nur geringe, und heben sich auch gegenseitig zum Theil auf, da sie eben sowohl positiv, wie negativ sein können. Dabei kommt aber noch die Frage in Betracht, ob der Pfahl auch feststeht, und nicht vielleicht durch das Gewicht der 10 bis 12 Fuls lohen Stange mit dem Tableau herabgedriickt wird. Namentlich in sumpfigem Wiesengrunde ist dieses sehr zu besorgen, und der Feldmesser pflegt alsdann auch wohl die Arbeiter anzuweisen, dals sie den Stab recht sanft aufstellen. Erfolgt dabei ein Eindriicken, so ist dasselbe zwar olnne Nachtheil, so lange noch nicht gegen den darauf stehnden Stab visirt ist, doch kann es auch später geschelın, namentlich beim Umdrehn des Stabes, indem das Tableau nach der andern Seite gekehrt wird. Die hierdurch veranlafsten Fehler treten jedesmal in demselben Sinn ein, summiren sich also, und das Nivellement zeigt ein dauerndes Ansteigen, weil die Latten während der Messung sich stets senkten.

Was die T able a us betrifft, so sind die Latten, an welchen sie anf- und abgeschoben werden, gemeinhin nicht so scharf eingetheilt, wie man mit dem Fernrohr selbst die Theilung ablesen könnte. Von den sehr grofsen Fehlern, die der Gehülfe aber begelın kann, wenn er die Einstellung nicht richtig macht, oder ric Tableaus verstellt, bevor der Feldmesser die Hölen alggelesen 
hat, war schon oben $(\S 41)$ die Rede. Auch wurde mitgetheilt (\$ 44), dafs es sich melir empfiehlt auf das Tableau vier Dreiecke, als vier Quarlrate zu zeichnen, weil im ersten Fall die Höhe des Punkts, in welchem die vier Spitzen der Dreiecke liegren, sich sicherer erkennen lärst.

\section{$\S 48$.}

Selhr wichtig ist die Frage, wie grofs der wahrscheinliche Fehler eines Nivellements ist, oder mit welcher Wahrscheinlichkeit man erwarten darf, dals der Fehler dic erlaubte Grenze nicht überschreitet. Im Allgemeinen läfst sich hierauf keine Antwort geben. Welches Instrument man auch anwenden mag, so wird die Sicherheit des Resultats jedesmal vorzugsweise von der Sorgfalt und Uebung des Beobachters abhängen. S'etzt man diese voraus, und nimmt zugleich an, dafs die Geliülfen zuverlässige Leute sind, die keine absichtlichen Täuschungen einlïhren, auch beim Aufstellen der Visirstäbe hinreichende Uebung haben, um gröfsere Fehler zu vermeiden, so läfst sich die Wahrscheinlichkeit der mit versehiednen Instrumenten erhaltnen Resultate ungefähr beurtheilen. Von der Mercurialwange mufs indessen abgesehn werden, weil die dabei vorkommenden Fehler leicht iibermärsig grols ausfallen und selbst durch volle Aufmerksamkeit nicht immer zu vermeiden sind.

Die Canalwagge ist in früherer Zeit vielfach als ein sehr zuverlässiges Nivellir-Instrument empfohlen worden. Gilly sagt *), dafs bei mehrfacher Verschiebung des Tableans, im Abstande von 10 Rutlien der Unterschied zwischen den einzelnen Ablesungen nie iiber ein $\Lambda$ chttheil Zoll betragen habe. Ich habe lıäufig nacla den Winken geiibter Feldmesser das Tableau selbst eingestellt und die Iö̈lıen abgelesen, die Abweichungen vom Mittel betrugen alsdann aber bei Entfernungen von 5 Ruthen schon ein Viertel Zoll. Nur einem Feldmesser, der aber besondre Uebung besals, gelang es, das Tableau so scharf einrichten zu lassen, dals der wahrscheinliche Felıler bei derselben Entfernung sich etwa auf

*) Praktische Anleitung zur Anwendung cles Nivellirens. Berlin 1800. 
0,1 Zoll stellte. Diese Genanigheit bleibt indessen noch immer sehr bedeutend hinter derjenigen zurtick, dic Gilly anfiilıt, und in allen diesen Fällen wurde ungewöhnliche Aufmerksamkeit und Sorgfult angewendet, wie auch die Fehler vermieden, welche aus der unrichtigen Aufstellung der Stäbe und unpassender IIandhabung der Tableaus oder der falsclien Ablesung der Höhen entspringen.

Ich habe aufserdem verschiedentlich Gelegenheit gelialut, Nivellements zu vergleichen, die sich gegenseitig controllinten. Die Unterschiede waren dabei aber stets so grols, dafs sie mit Rücksicht auf die wahrscheinliche Ausgleichung der Fehler, in der einzelnen 10 Ruthen langen Station auf einen wahrsclıeinlichen Fehler von nahe 1 Zoll schliefsen liefsen. In einem solchen Fall, der sich auf ein Nivellement vou mehr als 8 Meilen Länge bezog, das unter günstigen Umständen, nämlich während des Sommers auf den Kronen von Deichen und zwar von einem als zuverlässig anerkannten Geometer ausgeführt war, stellte sich der Unterschied so grofs heraus, dafs der wahrscheinliche Fehler für jede 20 Ruthen lange Station sich sogar auf $2 \frac{3}{4}$ Zoll stellte.

Die Angabe von Netto*), dals man mit der Canalwaage auf Entfernungen von 7 bis 8 Ruthen die Horizontale ,allerhöchstens bis auf einem halben Zoll verbürgen kann", erscheint liernach keineswegs übertrieben, vielmehr noch eine güinstige zu sein. Man dürfte wohl annehmen, dafs bei gehöriger Uebung und Aufmerksamkeit auf die ganze Operation der walırscheinliche Fehler des Visirens gegen die in 5 Ruthen Abstand aufgestellte Tafel $1 / 4$ Zoll beträgt. Alsdann ist der wahrscheinliche Fehler fïr eine Station von 10 Ruthen Länge

$$
\frac{1}{4} \cdot \sqrt{2} \text { Zoll }
$$

Indem aber jedes Nivellement vorschriftsmälsig noch in entgegengesetzter Richtung wiederholt werden soll, so vermindert sich der wahrscheinliche Fehler für die Station von 10 Ruthen wieder auf $1 / 4$ Zoll, und für 10 Stationen oder auf 100 Ruthen beträgt er $0,25 \sqrt{ } 10=0,79$ Zoll

ludem nun aber nach dem neuen Preufsischen Feldmesser-

*) Handluch der gesammten Vermessungskunde. 
Reglement auf 100 Ruthen Länge nur ein Fehler von 0,671 Zoll gestattet ist, so iiberschreitet der walıscheinliche Fehler schon die crlaubte Grenze, und es ist sonach wahrscheinlicher, dafs jede Messung, dic man mit der Canalwage ausfïhrt, bei einer Revision für falsch, als dafs sie für richtig anerkannt werden wird. Dieses Instrument darf daher niemals gebraucht werden, wo die Vorschrift in Betreff der erlaubten Fehlergrenze in Anwendung kommt.

$\$ 49$.

Mittelst eines Nivellir-Instruments, das mit einer e $m p$ fin dlichen Libelle und einem mäfsigen Fernrohr versehn ist, erreicht man leicht eine viel grölsere Genauigkeit, man darf jedoch nicht glauben, dafs die Anwendung eines solchen schon jede Gefahr vor bedeutenden Fehlern beseitige, vielmehr erfordert die richtige Behandlung desselben noch besondre Ueberlegung und Aufmerksamkeit, so wie auch Uebung in der Berichtigung und im Gebrauch. Ohne diese gewährt das Nivellir-Instrument keine Sicherheit gegen die Fehler, die bei der Aufstellung und Behandlung der Visirlatten und Tableaus vorkommen.

Um zu zeigen, wie man ein Instrument dieser Art prüft und manche Einzelheiten desselben untersucht, mag die Beschreibung eines $\mathrm{Nivea}$ us hier folgen, welches ich bei dem bereits erwälnten nusgedehnten Nivellement benutzte. Es gehörte keineswegs zu den gröIsern Instrumenten, wurde vielmehr von den in neuerer Zeit angefertigten in Bezug auf seine Dimensionen weit übertroffen, doch war die Libelle hinreichend empfindlich und das Fernrohr, das nur fünfmalige Vergröfserung hatte, zeigte sehr scharfe und farblose Bilder, so wie auch alle 'Theile desselben mit Sorgfalt und Ueberlegung ausgefülırt waren. Es war im Anfang dieses Jahrhunderts aus England bezogen.

Das Fernrohr, welches terrestrisch war, maals in der Länge $11 \frac{1}{2}$ Zoll und in der Oeffnung des Objectiv-Glases nur 8 Linien. Zwischen dem Ocular und dem Collectiv-Glase, neben der Blendung, befind sich ein starker Ring, der durch vier kreuzweise einander gegenüberstehnde Stelisclırauben mit der Ocular-Rölıre 
verbunden war. Die Köpfe dieser Schrauben waren versenkt, so dals sie die Bewegung der Röhre nicht hinderten, auch liefsen sie sich etwas seitwärts schieben, da die kegelfïrmigen Vertiefungen in der Röhre gröfsere Weiten hatten. Vier Schrauben mit breiten Köpfen auf' der einen Seite des Ringes dienten ursprünglich zur Befestigung der Silberfäden, die das Fadenkreuz bildeten.

Die Libelle, deren lichte Weite 6 Linien mals, war in der messingenen Fassung mittelst zweier Schrauben mit dem Fernrohr verburden, und zwar so, dafs sie ïber demselben lag. Die Oeffinung in der Fassung war $2 \frac{1}{2}$ Zoll lang, während die Länge der Luftblase gewöhnlich $1^{3 / 4}$ Zoll betrug.

Das Fernrolır mit der Libelle lag mittelst zweier broncenen Cylinder von 13 Linien 1)urchmesser auf' zwei $\mathbf{Y}$ förmigen 'Trägern, die 6 Koll ron einander entfernt waren. 1)er eine derselben konnte durch eine Schraube gehoben und gesenkt werden. Diese Schraube zeigte zwar weder todten Gang, noch Mangel an Festigkeit, da jedoch ein doppelter Gang in sie eingeschnitten war, so latte dieser eine ansehnliche Steigung und schon bei scliwacher Drehung wurde die Luftblase der Libelle stark bewegt. Durch das oben erwähnte Zurückdrehn gelang es jedoch sehr bald, die Blase zum Einspielen zu bringen.

Die beiden erwälnten Träger standen auf einem starken Prisma von Messing, und an dieses war die Büchse befestigt, die sich auf dem etwas conischen Zapfen, der nahe 1 Zoll im Durchmesser hatte, drehte. Um letzter'n vertical zu stellen, diente eine Nufs mit vier Stellschrauben.

IDie Silberfäden im Fernrohr waren viel zu dick, als dal's sie bei einer scharfen Messung häitten benutzt werden können. Statt derselben zog ich daher Spinnenfäden ein, die zwar sehr fein und sauber waren, aber weit geringere Haltbarkeit besafsen und daher zuweilen durch andre ersetzt werden mulsten. Das Verfalıen beim Einspannen neuer Fäden welches Bessel anwendete, ist ïberaus einfach und bequem und läfst sich, wenn man dabei eine Loupe benutzt, mit grolser Schärfe ausführen. Es besteht in Folgendem.

In einem Spinn-Gewebe, un dem nicht viel Stiub haftet, und welches wo möglich erst vor Kurzem gesponnen ist, sucht 
man einen längern feinen Faden aus. Finen gewöhnlichen Handzirkel älfinet man so weit, dals seine Spitzen sich etwa 3 Zoll von einander entfernen, und klebt auf jeden Schenkel in der Nähe der Spitze etwas weiches Wachs, am besten Baumwachs. Nunınclı liält man den Cirkel so, dafs der Faden an einern Schenkel das Wachs berïlut und drïckt ihn mit dem Finger ein, alsdann befestigt man den Faden in gleicher W cise an den andern Schenkel, um welchen inan ihn auch durch Drehn des Cirkels melirmals umschlingen kann. Hierauf untersucht man den gelösten Theil des Fadens mit einer Loupe, statt deren auch das ausgeschobene Ocular des Fernrohrs benutzt werden kann, und wenn er passend betunden wird, so kann man mit einem weichen Pinsel die daran etwa haftenden Stäubchen entfernen. Der Fraden besitzt, wenn or frisclı gesponnen ist, eine bedeutende Elasticität, man darf daher, um ihn scharf anzuspannen, den Cirkel etwas weiter ölfnen. 1)er Ring, an welchen der Faden befestigt werden soll, wird auf' der ebenen Grundfläclıe vorher mit den nöthigen Marken versehn, damit ïber die richtige Lage der Fäden kein $Z$ weifel ist. Man legt ilın auf ein Blittchen weifses Papier und darüber den Cirkel, so dals die beiden Spitzen desselben auf beiden Seiten des Ringes sich befinden und der Faden auf der ebenen Fläche des letztern liegt. Nunmeln untersucht man diese Lage mit der Loupe oder dem Ocular-Glase des Fernrohrs, und verschiebt den Cirkel so lange, bis der Faden die Marken genau schneidet. Bei frischen Fäden darf man ein Zerreifsen derselben während dieser Operation niclit besorgen, und bei vorsichtiger Behandlung zerreifsen auch ältere Fäden nicht leicht. Endlich wird der Fuden mittelst zweier Wachskigelchen, die man vorher durch Kneten weich gemacht hat, fest geklebt. In gleicher Weise wird auch der normal auf den ersten gerichtete Faden oder vielleicht mehrere l'arallel-Fäden befestigt.

Diese Fäden stellen sich besonders auf stark erleuchtetem Hintergrunde als scharf gezogne feine Linien dar, auf dunklem Laube sind sie weniger deutlich, doch ist mir nie der Fall vorgekommen, dafs ich aus diesem Grunde die Stationen hätte verändern müssen. Die scheinbare Dicke der Fäden entsprach in diesem Fernrohr einem Winkel von 8 Secunden, wie sich aus der Beobachtung besonderer Marken in weiten Entfernungen ergab. 
In einem Brief an Gaufs vom 5. Mär 1820*) beschreibt Bessel dieses Einziehn der Fäden in ähnlicher Weise, doch spricht or daselbst von den feinsten Fäden der Flockseide. Diese wurden also später vorgezogen. Als ich wenige Jahre frïher auf der Sternwarte war, fanden nur Spinnenfäden $\Lambda$ nwendung.

Zur Beurtheilung des Standes der Luftblase waren an den Enden derselben auf jeder Seite in die Libelle zwei Striche eingerissen, die $1 / 8$ Linie von einander entfernt waren. Sie begrenzten die Länge der Luftblase bei verschiednen 'Temperaturen. Hierdurch war Gelegenheit geboten, die Empfindlichkeit der Libelle zu prüfen. Der eine Visirstab wurde in 30 Ruthen Entfernung vom Instrument aufgestellt, und während ich das eine Ende der Blase abwechselnd mit dem einen und dem andern Striclı auf der Libelle in Berïlırung brachte, las ich die folgenden Höhen ab

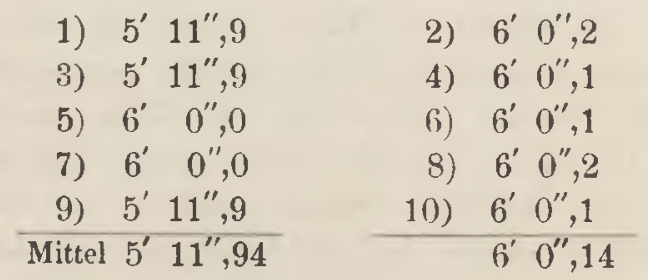

Wenn demnach die Lage der Blase sich um $1 / 3$ Linie verändert, so hebt sich die Visirlinie im Abstande von 30 Ruthen um 0,2 Zoll, oder im Winkel um $9 \frac{1}{2}$ Secunden. Es ergiebt sich daraus der Krümmungs-Radius der Libelle gleich $50 \mathrm{Fufs.}$ Der Fehler beim Einstellen wird, wenn nicht vielleicht ein starker Wind das Instrument in Schwankung versetzt, nicht leicht dem halben Abstande jener beiden Striche gleich kommen, oder 5 Secunden betragen. Der wahrscheinliche Fehler der Messung war, wie nachstehend gezeigt werden wird, in der 'That bedeutend geringer.

\section{$\S 50$.}

Lis ist schon erwähnt worden, wie selır durch Anwendung beweglicher Tableaus die Sicherheit der ganzen Operation becinträchtigt und die Einfüirung einer scharfen Controlle fust unmöglich

*) Briefwechsel zwischen Gaufs und Bessel. Leipzig 1880. S. 310 . 
gemacht wird. Diese Tableaus wurden daher von mir nicht benutzt, vielmehr die Latte mit einer seharf markirten Lintheilung versehn, die unmittelbar durch das Fernrohr abgelesen werden konnte. Dabei mufsten an die Latten eiserne Schuhe befestigt werden, damit sie sich leicht in den Boden stofsen liefsen, und indem ein Drelın derselben alsdann nicht möglich war, so mufsten sie auch auf beiden Seiten übereinstimmend eingetheilt sein.

Die Latten, aus geradefasrigem Kiefernholz geschnitten, waren 10 Fufs lang, $2 \frac{1}{2}$ Zoll breit und $1 \frac{1}{2}$ Zoll stark. Am untern Ende war jede mit einem pyramidal geformten eisernen Schuh versehn. Zwei solcher Latten wurden angefertigt und jede auf beiden Seiten übereinstimmend mit schwarzer Oelfarbe auf weifsem Grunde bezeichnet. Beide waren jedesmal im Gebrauch, so dals das Nivellement ganz sicher an die folgende Latte angeschlossen werden konnte, bevor die vorhergehende ausgezogen wurde.

Die Bezeichnung des Maafses mulste jedenfalls ziemlich einfach sein, um beim Ablesen Verwechselungen zu vermeiden. Aufserdem wäre es gewils erwünscht gewesen, wenn feinere Theilungen hätten gewählt werden dürfen, un etwa die einzelnen Zehntheile eines Zolls noch zu markiren. Letzteres mufste aber mit Rücksicht auf die Deutlichkeit unterbleiben, und es liefs sich auch ohne Nachtheil entbehren, indem diese U $\mathrm{n}$ t e r abtheilungen sehr sicher gesclsatzt werden konnten.

Gegen die Zuverlässigkeit solcher Schātzungen werden oft Zweifel erhoben. Dals diese jedoch ungegründet sind, ergiebt sich am deutlichsten aus den astronomischen Beobachtungen. So wird die Zeit des Durchganges eines Sterns durch einen Faden im Mittagsfernrohr in Zelıntheilen der Secunde notirt, während die Ulır nur ganze Secunden schlägt. Kleinere Intervalle darf sie auch nicht angeben, weil man dieselben doch nicht zählen könnte, und dadurch die Unsicherheit noch grölser würde. Das Verfahren bei diesen Beobachtungen ist folgendes. Man merkt sich die Stelle, wo der Stern im Moment desjenigen Secundenschlages steht, der dem Durchgange durch den Faden vorangeht, und vergleicht diese Entfernung vom Faden mit derjenigen, die beim folgenden Secundenschlage auf der andern Seite sich bildet. 
Man theilt also den Raum, dessen Begrenzung nur momentan und zwar nicht gleichzeitig gegeben ist, durch Schätzung in 10 Theile und bestimmt hierdurch das Maafs. Die Uebereinstimmung dieser Beobachtungen unter sich zeigt aber unverkennbar, dafs ein geübter Astronom dabei nicht um ein Zehntel Secunde irrt, wenn nur der Weg in der Secunde einige Ausdehnung hat, oder der Stern nicht zn nahe am Pol steht.

Die Anwendung eines ähnlichen Verfahrens auf den Fall, wo man dauernd die beiden Grenzen siehıt und mit voller Mufse die Schätzung ausfülıren kann, ist daher ganz sicher. Man wird gewifs nie $z$ weifellıaft sein, ob der Faden den dritten oder den vierten Theil des Raums abschneidet, und doch ist der Unterschied zwischen diesen beiden Grölsen nur 0,083 , also weniger, als ein Zehntel. Wenn nur die Einheit eine hinreichende Ausdelnung hat, deren Zehntheile sich noch erkennen lassen, so wird man diese mit einiger Uebung so sicher schätzen, dals man nie einen Fehler von einem ganzen Zehntel begeht. Nur in dem Fall, wenn das Maafs nahe in die Mitte zwischen zwei Zehntel fällt, geschieht es leicht, dafs man bei wiederholten Ablesungen bald dieses bald jenes der beiden zunäclıst liegenden trifft, aber der Fehler ist alsdann nur etwa ein halbes Zehntel.

Hiernach wählte ich die in nebenstehnder Figur dargestellte Eintheilung. Die einzelnen Zolle bilden abwechselnd weirse und schwarze Rechtecke, so dafs jeder Zoll, welcher einer geraden Zahl entspricht $(2,4,6,8,10$ und 12) durch ein schwarzes Viereck bezeichnet wird. Um das Zählen der Zolle aber zu erleichtern, befindet sich am obern Ende jedes sechsten Zolls ein schwarzer Kreis. Zur Unterscheidung der Fufse sind die betreffenden Zolle abwechselnd an der linken und rechten Seite aufgetragen, so dn $\left[s\right.$ jeler $\mathrm{Fu}_{\mathrm{u}} \mathrm{s}$, der einer geraden 
Zahl entspricht, auf der rechten Seite steht. Aufserdem ist der zwölfte Zoll des vierten und des achten Fufses durch die ganze Breite der Fliiche hindurchgezogen. Genau dieselbe Bezeichnung war auf der andern breiten Seite der Latte angebracht und zwar genan in gleicher Höhe, und eben so hatte ich auch die zweite Latte bezeichnet. Um aber die beiden Latten von einander zu unterscheiden und Verwechslungen zu vermeiden, wenn etwa irrthümlich zuerst das Fernrohr nach der vordern Latte gerichtet wäre, so war auf der einen Latte und zwar auf beiden Seiten derselben der zwölfte Zoll des zelinten Fufses über die ganze Breite fort ausgezogen, und diese Marke wurde jedesmal vor das notirte Maafs vorgeschrieben.

An diese Bezeichnung hatte ich mich in kurzer Zeit so gewöhnt, dafs im Ablesen der Fufse, wie der Zolle kein Irrthum jemals vorkam, der aus der Controlle sich segleich hätte ergeben miissen. Eben so zeigten auch die Controllen, von denen im Folgenden die Rede sein wird, dafs die Schätzungen durchaus zuverlïssig waren und der wahrscheinliche Feller derselben weniger als 0,1 Zoll betrug.

Bourdalouë hat, um die Schätzungen auf das geringste Maås zurückzuführen, viel complicirtere Bezeichnungen gewählt, und . zwar selir verschiedne, die bei gröfserer oder kleinerer Entfernung der Latten angewendet wurden. Fiir die geringsten Entfernungen konnten sogar einzelne Millimeter unmittelbar abgelesen werden. Die Benutzung verschiedner Visirlatten war indessen gewifs höchst unbequem, und man mufs bezweifeln, ob die dadurch erreichte Genanigkeit wirklich gröfser war, ḋ doch die Ocular-Röhre nicht füglich verstellt werden durfte, ohne die Berichtigung der Libelle aufzuheben. Kommt noch dazu, daf's diese Latten nicht fest in den Boden eingestofsen, sondern nur lose aufgestellt und beim Zurückvisiren umgedrelıt wurden, so dürfte wohl die vorstehnd beschriebne, ïberaus einfache Bezeichnungs-Art der Latten unbedingt den Vorzug vor dieser verdienen.

\section{$\S 51$.}

Das ausgedelinte Nivellement, bei dem der vorstehnd beschriebne Apparat henutzt wurde, bezog sich auf das 1824 wieder angeregte Project zur Darstellung einer schiffharen oder 
vielleicht nur flöfsbaren Verbindung der Masurischen Seen mit dem Pregel. Ich sollte zu diesem Zweck die Aufnahme des 'Terrains und das Nivellement leiten von der Alle, einem Nebenflufs des Pregels, längs der Guber von Schippenbeil bis Rastenburg anfwärts, von hier aber passende Canallinien bis zu den Masurischen Seen, sowie auch die Verbindungs-Linien zwisclien diesen aufsuchen, und diese gleichfalls aufnehmen und nivelliren lassen. Das Nivellement sollte wie üblich auf kleine Pfählchen die von $10 \mathrm{zu} 10$ Ruthen eingeschlagen würden, sich beziehn und sich möglichst oft an Festpunkte in der Nähe anschliefsen. Die Ausfiuhrung des Nivellements ïbernahm ich selbst, nachdem die von mir ausgesuchten Linien durch andre Feldmesser aufgenommen und vorschriftsmälsig durch Pfahlılehen markirt waren.

Zunächst schien es mir nothwendig zu untersuchen, welche Länge die Stationen bei dem mir von der Regierung eingehändigten Nivellir-Instrument erlaalten dürften. Bei einem Abstande von 35 Ruthen erschienen die kleinen Quadrate auf den Visirlatteu, welche die einzelnen Zolle bezeichneten, noch vollkommen scharf, und die Maafse liefsen sich durch Schätzung sicher bis auf 0,1 Zoll abnehmen. Bei weiterem Abstand des Instruments erschienen die Ecken abgerundet und die Zehntheile der Zolle waren nicht mehr sicher abzulesen. Hierauf wurde bei guter Beleuchtung der Abstand von etwa 33 Ruthen gewälit, und die Länge der ganzen Station mafs in der Regel 66 Ruthen. Bei eintretender Dunkelheit oder unklarer Luft mulste sie aber verkürzt werden.

Eine wesentliche $\mathbf{A} b$ weichung von der sonst üblichen Metlıode trat dabei in sofern ein, als weder das Instrument noclı jene Visirlatten ïber die Pfählchen gestellt, sondern die Punkte, wo die Latten standen, nur durch Abzählen von Schritten gegen die Pfähle normirt wurden, und das Haupt-Nivellement von letztern ganz unabhängig war, auch zuweilen wenn etwa die Sonne bei niedrigem Stande gerade in die Linie traf, sich von derselben im Zickzack entfernte, wie bereits erwähnt ist.

Die Latten wurden an die jedesmal von mir bezeiclıneten Stellen so eingestofsen und gerichtet, dals sie in passenden und möglichst gleichen Entfernungen vom Instrument sich befanden, und dafs von der vordern aus anch das Nivellement bequem weiter 
fortgesetzt werden konnte. Endlich mufste auch jede Latte lothrecht stehn. Zu diesem Zweck fülnte der Arbeiter ein Loth bei sich, und nach diesem prüfte ich jedesmal selbst die Stellung und zwar in zwei Richtungen. War eine Latte in diescr Weise eingestellt, so mufste der $\Lambda$ rbeiter sich sogleich davon entfernen, und Niemand durfte sie beriihren oder sich ihr auch nur nähern, bis das Nivellement auf' die folgende Latte vollständig ïbertragen war.

Das Niveau wurde jeden Morgen vor dem Beginn der Arbeit, wo mïglich üher stehndem Wasser, sonst aber zwischen den beiden Visirlatten, wie oben $(\$ 44)$ beschrieben, berichtigt. Dieses geschah auch während des Tages, wenn etwa eine zufïllige Erschütterung vorgekommen war, die möglicher Weise eine Verstellung der Libelle veranlafst haben konnte. Nach einer solchen Berichtigung durfte keiner der Gehülfen das Fernrohr mit der Libelle berïlıren oder es zugleich mit dem Stativ aufheben. Ich trug es jedesmal selbst frei in der Hand.

Sobald $z \mathbf{u}$ einer $\mathrm{n} \in \mathrm{u}$ en Station äbergegangen werden sollte, schickte ich einen Arbeiter zurück, um die hintere Visirlatte auszuzichn und herbeizubringen. Ich hob das Fernrolir ab, das Stativ nebst einer dritten leichtern Visirlatte und den ganzen übrigen Apparat trugen zwei Arbeiter und wir gingen alle zusammen bei der vordern Visirlatte vorbei, wobei immer und namentlich bei neuen Arbeitern grolse Aufmerksamkeit nüthig war, die Leute von dieser Latte entfernt zu halten. Namentlich war dieses erforderlich, wenn die Arbeiter in andern Verhältnissen an Scheindienste gewöhnt waren. Sie wollten alsdann immer den lothrechten Stand der Latte prïfen und denselben berichtigen. Nach Maafsgabe der vorher eingeschlagenen Pfühlchen liefs sich leicht der Punkt bestimmen, anf den das Instrument zu stellen war, doch vermied ich stets, es unmittelbar über eines der Pfählchen zu bringen. Das Stativ wurde anfgerichtet, die Fîfse gehörig fest in den Boden eingedriickt, und das Fernrohr darauf gelegt. Nunmelır ging ich mit dem Manne, der die zweite Latte trug, bis zu dem Punkt, wo diese stehn sollte. Er stiefs sie fest in den Boden und richtete sie nach dem Loth. Nachdem ich mich überzeugt, dafs dieses mit hinreichender Schärfe geschehn, auch die Eintlıeilung sowohl rückwärts, als vorwärts deutlich gesehn werden konnte, gingen wir zuriick.

Hagen, Walırscheinliclukeits-Reclunung. 3, Aufl. 
Hierauf wurde die Aufstellung des Instruments berichtigt und mittelst der vier Schrauben neben der Nufs die vertikale Achse lothrecht gerichtet, wobei die Libelle zur Norm diente. Wenn hierbei auch keineswegs eine grofse Genauigkeit erforderlich war, so mufsten doch merkliche $A b$ weichungen vermieden werden, weil sonst beim Umdrehn des Fernrohrs, dasselbe noch etwas gehoben oder gesenkt, seine Höhe also nicht dieselbe geblieben wäre. War dieses geschehn, so wurden mit möglichster Sorgfalt an der hintern und vordern Latte die Maalse algelesen und notirt, dabei aber auch jedesmal die Latte bezeiclınet, auf der die Ablesung geschah.

Alsdann ging der Arbeiter, der eine dritte Latte trug, zu den verschiednen auf diese Station treffenden Pfallichen und steltte sie an dieselben. Diese Latte war in gleicher Weise, wie die andern, jedoch nur auf einer Seite bezeichnet, auch hatte sie keine Spitze, und war nur unten mit Blech beschlagen. Ihre Länge betrug $12 \mathrm{Fufs}$, ihre Breite $1 \frac{1 / 2}{2}$ Zoll und ihre Stïrke $3 / 4$ Zoll. Sie wurde neben jedes Pfühlchen auf den Boden gestellt, und mit dem Fernrolur las ich an ihr das Maals ab. Auf die Höhe der Pfalılköpfe, die in gleicher Weise hätte ermittelt werden können, kam es nicht an, da diese Pfähle bis zur Ausfülırung des Projects (das bald darauf auch ganz aufgegeben wurde) doch nicht hätten erhalten werden können.

In gleicher Weise wurden auch die Querprofile, die Deiche, Brücken und andre Gegenstände und wenn es nöthig schien auch sonstige Erhebungen oder Senkungen des Terrains in der Nähe gemessen. Grofse Genanigkeit war dabei ganz entbebrlich, da man die Terrain-Höhen doch nur bis auf 1 Zoll sicher zu messen braucht, und die hierbei vorkommenden Fehler keinen Einflufs anf das Haupt-Nivellement hatten.

Nur der Wasserstand in der Guber daneben, deren Canalisirung in Aussiclıt genommen war, mufste mit grolser Schärfe gemessen werden. $\mathrm{Zu}$ diesem $\mathrm{Z}$ weck wurde diese dritte Stange in das Wasser fest eingesto[sen und nach dem Loth gerichtet. Nachdem ich daran das Maafs durch das Fernrohır abgelesen hatte, las ich noch das Maafs in der Höhe des Wasserspiegels ab. Dieser Bach trieb indessen mehrere Mühlen und sein Niveau war überaus veränderlich. Um dalıer aufser diesen zı- 
falligen Wasserstïnden, die sehr verschieden waren, noch ein etwas sicheres Urtheil iiber die Anschwellungen bei kräftigem Betrieh, der Mühlen zı gewinnen, wurden schon Tags vorher, wiihrend die Festpunkte eingerichtet wurden, an welche sich das Nivellement anschlors, olnfern eines jeden solchen ein höherer I'fahl am Rande des Bạches eingetrieben, und derselbe etwa 1 Fufs hoch üher Wasser mit zähem Thon bestrichen. So weit das Wasser in der 'Zwiselıenzeit gestiegen war, wurde dieser abgespïlt, und man konnte daher durch das Nivellement genau genng die grüfste Hülıe der vorangegangenen Anschwellung feststellen.

Um sogleich die Ueberzengung zu gewinnen, dafs in dem Haupt-Nivellement kein Fehler begangen sei, drückte ich hierauf die Füfse des Stativs etwas tiefer in den Boden ein, richtete aufs Neuc die verticale Achse und visirte nochmals gegen die beiden Houptlatten. Ich erhielt dabei andre Maafse als das erste mal, und berechnete sogleich aus jenen, wie aus diesen, die Höhendifferenzen. Stimmten diese bis auf 0,1 Zoll mit einander überein, so wurde zur nächsten Station übergegangen, im entgegengesetzten Fall aber die Operation nochmals wiederholt. Letzteres war jedoch nur selten erforderlich.

Die Festpunkte, an welche das Nivellement sich anschlofs, wurden in Entfernungen von einer Viertel-Meile ausgesucht oder eingerichtet, und nur wenn es sich um VerbindungsNivellements handelte, wobei also die Höhenlage des Terrains nicht in Betracht kam, wurden weitere Entfernungen, zuweilen sogar von einer lıalben Meile gewählt. Scharf markirte Plinthen massiver Gebiiude, Fachbäume, Merkpfähle an Mühlen und andre Gegenstiinde dienten als Festpunkte, doch meist sal ich mich gezwungen, daneben noch andre Bezeichnungen anzubringen, die, wenn sie auch nicht dauernd erhalten werden konnten, doch einen schärferen Anschlufs des Nivellements gestatteten und namentlich für die folgende Controlle notliwendig waren. Sie bestanden in starken Nägeln oder Bolzen von 5 Zoll Länge, die mit cylindrischen Köpfen von 1/2 Zoll Durchmesser und Höhe versehn waren. Diese Höhe war nothwendig, damit die Köpfe noch in das Holz eingetrieben, und alsdann nicht mehr mit einer Zange gefafst werden konnten. Zwei kreuzweise eingefeilte feine Rinnen 
markirten ihren Mittelpunkt. Sie wurden jedesmal so eingeschlagen, dafs eine der beiden Hauptlatten unmittelbar daneben eingestellt und gerichtet werden konnte. Durch Verlïngerung der Theilstriche der Latte mittelst eines darüber gelegten kleinen Lineals liefs sich alsdann die Höhe des Festpunktes sicher bestimmen.

Endlich wurde die ganze Linie zwischen je zwei Festpunkten wieder zuriick nivellirt. Das Instrument, wie die beiden Hauptlatten, die dabei allein benutzt wurden, nalımen alsdann auf jeder Station andere Höhen ein, woher alle Maalse von den frühern verschieden waren, und die Vergleichung mit der ersten Messung erst schliefslich angestellt werden konnte. Bei Anfstellung des Instruments und der Latten wurde dieselbe Vorsicht und Sorgfalt angewendet, wie das erste Mal, aber die sämmtlichen Neben-Messungen unterblieben. Welche Uebereinstimmung dadurch erreicht wurde, wird nachstelnd mitgetheilt werden.

\section{$\S 52$.}

Es ergielt sich aus vorstelınder Beschreibung der Mefsapparate und der Benutzung derselben, da「s viele der gewölınlichen Veranlassungen zu Fehlern dabei ganz vermieden, oder doch auf selır nalıe liegende Grenzen zurückgeführt wurden. Nach der gewählten Berichtigungs-Methode und der vorsichtigen Behandlung des berichtigten Instruments war eine falsche Einstellung des Niveaus nicht $z \mathrm{u}$ besorgen, und ich durfte daher, wenn die Umstände dieses erforderten, auch in ungleichen Entfernungen visiren, was jedoch im Allgemeinen immer vermieden ist, und wobei für bedeutende Ungleichheiten die nütligen Correctionen berechnet werden mufsten. Die Fehler beim Richten der Tablenus, beim Festhalten derselben bis zur Ablesung und beim Aufstellen und Umdrelın der Visirlatten fielen ganz fort. Es blieben in der That nur die Fehler übrig, die beim Einspielen der Luftblase und beim Ablesen der Marse begangen werden. Um diese zu ermitteln, und um zugleich zu erfahren, wie grol's dieselben bei versehiednen Entfernungen der Visirlatte sind, machte ich vor dem Beginn der Arbeit bei ruliger Witterung und günstiger Beleuclitung die folgenden Versuche. Vor jeder 
einzelnen Messung wurde aber die Libelle verstellt und darauf wieder die Blase zum Einspielen gebracht.

Die Resultate waren die nachstehnden. Die erste Columne giebt die abgelesenen IIöhen an, wobei jedoch die Fufse nicht berïcksichtigt sind, die zweite die Abweichungen derselben vom Mittel und die dritte die Quadrate der Abweichungen.

I. Im Abstande von 5 Ruthen. Das Bild war sehr undentlich.

\begin{tabular}{lll}
$10^{\prime \prime}, 85$ & $+0,01$ & 0,0001 \\
$10^{\prime \prime}, 85$ & $+0,01$ & 0,0001 \\
$10^{\prime \prime}, 8$ & -0.04 & 0,0016 \\
$10^{\prime \prime}, 8$ & $-0,04$ & 0,0016 \\
$10^{\prime \prime}, 9$ & $+0,06$ & 0,0036 \\
\hline
\end{tabular}

Nittel $10^{\prime \prime}, 84 \quad$ Summe 0,0070

Für die in $\S 31$ gewählte Bezeichnung ist also

$$
\begin{aligned}
x x & =0,0070 \\
m & =5
\end{aligned}
$$

daher der walırscheinliche Beobachtungsfehler

$$
\begin{aligned}
v & =0,6745 \mathrm{~V} \frac{0,0070}{4} \\
& =0,0282 \mathrm{Zoll}
\end{aligned}
$$

oder im Winkel 8,09 Secunden.

II. Im Abstande von 10 Ruthen. Das Bild war wegen der zu grofsen Nähe noch nicht deutlich.

\begin{tabular}{lll}
$5^{\prime \prime}, 05$ & $+0,06$ & 0,0036 \\
$5^{\prime \prime}, 0$ & $+0,01$ & 0,0001 \\
$5^{\prime \prime}, 0$ & $+0,01$ & 0,0001 \\
$4^{\prime \prime}, 95$ & $-0,04$ & 0,0016 \\
$4^{\prime \prime}, 95$ & $-0,04$ & 0,0016 \\
\hline $4^{\prime \prime}, 99$ & & 0,0070
\end{tabular}

der wahıscheinliche Fehler ergiebt sich hieraus

$$
\begin{aligned}
w & =0,0282 \text { Zoll } \\
& =4,04 \text { Secunden }
\end{aligned}
$$


III. Im Abstande von 20 Ruthen

$$
\begin{array}{lrr}
2^{\prime \prime}, 6 & -0,06 & 0,0036 \\
2^{\prime \prime}, 7 & +0,04 & 0,0016 \\
2^{\prime \prime}, 7 & +0,04 & 0,0016 \\
2^{\prime \prime}, 7 & +0,04 & 0,0016 \\
2^{\prime \prime}, 6 & -0,06 & 0,0036 \\
\hline 2^{\prime \prime}, 66 & & x x=0,0120 \\
& & \\
& w=0,0370 \text { Zoll } \\
& =2,65 \text { Secunden }
\end{array}
$$

IV. Im Abstande von 30 Ruthen

$$
\begin{array}{llr}
11^{\prime \prime}, 7 & -0,03 & 0,0009 \\
11^{\prime \prime}, 8 & +0,07 & 0,0049 \\
11^{\prime \prime}, 8 & +0,07 & 0,0049 \\
11^{\prime \prime}, 7 & -0,03 & 0,0009 \\
11^{\prime \prime}, 7 & -0,03 & 0,0009 \\
11^{\prime \prime}, 7 & -0,03 & 0,0009 \\
\hline 11^{\prime \prime}, 73 & \multicolumn{2}{c}{x x=0,0134} \\
& w=0,0345 \text { Zoll } \\
& =1,66 \text { Secunden }
\end{array}
$$

V. Im Abstande von 35 Ruthen

$$
\begin{array}{lrr}
0^{\prime \prime}, 2 & -0,10 & 0,01 \\
0^{\prime \prime}, 3 & 0,00 & 0,00 \\
0^{\prime \prime}, 3 & 0,00 & 0,00 \\
0^{\prime \prime}, 2 & -0,10 & 0,01 \\
0^{\prime \prime}, 4 & +0,10 & 0,01 \\
0^{\prime \prime}, 4 & +0,10 & 0,01 \\
0^{\prime \prime}, 3 & 0,00 & 0,00 \\
\hline 0^{\prime \prime}, 30 & \multicolumn{2}{c}{x x=0,04} \\
& \multirow{2}{*}{=0,0551 \text { Zoll }} \\
& =2,25 \text { Secunden }
\end{array}
$$

VI. Im Abstande von 40 Ruthen

$\begin{array}{lll}4^{\prime \prime}, 8 & -0,12 & 0,0144 \\ 4^{\prime \prime}, 9 & -0,02 & 0,0004 \\ 5^{i,}, 0 & +0,08 & 0,0064 \\ 4^{\prime \prime}, 9 & -0,02 & 0,0004\end{array}$




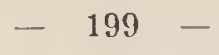

\begin{tabular}{lrr}
$5^{\prime \prime}, 0$ & $+0,08$ & 0,0064 \\
$5^{\prime \prime}, 1$ & $+0,18$ & 0,0324 \\
$4^{\prime \prime}, 9$ & $-0,02$ & 0,0004 \\
$4^{\prime \prime}, 8$ & $-0,12$ & 0,0144 \\
\hline $4^{\prime \prime}, 92$ & & $x x=0,0752$
\end{tabular}

lieraus folgt

$$
\begin{aligned}
w & =0,0699 \text { Zoll } \\
& =2,50 \text { Secunden }
\end{aligned}
$$

VII. Im $\Lambda$ bstande von 50 Ruthen

\begin{tabular}{lrr}
$4^{\prime \prime}, 0$ & $-0,04$ & 0,0016 \\
$4^{\prime \prime}, 3$ & $+0,26$ & 0,0676 \\
$4^{\prime \prime}, 1$ & $+0,06$ & 0,0036 \\
$3^{\prime \prime}, 8$ & $-0,24$ & 0,0576 \\
$4^{\prime \prime}, 2$ & $+0,16$ & 0,0256 \\
$4^{\prime \prime}, 0$ & $-0,04$ & 0,0016 \\
$4^{\prime \prime}, 1$ & $+0,06$ & 0,0036 \\
$3^{\prime \prime}, 8$ & $-0,24$ & 0,0576 \\
$4^{\prime \prime}, 2$ & $+0,16$ & 0,0256 \\
$3^{\prime \prime}, 9$ & $-0,14$ & 0,0196 \\
\hline $4^{\prime \prime}, 04$ & \multicolumn{2}{c}{$x x=0,2640$} \\
\multicolumn{3}{c}{$w=0,1155$ Zoll } \\
\multicolumn{3}{c}{$=3,31$ Secunden }
\end{tabular}

VIII. Im Abstaude von 60 Ruthen

\begin{tabular}{rrr}
$10^{\prime \prime}, 3$ & $+0,21$ & 0,0441 \\
$10^{\prime \prime}, 0$ & $-0,09$ & 0,0081 \\
$9^{\prime \prime}, 8$ & $-0,29$ & 0,0841 \\
$10^{\prime \prime}, 1$ & $+0,01$ & 0,0001 \\
$9^{\prime \prime}, 6$ & $-0,49$ & 0,2401 \\
$10^{\prime \prime}, 4$ & $+0,31$ & 0,0961 \\
$10^{\prime \prime}, 4$ & $+0,31$ & 0,0961 \\
\hline $10^{\prime \prime}, 09$ & \multicolumn{2}{c}{$x x=0,5687$} \\
& \multirow{2}{*}{$=0,2077$ Zoll } \\
& $=4,96$ Secunden
\end{tabular}

Aus diesen Versuchen gelıt hervor, dafs in $\Lambda$ bständen von etwa 30 Ruthen der Fehler im Winkel am geringsten ist. In geringern Euntfernungen wird er grö [ser, weil man durch blosse Schïtzung den Zoll nicht füglich weiter, als in 10 Theile eintheilen kann. Ueberdies ist das Bild nicht deutlich, da man die 
Ocular-Röhre nicht verstellen darf, olne die Berichtigung der Libelle aufzuheben. In grofsen Abständen nimmt der Fehler gleichfalls zu, da der einzelne Zoll zu klein wird, er auch die scharfen Ecken verliert, und daher die Schätzung der Zehntheile unsicher ist. Selbst die Abzählung der Zolle wird endlich mühsam und erfordert einen grölsern Zeit-Aufwand. Im Abstande von 60 Ruthen war es sogar schwierig, die einzelnen Zolle sicher zu erkennen.

Es darf kaum erwähnt werden, dals die vorstehnde Untersuchung und die daraus gezognen Resultate keineswegs allgemeine Gültigkeit haben, dafs sie vielmehr nur darüber Aufschlufs geben sollen, in welcher Weise für jenes Instrument die passendste Entfernung der Visirlatte ermittelt wurde. Es crgab sich, dals Abstände von 30 bis 35 Rutlıen zu wählen wären, weil diese den kleinsten Fehler im Winkel ergaben, und die Ablesung des Maalses dalei noch leicht und sicher erfolgen konnte. Die wa hr scheinlichen Fehler waren

bei 30 Ruthen gleich 0,0345 Zoll
bei 35 Ruthen gleich 0,0551 Zoll

also bei dem Abstande von $33 \frac{1}{3}$ Ruthen, der durchschnittlich gewählt wurde, 0,048 Zoll. Dieses giebt auf 100 Ruthen

$$
w=0,048 \cdot \gamma 3=0,0831 \mathrm{Zoll}
$$

Indem ich das Haupt-Nivellement mit dem rïckwärts ausgetïhrten Controlle-Nivellement verglich, hatte ich Gelegenheit, die Grösse der vorkommenden Fehler sicher zu erkennen.

Die erste Strecke des projectirten Canals war 2740 Rutlıen lang, sie zerfiel in fünf nahe gleich grofse Abtheilungen, deren Grenzen durch die beschriebenen Nagelköpfe markirt waren. Jede Abtheilung war daher ungeftihr 550 Ruthen ling, und das Haupt-Nivellement in derselben mit Linschluss der Controlle umfisste 1100 Ruthen. IDie Differenzen zwischen beiden in jeler von diesen Längen betrugen für die fünf $\Lambda$ ltheilungen

$$
0,4 \quad 0,0 \quad 0,1 \quad 0,3 \text { und } 0,4
$$

durchschnittlich also 0,24 Zoll. Es rechtfertigt sich indessen wohl, den gröIsern Fehlern eine höhere Bedeutung beizulegen. also die Fehlerquadrate zu berïcksichtigen. Das mittlere Fehlerquadrat ist 0,084 , woher der Fehler 0,29 Zoll. 
Dieser Fehler war durchsehnittlich bein Nivelliren einer 1100 Ruthen langen Strecke begangen worden, er muls daher für diese Länge als der wahrscheinliche angesehn werden. Hieraus ergiebt sich der wahrscheinliche Fehler fïr eine 11 mal kleinere Länge oder auf 100 Ruthen

$$
w=\frac{0,29}{\sqrt{11}}=0,087 \mathrm{Zoll}
$$

also um ein Geringes gröfser als jene Versuche ergeben hatten. Hieraus lassen sich leicht die wahrscheinlichen Fehler für gröfsere Längen berechnen, nämlich

$$
\begin{array}{ll}
\text { auf } \frac{1}{4} \text { Meile } & 0,20 \text { Zoll } \\
\text { auf } \frac{1}{2} \text { Meile } & 0,28 \text { Zoll } \\
\text { auf } 1 \text { Meile } & 0,39 \text { Zoll } \\
\text { auf } 2 \text { Meilen } & 0,55 \text { Zoll } \\
\text { auf } 5 \text { Meilen } & 0,87 \text { Zoll } \\
\text { auf } 10 \text { Meilen } & 1,24 \text { Zoll }
\end{array}
$$

Nach dem Preussischen Feldmesser-Reglement war auf 100 Ruthen Länge ein Fehler von 0,671 Zoll noch gestattet. Derselbe ist also 7,7 mal so grols, als jener walırscheinliche Fehler, und ich konnte daher 1 gegen 1 wetten, dafs unter einer Million Wiederholungen eines solchen Nivellements der Fehler, nur einmal diese Grenze erreicht würte. Die Wahrscheinlichkeit war daher nach gewöhnlichen Begriffen absolute Sicherheit.

Bei ungiinstiger Witternng wurden indessen die Felıler vicl bedeutender. So lange die Alweichungen auf die Länge einer Viertel Meile bei der Controlle sich noch unter 9 Linien herausstellten, liefs ich die Resultate gelten, indem die möglichste Beschleunigung geboten war, doch kamen nicht selten Abweichungen von 1 Zoll, und einmal sogar bei selır stürmischer Witterung von 1,7 Zoll vor. In diesen Fällen murste die Messung unter günstigern Umständen wiederholt werden.

Nach dem mir ertheilten Auftrage sollte auch die Höhenlage der verschiednen grölsern und kleinern Masurischen Seen gegen einander festgestellt werden. Zu diesem $Z$ weck fülırte ich ein Nivellement, das mit Einschlufs der Wasserfächen etwa 20 Meilen lıng war, wieder auf den Punkt zurück, von dem iclı ausgegangen war. Die Witterung blieb wälırend dieser Zeit überaus günstig 
und so ruhig, dafs ich keinen Anstand nahın, die Wasserflächen, in welchen keine Strömung statt fand, als horizontal anzusehen. Das Resultat war, dafs ich bis auf 0,9 Zoll wieder in den Horizont des Anfangspunkts zurückkam.

\section{$\S 53$.}

Der Vollständigkeit wegen mufs mit wenig Worten noch der trigonometrischen $\mathrm{Nivellements} \mathrm{gedacht} \mathrm{werden,}$ die man vielfach als besonders genau empfohlen hat. Sie unterscheiden sich von den beschriebenen theils durch die viel gröfsere Länge der Stationen und theils dadurch, dafs man nicht im Horizont visirt, sondern die $\mathrm{H}$ ö he $\mathrm{n} w \mathrm{ink}$ el $\mathrm{m}$ ifst. An jedem Endpunkte der Station wird ein Universal-Instrument aufgestellt. Beide richtet man gleichzeitig gegen einander und mifst die Zenith-Distanzen. Diese Winkel seien $A$ und $B$, und zwar $A$ derjenige, der vom liöhern Punkt aus gemessen ist. Es kommt darauf an, die beiden etwas grörsern Winkel $\alpha$ und $\beta$ zu finden, welche die Neigung der von dem einen Instrument nach dem andern gezognen geraden Linien gegen das Loth bezeichnen. Diese beiden Winkel würden sich zu 180 Grad ergänzen, wenn die Oberfläche der Erde nicht gekrümmt wäre. Diese Voraussetzung ist aber nur fiir kurze Entfernungen zulässig, bei diesen Nivellements mufs man die Krïmmung der Erde berïcksichtigen. Aus dem Abstande beider Punkte von einander und dem Radius der Erde ergiebt sich mit hinreichender Genanigkeit der Winkel $\psi$, unter dem zwei neben beiden Instrumenten liängende Lothe gegen einander convergiren. Man hat demnach

$$
\alpha+\beta=\pi+\psi
$$

Selır wichtig ist der Einflufs der Strahlenbrechung auf dicse Messungen. Mehrfache Untersuchungen haben, wie bereits $\S 45$ erwähnt, zu der Voraussetzıng gefühırt, dafs der Lichtstrahl auf seinem Wege durch die verschiednen Luftschichten iiber der Oberfäche der Erde einen $\mathrm{Kr}$ e is b o gen beschreibt. Hiernach bildet sich an beiden Enden zwischen ihm und der geführten geraden Linie ein Chordo-Tangentenwinkel. Beide sind einander gleich, weil sie denselben Kreislogen umfassen. Diese 
Winkel $=$ i bilden die Differenz zwischien den gemefsnen Winkeln $A$ und $B$ und den gesuchten $\alpha$ und $\beta$, und zwar ist

also

$$
\begin{aligned}
A & =\alpha-\varphi \\
B & =\beta-\varphi \\
A+B & =\alpha+\beta-2 \varphi \\
& =\pi+\psi-2 \varphi
\end{aligned}
$$

daraus ergiebt sich

also

$$
\begin{aligned}
& \varphi=\frac{1}{2}(\pi+\psi)-\frac{1}{2}(A+B) \\
& \alpha=\frac{1}{2}(\pi+\psi)+\frac{1}{2}(A-B) \\
& \beta=\frac{1}{2}(\pi+\psi)-\frac{1}{2}(A-B)
\end{aligned}
$$

Aus diesen Winkeln und den bekannten Entfernungen lälst sich die Erhebung des einen Punktes über dem andern leicht berechnen.

Gewifs ist diese Art des Nivellements durchaus passend, wenn man gezwungen ist, selır lange Stationen zu wählen. Dabei ist aber gleichzeitige Ausführung der Messungen auf beiden Seiten dringend geboten, weil die Strahlenbrechung sehr veränderlich, und von der Temperatur, so wie von der Feuchtigkeit der Luft alıängig ist, woher sie sich oft in kurzer Zeit wesentlich verändert. Namentlich bemerkt man dieses bei meilenweit ausgedehnten Wasserflächen, wo die dahinter liegenden Thürme zuweilen im Horizonte verschwinden und zuweilen äber denselben weit vortreten.

Vergleicht man indessen das trigonometrische Nivellement mit dem beschriebnen, so verschwindet der erwähnte Vortheil, weil man bei diesem durch die geringe Länge der Stationen und die möglichst gleichen Lintfernungen im Vor- und Zurückvisiren sich schon dem Einflufs der Strahlenbrechung beinalıe ganz entzielıt, auch die hierdurch vielleicht noch eingeführten kleinen Fehler sich grofsentheils aufheben oder in Rechnung gestellt werden können. Dazu kommt noclı, dafs man beim gewöhnlichen Nivellement vorzugsweise nur im Einstellen der Libelle fehlt, bei dem trigonometrischen aber in gleichem Maafse auch im Ablesen der Winkel. Jedenfalls sind dabei gröfsere und genauere Instrumente erforderlich, welche gestatten, die Winkel eben so scharf zu messen, wie die Libelle sich einstellen lärst. Hierdurch ist wieder eine selır sichere Aufstellung der Instrumente geboten und vielfache 
Vorbereitungen zur Messung, so wie auch die geoditische Festlegung der Stationspunkte nöthig wird. Die ganze Operation nimmt daher olnerachtet der viel geringern Anzahl der Stationen einen weit grölsern Zeitaufwand in Anspruch, wälrend die Höhenlage des dazwischen liegenden 'Terrains unbekannt bleibt. Endlich ist aber auch jeder Fehler in dem Höhenwinkel bei der langen Station nachtheiliger, als in der kurzen, weil die Anzalıl der letztern gröfser ist, und man hier ein gegenseitiges Aufheben der Fehler mit mehr Wahrscheinlichkeit erwarten darf. Dem letzten Uebelstande sucht man zwar dadurch zu begegnen, dafs man jene Zenithwinkel vielfach milst; da dieses aber unmittelbar hinter cinander geschehn mufs, so bietet es nicht die Sicherheit, welche man durch eben so viele partielle Messungen erreichen würde.

Aus diesen Grïnden empfiehlt es sich kaum, das trigonometrische Nivellement zu wählen, wenn nicht wegen Unzugänglichkeit des Terrains vom gewöhnlichen Verfahren Abstand genommen werden muls. In den Jahren 1839 und $1840 \mathrm{kam}$ ein trigonometrisches Nivellement längs del Oder von Oderberg unterhalb Küstrin bis zur Oesterreichischen Grenze zur Ausführung. Fïr dasselbe wurden die erforderlichen Instrumente von namhaften Künstlern beschafft, auch die Operation nicht iibereilt, vielmehr zwei Sommer darauf verwendet, und die ganze Ausfüirung erfolgte mit Sachkenntnils und Geschicklichkeit, die Resultate lassen indessen keineswegs irgend welche Vorzüge vor andern sorgfältigen Nivellements erkennen*).

1)as Haupt-Nivellement umfal'ste nahe 80 Meilen. Die Stationen sollten ungefảhr 2 Meilen lang sein, sehr häufig mufsten sie jedoch viel kürzer, zuweilen aber auch bedeutend länger gewählt werden. Die Anzahl der gleichzeitig von beiden Instrumenten jedesinal anzustellenden Messungen oder Repetitionen wurde auf vierzig f'estgesetzt. $\Lambda$ us den Unterschieden dieser einzelnen Messungen gegen das arithmetische Mittel wurden die wahrscheinlichen Fehler berechnet. Dabei ist freilich cin Versehn vorgekommen, indem das arithmetisclie Mittel als der walıre Werth, und die Albweichungen von demselben als die wirklichen Fehler

*) Trigonometrisches Nivellement der Oder von Oderberg unterhalb Küstrin bis zur Oesterreichischen Grenze von Hoffnann und Salzenberg. Berlin 1841. 
angesehn wurden. Wenn man indessen die in solclser Weise berechneten Fehler, die also etwas zu klein sind, zum Grunde legt, so ergeben sich dieselben für die Stationen von verschiednen Lüingen in folgenden mittlern Werthen. Dabei sind die selır kurzen Stationen von weniger als 750 Ruthen Länge unbeachtet geblieben, die Stationen von 750 lis 1250 Ruthen sind als eine laalle Meile, 1250 bis 1750 als drei Viertel Meilen lang und so fort berechnet, und so weiter.

\begin{tabular}{|c|c|c|}
\hline Anzahl & der Stationen & $\begin{array}{l}\text { wahrsch. Fehler } \\
\text { in Zollen }\end{array}$ \\
\hline 10 & $\frac{1}{2}$ Meile & 0,69 \\
\hline 7 & $\frac{3}{4}$ & 1,11 \\
\hline 5 & 1 & 3,43 \\
\hline 4 & $14-$ & 3,11 \\
\hline 7 & $1 \frac{1}{2}-$ & 2,75 \\
\hline 5 & $1_{4}^{3}-$ & 3,47 \\
\hline 7 & 2 & 4,03 \\
\hline 6 & $21=$ & 3,96 \\
\hline 4 & 21. & 3,84 \\
\hline 2 & $23-$ & 4,32 \\
\hline 1 & $3-$ & 12,66 \\
\hline 1 & $3 \frac{1}{4}=$ & 9,55 \\
\hline 2 & $3 \frac{1}{2} \quad-$ & 11,76 \\
\hline
\end{tabular}

Um aus diesen verschiednen Werthen der wahrscheinlichen Felıler auf die Sicherheit der Messung zu schliessen, machte ich die Voraussetzung, dals die wahrscheinlichen Fehler $v$ einer gewissen, noch unbekannten Potenz der Längen der Stationen $l$ proportional seien. Also

$$
w=r \cdot l^{\tau}
$$

Nach der Methode der kleinsten Quadrate fand ich

und

$$
r=1,886
$$

$$
x=1,433
$$

dalıer

$$
w=1,886 \cdot l^{1,433}
$$

Indem die berchneten $\mathrm{Werthe}$ von $w$ höchst unregelmässig fallen, so ist dieser Werth von $x$ keineswegs besonders sicher, sondern nur der wahrscheinlichste. Eine Ausgleichung der Fehler 
in clen Winkel-Messungen findet hier niclit statt, wie solche beim gewöhnlichen Nivellement cintritt, weil die Anzahl der Repetitionen bei längern und kürzern Stationen ungefähr dieselbe geblieben ist. Der Fehler in der Hïhen-Differenz sollte daher der Länge der Station proportional sein. Dagegen nimmt in grölserer Entfernung die Deutlichkeit $a b$, auch ist vielleicht jene Voraussetzung, dafs der gebrochene Lichtstrahl in verticaler Richtung einen Kreisbogen bildet, nicht richtig, wodureh sich erklären liefse, dafs der lixponent $x$ grörser als 1 wird. Gewifs empfichlt es sich aber nicht nach diesen Erfahrungen, sehr lange Stationen zu wählen.

Unter Zugrundelegung des vorstehnden Ausdrucks sind die wahrscheinlichen Fehler auf die Entfernung

\begin{tabular}{|c|c|c|}
\hline von & $\frac{1}{2}$ Meile & 0,70 \\
\hline - & 1 Meile & 1,89 \\
\hline 2 & 2 Meilen & 5,09 \\
\hline - & 3 Meilen & 9,10 \\
\hline 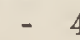 & 4 Meilen & 13,75 \\
\hline
\end{tabular}

also namentlich bei gröfsern Längen viel bedeutender, als bei Nivellements, die nur mit der Libelle und Fernrohr unter Beobachtung der nöthigen Vorsichts-Maafsregeln ausgeführt werden. Dazu kommt noch, dafs die angebenen wahrscheinlichen Fehler nicht durch eine vollständige, und von der ersten Messung unabhängige Controlle ermittelt sind, sondern nur durch vielfache Wiederholung bei derselben Aufstellung des Instruments, wobei leicht die einzelnen Ablesungen in gröfsrer Uebereinstimmung gefunden wurden, als sie in einer nenen Messung unter anderu äufsern Umständen gewesen wären. 
Anhang. 


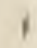

www.rcin.org.pl 


\section{A. Quadrat-Tabelle}

enthaltend die Quadrate der davor stehenden Zahlen und die

Differenzen der Quadrate.

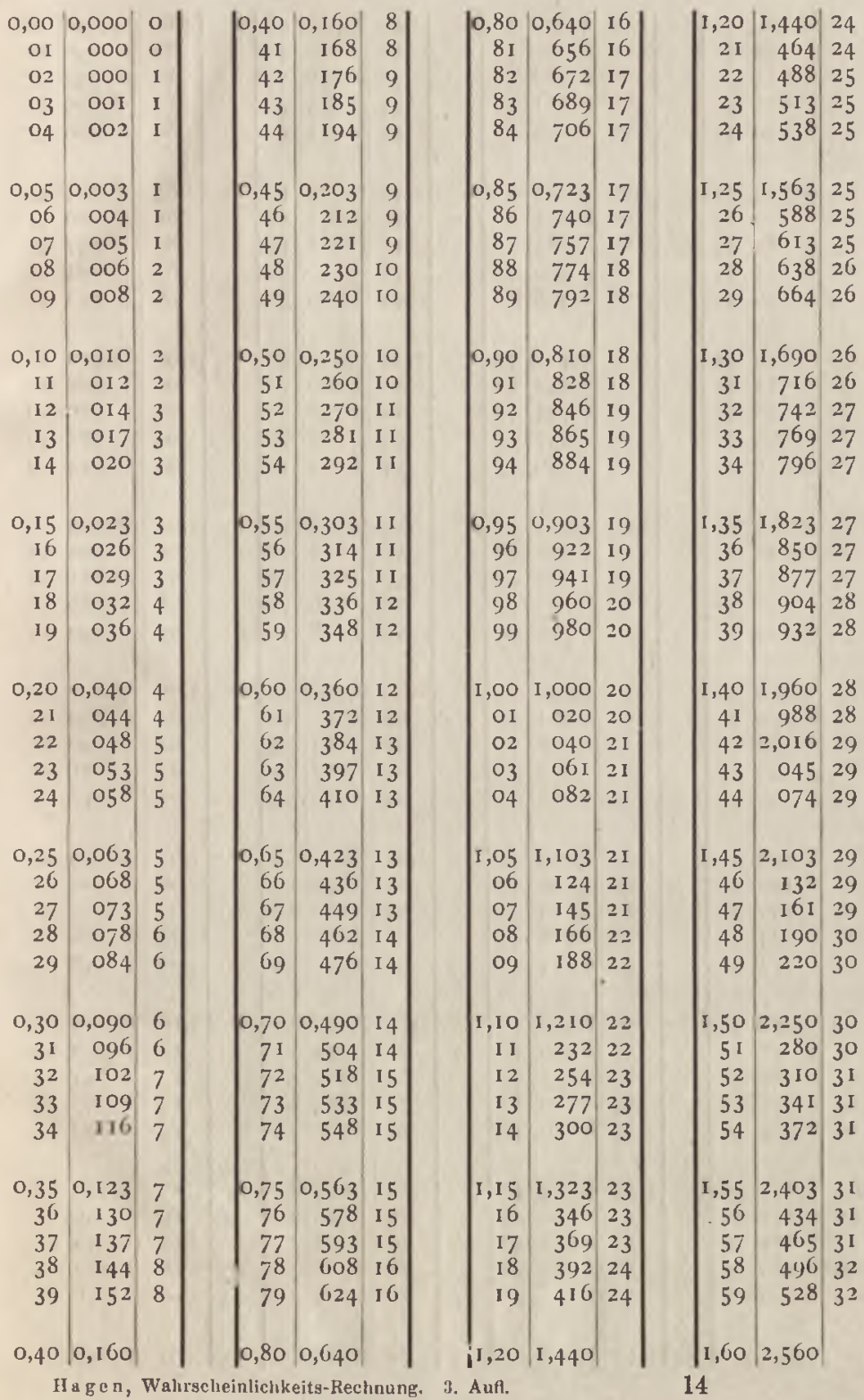


A. Quadrat-Tabelle. (Fortsetzung.)

\begin{tabular}{|c|c|c|c|c|c|c|c|c|c|c|}
\hline 1,60 & $2,560 \mid$ & 32 & 2,00 & $4,000 \mid$ & 40 & 2,40 & 5,760 & 48 & 2,80 & 7,840 \\
\hline $6 I$ & 592 & 32 & OI & 040 & 40 & $4 I$ & 808 & 48 & $8 I$ & 896 \\
\hline 62 & 624 & 33 & 02 & 080 & 4 I & 42 & 856 & 49 & 82 & 952 \\
\hline $6_{3}$ & 657 & 33 & 03 & I 2 I & $4 I$ & 43 & 905 & 49 & 83 & 8,009 \\
\hline 64 & 690 & 33 & 04 & I 62 & $4 I$ & 44 & 954 & 49 & 84 & 066 \\
\hline$I, 65$ & 2,723 & 33 & 2,05 & 4,203 & 4 I & 2,45 & 6,003 & 49 & 2,85 & 8,123 \\
\hline 66 & 756 & 33 & 06 & 244 & 41 & 46 & 052 & 49 & 86 & 180 \\
\hline 67 & 789 & 33 & 07 & 285 & $4 I$ & 47 & 101 & 49 & 87 & 237 \\
\hline 68 & 822 & 34 & 08 & 326 & 42 & 48 & 150 & 50 & 88 & 294 \\
\hline 69 & 856 & 34 & 09 & 368 & 42 & 49 & 200 & 50 & 89 & 352 \\
\hline 1,70 & 2,890 & 34 & 2,10 & 4,4 I0 & 42 & 2,50 & 6,250 & 50 & 2,90 & 8,4 I 0 \\
\hline 71 & 924 & 34 & I I & 452 & 42 & 51 & 300 & 50 & 91 & 468 \\
\hline 72 & $95^{8}$ & 35 & 12 & 494 & 43 & 52 & 350 & $5 \mathrm{I}$ & 92 & 526 \\
\hline 73 & 993 & 35 & I 3 & 537 & 43 & 53 & 401 & $5 \mathrm{I}$ & 93 & 585 \\
\hline 74 & 3,028 & 35 & I 4 & 580 & 43 & 54 & $45^{2}$ & $5 I$ & 94 & 644 \\
\hline $\mathbf{I}, 75$ & 3,063 & 35 & 2,15 & 4,623 & 43 & 2,55 & $6,5 \circ 3$ & $5 I$ & 2,95 & $8,7 \circ 3$ \\
\hline 76 & 098 & 35 & 16 & 666 & 43 & 56 & 554 & 51 & 96 & 762 \\
\hline 77 & 13.3 & 35 & 17 & 709 & 43 & 57 & 605 & 51 & 97 & 821 \\
\hline 78 & 168 & 36 & 18 & 752 & 44 & 58 & 656 & 52 & 98 & 880 \\
\hline 79 & 204 & 36 & 19 & 796 & 44 & 59 & 708 & 52 & 99 & 940 \\
\hline I, 80 & 3,240 & 36 & 2,20 & 4,840 & 44 & 2,60 & 6,760 & 52 & 3,00 & 9,000 \\
\hline $8 I$ & 276 & 36 & $2 I$ & 884 & 44 & 6I & 812 & 52 & o I & 060 \\
\hline 82 & 312 & 37 & 22 & 928 & 45 & 62 & 864 & 53 & 02 & 120 \\
\hline 83 & 349 & 37 & 23 & 973 & 45 & $6_{3}$ & 917 & 53 & 03 & $18 I$ \\
\hline 84 & 386 & 37 & 24 & 5,018 & 45 & 64 & 970 & 53 & 4 & 42 \\
\hline $\mathrm{J}, 85$ & 3,423 & 37 & 2,25 & $5,06_{3}$ & 45 & 2,65 & 7,023 & 53 & 3,05 & $9,3^{\circ} 3$ \\
\hline 86 & 460 & 37 & 26 & 108 & 45 & 66 & 0,6 & 53 & 06 & 364 \\
\hline 87 & 497 & 37 & 27 & I 53 & 45 & $G_{7}$ & 129 & 53 & 07 & 425 \\
\hline 88 & 534 & $3^{8}$ & 28 & 198 & 46 & 68 & 182 & 54 & 08 & 486 \\
\hline 89 & 572 & $3^{8}$ & 29 & $2+4$ & 46 & 69 & $23^{6}$ & 54 & og & $54^{8}$ \\
\hline 1,90 & 3,610 & $3^{8}$ & 2,30 & 5,290 & 46 & 2,70 & 7,290 & 54 & 3,10 & 9,610 \\
\hline 91 & 648 & $3^{8}$ & 3 I & 336 & 46 & $7 I$ & 344 & 54 & II & 672 \\
\hline 92 & 686 & 39 & 32 & 382 & 47 & 72 & 398 & 55 & 12 & 734 \\
\hline 93 & 725 & 39 & 33 & 429 & 47 & 73 & 453 & 55 & 13 & 797 \\
\hline 94 & 704 & 39 & 34 & $47^{6}$ & 47 & 74 & 508 & 55 & 14 & \\
\hline 1,95 & 3,803 & 39 & 2,35 & 5,523 & 47 & 2,75 & 7,563 & 55 & 3,15 & 9,923 \\
\hline 96 & 842 & 34 & $3^{6}$ & 570 & 47 & $7^{6}$ & 618 & 55 & 16 & 986 \\
\hline 97 & $88 \mathrm{I}$ & 39 & 37 & 617 & 47 & 77 & 673 & 55 & 17 & I 0,049 \\
\hline 98 & 920 & 40 & $3^{8}$ & 664 & 48 & 78 & 728 & 50 & 18 & 112 \\
\hline 99 & 960 & 40 & 29 & 712 & $4^{8}$ & 79 & 784 & 56 & 19 & 176 \\
\hline 2,00 & 4,000 & & 2,40 & 5,760 & & 2,80 & 7,840 & & 13,20 & 10 \\
\hline
\end{tabular}


A. Quadrat-Tabelle. (Fortsetzung.)

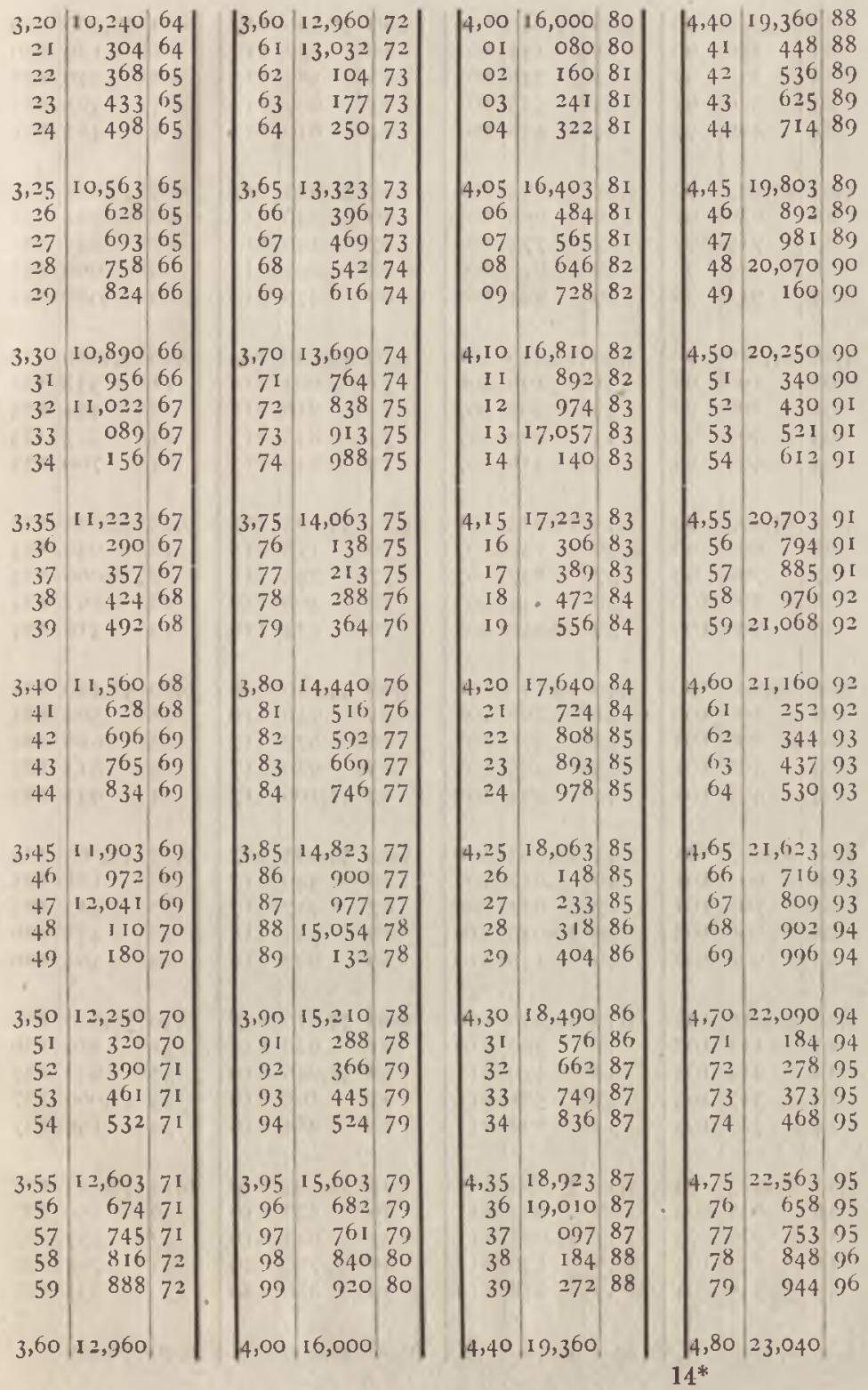


A. Quadrat-Tabelle. (Fortsetzung.)

\begin{tabular}{|c|c|c|c|c|c|c|c|c|c|c|c|}
\hline 4,80 & 23,040 & 96 & $\mid 5,20$ & 27,040 & 104 & 5,60 & 31,360 & 112 & 6,00 & 36,000 & 120 \\
\hline $8 I$ & I 36 & 96 & $2 \mathrm{I}$ & 144 & 104 & $6 I$ & 472 & I I 2 & OI & I 20 & 120 \\
\hline 82 & 232 & 97 & 22 & 248 & 105 & 62 & 584 & 113 & $\mathrm{O} 2$ & 240 & 121 \\
\hline 83 & 329 & 97 & 23 & 353 & 105 & 63 & 697 & 113 & 03 & 361 & 121 \\
\hline 84 & 426 & 97 & 24 & 458 & I05 & 64 & 810 & 113 & 04 & 482 & I 2 I \\
\hline 4,85 & 23,523 & 97 & 5,25 & 27,563 & 105 & 5,65 & 31,923 & I 13 & 6,05 & 36,603 & 121 \\
\hline 86 & 620 & 97 & 26 & 668 & 105 & 66 & $32,(136$ & 113 & 06 & 724 & 121 \\
\hline 87 & 717 & 97 & 27 & 773 & 105 & 67 & 149 & I 13 & 07 & 845 & 121 \\
\hline 88 & 814 & 98 & 28 & 878 & 106 & 68 & 262 & 114 & 08 & 966 & 122 \\
\hline 89 & 912 & 98 & 29 & 984 & 106 & 69 & 376 & 114 & on & 37,088 & I 22 \\
\hline 4,90 & 24,010 & 98 & 5,30 & 28,090 & 106 & 5,70 & 32,490 & 114 & 6,10 & 37,210 & 122 \\
\hline 91 & 108 & 98 & $3 I$ & 196 & 106 & 71 & 604 & 114 & I I & 332 & 122 \\
\hline 92 & 206 & 99 & 32 & 302 & 107 & 72 & 718 & 115 & 12 & 454 & 123 \\
\hline 93 & 305 & 99 & 33 & 409 & 107 & 73 & 833 & 115 & 13 & 577 & 123 \\
\hline 94 & 404 & 99 & 34 & 516 & 107 & 74 & $94^{8}$ & I I 5 & 14 & 700 & 123 \\
\hline 4,95 & 24,503 & 99 & 5,35 & 28,623 & 107 & 5,75 & 33,063 & I I 5 & 6,15 & $37,8 \geq 3$ & 123 \\
\hline 96 & 602 & 99 & 36 & 730 & 107 & 76 & 178 & I I 5 & 16 & 946 & 123 \\
\hline 97 & 701 & 99 & 37 & 837 & 107 & 77 & 293 & 115 & 17 & $3^{8,069}$ & 123 \\
\hline 98 & 800 & 100 & $3^{8}$ & 944 & 108 & 78 & 408 & 116 & 18 & 192 & 124 \\
\hline 99 & 900 & 100 & 39 & 29,052 & I 08 & 79 & 524 & I 16 & 19 & 316 & I 24 \\
\hline $5,(10)$ & 25,000 & 100 & 5,40 & 29,160 & 108 & 5,80 & 33,640 & 116 & 6,20 & 38,440 & 124 \\
\hline OI & 100 & 100 & $4 I$ & 268 & 108 & $8 I$ & 756 & I 16 & $2 I$ & 564 & I 24 \\
\hline 012 & 200 & IOI & 42 & 376 & 109 & 82 & 872 & I 17 & 22 & 688 & 125 \\
\hline 03 & 301 & 101 & 43 & 485 & I09 & 83 & 989 & 117 & 23 & 813 & 125 \\
\hline 04 & 402 & IOI & 44 & 594 & IO9 & 84 & 34,106 & 117 & 24 & $93^{8}$ & 125 \\
\hline 5,05 & 25,503 & IOI & 5,45 & 29,703 & 109 & 5,85 & 34,223 & 117 & 6,25 & 39,063 & 125 \\
\hline 06 & 604 & IOI & 46 & 812 & 109 & 86 & 340 & 117 & 26 & I 88 & 125 \\
\hline 07 & 705 & IOI & 47 & 921 & 109 & 87 & 457 & 117 & 27 & 313 & 125 \\
\hline 08 & 806 & 102 & 48 & 30,030 & 110 & 88 & 574 & I 18 & 28 & $43^{8}$ & 126 \\
\hline 09 & 908 & 102 & 49 & 140 & I IO & 89 & 692 & I 18 & 29 & 564 & 126 \\
\hline 5,10 & 26,010 & 102 & 5,50 & 30,250 & 110 & 5,90 & 34,810 & II 8 & 6,30 & 39,600 & 126 \\
\hline II & 112 & 102 & $5 I$ & 360 & I IO & 91 & 928 & I I 8 & $3 I$ & 816 & 126 \\
\hline 12 & 214 & 103 & $5^{2}$ & 470 & I I I & 92 & 35,046 & 119 & 32 & 942 & 127 \\
\hline 13 & 317 & 103 & 53 & $58 \mathrm{I}$ & I I I & 93 & 165 & 119 & 33 & 40,069 & 127 \\
\hline 14 & 420 & 103 & 54 & 692 & I I I & 94 & 284 & I 19 & 34 & 196 & 127 \\
\hline 5,15 & 26,523 & 103 & 5,55 & $3^{\circ}, 8 \mathrm{O}_{3}$ & I I I & 5,95 & 35,403 & I I 9 & 6,35 & 40,323 & 127 \\
\hline I 6 & 626 & $\mathrm{IO}_{3}$ & 56 & $9 \mathrm{I}_{4}$ & I I I & 96 & 522 & I I 9 & 36 & $45^{\circ}$ & 127 \\
\hline 17 & 729 & 103 & 57 & 31,025 & I I 1 & 97 & $64 \mathrm{I}$ & I I 9 & 37 & 577 & I 27 \\
\hline I 8 & 832 & 104 & 58 & 136 & I 12 & 98 & 760 & 120 & $3^{8}$ & 704 & 128 \\
\hline 19 & 936 & 104 & 59 & 248 & I 12 & 99 & 880 & I 20 & 39 & 832 & I 28 \\
\hline & 27,040 & & 90 & 31,360 & & 6,00 & 36,000 & & 6,40 & 40,960 & \\
\hline
\end{tabular}


A. Quadrat-Tabelle. (Fortsetzung.)

\begin{tabular}{|c|c|c|c|c|c|c|c|c|c|c|c|}
\hline 6,40 & 40,960 & 128 & 6,80 & 46,240 & I 36 & 7,20 & 51,840 & I 44 & 7,60 & 57,760 & 152 \\
\hline $4 I$ & $4^{1}, 088$ & 128 & 81 & 376 & 136 & $2 I$ & 984 & 144 & $6 I$ & 912 & 152 \\
\hline 42 & 216 & 129 & 82 & 5 I 2 & 137 & 22 & $5^{2}, 128$ & 145 & 62 & 58,064 & 153 \\
\hline 43 & 345 & 129 & 83 & 649 & I 37 & 23 & 273 & I 45 & 63 & 217 & 153 \\
\hline 44 & 474 & 129 & 84 & 786 & I 37 & 24 & $4 I 8$ & 145 & 64 & 370 & 153 \\
\hline 6,45 & $4^{1,603}$ & 129 & 6,85 & 46,923 & I 37 & 7,25 & 52,563 & I 45 & 7,65 & 58,523 & 153 \\
\hline $4^{6}$ & 732 & I 29 & 86 & 47,060 & 137 & 26 & 708 & I 45 & 66 & 676 & 153 \\
\hline 47 & $86 \mathrm{I}$ & 129 & 87 & 197 & 137 & 27 & 853 & 145 & 67 & 829 & 153 \\
\hline $4^{8}$ & 990 & 130 & 88 & 334 & 138 & 28 & 998 & 146 & 68 & 82 & I 54 \\
\hline 49 & 42,120 & 130 & 89 & 472 & 138 & 29 & 53,144 & 146 & 69 & 59, I 36 & 154 \\
\hline $6,5^{\circ}$ & $42,25^{\circ}$ & 130 & 6,90 & 47,610 & $13^{8}$ & 7,30 & 53,290 & 146 & 7,70 & 59,290 & 54 \\
\hline $5 I$ & 380 & 130 & 91 & $74^{8}$ & I 38 & $3 \mathrm{I}$ & 436 & 146 & 71 & 444 & 4 \\
\hline 52 & 510 & I 3 I & 92 & 886 & 139 & 32 & 582 & I 47 & 72 & 598 & 55 \\
\hline 53 & 641 & I 3 I & 93 & $4^{8,025}$ & 139 & 33 & 729 & 147 & 73 & 753 & 5 \\
\hline 54 & 772 & 131 & 94 & 164 & I 39 & 34 & 876 & 47 & 74 & 88 & 55 \\
\hline 6,55 & 42,903 & I 3 I & 6,95 & $4^{8,303}$ & I 39 & 7,35 & 54,023 & 147 & 7,75 & 60,063 & 55 \\
\hline 56 & 43,034 & I 3 I & 96 & 442 & 139 & 36 & 170 & 147 & 76 & 218 & 155 \\
\hline 57 & 165 & I 3 I & 97 & $58 \mathrm{I}$ & 139 & 37 & 317 & 147 & 77 & 373 & I 55 \\
\hline $5^{8}$ & 269 & 132 & 98 & 720 & 140 & 38 & 464 & $14^{8}$ & 78 & 528 & $15^{6}$ \\
\hline 59 & 428 & 132 & 99 & 860 & 140 & 39 & 612 & 148 & 79 & 684 & I 56 \\
\hline 6,60 & 43,560 & 132 & $7,(x)$ & 49,000 & $14^{\circ}$ & 7,40 & 54,760 & I 48 & 7,80 & 60,840 & 156 \\
\hline $6 I$ & 692 & 132 & OI & I 40) & 140 & 41 & 908 & 148 & 81 & 996 & 56 \\
\hline 62 & 824 & I 33 & $\mathrm{O}_{2}$ & 280 & I 4 I & 42 & 55,056 & I 49 & 82 & 61,152 & 57 \\
\hline 63 & 957 & 133 & (1) 3 & 42 I & 14 I & 43 & 205 & 149 & $8_{3}$ & 309 & 57 \\
\hline 64 & $44,09()$ & I 33 & 04 & 562 & 141 & 44 & 354 & I 49 & 84 & 466 & 157 \\
\hline 6,65 & 44,223 & 133 & 7,05 & 49,703 & 14 I & 7,45 & 55,503 & 149 & 7,85 & 61,623 & 57 \\
\hline 66 & 356 & 133 & 06 & 844 & 141 & 46 & 652 & 149 & 86 & 780 & 157 \\
\hline 67 & 489 & I 33 & 07 & $9^{85}$ & 141 & 47 & $80 \mathrm{I}$ & I 49 & 87 & 937 & 57 \\
\hline 68 & 622 & I 34 & 08 & 50,126 & 142 & $4^{8}$ & 950 & 150 & 88 & 62,094 & $15^{8}$ \\
\hline 69 & 756 & 134 & 09 & 268 & 142 & 49 & 56,100 & 150 & 89 & 252 & $15^{8}$ \\
\hline 6,70 & 44,890 & 134 & 7,10 & $50,4^{10}$ & 142 & 7,50 & 56,250 & I 50 & 7,90 & 62,410 & 158 \\
\hline $7 \mathrm{I}$ & $45,(124$ & 134 & I I & 552 & 142 & $5 I$ & 400 & I 50 & $9 \mathrm{I}$ & 568 & $5^{8}$ \\
\hline 72 & $15^{8}$ & 135 & 12 & 694 & 143 & 52 & 550 & I 5 I & 92 & 726 & 59 \\
\hline 73 & 293 & 135 & 13 & 837 & 143 & 53 & 701 & I 5 I & 93 & 885 & 59 \\
\hline 74 & 428 & I 35 & 14 & 980 & 143 & 54 & 52 & I 5 I & 94 & 63,044 & 59 \\
\hline 6,75 & 45,563 & 135 & 7, I 5 & 51,123 & 143 & 7,55 & 57,003 & I 5 I & 7,95 & 63,203 & 159 \\
\hline 76 & 698 & 135 & 16 & 266 & 143 & 56 & I 54 & I 5 I & 96 & $3^{62}$ & 59 \\
\hline 77 & 833 & 135 & 17 & $4(0)$ & 143 & 57 & 305 & I 5 I & 97 & $52 \mathrm{I}$ & 159 \\
\hline 78 & 968 & 136 & 18 & & I 44 & $5^{8}$ & 456 & 152 & 98 & 680 & 60 \\
\hline 79 & 46, I04 & I 36 & 19 & 696 & I 44 & 59 & 608 & 152 & 99 & 840 & 0 \\
\hline 6,80 & 46,240 & & 7,20 & $5 \mathrm{I}, 840$ & & 17,60 & 57,760 & & 8,00 & 64,000 & \\
\hline
\end{tabular}


A. Quadlat-Tabelle. (Fortsetzung.)

\begin{tabular}{|c|c|c|c|c|c|c|c|c|c|c|c|}
\hline 8,00 & $64,000 \mid$ & 160 & 8,40 & 70,560 & 168 & 8,80 & $77,440 \mid$ & 176 & 9,20 & $84,640)$ & 184 \\
\hline or & 160 & 160 & 41 & 728 & I 68 & 81 & 616 & 176 & 21 & $8: 4$ & 184 \\
\hline 02 & 320 & 161 & $4^{2}$ & 896 & 169 & 82 & 792 & 177 & 22 & 85,008 & 185 \\
\hline $0_{3}$ & $48 \mathrm{I}$ & $16 \mathrm{I}$ & 43 & 71,065 & 169 & 83 & 969 & 177 & 23 & 193 & 185 \\
\hline 04 & 642 & $\{61$ & 44 & 234 & 169 & 84 & $7^{8}, 14^{6}$ & 177 & 24 & 378 & 185 \\
\hline 8,05 & $64,80_{3}$ & 161 & 8,45 & 71,403 & 169 & 8,85 & 78,323 & 177 & 9,25 & 85,563 & og \\
\hline 06 & 964 & 161 & $4^{6}$ & 572 & 169 & 86 & 500 & 177 & 26 & $74^{8}$ & \\
\hline$\infty 7$ & 65,125 & $16 \mathrm{I}$ & 47 & 741 & 169 & 87 & 677 & 177 & 27 & 933 & 05 \\
\hline 08 & 286 & 162 & $4^{8}$ & 910 & 170 & 88 & 854 & 178 & 28 & 86,118 & 6 \\
\hline 09 & $44^{8}$ & 162 & 49 & 72,080 & 170 & 89 & 79,032 & 178 & 29 & 304 & 186 \\
\hline 8,10 & 65,610 & 162 & 8,50 & 72,250 & 170 & 8,90 & 79,210 & 178 & 9,30 & 86,490 & 86 \\
\hline 11 & 772 & 162 & 51 & 420 & 170 & $9 \mathrm{f}$ & $3^{88}$ & 178 & 31 & 676 & 86 \\
\hline 12 & 934 & 163 & 52 & 590 & 171 & 92 & 566 & 179 & $3^{2}$ & 862 & 87 \\
\hline 13 & 66,097 & 163 & 53 & 761 & 171 & 93 & 745 & $17^{\circ}$ & 33 & 87,049 & 87 \\
\hline 14 & 260 & 163 & 54 & 932 & 171 & 94 & 924 & 179 & 34 & 236 & 2 \\
\hline 8,13 & 66,423 & 163 & 8,55 & 73,103 & 171 & 8,95 & $80,10_{3}$ & 179 & 9,35 & $87,4^{23}$ & 87 \\
\hline 16 & $5^{86}$ & 163 & 56 & 274 & 171 & 96 & 282 & 179 & 36 & 610 & 187 \\
\hline 17 & 749 & 163 & 57 & 445 & 171 & 97 & $4^{61}$ & 179 & 37 & 797 & 87 \\
\hline I8 & 912 & 164 & $5^{8}$ & 616 & 172 & 98 & 640 & 180 & $3^{8}$ & 984 & 188 \\
\hline I9 & 67,076 & 164 & 59 & 788 & 172 & 99 & 820 & 180 & 39 & 88,172 & 8 \\
\hline 8,20 & 67,240 & 164 & 8,60 & 73,960 & 172 & 9,00 & 81,000 & 180 & $9.4^{\circ}$ & 88,360 & 88 \\
\hline 21 & 404 & 164 & 61 & $74,13^{2}$ & 172 & $O t$ & 180 & 180 & 41 & $54^{8}$ & 188 \\
\hline 22 & 568 & 165 & 2 & 304 & 173 & 02 & 360 & 181 & 42 & 736 & 89 \\
\hline 23 & 733 & 165 & 63 & 477 & 173 & $0_{3}$ & 541 & 181 & 43 & 925 & 89 \\
\hline 24 & 898 & 165 & 64 & 650 & 173 & 04 & 722 & 181 & 44 & 89,114 & 9 \\
\hline 8,25 & 68,063 & 165 & 8,65 & 74,823 & 173 & 9,05 & 81,903 & 181 & 9,45 & 89,303 & 9 \\
\hline 26 & 228 & 165 & 66 & 996 & 173 & 06 & 82,084 & 181 & $4^{6}$ & 492 & 9 \\
\hline 27 & 393 & 165 & 67 & 75,169 & 173 & 07 & 265 & 181 & 47 & 681 & 9 \\
\hline 28 & $55^{8}$ & 166 & 68 & 342 & 174 & 08 & $44^{6}$ & 182 & $4^{8}$ & 870 & 190 \\
\hline 29 & 724 & 166 & 69 & 516 & 174 & 09 & 628 & 182 & 49 & 90,060 & 0 \\
\hline 8,30 & 68,890 & 166 & 8,70 & 75,600 & 174 & 9,10 & 82,810 & 182 & 9,50 & 90,250 & 190 \\
\hline 31 & 69,056 & 166 & 71 & 864 & 174 & II & 992 & 182 & 51 & 440 & 190 \\
\hline 32 & 222 & 167 & 72 & 76,038 & 175 & 12 & 83,174 & 183 & 52 & 630 & 191 \\
\hline 33 & $3^{89}$ & 167 & 73 & 213 & 175 & 13 & 357 & 183 & 53 & 821 & 191 \\
\hline 34 & 556 & 167 & 74 & 388 & 175 & 14 & 540 & 183 & 54 & 91,012 & 191 \\
\hline 8,35 & 69,723 & 167 & 8,75 & 76,563 & 175 & 9,15 & 83,723 & 183 & 9,55 & 91,203 & 191 \\
\hline 36 & 890 & 167 & 76 & $73^{8}$ & 175 & 16 & 906 & 183 & 56 & 394 & 191 \\
\hline 37 & 70,057 & 167 & 77 & 913 & 175 & 17 & 84,089 & 183 & 57 & 585 & $19 \mathrm{t}$ \\
\hline 3 & 224 & 168 & 78 & 77,088 & 176 & 18 & 272 & 184 & $5^{8}$ & 776 & 192 \\
\hline 39 & 392 & 168 & 79 & 264 & $17^{6}$ & 19 & $45^{6}$ & 184 & 59 & 968 & 2 \\
\hline 40 & .560 & & 8,80 & 77,440 & & 19,20 & 84,640 & & 19,60 & 92,160 & \\
\hline
\end{tabular}




\section{A. Quadrat-Tabelle. (Schlufs.)}

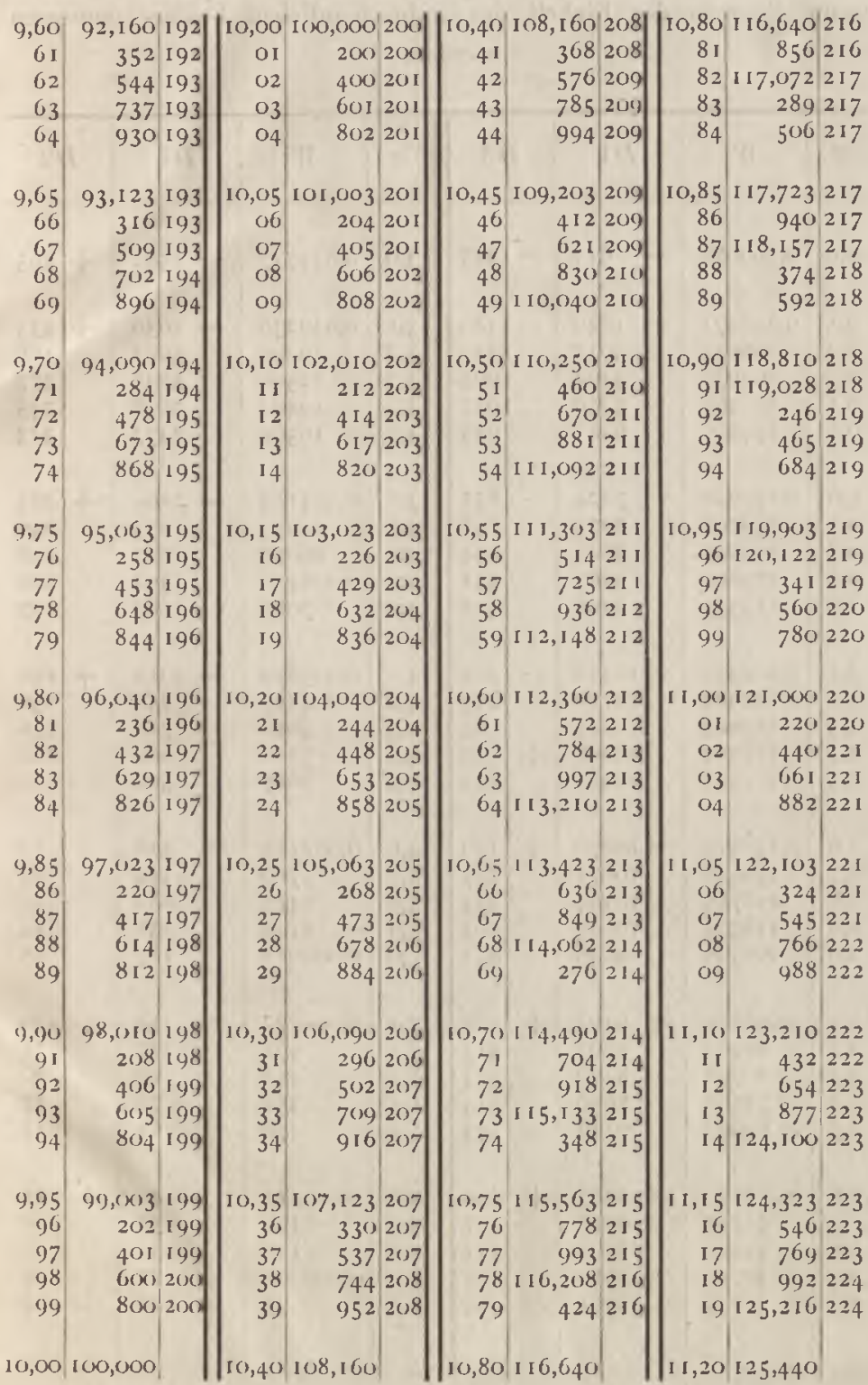




\section{$-216-$ \\ Tabelle $B$.}

Relative Wahrscheinlichkeit (W) der positiven und negativen Fehler $(x)$, wenn diese in der Finheit des wahrscheinlichen Fehlers gemessen werden.

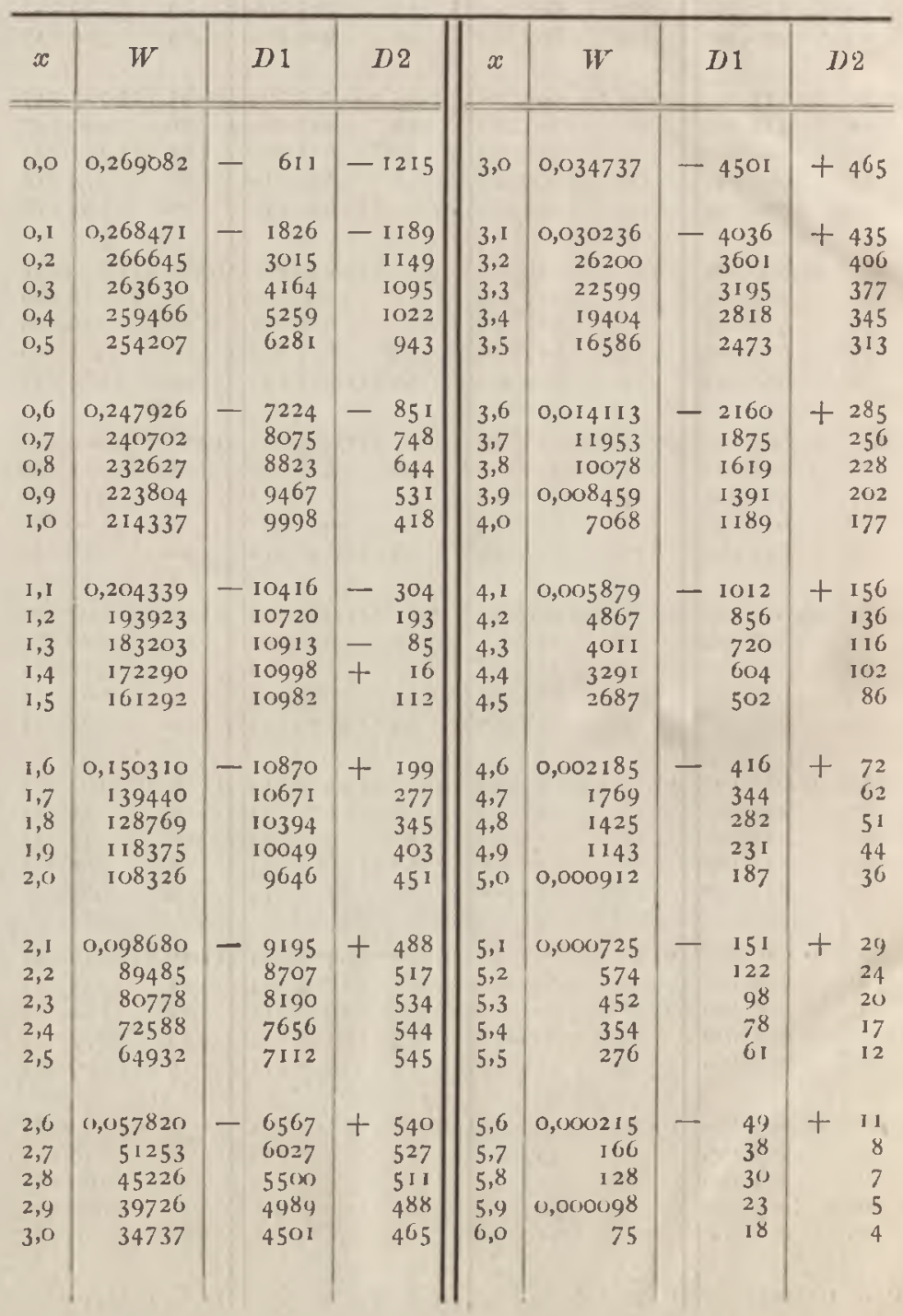


Tabelle $B$. (Fortsetzung.)

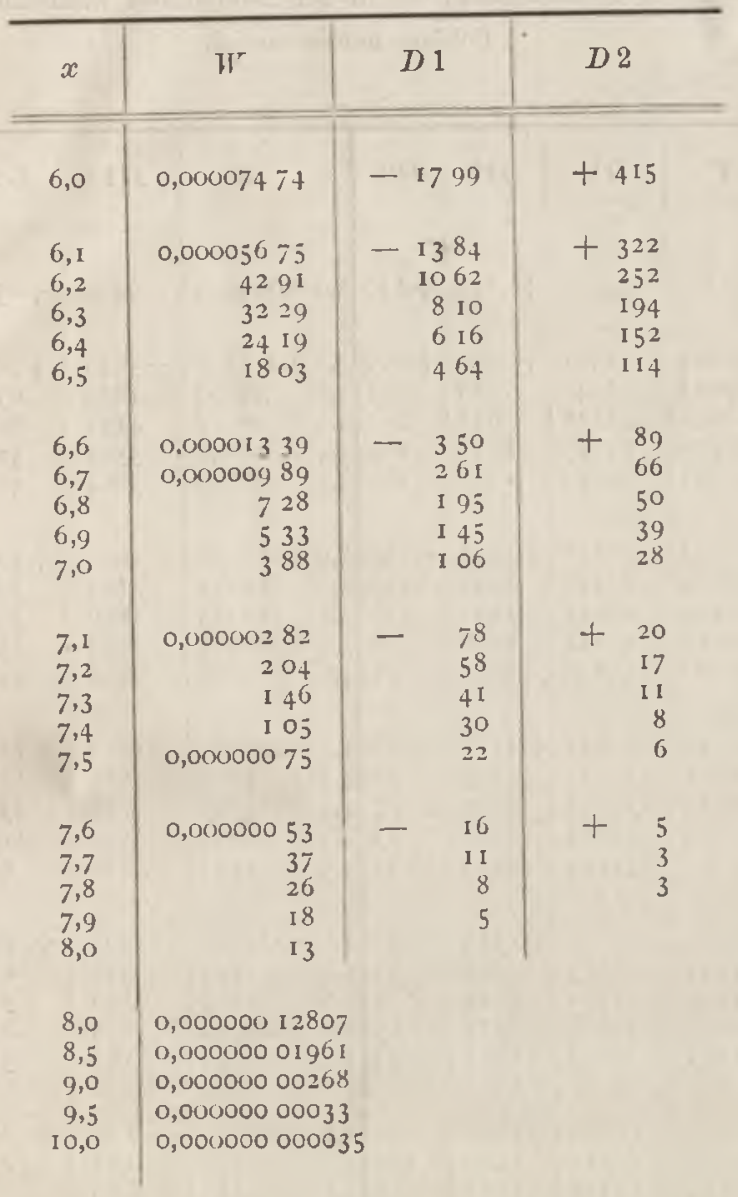




\section{Tabelle $C$.}

Wirhrscheinlichkeit $(W)$, dals positive oder negative Fehler die Grenze $x$ überschreiten, die in der Einheit des wahrscheinlichen

Fehlers gemessen ist.

\begin{tabular}{|c|c|c|c|c|c|c|c|c|c|}
\hline$x$ & $W$ & $D 1$ & $D 2$ & $D 3$ & $x$ & $W$ & $D 1$ & $D_{2}$ & $D 3$ \\
\hline 0.0 & 1,000000 & -53776 & +245 & +239 & 3,0 & 0,043025 & -6489 & +853 & -90 \\
\hline 0,1 & 0,946224 & -53531 & +484 & +235 & 3,1 & 0,036536 & -5636 & +763 & -84 \\
\hline 0,2 & 892693 & 53047 & 719 & 224 & 3,2 & 30900 & 4873 & 679 & 79 \\
\hline 0,3 & 839646 & 52328 & 943 & 212 & 3,3 & 26027 & 4194 & 601 & 72 \\
\hline 0,4 & 787318 & $5^{1} 3^{85}$ & 1155 & I 97 & 3,4 & 21833 & 3593 & 529 & 67 \\
\hline 0,5 & 735933 & 50230 & 1352 & 180 & 3,5 & 18240 & 3064 & 462 & 59 \\
\hline 0,6 & 0,685703 & -48878 & +1532 & +159 & 3,6 & 0,015176 & -2602 & +403 & -54 \\
\hline 0,7 & 636825 & 47346 & 1691 & I 40 & 3,7 & 12574 & 2199 & 349 & 48 \\
\hline 0,8 & 589479 & 45655 & $183 \mathrm{I}$ & II 7 & 3,8 & 10375 & 1850 & 301 & 44 \\
\hline 0,9 & 543824 & 43824 & 1948 & 96 & 3,9 & 0,008525 & I 549 & 257 & 37 \\
\hline 1,0 & 500000 & -41876 & 2044 & 71 & 4,0 & 6976 & I 292 & 220 & 33 \\
\hline $\mathrm{I}, \mathrm{I}$ & 0,458124 & -39832 & +2115 & +50 & $4, \mathrm{I}$ & 0,005684 & -1072 & +187 & -30 \\
\hline 1,2 & 418292 & 37717 & 2165 & 28 & 4,2 & 4612 & 885 & 157 & 25 \\
\hline 1,3 & 380575 & $3555^{2}$ & 2193 & +7 & 4,3 & 3727 & 728 & 132 & 22 \\
\hline 1,4 & 345023 & 33359 & 2200 & -13 & 4,4 & 2999 & 596 & 110 & 18 \\
\hline $\mathrm{I}, 5$ & 315664 & 31 I 59 & 2187 & 32 & 4,5 & 2403 & 486 & 92 & 16 \\
\hline 1,6 & 0,280505 & -28972 & +2155 & -47 & 4,6 & 0,001917 & -394 & +76 & --14 \\
\hline 1,7 & 251533 & 26817 & 2108 & 63 & 4.7 & $15^{2} 3$ & 318 & 62 & II \\
\hline I, 8 & 224716 & 24709 & 2045 & 74 & 4,8 & 1205 & 256 & 51 & 9 \\
\hline 1,9 & 200007 & 22664 & 1971 & 87 & 4,9 & 0,000049 & 205 & 42 & 8 \\
\hline 2,0 & $\mathrm{I} 77343$ & 20693 & 1884 & 93 & 5,0 & 744 & 163 & 34 & 7 \\
\hline $2, I$ & 0,156650 & -18809 & +1791 & -IOI & 5,1 & $0,00058 \mathbf{I}$ & -129 & +27 & \\
\hline 2,2 & 137841 & 17018 & 1690 & 105 & 5,2 & $45^{2}$ & 102 & 22 & \\
\hline 2,3 & 120823 & I 5328 & 1585 & 108 & 5,3 & 350 & 80 & 17 & \\
\hline 2,4 & 105495 & 13743 & 1477 & 109 & 5,4 & 270 & 63 & 14 & \\
\hline 2,5 & 0,091752 & I 2266 & I 368 & 109 & 5,5 & 207 & 49 & I I & \\
\hline 2,6 & 0,079486 & - 10898 & +1259 & -106 & 5,60 & $0,00015^{8}$ & $-3^{8}$ & +9 & \\
\hline 2,7 & 68588 & 9639 & I 153 & 105 & 5,7 & 120 & 29 & 7 & \\
\hline 2,8 & 58949 & 8486 & 1048 & 99 & 5,8 & 0,00009 I & 22 & & \\
\hline 2,9 & 50463 & 7438 & 949 & 96 & 5,9 & 69 & 17 & & \\
\hline 3,0 & 43025 & 6489 & 853 & 90 & 5,0 & 52 & 13 & & \\
\hline
\end{tabular}


Tabelle C. (Fortsetzung.)

\begin{tabular}{|c|c|c|c|c|}
\hline$x$ & $W$ & $D 1$ & $x$ & $W$ \\
\hline 6,0 & 0,000052 & -13 & 7,0 & 0,000004 \\
\hline 6,1 & 0,000039 & -10 & 7,1 & 0,000004 \\
\hline 6,2 & 29 & 7 & 7,2 & 3 \\
\hline 6,3 & 22 & 6 & 7,3 & 3 \\
\hline 6,4 & 16 & 4 & 7,4 & 3 \\
\hline 6,5 & 12 & 3 & 7,5 & 3 \\
\hline 6,6 & 0,000009 & & 7,6 & 0,000003 \\
\hline 6,7 & 8 & & 7,7 & 3 \\
\hline 6,8 & 6 & & 7,8 & 3 \\
\hline 6,9 & 5 & & 7,9 & 2 \\
\hline 7,0 & 4 & & 8,0 & 2 \\
\hline
\end{tabular}

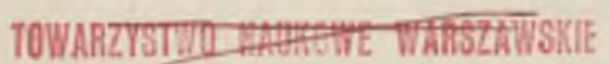
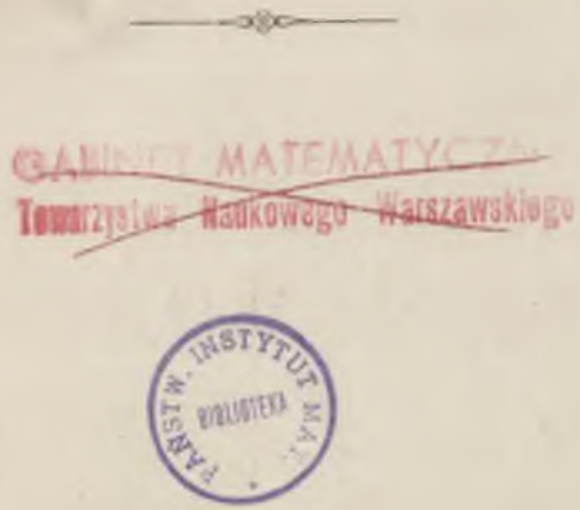
Druck von Oskar Bonde in Altenburg. 

